\title{
SPECTRAL PROSPECTIVITY MAPPING OF THE DESEADO MASSIF, ARGENTINA - DECIPHERING THE GEOCHEMISTRY AND MINERALOGY OF A LOW TO INTERMEDIATE SULFIDATION EPITHERMAL SYSTEM
}


Examining committee:
Prof.dr. V.G. Jetten
Prof.dr. Z. Su
University of Twente, ITC
Prof.dr. S.H. Marsh
University of Twente, ITC
Prof.dr. E. Pirard
University of Nottingham
Dr. M.W.N. Buxton
Université de Liège
Delft University of Technology

ITC dissertation number 274

ITC, P.O. Box 217, 7500 AE Enschede, The Netherlands

ISBN 978-90-365-3906-7

DOI $10.3990 / 1.9789036539067$

Cover designed by Benno Masselink

Printed by ITC Printing Department

Copyright (C) 2015 by R.P. Andrada de Palomera 


\title{
SPECTRAL PROSPECTIVITY MAPPING OF THE DESEADO MASSIF, ARGENTINA - DECIPHERING THE GEOCHEMISTRY AND MINERALOGY OF A LOW TO INTERMEDIATE SULFIDATION EPITHERMAL SYSTEM
}

\author{
DISSERTATION
}

to obtain

the degree of doctor at the University of Twente, on the authority of the rector magnificus, prof.dr. H. Brinksma,

on account of the decision of the graduation committee, to be publicly defended

on Wednesday, July 1, 2015 at 12:45

by

Raul Pablo Andrada de Palomera born on August 11, 1967

in Río Gallegos, Argentina 
This thesis is approved by

Prof. dr. Freek D., van der Meer, promoter

Dr. Frank J.A., van Ruitenbeek, co-promoter 


\section{Acknowledgements}

The completion of this thesis was possible thanks to the contributions of four organizations and many persons. The ITC Faculty of the University of Twente, Fomicruz S.E., Cerro Vanguardia S.A., and Cerro Cazador S.A. provided the infrastructure, equipment, data, and financial and logistical support necessary for this research.

I sincerely thank my promoter, Prof. dr. Freek van der Meer, for his always helpful advice, his knowledgeable scientific contributions, and his confidence that I would complete my PhD. I am particularly grateful to my co- promoter, Dr. Frank van Ruitenbeek, for his guidance and continuous contributions, suggestions and meetings either in person or remote, but also for his friendship and patience. I also thank Professor Martin Hale for his help and advice during the early stages of my PhD research.

For their continuous support, I am very grateful to the current and former managers of Fomicruz: Oscar Vera, Jorge Valvano, Maria Jose Llorens, Miguel Ferro, Norma Abuin, and especially Roberto Traba for encouraging me to undertake this research. I also thank Daniel Pérez and Sergio Albornoz, for their support and fellowship.

I thank Boudewijn de Smeth, for his friendship and help during every one of my visits to ITC, and for carrying out XRD and XRF analysis for this thesis. I thank John Carranza, for his friendship, critical comments and scientific input for part of this thesis. I also thank other people from ITC who helped me in several ways, or with whom I shared many chats and technical discussions during lunch/coffee brakes: Bart Krol, Chris Hecker, Dhruba Shrestha, Wim Bakker, Harald van der Werff, Mark van der Meijde, Yijian Zeng, Javier Martinez, Ruben Vargas, Iris van Duren, Loes Colenbrander, Aiko Mulder, Bettine Geerdink, Petra Weber, and Tina Tian.

I am very grateful to Sanaz Salati, Xiaogang (Marshall) Ma and Lyande Eelderink, my very good friends from ITC; thanks for your help and the good moments we enjoyed together during my stay in Enschede.

I thank my mother, Maria de la Paz, for her love and continuous support.

Finally, my strongest gratitude is for my wife Pía, and our children Pilar and Federico, for their love, support and understanding, and also for tolerating my partial absence, before and during my PhD research. 


\section{Contents}

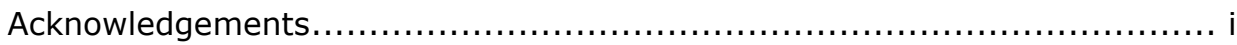

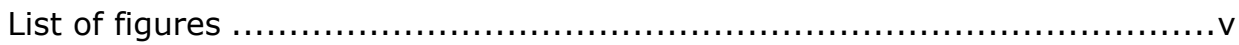

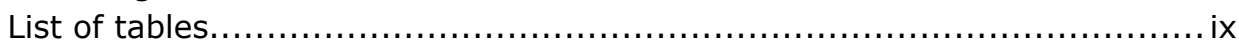

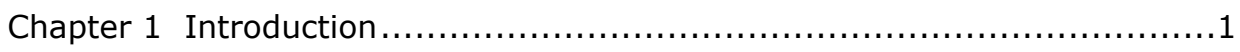

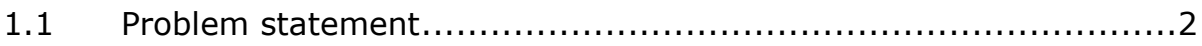

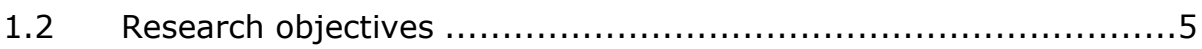

1.3 Gold-silver low- and intermediate-sulfidation epithermal deposits .. 5

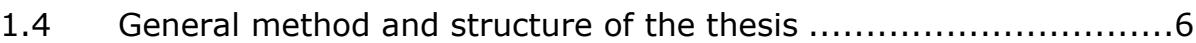

Chapter 2 Geology and epithermal mineralization in the Deseado Massif .....9

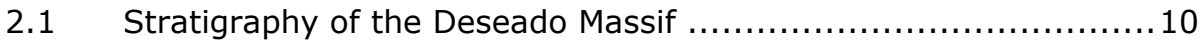

2.2 Structural geology and geodynamic setting of the

Deseado Massif .................................................... 14

2.3 Epithermal gold-silver mineralization in the Deseado Massif ........ 15

Chapter 3 Prospectivity for epithermal gold-silver deposits in the

Deseado Massif, Argentina............................................. 19

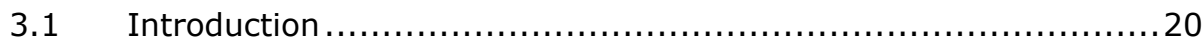

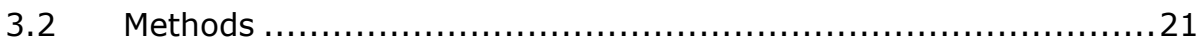

3.2.1 Weights-of-evidence method ............................. 22

3.2.2 Preparation of evidence layers ............................. 23

3.2.3 Spatial association analysis and predictive mapping ...........31

3.2.4 Assessment of predictions at regional- and district-scales .... 32

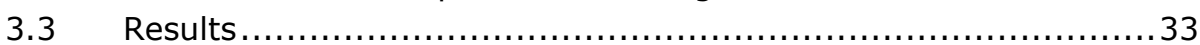

3.3.1 CI tests of the different models ............................ 33

3.3.2 Spatial association analysis and predictive mapping in the

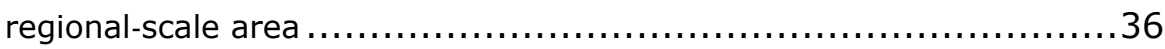

3.3.3 Spatial association analysis and predictive mapping in the

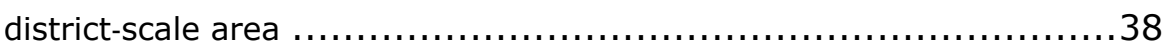

3.3.4 Assessment of regional- and district-scale predictions . ......42 42

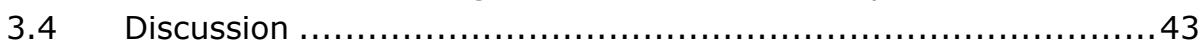

3.4.1 Prospectivity mapping for LISEDs in the Deseado Massif ....43

3.4.2 Regional-scale vs. district-scale prospectivity mapping . ......45

3.4.3 Assessing the usefulness of evidence layers and improving the prospectivity mapping ......................46

3.5 Conclusions.................................................... 49

Chapter 4 Geology and mineralization of the La Josefina deposit ............51

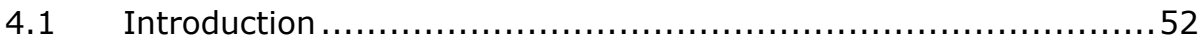

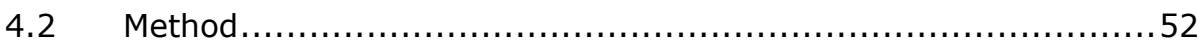

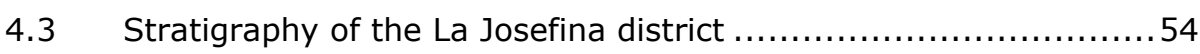

4.4 Mineralization in the La Josefina deposit ........................... 56

4.5 Rock alterations and other hydrothermal products ................. 58

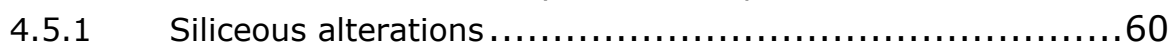




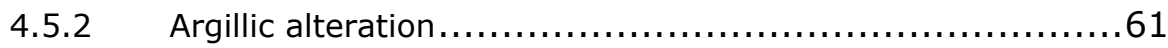

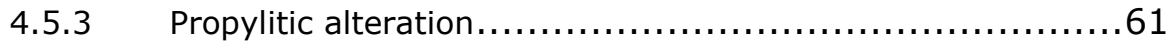

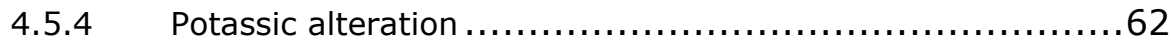

4.5.5 Other epithermal products ................................... 62

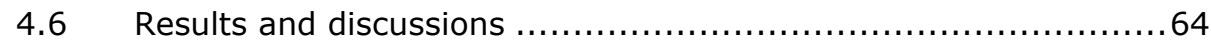

4.6.1 Conceptual model of the epithermal paleo-system at La Josefina................................................. 64

4.6.2 The upper portions of the paleo-system ......................6 64

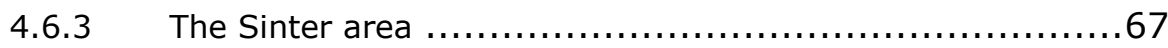

4.6.4 The lower portions of the paleo-system ......................69

4.6.5 Hypothetical model of the epithermal paleo-system ..........72

4.7 Conclusions.............................................................. 75

Chapter 5 Geochemical indicators of gold-rich zones in the

La Josefina epithermal deposit ...................................................... 77

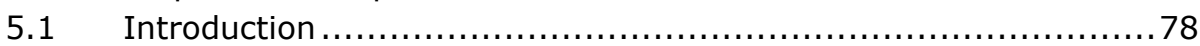

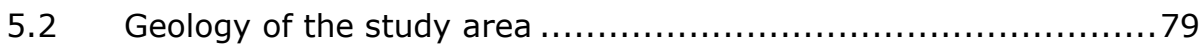

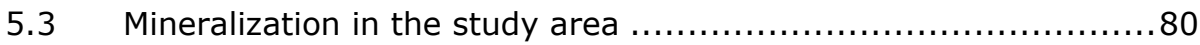

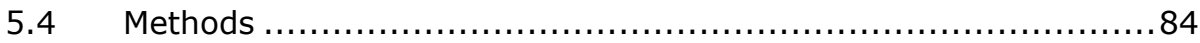

$5.4 .1 \quad$ Geochemical data.......................................... 85

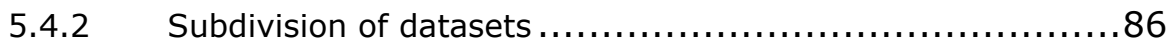

5.4.3 Statistical treatment of the geochemical data................ 88

5.4.4 Geochemical study at deposit-scale .......................... 88

5.4.5 Geochemical study at detailed-scale ....................... 90

5.5 Results and Discussion .............................................. 91

5.5.1 Hydrothermal alteration in the study area ...................91

5.5.2 Timing and relation between mineralization and hydrothermal alterations .................................. 93

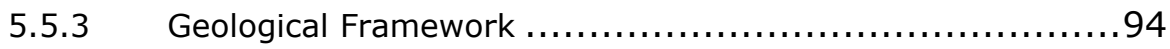

5.5.4 Results of the study at deposit-scale ......................95

5.5.5 Result of the study at detailed-scale ....................... 101

5.5.6 Geochemical indicators ................................. 106

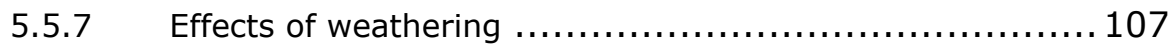

5.5.8 Implications for exploration............................... 109

5.6 Conclusions........................................................ 111

Chapter 6 Characterizing the hydrothermal alteration system

at the La Josefina deposit with reflectance spectroscopy ....................... 113

$6.1 \quad$ Introduction ......................................................... 114

H.2 Hydrothermal alteration in Low- and
Intermediate-Sulfidation Epithermal Deposits (LISEDs) ............ 115

6.3 Background of Reflectance Spectroscopy .......................... 117

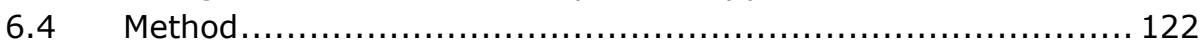


6.4.1 Generalities ............................................ 122

6.4.2 Spectroscopic data acquisition and processing ............. 123

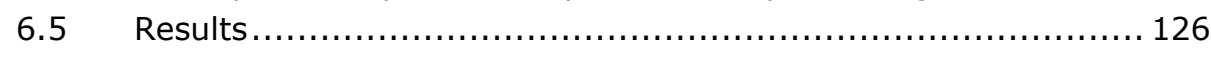

6.5.1 Spectroscopic determinations in comparison with

XRD analyses......................................... 126

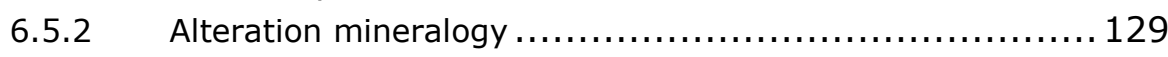

6.5.3 Variations of the position of the AlOH absorption

feature in white micas and smectites .................... 137

6.5.4 Variations in white mica crystallinity ..................... 140

6.5.5 Variations in kaolinite crystallinity ....................... 142

6.5.6 Spatial distribution of selected chemical elements ......... 145

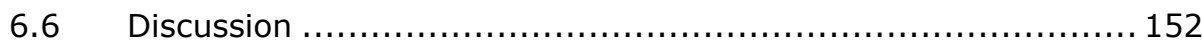

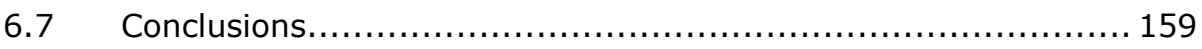

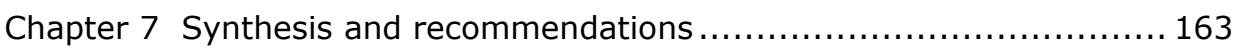

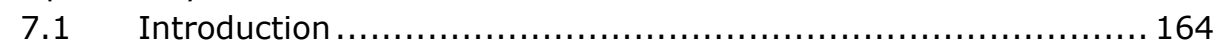

7.2 Assessing the efficiency of geological evidence $\ldots \ldots \ldots \ldots \ldots \ldots \ldots \ldots . \ldots 164$

7.3 Geochemical and hydrothermal clay alteration evidence ........... 165

7.3.1 Geochemistry of the La Josefina epithermal deposit ........ 166

7.3.2 Hydrothermal alteration mineralogy in the epithermal paleo-system at La Josefina ................... 167

7.3.3 Geochemical and spectral indicators ..................... 173

7.4 Towards new insights in LISED in the Deseado Massif ............. 175

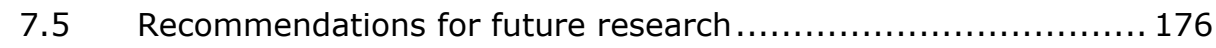

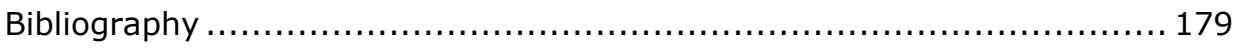

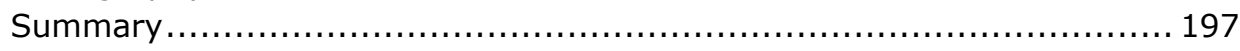

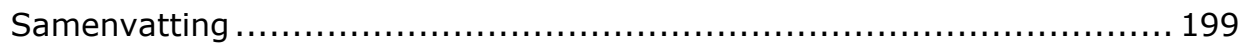

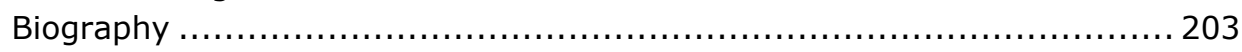

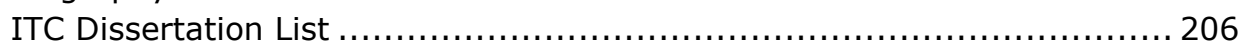




\section{List of figures}

Figure 1.1: Location map of the Deseado Massif and the areas studied in the following chapters.

Figure 2.1: Geology of the study area, comprising most of the Deseado Massif. It includes the regional-scale and the district-scale areas studied in chapter 3. Lithology was extracted from 1:250,000 scale geological maps published by SEGEMAR. 10

Figure 2.2: Summarized stratigraphic chart for the Deseado Massif. The Bajo Grande and younger Formations are considered post-mineralization. 12 Figure 3.1: Mosaic of 11 Landsat 7 ETM+ scenes, showing bands 7 and 5 used to calculate the band ratio $5 / 7$ (Figure 3.2 ) representing hydrothermal clay alteration evidence .27

Figure 3.2: Ratio of Landsat band 5 over band 7, considered representative of clay alteration and used for extracting the binary map of alteration evidence for regional-scale mapping. .28

Figure 3.3: Spectra of five alteration minerals commonly found in LISEDs (Grove et al., 1992-JPL1 data), and wavelength ranges of ASTER and Landsat 7 ETM+ bands. 28

Figure 3.4: Mosaic of four ASTER scenes showing SWIR bands 4 and 6 . These bands were used to calculate the band ratio 4/6 (Figure 3.5) representing hydrothermal clay alteration evidence for district-scale mapping. 29 Figure 3.5: Resultant images from processing of ASTER SWIR and TIR bands. Band ratio $4 / 6$ represents clay alteration. The $K_{\text {silica }}$ index represents silica abundance and was calculated using TIR bands 10, 11, 12 and $13 . \ldots \ldots \ldots . . .30$ Figure 3.6: a), b), c) Binary predictor maps representing results from the spatial association analysis (Table 3-3) of the regional-scale dataset corresponding to model Reg-1 (Table 3-2). These maps are useful for conditional independence tests and generating posterior probability maps. d) Results of pairwise test of conditional independence for the predictor maps.37 Figure 3.7: Regional-scale posterior probability map. Classes of posterior probability are discrete values produced directly from the WofE calculations.

Figure 3.8: Regional-scale favourability map. Favourable areas are those with posterior probabilities higher than the prior probability. ................... 39 Figure 3.9: Binary predictor maps representing the generalization of cumulative percentile evidence classes (Table 3-4) into two classes with predictor patterns present and absent, which are awarded the values of $\mathrm{W}^{+}$ and $W^{-}$respectively. Dark grey shows the predictor patterns present. ....... 41 Figure 3.10: District-scale probability maps. (a) Posterior probability map of LISEDs occurrence, showing the eight discrete classes of posterior probability produced by the WofE statistical calculations. (b) Favourability map for LISEDs occurrence. 
Figure 4.1: Location and general geology of the La Josefina deposit. Lithology modified from Moreira (2005). Magnetic lineaments extracted from Peñalva et al. (2005) .53

Figure 4.2: Volcanic stratigraphy in the La Josefina district. The Chon Aike Formation is divided in Members. Summarized from Moreira (2005), Moreira et al. (2009) and Peñalva et al. (2005). A belt of hydrothermally altered rocks is defined by the location of the seven indicated areas................. 55 Figure 4.3: Pervasive silicification in the Lejano area. The picture on the left shows preserved laminations. .............................................. 60 Figure 4.4: Outcrops of the siliceous layer in the north of the Sinter area (Loma del Plato hill). ..................................................63 Figure 4.5: Schematic interpreted cross section across the Lejano and Subsinter areas (see location in Figure 4.2) . .............................65 Figure 4.6: Sinter-breccia in the east of Lejano area..........................66 Figure 4.7: View of the Sinter area from the east (Lejano area), showing the siliceous layer's outcrops. The Mogote Hormigas hill is located on a NNW trending branch of the siliceous outcrops, which follows the Mogote Hormigas fracture zone. Other branch of outcrops follows a NE trend and it passes nearby the Mogote Divisoria hill. Aligned white dots are pit-shaped trenches used for geochemical and spectroscopic sampling (see Chapter 6)..........68 Figure 4.8: Schematic interpreted cross section across the Sinter area

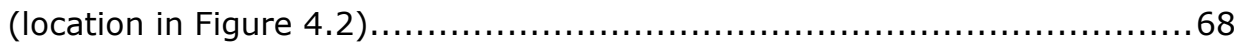
Figure 4.9: Schematic interpreted cross section across the Veta Norte area

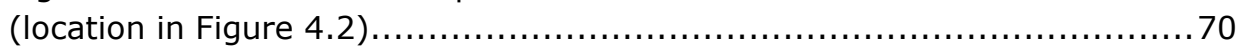
Figure 4.10: Schematic interpreted cross section across the Central area

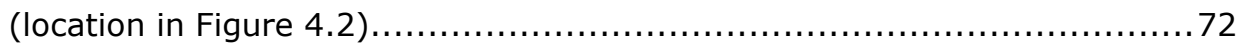
Figure 4.11: Hypothetical conceptual model of the La Josefina deposit. Most information was extracted from literature. The alteration zones represent general areas where the indicated minerals are expected to predominate. The configuration of the system is only conceptual with just some customizations to the La Josefina case. The graph represents a snapshot in time of an ideal paleo-system ............................................................. 74 Figure 5.1: Map of the study area in the northern portion of the Veta Norte area (see location in Figure 4.1). Boreholes were drilled sub-parallel to the cross sections, towards SW............................................. 81 Figure 5.2: Paragenetic sequence of the La Josefina deposit (modified from

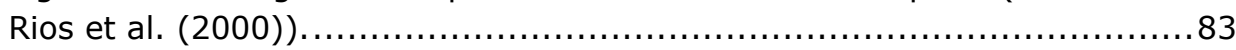
Figure 5.3: Vertical cross sections of the mineralized zone (VNS01b/04b/05b) and non-mineralized zone (VNS03b) showing the drillcore samples used during this research and buffers at every $10 \mathrm{~m}$ from mineralized paleo-

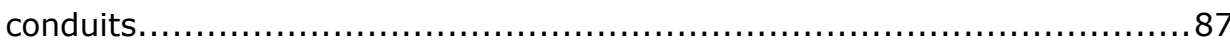

Figure 5.4: Hydrothermal alterations in cross sections synthesized from descriptions of drill cores. The system of veins and its footwall and hanging wall are indicated. 
Figure 5.5: Histograms showing bimodal distributions of $\mathrm{Mn}, \mathrm{TiO} 2$ and $\mathrm{Sr}$ in the mineralized zone (MZ), and of $\mathrm{Zn}, \mathrm{Na} 2 \mathrm{O}, \mathrm{CaO}, \mathrm{AI}$ and $\mathrm{K} 2 \mathrm{O} / \mathrm{Na} 2 \mathrm{O}$ in the non-mineralized zone (NMZ).EP = estimated protolith. Arrows indicate median concentrations in the other datasets. ...............................97 Figure 5.6: Isocon diagram and table based on median concentrations for the mineralized and non-mineralized zones. The isocon line (slope $=0.89$ ) is based on the concentrations of aluminum as immobile element. The median concentrations of elements were scaled to represent them in the same diagram. The table shows a comparison between the gains and losses of elements calculated with the isocon method of mass balance and the change in concentration calculated without mass balance (from Table 5-1); both are represented in percentages of the concentrations in the estimated protolith (CiO). Zinc, $\mathrm{Sr}, \mathrm{Na}_{2} \mathrm{O}, \mathrm{CaO}$ and $\mathrm{TiO}_{2}$ show bimodal distributions in one of the zones; thus, the approximate values of both modes were plotted with distinct symbols but were not shown in the table. Elements that show concentrations below $\mathrm{DL}$ in $>15 \%$ of the samples from one or both zones are not shown in the figure. 100

Figure 5.7: Boxplots and models of compositional variation with data from the mineralized zone. Distance 0 coincides with the mineralized paleoconduits. Small circles are regular outliers; asterisks are extreme outliers.102 Figure 6.1: Generalized distribution of hydrothermal alterations in LISEDs. Temperature, position of boiling zone, and depth of water table are important controlling factors on distribution of alterations....

Figure 6.2: Example of trenches in the Sinter area, from which samples were collected a) and b) pit-shaped trenches representing a sampling point; c) E$\mathrm{W}$ line of pit-shaped trenches; d) regular elongated trench in the Veta Norte area. 124

Figure 6.3: Calculation of white micas crystallinity and kaolinite crystallinity.

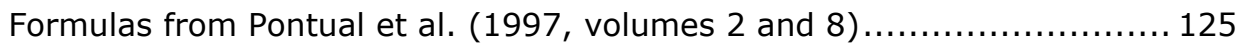
Figure 6.4: Reflectance spectrum of a sample from the east of Lejano area, interpreted as predominant smectite. 128

Figure 6.5: Reflectance spectrum of sample 11.004, containing chlorite, phengite and probably smectite.......................................... 129 Figure 6.6: Spatial distribution and degree of predominance of white micas in the la Josefina deposit. ................................................... 130 Figure 6.7: Spatial distribution and degree of predominance of smectites in

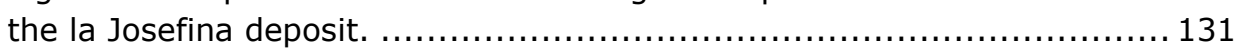
Figure 6.8: Reflectance spectrum of pervasively silicified rock collected from the Subsinter area (sample AL.002).

Figure 6.9: Spatial distribution and degree of predominance of kaolinite in the la Josefina deposit. 134

Figure 6.10: Spatial distribution and degree of predominance of chlorite in the la Josefina deposit. 135 
Figure 6.11: Reflectance spectrum of rock that contains minor chlorite from the eastern part of the Sinter area......................................... 136 Figure 6.12: Histrogram of wavelengths positions of the AlOH feature of white

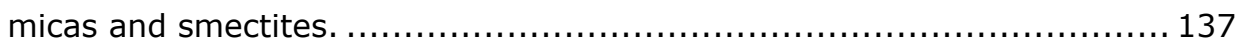

Figure 6.13: Box-and-whisker plots of the variation of wavelength of the AlOH absorption feature in white micas using only samples showing

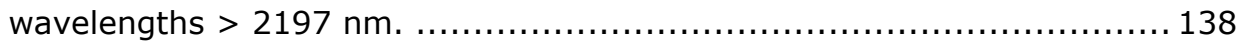

Figure 6.14: Spatial distribution of the wavelength positions of $\mathrm{AlOH}$ absorption feature in white micas and smectites. The Lejano and Subsinter areas show wide ranges of values and include the shortest wavelength positions in La Josefina. Note the sharp contrast in the Sinter area. 139 Figure 6.15: White micas crystallinity in three areas that show bimodal distributions. ........................................................ 140

Figure 6.16: Spatial distribution of the crystallinity values of white micas. 141 Figure 6.17: Histogram of kaolinite crystallinity values, calculated from all samples with predominant kaolinite (398 samples). .................... 142 Figure 6.18: Box-and-whisker plots of kaolinite crystallinity values in different areas of the deposit. The Subsinter and Lejano areas show a clear difference with the areas containing veins. Low values in the Sinter area fit with the data from the Subsinter and Lejano areas............................... 143

Figure 6.19: Spatial distribution of kaolinite crystallinity values............. 144 Figure 6.20: Kaolinite crystallinity distributions in Veta Norte and Lejano.. 145 Figure 6.21: Bimodal distribution of log-transformed Pb concentrations.... 146 Figure 6.22: Spatial distribution of Au concentrations. ...................... 147 Figure 6.23: Spatial distribution of Ag concentrations. ....................... 148

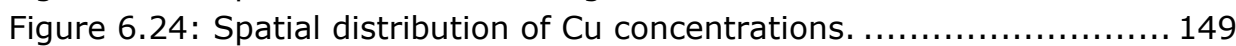
Figure 6.25: Spatial distribution of Pb concentrations. ...................... 150 Figure 6.26: Spatial distribution of As concentrations. ..................... 151 Figure 6.27: Cross sections showed in chapter 4, updated with the incorporation of mineralogical information produced in chapter 6 . WMx $=$ white micas crystallinity; $\mathrm{Kx}=$ kaolinite crystallinity. 156 Figure 7.1: Samples that show white micas, smectites or kandites (kaolinite or dickite) as predominant minerals overlain on the binary predictor map derived from the ASTER band ratio 4/6, and used for district-scale predictive mapping. 171 Figure 7.2: Samples showing white micas, smectites or kandites (kaolinite or dickite) as predominant minerals overlain on the binary predictor map derived from the Landsat band ratio 5/7, and used for regional-scale predictive mapping. 172 


\section{List of tables}

Table 2-1. Characteristics of the four most widely observed faults systems in the Deseado Massif (extracted from Panza (1982), Panza (1994b), and Reimer et al. (1996) .................................................. 14 Table 3-1. Recognition criteria for epithermal deposits in the Deseado Massif at regional- and district-scale, concepts used to define the criteria and

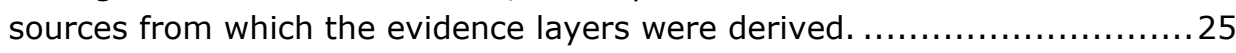
Table 3-2. Results of the tests of conditional independence produced from six models. .35

Table 3-3. Results from the spatial association analysis between regionalscale evidence and LISEDs, including weights (W), contrasts (C), and studentized contrast (SigC). Favourable lithology includes the Chon Aike, La Matilde and Bajo Pobre Formations. Underlined classes show optimum spatial association with LISEDs, and were considered as predictor patterns. .........36 Table 3-4. Results from the spatial association analysis between LISEDs and district-scale evidence layers inside areas of favourable lithology of the highresolution lithological map. The spatial association parameters include weights (W), contrast (C), and studentized contrast (SigC). Underlined classes show optimum spatial association and were considered predictor patterns. 40

Table 3-5. Confusion matrix derived from cross operation of regional and district-scale favourability maps, in areas of favourable lithology of the district-scale area. Values are number of $100 \times 100 \mathrm{~m}$ cells in the maps. .....43 Table 4-1. Hydrothermal alterations observed in the La Josefina deposit. ...59 Table 5-1. Comparison of median element concentrations and alteration indices of three datasets: estimated protolith, mineralized zone and nonmineralized zone. ............................................................. 96 Table 5-2. Statistics for element concentrations in distance intervals from mineralized paleo-conduits, using separate datasets for strongly oxidized and weakly oxidized rocks. 105

Table 5-3. Median concentrations, and percentage of samples with element concentrations below detection limit (DL) in weakly oxidized mineralized paleo-conduits and their immediate host-rocks, for elements that show concentrations below DL in $>15 \%$ of the samples of the mineralized zone (not included in Table 5-2). 106

Table 5-4. Strengths and ranges of elements that show compositional drifts in weakly oxidized rocks. The range is the distance from mineralized paleoconduits, up to which the compositional drifts of the median concentration is preserved. Changes in median concentrations between every two consecutive distance intervals along the curves were calculated as percentage of the shorter-range interval. The "strength" is the average of all the percentages of change between pairs of intervals up to the considered range.... 
Table 6-1. Changes in spectral features with composition (Compiled from Bierwirth et al., 2002; Huston et al., 1999; McLeod et al., 1987; Pontual et al., 1997; Scott et al., 1998; Thompson et al., 1999)........................... 119 Table 6-2. Comparison between determinations made by spectroscopy and those made with XRD. Minerals are listed in order of importance.............127 Table 7-1. Comparison of the field alteration data that was acquired from the La Josefina deposit with the binary predictor maps of hydrothermal clay alteration that were used for prospectivity mapping (in Chapter 3 )......... 170 
Chapter 1

Introduction 


\subsection{Problem statement}

The "low- and intermediate-sulfidation epithermal deposits" (LISEDs) are amongst the most common sources of gold and silver for our society. They are formed in the upper part of the Earth crust by hot watery fluids that travel from depth through fractures and can deposit $\mathrm{Au}$ and $\mathrm{Ag}$ in relatively narrow quartz veins and breccias at certain level of the epithermal system, where the ascending fluids encounter the right physiochemical conditions. These fluids also produce hydrothermal alteration and rock geochemical variations around the feeder conduits because the host rocks are not in equilibrium with the new conditions imposed by the fluids. As these modifications occur in zones that are wider than the veins or breccias containing $\mathrm{Au}$ and $\mathrm{Ag}$, they are easier to identify.

The exploration for LISEDs at different scales is expensive and timeconsuming. At regional-scale, the areas to explore are large; and thus, prioritizing some of the areas to be studied with more detail is necessary for using the resources more efficiently. At more detailed scales, expensive techniques like trenching and drilling should be used. The methods used at different scales are often unsuccessful to find ore, and thus inefficient. This often occurs because of a poor understanding of the epithermal systems in the explored regions and because of the small size of the mineralized areas.

The prioritization of areas can be achieved after estimating the possibility to find LISEDs in those areas by using the geological evidence that is known to be associated with these types of deposits. This estimation can be done qualitatively by traditional mineral exploration methods, which include overlapping different types of evidence, either in the form of maps or concepts; but it can also be done quantitatively by different methods of prospectivity mapping, such as using statistical calculations involving those types of evidence in the form of maps.

Whichever method is used, the relationship between mineralization and the types of evidence used should be well known to produce useful results. Mineral deposits prospectivity can be better mapped by increasing our understanding of the different types of geological evidence that they produce, which are mainly the hydrothermal alterations, and the inseparable geochemical compositional rock changes. These two modifications produced in the host rocks are mainly functions of the paleo-fluid's physiochemical conditions and the original composition of the rocks.

Although LISEDs have been studied for long time, some of their components are still not known in detail, especially in areas that have been poorly explored, such as the Deseado Massif in the south of Argentina. The 
distribution of hydrothermal alteration minerals and elements around LISEDs are known only in general. Many details that are potentially useful for exploration are still poorly known, such as the compositional and crystallinity variations of white micas and kaolinite in the epithermal paleo-systems; as well as the variation of elements concentrations as a function of distance from feeder conduits and depth in the paleosystems, and how these concentrations differ between areas with mineralized and non-mineralized feeder conduits. This lack of knowledge is specially noticed in the Deseado Massif. Alteration minerals, and with limitations, their relative abundance, compositions and crystallinity, can be determined using reflectance spectroscopy, which is relatively cheap, easy and fast to use, but it has not been much studied in LISEDs yet.

In addition to the lack of knowledge about the distribution of alteration minerals and elements in epithermal paleo-systems of the Deseado Massif, other important reason for studying those paleo-systems resides in the difficulty for reconciling some assumptions about the genesis of epithermal deposits in the area with assumptions about their volcano-tectonic setting. The Chon Aike and Bajo Pobre Formations in the Deseado Massif were likely produced in a rift-related extensional setting. However, the geochemistry of the Chon Aike Formation indicates a continental volcanic arc signature (Pankhurst et al., 1998; Riley et al., 2001), similar to subduction-related magmatic series (Sruoga et al., 2014). Several authors referred to the Deseado Massif and its epithermal deposits as produced in a back-arc setting (Echavarría et al., 2005; Giacosa et al., 2010; Moreira and Fernández, 2015; Sillitoe, 2002), implying that there was already subduction operating when the rhyolitic volcanism occurred.

Considering the whole "Chon Aike siliceous large igneous province (LIP)", several authors (Bryan et al., 2002; Pankhurst et al., 2000; Riley et al., 2010) suggested that the rhyolitic volcanism evolved from rocks with intraplate geochemical signatures to rocks with calcalkaline signatures. Those with intraplate signature formed at $\sim 188-178 \mathrm{Ma}$, near the locus of flood basalt volcanism (Karoo and Ferrar provinces), and are located in Antarctica and north east of Patagonia. Those with calcalkaline signatures formed at 157-153 Ma, further away from the Karoo and Ferrar provinces, and are located in the Andes of Argentina and Chile. Between those two areas, the Chon Aike and Bajo Pobre rocks are located, showing also arc signatures and ages of $\sim 171-167 \mathrm{Ma}$. According to the definitions of Bryan et al. (2002) and Bryan and Ernst (2008), the inclusion of the Deseado Massif in the Chon Aike LIP should imply its intraplate tectonic setting, which seems to contradict the inferred back arc formation setting. However, it seems common to have arclike geochemical signatures reflecting subduction contamination of lithospheric mantle sources, apparently contradicting the intracontinental 
settings in which they were emplaced after the end of subduction (de Boorder, 2012; Pirajno and Santosh, 2014).

Low-sulfidation epithermal deposits can occur in a variety of continental and island arc rifts, such as intra-, near-, or back-arc settings, during or after subduction, as well as after collision (Sillitoe, 2002; Sillitoe and Hedenquist, 2003). Examples of low-sulfidation epithermal deposits (LSEDs) hosted in extensional intra-arc settings with bimodal rocks suites are the Middle to Late Jurassic Esquel veins (Patagonian Andes), the Paleocene El Peñon veins (Chile), and the Hishikari veins (Japan). Some in back-arc settings are the Miocene deposits within and near the northern Nevada rift in the Great Basin of the USA (Ivanhoe, Midas, Mule Canyon, Sleeper). Also deposits in the Katami region such as Konomai, and those in the north of Washington (USA). In extensional post-collision settings, there are examples (such as Baley) in the Cretaceous rifts of the Mongol-Okhotsk belt in Russia and Mongolia.

The bimodal rocks suite in the Deseado Massif region is expected to host lowsulfidation epithermal deposits if they were produced in a rift-related extensional setting; in contrast to intermediate- and high-sulfidation deposits, which are expected to occur in subduction-related convergent plate margins (John, 2001; Sillitoe, 2002; Sillitoe and Hedenquist, 2003). Most deposits in the Deseado Massif are from the low-sulfidation style, but interestingly, some deposits are of the intermediate-sulfidation style. Is the presence of intermediate-sulfidation epithermal deposits other evidence that the rocks in the Deseado Massif were related with subduction? Can the distribution of these types of epithermal deposits (low- and intermediatesulfidation) also indicate the evolution of the volcanism from intraplate to plate margin setting? It is beyond the scope of this research to answer these questions, but it is hoped to add information about epithermal deposits in the Deseado Massif that will eventually contribute to answer it.

The aim of this research is to provide extra knowledge about LISEDs in the Deseado Massif, mainly regarding the distribution of alteration minerals and elements concentrations in LISEDs, which is applicable during exploration to increase the possibilities to find Au mineralization, optimizing the necessary resources. The distribution of some minerals and some of their characteristics are potentially detectable with remote sensing datasets. During this research, the weights of evidence (WofE) data driven method was used for prospectivity mapping in the Deseado Massif. With this method, prospectivity maps for Au-Ag LISEDs were generated at regional and district scales, and further investigation of the geochemistry and hydrothermal alterations in this region surged as a need. Then, the spatial distribution of element concentrations, hydrothermal alteration minerals and some mineral characteristics, were studied with the objective of better understanding their 
relationships with mineralization and ultimately for improving future predictions of prospectivity. In addition, the possible effects of weathering on the geochemical distributions in surface and subsurface materials were investigated to get an idea of the reliability on data extracted from outcrops, regolith and trench materials. Field reflectance spectroscopy of outcrops and regolith was used to determine the hydrothermal alteration minerals and spectral parameters of some of them.

\subsection{Research objectives}

This research had three main objectives:

1) To determine the geological types of evidence that need to be further investigated for improving the results of prospectivity mapping and mineral exploration for low- and intermediate-sulfidation epithermal deposits in the Deseado Massif.

2) To determine the spatial relationships between mineralized zones and the types of evidence that need to be better understood, and to derive indicators for the different vertical position in the paleo-system and relative proximity to mineralized areas.

3) To increase the knowledge about low- and intermediate-sulfidation epithermal deposits in the Deseado Massif, to better understanding their mechanisms of formation, the effects they produce on the host rocks, and the nature of their volcano-tectonic setting.

\subsection{Gold-silver low- and intermediate-sulfidation epithermal deposits}

For many years, the epithermal Low-sulfidation and intermediate sulfidation deposits were considered the same deposit type (low-sulfidation). Later, enough differences were recognized as to consider a separate type, the "intermediate sulfidation epithermal deposits", which were defined by Hedenquist et al. (2000). However, because these deposit types are often difficult to differentiate they were not separated in this research, referring to them as "low- and intermediate-sulfidation epithermal deposits" (LISEDs).

In general, these two deposit types show many similarities. Both are hosted in veins, with fine to coarse quartz and variable amounts of calcite, barite, adularia, fluorite illite, smectite, rhodochrosite, K-mica and chlorite as gangue and alteration minerals; a minority is hosted in stockworks and breccias, or as disseminated ore in Fe-sulfides. Their ore minerals can be electrum, native gold, Ag-sulfosalts and Au-tellurides. They are controlled by structures that 
drive the epithermal fluids, and their host rocks can be of variable composition from andesitic to rhyolitic or other rocks crossed by the epithermal fluids. Their sulfide assemblages can include pyrite, chalcopyrite, marcasite, pyrrhotite, arsenopyrite, galena, sphalerite, silver selenides, stibnite, tetrahedrite-tennantite, tellurides and acanthite. LISED are anomalously high in $\mathrm{Au}, \mathrm{Ag}, \mathrm{As}, \mathrm{Sb}, \mathrm{Hg}, \mathrm{Tl}, \mathrm{Pb}, \mathrm{Zn}, \mathrm{Se}, \mathrm{K}$, and $\mathrm{Cu}$. Some elements like $A s, S b$, and $\mathrm{Zn}$ form relatively wide halos around the ore. Arsenic, $\mathrm{Sb}, \mathrm{Hg}, \mathrm{B}, \mathrm{Tl}$, and $\mathrm{Au}$ tend to be concentrated in the upper part of the systems while $\mathrm{Cu}, \mathrm{Pb}, \mathrm{Zn}, \mathrm{Bi}, \mathrm{Se}, \mathrm{Te}, \mathrm{Co}$, and up to some extent $\mathrm{Ag}$ are more abundant in deeper levels and higher temperatures (Silberman and Berger, 1985).

However, in detail these two deposit types show some clearly different features (Einaudi et al., 2003; Hedenquist et al., 2000; John, 2001; Sillitoe and Hedenquist, 2003), mainly in their sulfide assemblages, the salinity of their fluids, geochemistry, and volcano-tectonic setting. The intermediatesulfidation deposits show i) more tennantite-tetrahedrite and Au-tellurides; ii) lower FeS content in sphalerite $(1-20 \mathrm{~mol} \%)$ in contrast to low-sulfidation deposits (20-40 mol\%S); iii) higher salinity of their forming fluids ( $>\sim 3 \mathrm{wt} \%$ $\mathrm{NaCl}$ eq. vs $<1 \mathrm{wt} \% \mathrm{NaCl}$ eq); iv) more abundant sulfides (> 5 vol \% vs < 1-2 vol \% in low sulfidation); $v$ ) higher total base metals content $(\mathrm{Cu}+\mathrm{Pb}+\mathrm{Zn})$ and higher $\mathrm{Ag} / \mathrm{Au}$ ratio; vi) higher amounts of $\mathrm{Ag}, \mathrm{Mn}$ and $\mathrm{Ba}$ (likely from barite), and lower amounts of $\mathrm{Au}, \mathrm{As}$ and $\mathrm{Hg}$; vii) finally, their volcano-tectonic setting is different; while the intermediate-sulfidation deposits are mainly formed in andesitic volcanic arcs, low-sulfidation deposits are mainly formed in extensional rift settings, often with bimodal volcanism, including abundant acid to mesosilicic rocks.

\subsection{General method and structure of the thesis}

The general method applied during this research begun with acquiring the necessary knowledge about LISEDs, which included mainly the general relationship established between mineralization and some geological evidence that can be applied for mapping the prospectivity of this deposit types. This was done by studying available literature of these deposits types worldwide, and studying the geology and mineralization in the Deseado Massif region, located in southern Argentina (Figure 1.1). This is shown in chapter 2 and part of chapter 3 . 


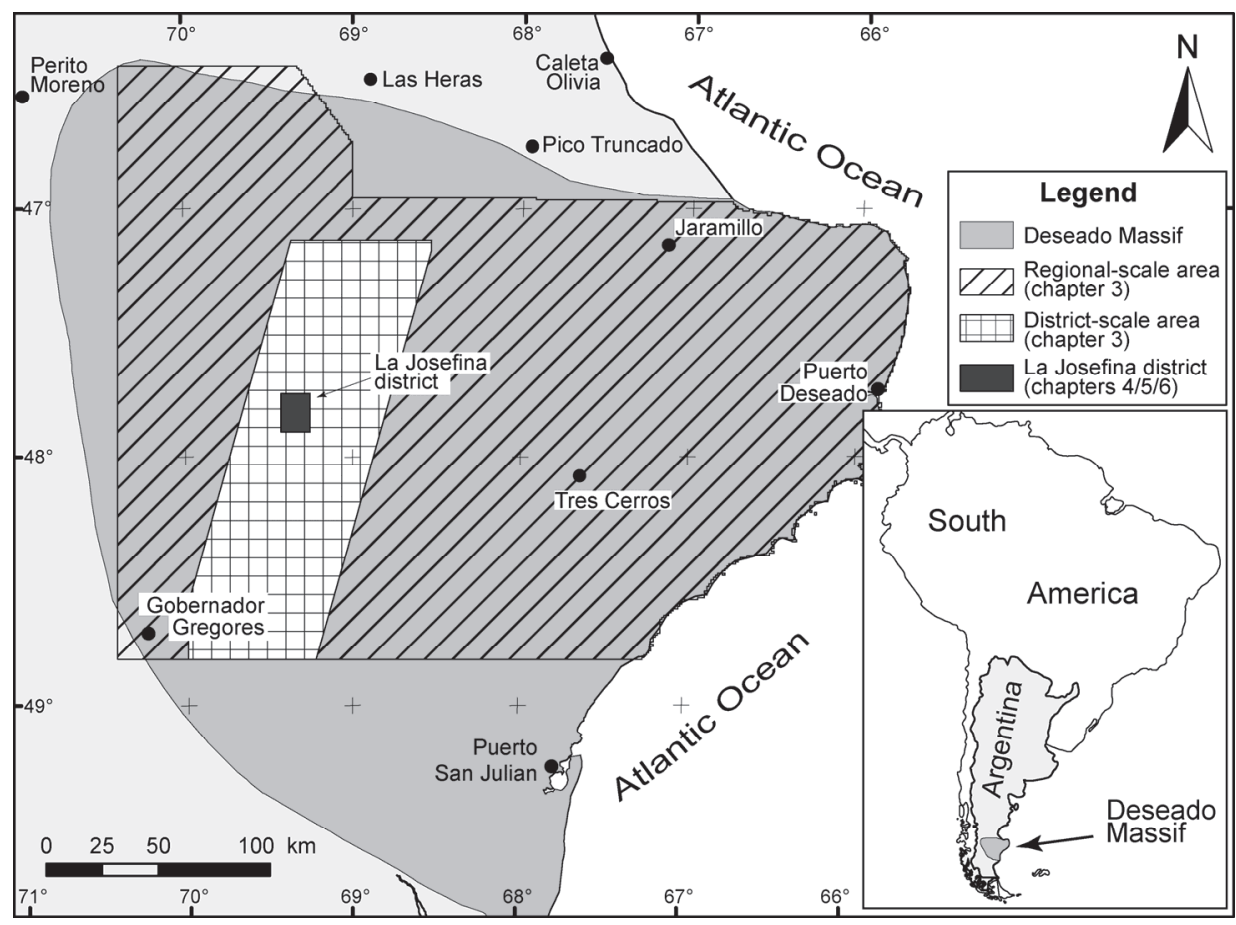

Figure 1.1: Location map of the Deseado Massif and the areas studied in the following chapters.

In chapter 3, different types of evidence were extracted from datasets available for most part of the Deseado Massif, and were transformed into evidence maps. The weights of evidence method was used for studying the spatial association between evidence maps and the most relevant LISEDs known in the region, and to produce probability and favourability maps. This was done at two scales, for which two sets of evidence maps were used. At regional-scale clay alteration, structural, and lithological evidence maps were used for the predictions; while at district-scale, clay alteration, silica abundance, and structural, evidence maps were used for predicting, and a lithological map was used to constrain the area of predictions to only the favourable lithology. From this work, two prospectivity maps were produced, one is at regional-scale and comparable with an available prospectivity map for the region; the other is at a more detailed scale, which conveys higher detail and is more suitable for the exploration of districts or smaller areas. This exercise suggested that the clay alterations evidence maps should be improved for producing better predictions. It was also inferred that geochemistry is probably another evidence to include in future prospectivity mappings to enhance the results.

Therefore, those two types of evidence (i.e., geochemistry and clay alteration) were studied in detail. For that, the La Josefina epithermal 
deposit, located in the centre-west of the Deseado Massif (Figure 1.1) was selected as laboratory. That deposit is currently in a relatively advanced stage of exploration, and has the advantage of showing different vertical portions of an epithermal paleo-system, at the current erosion level. Before studying the geochemistry and alterations, a compilation and interpretation of the available information of the deposit was carried out, constructing a hypothetical geological conceptual model of the deposit, in which seven explored areas with evidence of epithermal activity were represented. This is shown in chapter 4.

In chapter 5, the geochemistry was studied inside and immediately around the most mineralized part of the La Josefina deposit, but including a small adjacent area that is non-mineralized. The geochemistry was analysed in two general ways: i) in cross sections perpendicular to the veins, using data from diamond boreholes and studying the variation of elements concentrations with distance to the mineralized veins on the plane of each cross section; and ii) comparing the overall element concentrations in the host rocks of the mineralized area with those in the host rocks of the non-mineralized area. From these analyses, elements that can be used as geochemical indicators of mineralization were determined. In addition, the effect of weathering on the geochemistry was investigated by comparing elements concentrations below and above the limit of oxidation, which was considered as representative of the limit of weathering.

Then, in chapter 6, reflectance spectroscopy was used to study clay alterations in the seven mentioned areas, which are spread along the whole area affected by hydrothermal alteration and mineralization in the La Josefina deposit. This was done with the objectives of finding indicators of different levels of the epithermal paleo-system and of proximity to the mineralized veins, as well as to add information about LISEDs in the Deseado Massif. In different portions of the epithermal paleo-system, the mineralogy and spectral parameters were studied. This part of the research produced results that lead to identification of mineralogical and spectroscopic indicators.

Finally, in chapter 7 the results from the previous chapters were synthesized and the concepts acquired from the spectroscopic study were used to test the accuracy of the predictor maps that were previously used for the prospectivity mapping analysis.

The detailed methods applied during each steep of the research are explained in the corresponding chapters. 


\section{Chapter 2}

\section{Geology and epithermal mineralization in the Deseado Massif ${ }^{*}$}

\footnotetext{
* This chapter is mainly based on: Andrada de Palomera, P., van Ruitenbeek, F.J.A., Carranza, E.J.M., Prospectivity for epithermal gold-silver deposits in the Deseado Massif, Argentina, Ore Geology Reviews (2014), doi:

10.1016/j.oregeorev.2014.12.007.
} 


\subsection{Stratigraphy of the Deseado Massif}

The oldest rocks in the Deseado Massif (Figure 2.1) belong to the La Modesta Formation (Figure 2.2) of Upper Precambrian to Lower Paleozoic age (Schalamuk et al., 2002). They are schists, phyllites, slates, quartzites, gneisses, and amphibolites, which are intruded by granitic and tonalitic rocks with ductile to ductile-fragile deformations (Giacosa et al., 2002; Ramos, 2002a). Continental sedimentary rocks of the La Golondrina, La Juanita, and El Tranquilo Formations uncomformably overlie this formation. The Permian La Golondrina and La Juanita Formations include quartz-feldspathic sandstones, siltstones, lithic sandstones, orthoquartzites, and conglomerates. These are only present in the eastern part of the Deseado Massif. (Figure 2.1) The El Tranquilo Formation of Middle or Upper Triassic age (De Giusto et al., 1980) consists of alternating fine- to coarse-grained quartz sandstones, shales, fine-grained conglomerates (Sanders, 2000), and some intercalations of syn-sedimentary volcanic materials.

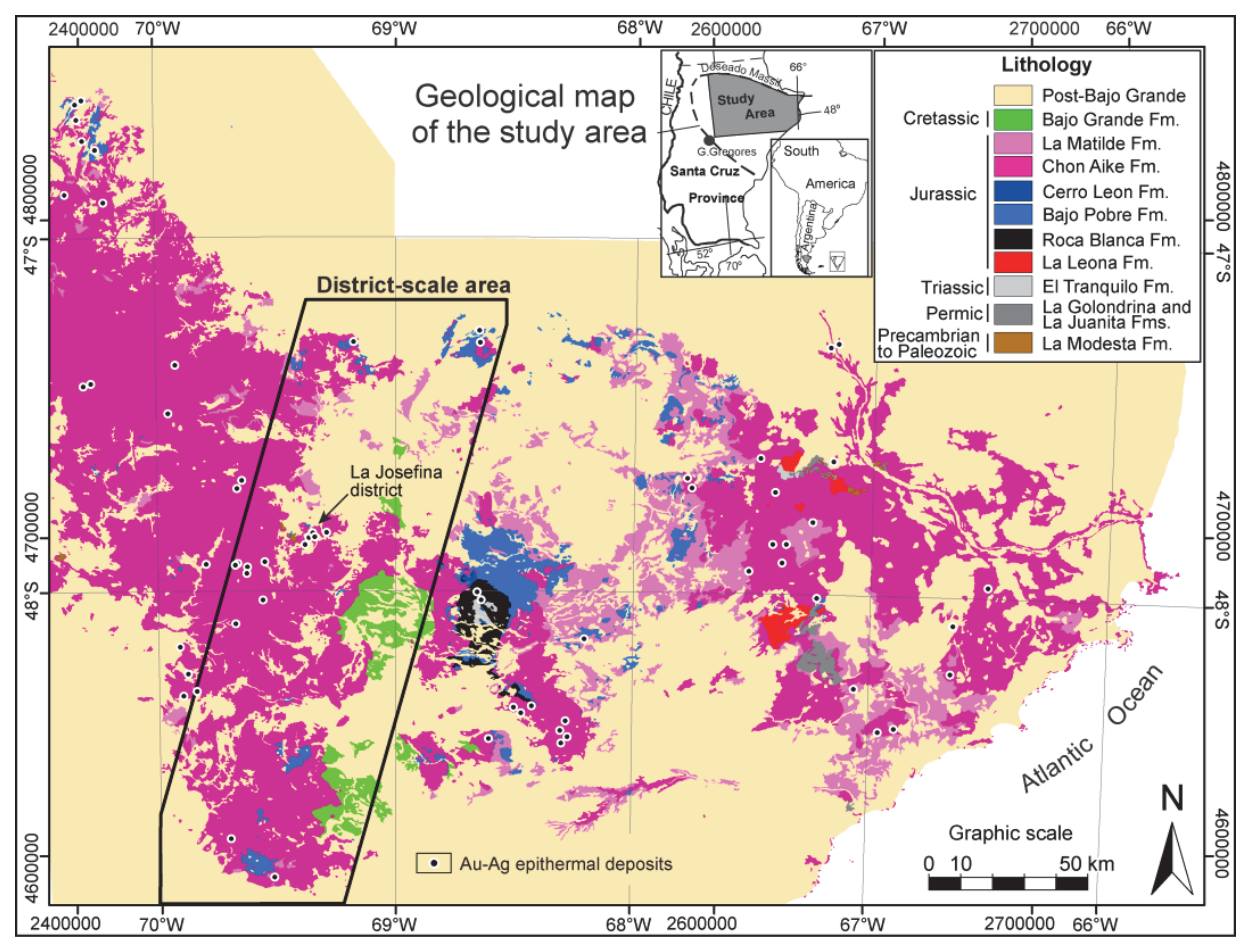

Figure 2.1: Geology of the study area, comprising most of the Deseado Massif. It includes the regional-scale and the district-scale areas studied in chapter 3. Lithology was extracted from 1:250,000 scale geological maps published by SEGEMAR.

During the Lower Jurassic, after the deposition of the El Tranquilo Formation, I-type granitic rocks of the La Leona Formation were intruded in the NE of the region (Márquez et al., 2002; Varela et al., 1991). These rocks are calc- 
alkaline granodiorites, granites, adamellites, tonalites and diorites (Godeas, 1985). During the rest of the Jurassic, abundant pyroclastic materials corresponding to the Roca Blanca, Bajo Pobre, Chon Aike, and La Matilde Formations were deposited. These formations filled NNW-trending grabens produced by the generalized extension that broke-up Gondwanaland and opened the South Atlantic Ocean.

The Roca Blanca Formation of Lower Jurassic (Liassic) age comprises a subaerial sequence of tuffs, sandstones, mudstones and volcanoclasticsedimentary rocks. It has a maximum thickness of $900 \mathrm{~m}$ (Panza, 1982) and was deposited in active rift basins (Sanders, 2000).

The Bajo Pobre Formation (Figure 2.2) of middle Jurassic age is composed of predominant porphyritic to aphanitic olivine basalts, subordinate porphyritic andesites and basaltic agglomerates, and minor mafic tuffs, conglomerates and sandstones (Sanders, 2000). Its thickness varies from 150 to $200 \mathrm{~m}$ in most outcrops, but locally reaches up to $600 \mathrm{~m}$ (Panza, 1994b). Related to the magmatic episode that produced the Bajo Pobre Formation, hypabyssal porphyritic andesites of the Cerro Leon Formation intruded the El Tranquilo, Bajo Pobre and Roca Blanca Formations (Panza, 1982). These are likely intrusive equivalents of the Bajo Pobre Formation (de Barrio et al., 1999; Jovic et al., 2011), and are covered unconformably by the Bahía Laura Group.

During the Middle to Upper Jurassic, rocks of the Bahía Laura Group (Feruglio, 1949; Lesta and Ferello, 1972), which is composed of the Chon Aike and La Matilde Formations, built up a pyroclastic volcanic-sedimentary complex of predominantly rhyolitic and partly dacitic compositions. The volcanism that produced the Bahía Laura Group probably lasted for about 50 Ma (Schalamuk et al., 1999); having radiometric ages of 177-125 Ma. However, the age of the Bahía Laura Group in relation to the Bajo Pobre Formation is controversial, and radiometric ages of these two units, obtained in different sectors of the Deseado Massif, show some overlap. 


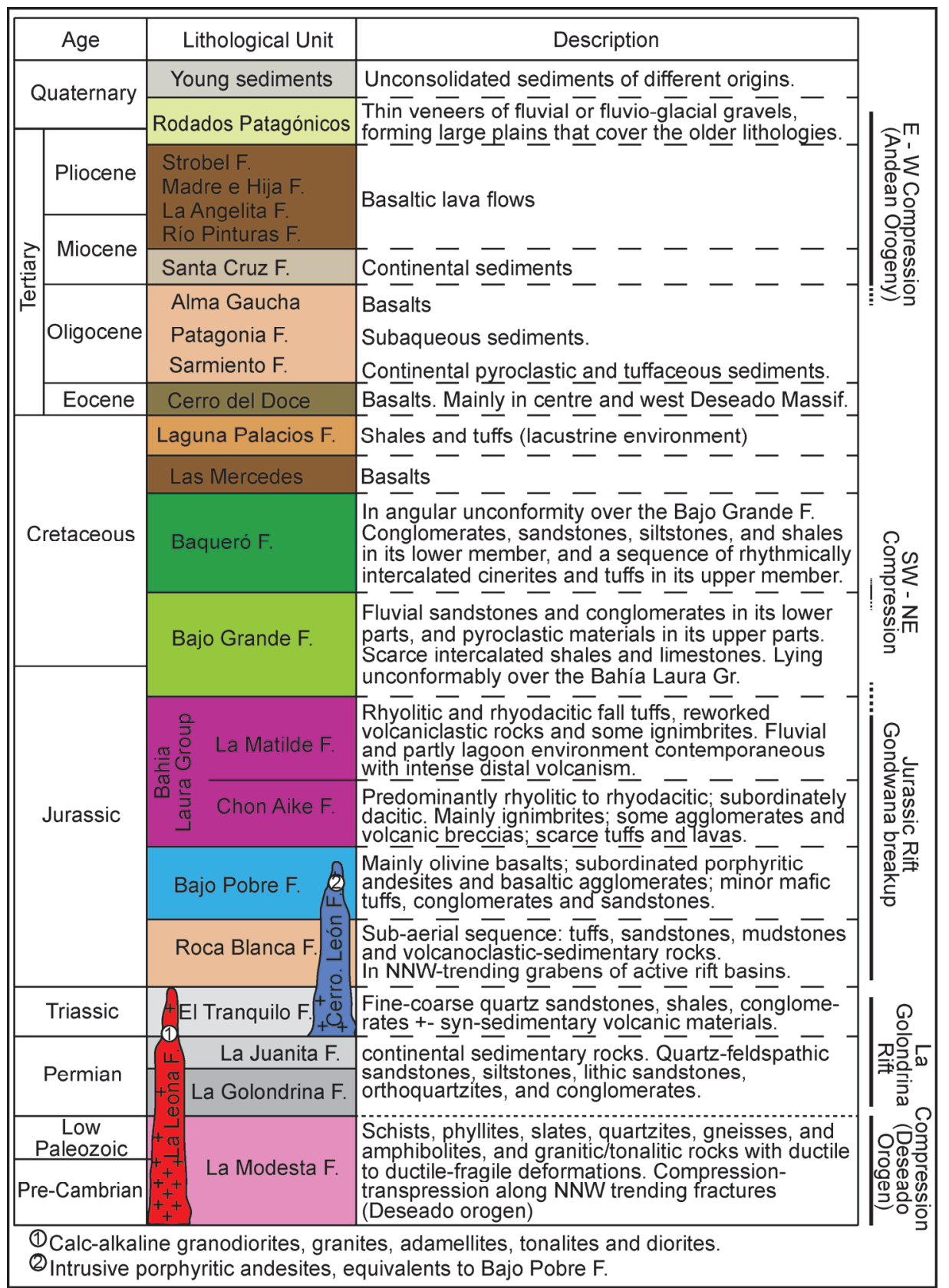

Figure 2.2: Summarized stratigraphic chart for the Deseado Massif. The Bajo Grande and younger Formations are considered post-mineralization.

The Chon Aike Formation is a thick sequence of rhyolitic to rhyodacitic ignimbrites, with subordinate agglomerates and volcanic breccias, and scarce tuffs and rhyolitic lava domes (Panza, 1994b). The individual ignimbrite 
layers are compact and usually of 5 to $15 \mathrm{~m}$ thick, but locally reaching $30 \mathrm{~m}$. The thickness of the whole formation is difficult to determine because of upper and lower erosional boundaries (Panza, 1982), but in general it varies between 200 and $600 \mathrm{~m}$ (Panza, 1994b), reaching occasionally $1200 \mathrm{~m}$ (Sanders, 2000). The Chon Aike Formation is intercalated with the La Matilde Formation but stratigraphic relationships are not very well understood because of rapid lateral changes of facies and thickness of the volcanic pile (de Barrio et al., 1986).

The La Matilde Formation includes mainly tuffs and volcaniclastic-sedimentary rocks with intercalations of thin ignimbrite layers (Panza, 1994b). The tuffs are dominant, generally fine-grained or slightly sandy, either glassy or crystalline, and usually compact. The thickness of this formation is also difficult to determine, but Panza (1994b) inferred a maximum thickness of $150 \mathrm{~m}$ for part of the region. This formation represents a continental fluvial and partly lagoon environment contemporaneous with intense volcanic activity in distal areas.

During the last part of the Jurassic (Kimmeridgian-Tithonian) and the Cretaceous, continental sediments of the Bajo Grande and Baqueró Formations were deposited. The Bajo Grande Formation of Upper Jurassic to Lower Cretaceous age is a continental sequence lying unconformably over the Chon Aike Formation (de Barrio et al., 1986); its thickness is variable between 80 and 350 m (Panza and Marín, 1998). The Baqueró Formation of lower Cretaceous age lies on an angular unconformity over the Bajo Grande Formation. It has a thickness of $100-140 \mathrm{~m}$ and is composed of conglomerates, sandstones, siltstones, and shales in its lower member, and a sequence of rhythmically intercalated cinerites and tuffs in its upper member (Panza and Marín, 1998).

These Cretaceous rocks were partially covered by Upper Cretaceous basalts of the Las Mercedes Formation (Panza, 1982), and shales and tuffs of the Laguna Palacios Formation (lacustrine environment). Then, Eocene basalts of the Cerro del Doce Formation were deposited mainly in the centre and west portions of the Deseado Massif.

In the Oligocene, continental pyroclastic and tuffaceous sediments of the Sarmiento Formation (Feruglio, 1949) were deposited in the eastern part of the Deseado Massif, and subaqueous sediments of the Patagonia Formation followed by basalts of the Alma Gaucha Formation were also deposited. Then, continental sediments of the Santa Cruz Formation (Miocene) were deposited. Finally, large Mio-Pliocene basaltic lava flows of the Strobel, Madre e Hija, La Angelita, and Río Pinturas Formations, as well as relatively thin veneers of gravels of fluvial or fluvio-glacial origin, covered the older lithologies. 


\subsection{Structural geology and geodynamic setting of the Deseado Massif}

The Deseado Massif is structurally characterized by rigid blocks that were deformed into gentle folds with limbs dipping less than $20^{\circ}$ (Fernández et al., 1996). Several tectonic events produced a series of grabens, half-grabens, and horsts, which are slightly tilted to the east and have a complex internal structure with transverse faults (Ramos, 2002b). There are several fault systems in different sectors of the Deseado Massif, but the most widely observed (Table 2-1) are the El Tranquilo, Bajo Grande (Panza, 1982), La Frisia, and Zanjón del Pescado systems (Reimer et al., 1996).

Table 2-1. Characteristics of the four most widely observed faults systems in the Deseado Massif (extracted from Panza (1982), Panza (1994b), and Reimer et al. (1996).

\begin{tabular}{|c|c|c|}
\hline \multirow{2}{*}{ System } & \multicolumn{2}{|c|}{ Movement / Azimuth } \\
\hline & Principal direction & Conjugated direction \\
\hline El Tranquilo & sinistral / $143^{\circ}-160^{\circ}$ & dextral / $57^{\circ}-65^{\circ}$ \\
\hline Bajo Grande & sinistral / $116^{\circ}-130^{\circ}$ & dextral / $21^{0}-36^{\circ}$ \\
\hline La Frisia & dextral / $170^{\circ}$ & sinistral / $40^{\circ}$ \\
\hline Zanjón del Pescado & sinistral / $15^{\circ}$ & dextral / $145^{\circ}$ \\
\hline
\end{tabular}

The tectonic events during the Paleozoic in the area included a Cambrian to Devonian compressional to transpressional deformation (Deseado orogen) along NNW trending fractures (Giacosa et al., 2010). During the Permian to Triassic, there was extensional brittle deformation along NNW fractures, which produced the La Golondrina rift. This period includes the emplacement of the La Golondrina, La Juanita, El Tranquilo and La Leona Formations.

The evolution of the Deseado Massif during the Mesozoic is closely related to the breakup of Gondwana and the opening of the South Atlantic Ocean (Ramos, 2002b; Reimer et al., 1996). However, some details of its geodynamic evolution are still not clear. During the Jurassic, the western margin of southern South America was a subducting margin (Gust et al., 1985; Nelson et al., 1980), while the backarc area was undergoing extension. Contemporaneous with this tectonism a widespread bimodal volcanism occurred, which included the deposition of the Roca Blanca, Bajo Pobre, Chon Aike and La Matilde Formations.

At a broader scale, these volcanic rocks are considered part of the "Chon Aike silicic large igneous province", which includes volcanic rocks located between the Atlantic coast in the Argentinean Patagonia and the Andes of Chile, and in the Antarctic Peninsula (Pankhurst et al., 1998; Pankhurst et al., 2000; Riley et al., 2010; Riley and Knight, 2001). 
According to some authors (Echavarría et al., 2005; Uliana et al., 1985), the Jurassic extension produced large, NNW-trending half-grabens, bounded by steeply dipping normal faults, most of which were reactivated structures of the former Permo-Triassic rift (Echavarría et al., 2005; Gust et al., 1985). According to Giacosa et al. (2010) however, the most relevant structures produced by the Jurassic rifting were large WNW transtensional faults that crosscut and interacted with pre-existing NNW Paleozoic orogenic structures. The general extension would have also produced NNE structures, and purely extensive NW-oriented faults.

During the Cretaceous, SW-NE compression produced tectonic inversion and reactivation of WNW and NW normal faults, as well as thrusting, wrenching, intense folding, and formation of some NW (or NNW) trending anticlines (Giacosa et al., 2010). During the Cenozoic, general E-W compression of the Andean orogeny produced tectonic inversion again, reactivating mainly preexisting $N$ to NNE normal faults, and uplifting a series of narrow and submeridional ranges, one of which divides the entire Deseado Massif into two structural domains (Giacosa et al., 2010; Japas et al., 2013). The eastern domain shows well-preserved WNW Jurassic and Cretaceous structures; while the western domain, more influenced by the Andean deformation, shows strong NNW trends, probably influenced by the inherited Paleozoic fabric (Giacosa et al., 2010). The predominance of different directions of fracturing in different sector of the Deseado Massif may have been the result of differential tectonic rotations (Japas et al., 2013) that were detected in the area, and may have occurred sometime in the Jurassic or early Cretaceous (Somoza et al., 2008).

\subsection{Epithermal gold-silver mineralization in the Deseado Massif}

The Deseado Massif in the south of Argentina (Figure 1.1) is a geological and metallogenic province (Schalamuk et al., 1999), which is recognized as a valuable region for gold exploration. Most $\mathrm{Au}-\mathrm{Ag}$ deposits in the Deseado Massif are of the low-sulfidation epithermal style (Schalamuk et al., 2002; Schalamuk et al., 1997). They are characterized predominantly by multiepisodic quartz veins, and partly by stockworks, breccias and disseminations. Native gold, electrum, native silver, argentite, and variable amounts of pyrargirite, freibergite, petzite and other sulfosalts compose the ore. Sometimes the precious metals are associated with sulfides such as galena, sphalerite, and chalcopyrite. The gangue consists mainly of different varieties of silica, together with pyrite, arsenopyrite, calcite, barite, adularia, rhodochrosite, siderite, and rare monazite. As in other low-sulfidation epithermal deposits, boiling has often been considered the main cause of Au precipitation in the Deseado Massif (Echavarría, 2004; Echavarría et al., 
2005; Moreira, 2005; Rios et al., 2000). The minerals in these deposits precipitated in the temperature range $150-300^{\circ} \mathrm{C}$ (Fernández et al., 2008), which is consistent with the temperature of formation of epithermal deposits (Simmons et al., 2005). According to data obtained from stable isotopes in several deposits (Echavarría, 2004; Guido, 2004; Guido, 2002; Moreira, 2005) and the relatively low salinity in fluid inclusions, the epithermal fluids may have been a mixture of magmatic and meteoric fluids (Fernández et al., 2008).

Several deposits in the Deseado Massif exhibit features of the intermediatesulfidation style (Andrada de Palomera et al., 2012; Cedillo Frey et al., 2009; Dietrich et al., 2012; Echavarría et al., 2005; Gonzalez Guillot et al., 2004; Guido et al., 2005; Jovic et al., 2004; Moreira et al., 2004a). Although in general, low-sulfidation (LS) and intermediate-sulfidation (IS) epithermal deposits are similar, they show some clearly different features (Einaudi et al., 2003; Hedenquist et al., 2000; John, 2001; Sillitoe and Hedenquist, 2003). Some characteristic features of IS state, such as FeS content in sphalerite, relatively high salinity in fluid inclusions, and their sulfide assemblages were observed in several deposits in the Deseado Massif, two of which have been classified as intermediate-sulfidation epithermal deposits (i.e., Martha and San José).

The dominant hydrothermal alteration styles related to low-and intermediatesulfidation epithermal deposits (LISEDs) in the Deseado Massif are silicic and argillic. Silicification is the most conspicuous type of alteration and it produced features that are resistant to erosion such that they can be recognized at ground surface and are excellent features for prospection of Au-Ag deposits (Schalamuk et al., 2002). At depth in the epithermal paleosystems, silicification produced narrow silicified areas around epithermal fluid pathways (Andrada de Palomera et al., 2012); near the surface, it produced wider blanket-shape silicified areas. In addition, silica sinters formed at the surface in several areas like Manantial Espejo, La Josefina, and El Macanudo (Schalamuk et al., 1997). Enveloping the silicification zones around veins are argillic alteration halos consisting of illite, illite-smectite, and kaolinite, which may grade outwards to propylitic alteration halos (Dietrich et al., 2012; Mykietiuk et al., 2005). However, the propylitic alteration may occasionally be a product of deuteric alteration and therefore, unrelated to the epithermal systems (Hedenquist et al., 2000). In the upper parts of the epithermal paleo-systems, kaolinite-rich blankets occur, often associated with silicification (Mykietiuk et al., 2005; Rolando and Fernández, 1996), which may have been produced by precipitation from steam-heated waters in the paleo-water table (Fernández et al., 2008). Supergene minerals such as limonite, manganese oxides, and scarce alunite and gypsum, have also been 
identified and may reflect exposure of sulfide-bearing rocks to weathering processes.

The epithermal deposits in the Deseado Massif formed in a backarc rift setting (Echavarría et al., 2005) and are temporally associated with Jurassic bimodal volcanism (Schalamuk et al., 2002). Radiometric dating of alteration minerals indicate that the mineralization occurred during the Jurassic, and probably the upper Jurassic, as pointed out by Fernández et al. (2008); however, detailed correlations with the age of the volcanic host rocks are arguably, because most dates are derived from K/Ar or Ar/Ar methods, which are potentially unreliable due to possible loss of argon. The age of part of the mineralization in the Huevos Verdes system (around $140 \mathrm{Ma}$ ) is amongst the youngest reported ages in the Deseado Massif (Dietrich et al., 2012), yet, these mineralized rocks are in the Bahía Laura Group and no other mineralization has been reported in younger Formations in the Deseado Massif. The Chon Aike Formation is the most frequent host rock of LISEDs, but the Bajo Pobre Formation and sometimes the La Golondrina, La Leona, Roca Blanca, and La Matilde Formations host some of those deposits (Schalamuk et al., 1997). Because of the temporal association of LISEDs with Jurassic volcanism, and the seemingly lack of mineralization in the Bajo Grande and younger Formations, those formations were considered as postepithermal mineralization and therefore, not associated with that mineralization.

The Au-Ag deposits in the Deseado Massif are structurally controlled (Dietrich et al., 2012; Fernández et al., 2008). The epithermal vein systems were controlled by a dilatation direction consistent with the SW-NE Jurassic extension (Giacosa et al., 2010). The NNW to NW-trending faults produced the most continuous and wider veins with the highest Au-Ag grades. Locally, faults with NE-SW orientation are predominant controls on mineralization, mainly in the eastern sector of the Deseado Massif (Andrada de Palomera and Carranza, 2005); however, they produced generally thin and discontinuous mineralized veins, with low Au-Ag grades (Echavarría et al., 2005). NNE shear zones in La Josefina (Moreira et al., 2008), San Jose (Dietrich et al., 2012) and El Dorado-Monserrat (Echavarría et al., 2005), may have produced local extension and ore deposition in opening bends along general NW oriented fractures. In addition, although many deposits are spatially associated with NE $\left(40-60^{\circ}\right)$ oriented regional faults, the faults with orientations between $140^{\circ}$ and $170^{\circ}$ are more efficient evidence of LISEDs occurrence than the NE-trending faults whereas faults with orientations between $120^{\circ}$ and $130^{\circ}$ show weak or no spatial association with epithermal deposits (Carranza and Andrada de Palomera, 2005). This is consistent with the poor mineralization of WNW-oriented veins in districts such as San José (Dietrich et al., 2012). 
In the western sector of the Deseado Massif, the mineralization was controlled along three predominant orientations: $160-170^{\circ}, 140-150^{\circ}$, and 120-130 (Andrada de Palomera and Carranza, 2005). Orientations of 160 $170^{\circ}$ likely represent regional-scale faults limiting large blocks in the Deseado Massif (Ramos, 2002b) and are probably related to grabens formation; the orientations of these faults coincide with those of the La Frisia fault system (Table 2-1). Orientations of $140-150^{\circ}$ correspond with the general trends of the El Tranquilo fault system, which is related to mineralization in some deposits (e.g., the La Josefina deposit; Moreira et al., 2008). Orientations of $120-130^{\circ}$ correspond with directions of the Bajo Grande faults system. 


\section{Chapter 3}

\section{Prospectivity for epithermal gold-silver deposits in the Deseado Massif, Argentina}

* This chapter is based on: Andrada de Palomera, P., van Ruitenbeek, F.J.A., Carranza, E.J.M., Prospectivity for epithermal gold-silver deposits in the Deseado Massif, Argentina, Ore Geology Reviews (2014), doi: 10.1016/j.oregeorev.2014.12.007. 


\subsection{Introduction}

The Deseado Massif in southern Argentina has been explored for epithermal Au-Ag deposits because of its favourable geological setting for this type of deposits (Schalamuk et al., 2002; Schalamuk et al., 1997). The exploration activities resulted in the discovery of several new epithermal deposits, of which five have undergone mining, namely Cerro Vanguardia (Zubia et al., 1999), Manantial Espejo (Echeveste, 2010), Mina Marta (Páez et al., 2011), San José (Dietrich et al., 2012), and Lomada de Leiva (Sandefur, 2007). Other deposits are in advanced stages of exploration, such as Cerro Negro (Shatwell et al., 2011), Cerro Moro (Coupland, 2009), La Josefina (Andrada de Palomera et al., 2012; Schalamuk et al., 1999), El Dorado-Monserrat (Echavarría, 2004; Echavarría et al., 2005), and Bajo Pobre (Schalamuk et al., 1997; Zubia and Genini, 2003).

Identification of exploration targets by mineral prospecting often includes reviews of available information, interpretation of remote sensing data, geological mapping, and geochemical and geophysical surveys (Marjoribanks, 2010; Moon et al., 2006); and more recently, GIS-based mineral prospectivity mapping (e.g.,Behnia, 2007; Boleneus et al., 2001; Carranza and Sadeghi, 2010; Ford and Hart, 2013; González-Álvarez et al., 2010; Nykänen and Ojala, 2007; Porwal et al., 2010; Raines, 1999). GIS-based methods convey objectivity and reproducibility, making them useful for assigning priorities to exploration targets, helping with the assessment of different types of geological evidence, and justifying the need of additional investigation.

There are different GIS-based methods for mineral prospectivity mapping, these include logistic regression (Harris and Pan, 1999), the use of evidential belief functions (Carranza and Hale, 2003), fuzzy logic (Carranza and Hale, 2001; Porwal et al., 2003), neural network techniques (Singer and Kouda, 1999), weights-of-evidence modelling (Bonham-Carter et al., 1989), and bayesian network classifiers (Porwal et al., 2006). Weights-of-evidence (WofE) technique is transparent and easy to interpret compared to alternative methods, such as neural networks, neuro-fuzzy, and bayesian network classifiers (Agterberg, 2011; Agterberg and Cheng, 2002; BonhamCarter et al., 1989; Ford and Hart, 2013; Porwal et al., 2010). Logistic regression is computationally intensive and its regression coefficients are hard to interpret (Deng, 2009), and although weighted logistic regression produces unbiased probabilities, its coefficients generally have relatively large variances (Agterberg, 2011). Fuzzy logic allows the use of multiclass variables but, up to a certain degree, it depends on reliable and correct exploration models. WofE is considered to provide conservative estimates and is suitable for areas that are only partially studied (de Quadros et al., 2006). 
In addition, WofE allows using zero weights for unknown or missing data, avoiding the exclusion of some layers of evidence, as in logistic regressions (Agterberg, 2011; Bonham-Carter et al., 1989; Deng, 2009).

A limitation of WofE is the requirement for conditional independence (CI) between layers of evidence. If this requirement is violated, then bias of estimated probabilities will result (Agterberg, 2011). In general, the bias leads to overestimation of probabilities. The degradation of performance increases with the number of predictor variables (Singer and Kouda, 1999). Therefore, the assumption of conditional independence should be tested when applying WofE modelling (Bonham-Carter et al., 1989).

In the Deseado Massif, regional-scale GIS-based favourability mapping of low-sulfidation epithermal deposits was tested by Carranza and Andrada de Palomera (2005) by using evidential belief functions and a limited number of training deposits. Their resultant regional-scale prospectivity maps provided limited help in guiding exploration within districts or smaller areas, partially because of their low level of detail. Prospectivity maps produced with higher detail and adequate effectiveness will be more helpful in guiding the exploration in those areas, and prospectivity mapping in the Deseado Massif could be improved by acquiring the most relevant types of geological evidence for the epithermal deposits being sought and representing them by the most suitable layers of evidence.

This study has three main objectives: (a) to map prospectivity of low- and intermediate-sulfidation epithermal deposits (LISEDs) in the Deseado Massif by training models with most deposits currently known in the region; (b) to test whether more detailed and diverse geological evidence can improve prospectivity mapping, particularly at district-scale; and (c) to determine the types of evidence that should be investigated further to improve prospectivity mapping in the Deseado Massif, mainly at district or larger scales. To reach these objectives, the GIS-based WofE method, and the leave-one-out cross validation method (LOOCV) were applied to two datasets with different levels of detail. The results of mapping with each dataset were compared, and the contributions of different types of evidence to the models' predictions were assessed to determine the types of evidence that need further investigation to improve prospectivity.

\subsection{Methods}

The WofE method was used to map prospectivity for LISED in the Deseado Massif (Figure 1.1), using two different geological datasets. One dataset is relatively general, and was produced from available data easy to combine for the whole study area. This dataset is hereafter called the regional-scale 
dataset, while the whole study area is called the regional-scale area $(70,828$ $\mathrm{km}^{2}$ ), which includes most of the Deseado Massif (Figure 1.1). The other dataset, hereafter called the district-scale dataset, contains more detail, and the area it covers is called the district-scale area $\left(11,947 \mathrm{~km}^{2}\right)$; it was derived from data that are more tedious to process and more difficult to combine appropriately for the whole regional-scale area. Regional-scale and district-scale models were produced from the WofE analysis of the regionaland district-scale datasets, respectively. These two models were selected amongst six models produced by using different combinations of data layers with the aim of obtaining statistically robust models, and were tested by means of conditional independence (CI) tests.

The LISED prospectivity was mapped based upon the locations of 65 LISEDs and lithological, structural, and alteration evidence. These features were represented in raster maps, with $1,000 \mathrm{~m}$ and $100 \mathrm{~m}$ spatial resolutions in the regional-and district-scale areas, respectively. The locations of known LISEDs were digitized from mining cadastral maps, published maps, and data known by the authors. The relevance of each geological evidence layer was assessed by WofE modelling.

The WofE calculations and CI tests were carried out using the Spatial Data Modeller (SDM) module for the ArcGIS software (Sawatzky et al., 2009) (http://www.ige.unicamp.br/sdm/default_e.htm).

\subsubsection{Weights-of-evidence method}

Weights-of-evidence is a quantitative data-driven method that uses a loglinear form of the Bayesian probability model (Bonham-Carter, 1994). In mineral prospectivity mapping, this method can estimate the relative importance of individual layers of evidence by statistical means, minimizing subjective bias in quantifying spatial associations between every layer of evidence and mineral deposits used for training. It allows the user to calculate weights for different classes in every evidential layer, and to produce a probability map of the occurrence of the type of deposits used for training. This can be done even using a limited number of mineral deposits (Carranza, 2004).

Given a study area, $T$, composed of a number of area units $N[T]$ (unit cells in a raster map) containing a number of deposits $N[D]$ and assuming that each deposit occupies one cell, the prior probability that a randomly selected cell in the map contains a deposit, when no other information is available, can be estimated as $P[D]=N[D] / N[T]$. If evidence $B$ (represented by a binary map) is present, the probability of finding a new deposit can be expressed as a conditional (or posterior) probability ( $\mathrm{P}[\mathrm{D} \mid \mathrm{B}])$ ). The algorithms used as basis 
of the WofE calculations can be found in Agterberg and Cheng (2002), Bonham-Carter (1994), Carranza (2004), and Carranza and Hale (2000).

In WofE modelling, updating of posterior probabilities by the use of two or more evidence maps (B1 and B2), is only possible if those maps are approximately conditionally independent of each other with respect to the pattern of mineral deposits (D) (Agterberg and Cheng, 2002). The assumption of $\mathrm{CI}$ can be verified with two tests.

A pairwise test between binary maps $B 1$ and $B 2$ can be executed before combining the maps. If $\mathrm{B} 1$ and $\mathrm{B} 2$ are conditionally independent, then, in their overlap region the number of predicted $D$ should be equal to the number of observed $D$. The possible overlap conditions of observed and predicted deposits with B1 and B2 can be represented in a $2 \times 2$ contingency table, and the divergence between numbers of observed and predicted $\mathrm{D}$ can be calculated with the chi-square $\left(X^{2}\right)$ statistic (Moor and McCabe, 1999). Values of $X^{2}$ above 3.84, which is the critical value with one degree of freedom at the 95\% significance level (Davis, 1986), indicate that the assumption of CI has been violated (Bonham-Carter, 1994). Frequencies in each cell of the contingency table should be at least 5 (Carranza, 2004; Snedecor and Cochran, 1967); therefore, the $X^{2}$ test of CI was only applicable to the final regional-scale predictive model.

After all evidence maps are combined, the "new omnibus test" (NOT) (Agterberg and Cheng, 2002) of CI can be used to test whether the difference between the number of predicted $D\left(N[D]_{\text {pred }}\right)$ and that of observed $D(N[D])$ is significantly greater than zero. The NOT is a one-tailed test of the null hypothesis that $N[D]_{\text {pred }}-N[D]=0$; being $\left(N[D]_{\text {pred }}-N[D]\right) / \sigma N[D]_{\text {pred }}$ the test statistic $\left(\sigma N[D]_{\text {pred }}=\right.$ standard deviation of predicted $\left.D\right)$. Because the values of NOT are assumed to approximate a standard normal distribution, the probability that $N[D]_{\text {pred }}-N[D]$ is statistically greater than zero can be estimated (from statistical tables). A probability of $50 \%$ is expected when two layers of evidence are conditionally independent; higher probabilities indicate conditional dependence, and when they are greater than $95 \%$ or $99 \%$ the hypothesis of CI should be rejected (Agterberg and Cheng, 2002).

\subsubsection{Preparation of evidence layers}

Based on the characteristics of the LISEDs in the Deseado Massif, and considering the characteristics of these types of deposits worldwide, a set of deposit recognition criteria was defined for each mapping scale (Table 3-1), and employed for extracting the lithological, alteration and structural evidence used as input for the WofE modeling. 


\subsubsection{Lithology}

For prospectivity mapping, lithological units older than the Bajo Grande Formation were considered favourable for mineralization. The favourable lithologies include the La Modesta, La Golondrina, La Juanita, El Tranquilo and Roca Blanca Formations. The Bajo Grande and younger units were considered unfavourable because they are interpreted as post-epithermal mineralization.

Lithological evidence was extracted from two sources with different detail of mapping, both published by the Argentinean Geological Mining Service. One is a $1: 750,000$ scale geological map (Dirección Nacional del Servicio Geológico, 1994), hereafter called the "generalized lithological map". The second source is a set of seven geological maps published at a scale of 1:250,000 (Cobos and Panza, 2003; Giacosa et al., 1998; Panza, 1994a; Panza, 1994b; Panza, 2001; Panza and Cobos, 2001; Panza and Marín, 1998), hereafter called the "detailed lithological map". Those maps were georeferenced, and the boundaries of favourable lithology (Figure 2.1) were digitized on-screen. Then, the resulting maps were converted into binary raster maps of favourable lithology for LISED occurrence.

Accuracy is not indicated in any of the geological maps, but we estimated the error for the georeferenced maps by comparing the position of features in the maps (e.g., intersections of roads, small lagoons, etc.) with their position on well georeferenced Landsat images. The median of errors for 105 points observed in the detailed lithological map is $268 \mathrm{~m}$, while that of 46 points observed in the generalized lithological map is $1,249 \mathrm{~m}$. Most of these errors are likely products of the original mapping process, but scanning and georreferencing may have also contributed to them. 
Table 3-1. Recognition criteria for epithermal deposits in the Deseado Massif at regional- and district-scale, concepts used to define the criteria and sources from which the evidence layers were derived.

\begin{tabular}{|c|c|c|c|}
\hline & \multirow{2}{*}{$\begin{array}{c}\text { General concepts used to } \\
\text { define the deposit } \\
\text { recognition criteria }\end{array}$} & \multicolumn{2}{|c|}{$\begin{array}{l}\text { Deposit recognition criteria }(\mathrm{RC}) \text { and } \\
\text { sources of evidence }\end{array}$} \\
\hline & & Regional-scale & District-scale \\
\hline $\begin{array}{l}\text { वे } \\
\text { 응 } \\
\text { ำ }\end{array}$ & $\begin{array}{l}\text { Only rocks contemporaneous or } \\
\text { older than the epithermal } \\
\text { mineralizing events are } \\
\text { mineralized. Bajo Grande and } \\
\text { younger Formations were not } \\
\text { recognized as hosts of } \\
\text { epithermal deposits in the } \\
\text { Deseado Massif. }\end{array}$ & $\begin{array}{l}\text { RC: Outcropping } \\
\text { rocks older than the } \\
\text { Bajo Grande } \\
\text { Formation. } \\
\text { Evidence extracted } \\
\text { from a generalized } \\
\text { lithological map }\end{array}$ & $\begin{array}{l}\text { RC: Outcropping rocks } \\
\text { older than the Bajo } \\
\text { Grande Formation. } \\
\text { Evidence extracted } \\
\text { from a detailed } \\
\text { lithological map. Used } \\
\text { to restrict the area to } \\
\text { analyse with WofE. }\end{array}$ \\
\hline 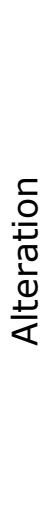 & $\begin{array}{l}\text { The epithermal paleo-systems } \\
\text { deposited silica and some } \\
\text { kaolinite in veins; silicification } \\
\text { is immediately around veins; } \\
\text { illite and smectite surrounding } \\
\text { the silicification; and chlorite- } \\
\text { rich propylitic alterations } \\
\text { surrounding laterally and below } \\
\text { the other alterations, and may } \\
\text { occasionally be unrelated to the } \\
\text { epithermal system (deuteric). } \\
\text { Silica and kaolinite were also } \\
\text { deposited in the upper parts of } \\
\text { paleo-systems above the zone } \\
\text { of fluid boiling. }\end{array}$ & $\begin{array}{l}\text { RC: Abundance of } \\
\text { kaolinite, illite, } \\
\text { smectite and } \\
\text { probably chlorite. } \\
\text { Evidence extracted } \\
\text { from Landsat (band } \\
\text { ratio } 5 / 7 \text { ). }\end{array}$ & $\begin{array}{l}\text { RC: Abundance of } \\
\text { kaolinite, illite, and } \\
\text { smectite. } \\
\text { Evidence extracted } \\
\text { from ASTER (band ratio } \\
4 / 6 \text { ). } \\
\text { RC: Abundance of } \\
\text { silica. } \\
\text { Evidence extracted } \\
\text { from ASTER ( } \mathrm{K}_{\text {silica }} \\
\text { index). }\end{array}$ \\
\hline 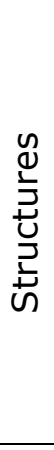 & $\begin{array}{l}\text { Regional-scale structural zones } \\
\text { with orientations in the NW-SE } \\
\text { quadrants were produced or } \\
\text { reactivated by general SW-NE } \\
\text { extension at the time of } \\
\text { mineralization, and therefore, } \\
\text { some of them likely acted as } \\
\text { the main conduits for } \\
\text { ascendant paleo-fluids. Locally, } \\
\text { rock permeability is an } \\
\text { important control for fluid flow } \\
\text { and mineral deposition. }\end{array}$ & $\begin{array}{l}\text { RC: Proximity to } \\
140-170^{\circ} \text { oriented } \\
\text { fracture zones. } \\
\text { Evidence extracted } \\
\text { from different } \\
\text { remote sensing } \\
\text { products } \\
\text { (lineaments } \\
\text { digitized at } \\
1: 1,500,000 \text { or } \\
\text { smaller displayed } \\
\text { scale). }\end{array}$ & $\begin{array}{l}\text { RC: Overall rock } \\
\text { permeability } \\
\text { Evidence extracted } \\
\text { from different remote } \\
\text { sensing datasets } \\
\text { (density of lineaments } \\
\text { digitized at displayed } \\
\text { scale } \sim 1: 100,000 \text { ). }\end{array}$ \\
\hline
\end{tabular}

\subsubsection{Hydrothermal alteration}

We considered silicic and clay alterations as good indicators of LISEDs, and mapped them with remote sensing data, after testing several techniques of image processing and comparing the results with ground control areas located in the La Josefina district (Figure 1.1 and Figure 2.1). These areas contained indications of kaolinite alteration, argillic alteration (smectite and illite), and silicic rocks (silicified rocks, silica sinter and opaline bodies). 
At regional-scale, the band ratio 5/7 of 11 Landsat 7 ETM+ scenes was used to map clay alteration (Figure 3.1 and Figure 3.2). The scenes were acquired in different years, seasons and times (from 1999 to 2002 and from September to February); therefore, for minimizing the difference in illumination between scenes, a sun angle correction was applied before calculating the band ratio; this correction consisted in dividing the pixel value by the sine of the solar elevation (Prakash, 2001). The band ratio 5/7, which takes advantage of strong absorption in band 7 (Sabins, 1999) due to clays (Figure 3.3), was preferred to the Crósta technique using bands 1, 4, 5 and 7 (Crósta and Moore, 1989), because the former better indicates areas of alteration in the La Josefina deposit and it is simpler to calculate and interpret. After the band ratio was calculated a low pass 9x9 kernel filter was applied to minimize the pepper-salt effect. Areas with band 5/7 ratio values larger than 1.18 (threshold based on ground control in the La Josefina deposit) were considered altered. Unfortunately, several lagoons and small wet valleys were identified as altered areas, presumably because of clays deposited from water. Because water has a strong absorption in band 5, a mask of DN-pixel values below 70 in band 5 (empirically determined) was applied to eliminate false anomalies, finally resulting in a binary regional clay alteration evidence map.

At district-scale, four on-demand ASTER L2 scenes (Abrams et al., 2002) were used to map clays with short-wave infrared (SWIR) bands (Figure 3.4), and silica with thermal infrared (TIR) bands. The SWIR bands consist of surface reflectance, calculated by NASA after applying atmospheric corrections on ASTER Level-1B data; while the TIR bands consist of surface emissivity, obtained by separating emissivity from temperature. The four scenes were acquired at around 14:25 of the 2nd of March of 2002.

After comparing with the spectral angle mapper classifier, the Crósta technique, and other band ratios methods, the ASTER band ratio 4/6 (Figure 3.5) was selected to map clay alterations, for it enhances better the known areas of alteration in the La Josefina deposit, and it is simpler to generate and interpret. This ratio, already used by Carranza et al. (2008), is aimed to detect illite, montmorillonite, and kaolinite (Figure 3.3), which are abundant in LISEDs. The $4 / 6$ band ratio image was then filtered with a $5 \times 5$ kernel low pass filter to minimize the pepper-salt effect. 


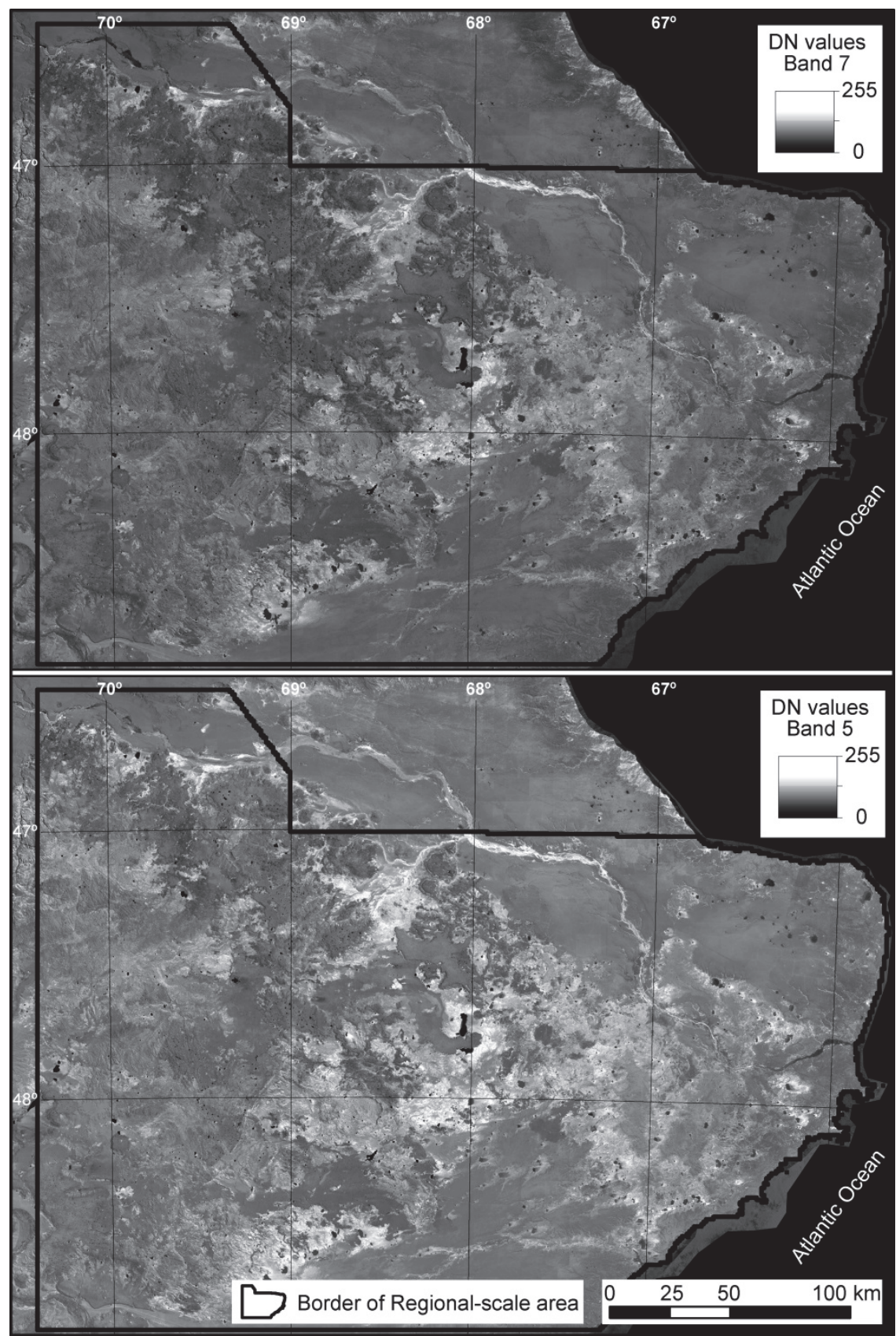

Figure 3.1: Mosaic of 11 Landsat 7 ETM+ scenes, showing bands 7 and 5 used to calculate the band ratio $5 / 7$ (Figure 3.2) representing hydrothermal clay alteration evidence 


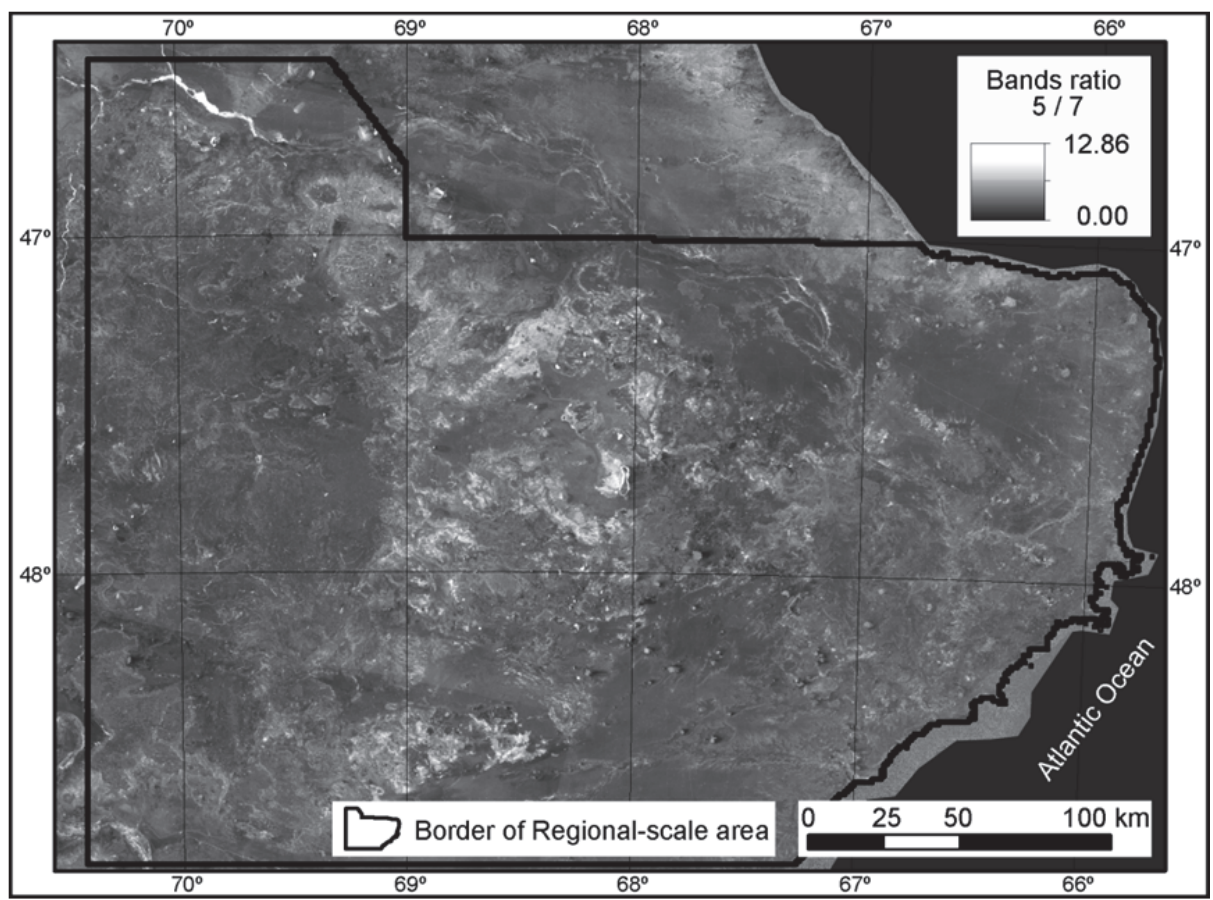

Figure 3.2: Ratio of Landsat band 5 over band 7, considered representative of clay alteration and used for extracting the binary map of alteration evidence for regionalscale mapping.

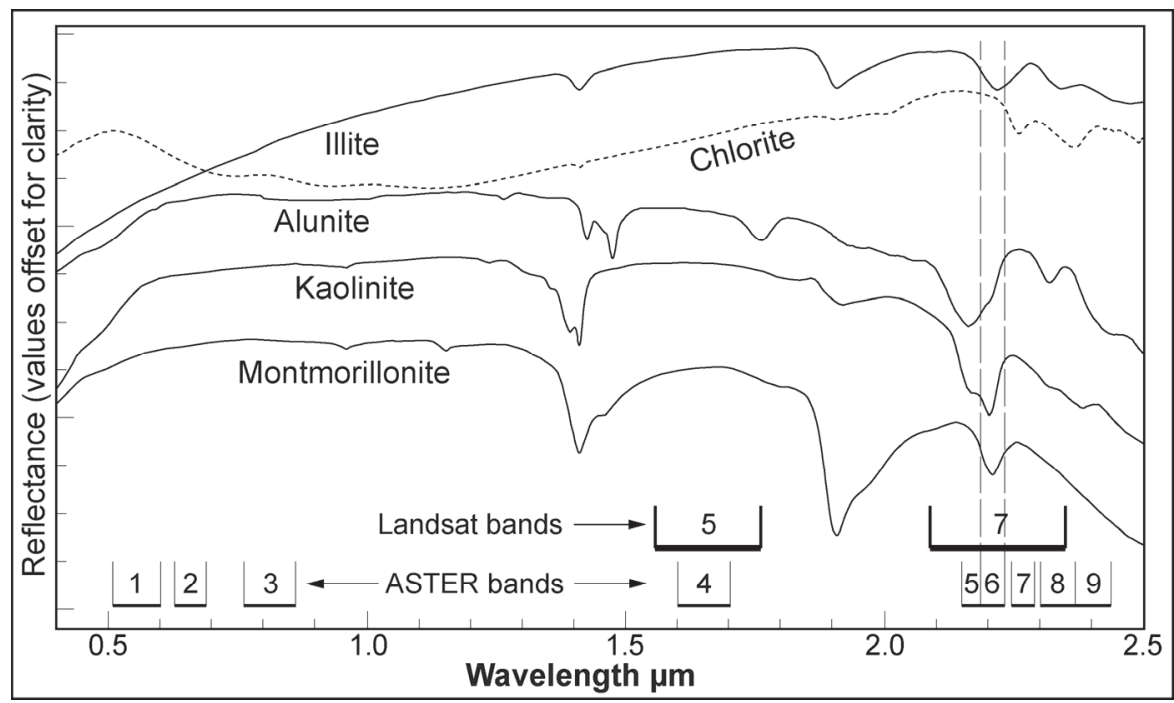

Figure 3.3: Spectra of five alteration minerals commonly found in LISEDs (Grove et al., 1992-JPL1 data), and wavelength ranges of ASTER and Landsat 7 ETM+ bands. 


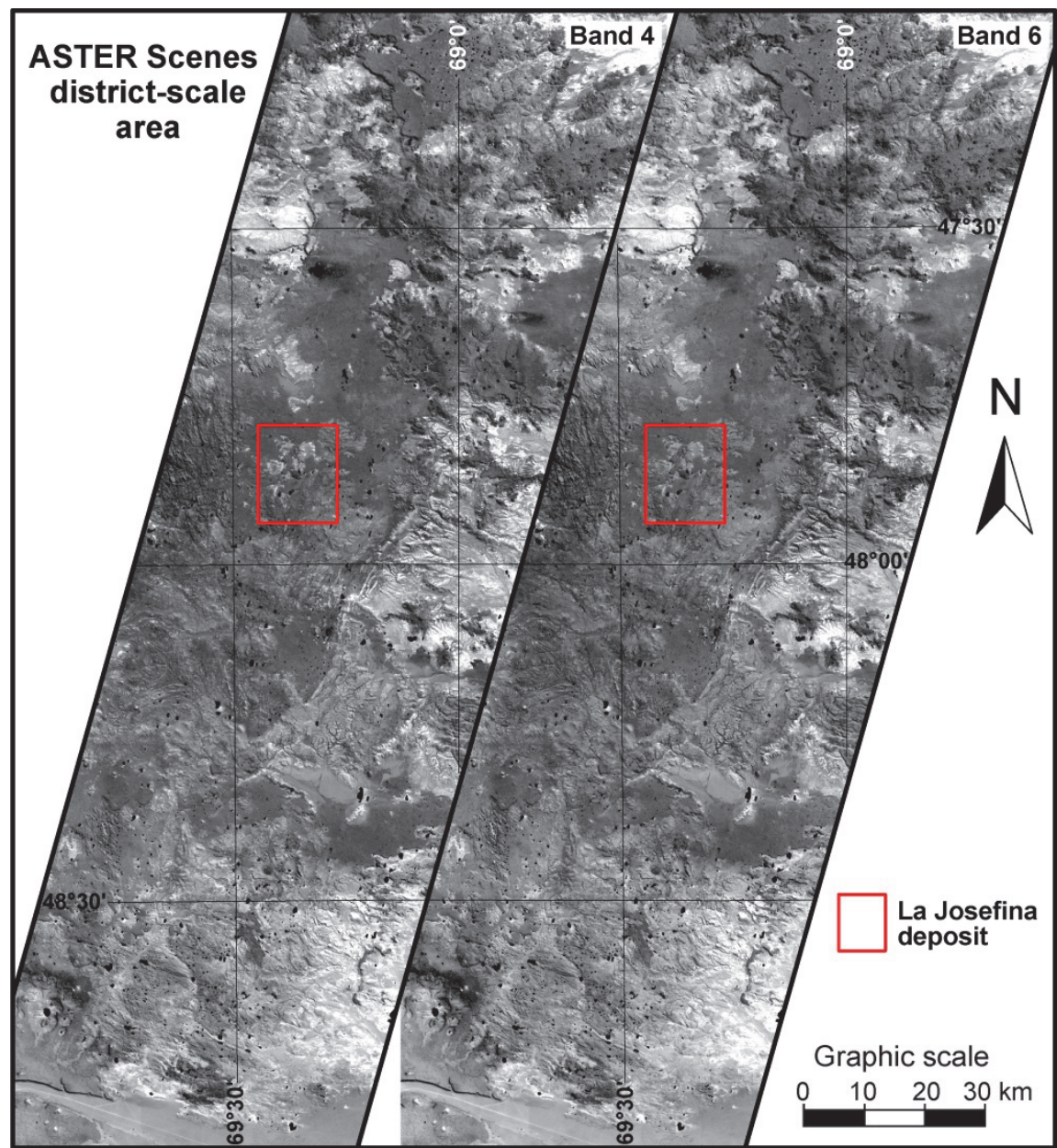

Figure 3.4: Mosaic of four ASTER scenes showing SWIR bands 4 and 6 . These bands were used to calculate the band ratio 4/6 (Figure 3.5) representing hydrothermal clay alteration evidence for district-scale mapping.

The silica abundance was represented by the $\mathrm{K}_{\text {silica }}$ index (Miyatake, 2002; MMAJ, 2000), calculated as $\mathrm{K}_{\text {silica }}=\log$ $((E[10]+E[11]+E[12]) / 3 / E[13]) *(-1)$, where $E[n]$ are values in each ASTER TIR band $\mathrm{n}$. Prior to calculating this index, a $3 \times 3$ kernel averaging filter was applied to reduce the effect of striping. The resultant image shows anomalously high values, coincident with siliceous outcrops. An image of band ratio $13 / 12$ showed similar results but the image of the Ksilica index (Figure 3.5) showed better definition of siliceous outcrops. 


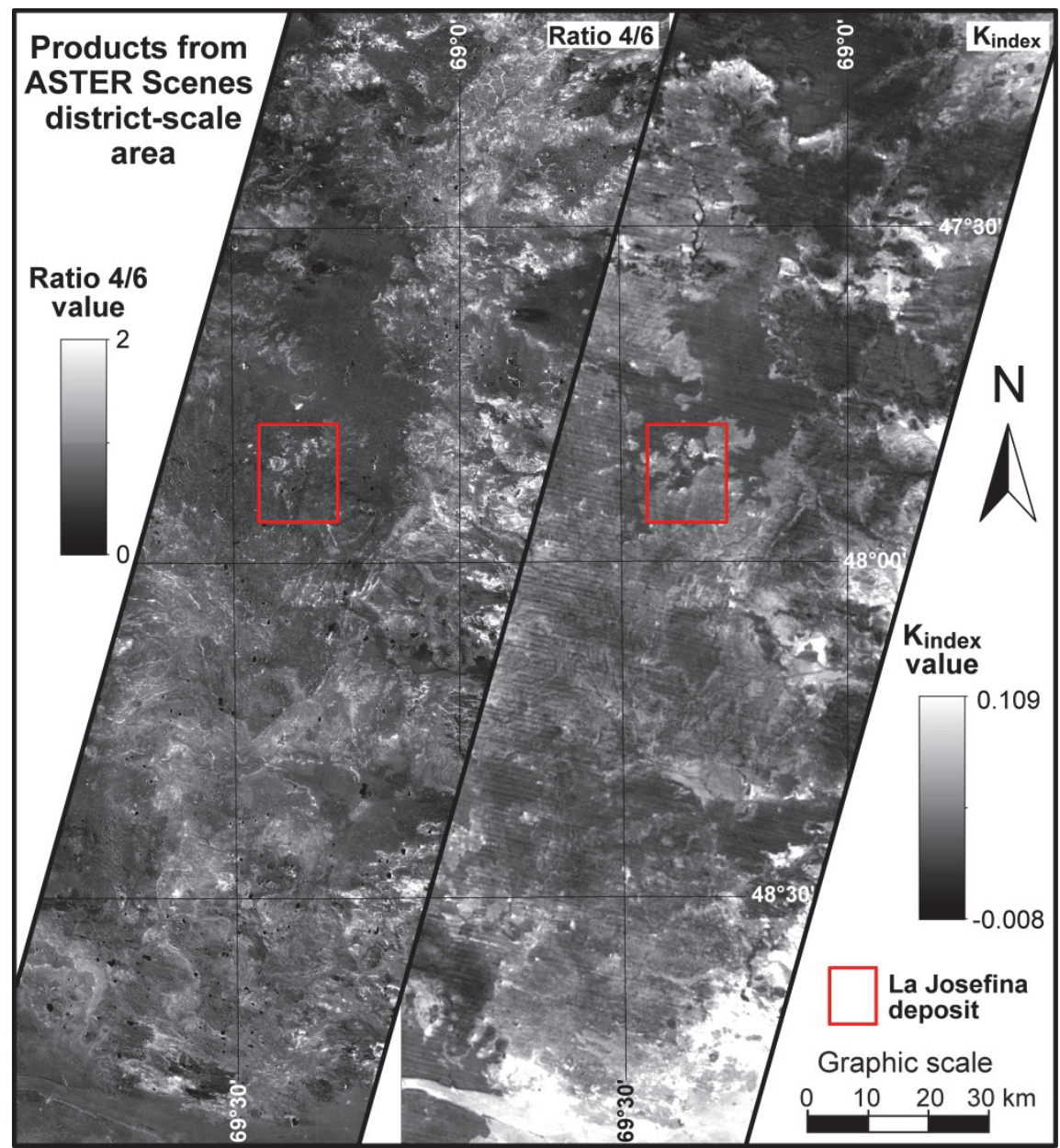

Figure 3.5: Resultant images from processing of ASTER SWIR and TIR bands. Band ratio $4 / 6$ represents clay alteration. The $K_{\text {silica }}$ index represents silica abundance and was calculated using TIR bands 10,11, 12 and 13 .

The district-scale alteration data from the studied areas were classified based on percentiles of $4 / 6$ band ratios and $K_{\text {silica }}$ index, producing evidence maps for the spatial analysis at the district scale.

\subsubsection{Structures}

In epithermal systems, areas of structural weakness can act as pathways of hydrothermal fluids, and localize mineralization. However, structural controls on mineralization may be scale-dependant, and therefore, while structural zones should be distinguished for regional-scale exploration (White and Hedenquist, 1990), they may not be useful for target generation at larger scales (Austin and Blenkinsop, 2009), where local controls (even small 
fractures) should be considered because they modify rock permeability and may control the location of deposits.

In this study, regional structural controls, predominant in the western sector of the Deseado Massif, were considered representative for the whole area of study because they are the most persistent structural controls throughout the entire region (Andrada de Palomera and Carranza, 2005). Regional structural features trending $140-150^{\circ}$ and $160-170^{\circ}$ were combined and referred to as NW to NNW trending structural controls $\left(140-170^{\circ}\right)$. Regional structural features with orientations of $120-130^{\circ}$ were not used because they show weak or no spatial association with LISEDs (Carranza and Andrada de Palomera, 2005).

Regional-scale fault zones with orientations of $140-170^{\circ}$ were inferred from lineaments digitized on-screen at a scale of $1: 1,500,000$ or smaller, mainly on Landsat and $90 \mathrm{~m}$ resolution shaded-relief images, derived from Shuttle Radar Topography Mission data. To enhance lineaments with different orientations, several directions of illumination were applied as done by Asadi (2000) and Carranza (2002). Inferred fault zones were represented by linear patterns of 2,000 m width, which were buffered outwards in steps of 2,000 $\mathrm{m}$, up to $20,000 \mathrm{~m}$, producing a map of proximity to regional-scale structures.

Lineaments for the district-scale modelling were digitized on images displayed on-screen at a scale of around 1:100,000. Following Carranza (2002), Dinger et al. (2002), Koike et al. (1995), Hung et al. (2005) and Lepage et al. (2000), we considered most lineaments as representative of fractures (either faults or joints). Landsat R-G-B colour composite 7-4-1 were the mostly used images, but combinations of the 7-4-1 composite with shaded-relief images, and edge-enhanced band 7 images, were also used. Density of lineaments (total length of lineaments per pixel area) was calculated for an output resolution of 2,000 m; the pixel size of the lineament density image was then reduced to $500 \mathrm{~m}$, and the image resampled to 100 $\mathrm{m}$ resolution. Finally, density values were classified using percentiles of lineament density, and prepared as an evidence map.

\subsubsection{Spatial association analysis and predictive mapping}

The spatial associations of LISEDs with lithology, hydrothermal alteration, and structures were investigated using positive and negative weights $\left(\mathrm{W}^{+}\right.$ and $\left.\mathrm{W}^{-}\right)$, the contrast (C), and the studentized contrast (SigC), derived from the WofE calculations. These spatial association parameters were calculated for patterns in six evidence maps, including the binary patterns of lithological and clay alteration regional maps, the cumulative classes in the map of 
proximity to regional structures, and the cumulative classes in the evidence maps of clay alteration (band ratio 4/6), silica (Ksilica index), and density of lineaments.

Each of the six mentioned evidence maps were generalized to a binary map with one class (predictor pattern present) carrying the value of $\mathrm{W}^{+}$, and the other (predictor pattern absent) carrying the value of $\mathrm{W}^{-}$. For each multiclass evidence map, a cumulative class with optimum spatial association with LISEDs was defined as that with the highest $C$, being $\operatorname{Sig} C \geq 2$, and was used as threshold for the generalization. The predictor pattern present includes from the percentile class $90-100$ to the class with optimum spatial association; the predictor pattern absent includes the remaining cumulative classes. For the regional evidence maps of lithology and clay alteration, no generalization was necessary. The binary maps were then used for the pairwise CI test described earlier.

These binary predictor maps can also be used to calculate the posterior probability maps, but the SDM software does this directly from the weights tables, as well as carrying out the NOT test for conditional independence, without the need of generating binary maps. The posterior probability maps were later re-classified into binary favourability maps; posterior probabilities higher than the prior probability were considered favourable to explore for LISEDs, while those lower than the prior probability were considered unfavourable.

\subsubsection{Assessment of predictions at regional- and district- scales}

Seven indicators were used to evaluate the effectiveness and usefulness of mapping at the district and regional scales: success rate, prediction rate, weights, C, SigC, NOT test of $\mathrm{CI}$, and percentage of area reduction when determining favourable areas.

The success rate was based on the total number of deposits N[D], for training as well as validating, and calculated as the percentage of N[D] located in favourable areas of the favourability map, and considered indicative of the goodness of fit and overall efficiency of the model's predictions. The prediction rate was based on the leave-one-out cross validation (LOOCV) method, and calculated using the procedure of spatial association analysis and posterior probability and favourability maps calculation that was repeated $N[D]$ times, selecting a different training set of $N[D]-1$ deposits every time; the resulting favourability map was validated with the single deposit left out. Then, the prediction rate is defined as the percentage of the $\mathrm{N}[\mathrm{D}]$ instances with the validation deposit located in favourable cells, and 
also considered as indicative of the efficacy of the predictive models and favourability maps

Then, we compared the predictions inside the district-scale area based on the regional- and district-scale models. This allowed us to evaluate the effectiveness and usefulness of each model.

\subsection{Results}

\subsection{1 $\mathrm{Cl}$ tests of the different models}

The results of testing the $\mathrm{CI}$ for six different contrasting models are shown in Table 3-2. For regional-scale mapping, using the generalized lithological map and the alteration and regional structural evidence layers (model Reg-1), the results from NOT are sufficient to accept the assumption of $\mathrm{CI}$, although they indicate that there is considerable conditional dependence between layers. In addition, values from the $X^{2}$ test of CI for the pair of structural and lithological evidence layers (3.53) is very close to the 3.84 critical value, suggesting relatively high conditional dependence between these two layers. The structural-alteration and alteration-lithology pairs show low $X^{2}$ values.

By using the detailed lithological map and the alteration and regional structural evidence layers (model Reg-2), the results from NOT are less satisfactory than with the previous dataset. Results from NOT indicate that the hypothesis of CI could still be accepted, but the "CI ratio" (simple ratio $N[D] / N[D]_{\text {pred }}$ ), is below 0.85, which may indicate a CI problem (BonhamCarter, 1994).

Because models Reg-1 and Reg-2 show relatively high conditional dependence, probably resulting from pairs that include lithology, two other models (Reg-3 and Reg-4) were produced based on restricting the area for WofE calculations to only the favourable lithology, and carrying out the predictions using the alteration and structural evidence layers. Restricting the area to the favourable lithology of the generalized lithological map (model Reg-3), only 51 training deposits were used. The remaining 14 deposits are in areas mapped as unfavourable lithology; although it is known that most of them are in reality hosted by favourable lithological units, reflecting the effects of low accuracy of the generalized lithological map. Restricting the area to the favourable lithology of the detailed lithological map (model Reg4), allows using most of the original training deposits, reflecting the higher accuracy of the detailed lithological map in contrast to the generalized lithological map. For both of these models (Reg-3 and Reg-4), values from NOT decreased below $50 \%$, the value of the NOT statistic is negative, and the 
CI ratio is above 1 , because the number of predicted deposits is lower than the number of training deposits. This may have resulted from a decrease of spatial association noticed for the structural evidence when using Reg-3 and Reg-4, probably as a consequence of omitting some deposits; and because of decreasing the number of predictor maps, with potentially negative effects (Harris and Sanborn-Barrie, 2006), although with the positive effect of decreasing the conditional dependence, which agrees with the idea of Agterberg and Cheng (2002) that CI decreases as additional map layers are included.

For district-scale mapping, two models (Dist-1 and Dist-2) were tested. Model Dist-1 (Table 3-2) included 18 training deposits, located in the districtscale area, and four evidence layers: clay alteration (ratio 4/6), silica abundance $\left(\mathrm{K}_{\text {silica }}\right.$ index), detailed lithology and density of lineaments. The results from the CI test were not satisfactory; the NOT-probability is relatively high and the CI ratio is too low, showing that there is relatively high conditional dependence. Model Dist- 2 was produced only with data restricted to areas of favourable lithology of the detailed lithological map. Evidence layers of clay alteration (ratio $4 / 6$ ), silica abundance ( $K_{\text {silica }}$ index) and density of lineaments, as well as the 17 deposits located in the restricted area, were used in this model. The CI tests for this dataset improved significantly, with the CI ratio and NOT probability very close to the optimum values for a conditionally independent dataset.

Finally, model Reg-1 was selected as the most suitable for regional-scale predictions, because it is statistically robust, and it uses for the WofE calculations in the whole study area all the training deposits and all three evidence layers. Model Dist- 2 was selected as the most suitable prospectivity model for district-scale predictions, because it yields satisfactory results from the $\mathrm{CI}$ tests, and the number of training deposits remained almost the same after the lithological restriction. 


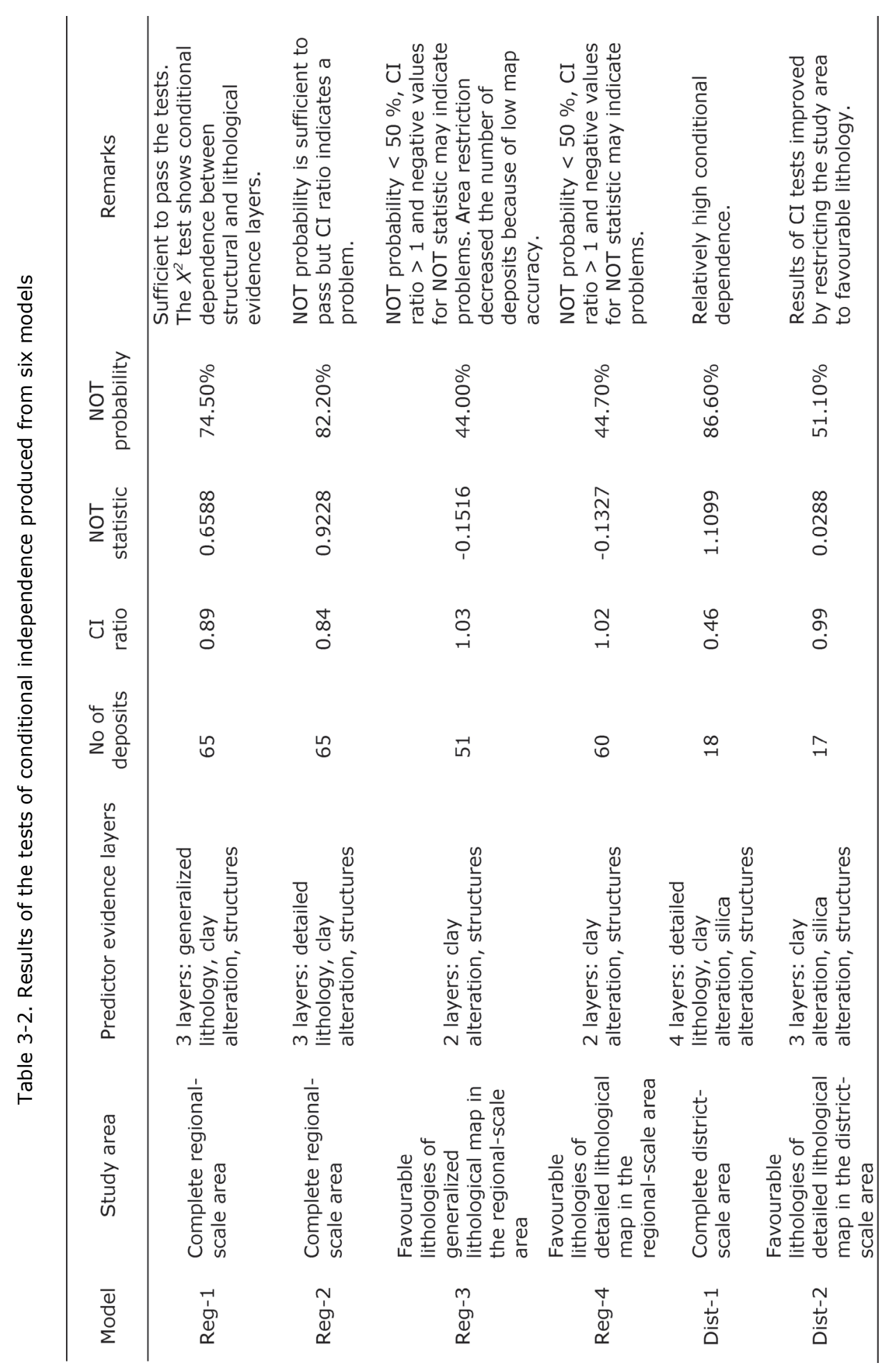




\subsubsection{Spatial association analysis and predictive mapping in the regional-scale area}

The results of the spatial association analysis (Table 3-3) show that the highest and most reliable values of contrast (highest $C$ and SigC) are for the lithological evidence (Figure 3.6aa), while the lowest are for the clay alteration evidence (Figure 3.6bb). The cumulative class 10,000$12,000 \mathrm{~m}$ from regional-scale structures shows optimum spatial association with LISEDs, including high number of deposits and showing high $C$ and SigC (Table 3-3). Therefore, the 12,000 m distance around structures became the external border of the predictor pattern present, in the regional-scale predictor map (Figure 3.6c). The predictor maps (Figure $3.6 a, b, c)$ represent results from the spatial association analysis (Table 3-3) that can be used for the generation of the posterior probability map and for the tests of $\mathrm{CI}$.

Table 3-3. Results from the spatial association analysis between regional-scale evidence and LISEDs, including weights (W), contrasts (C), and studentized contrast (SigC). Favourable lithology includes the Chon Aike, La Matilde and Bajo Pobre Formations. Underlined classes show optimum spatial association with LISEDs, and were considered as predictor patterns.

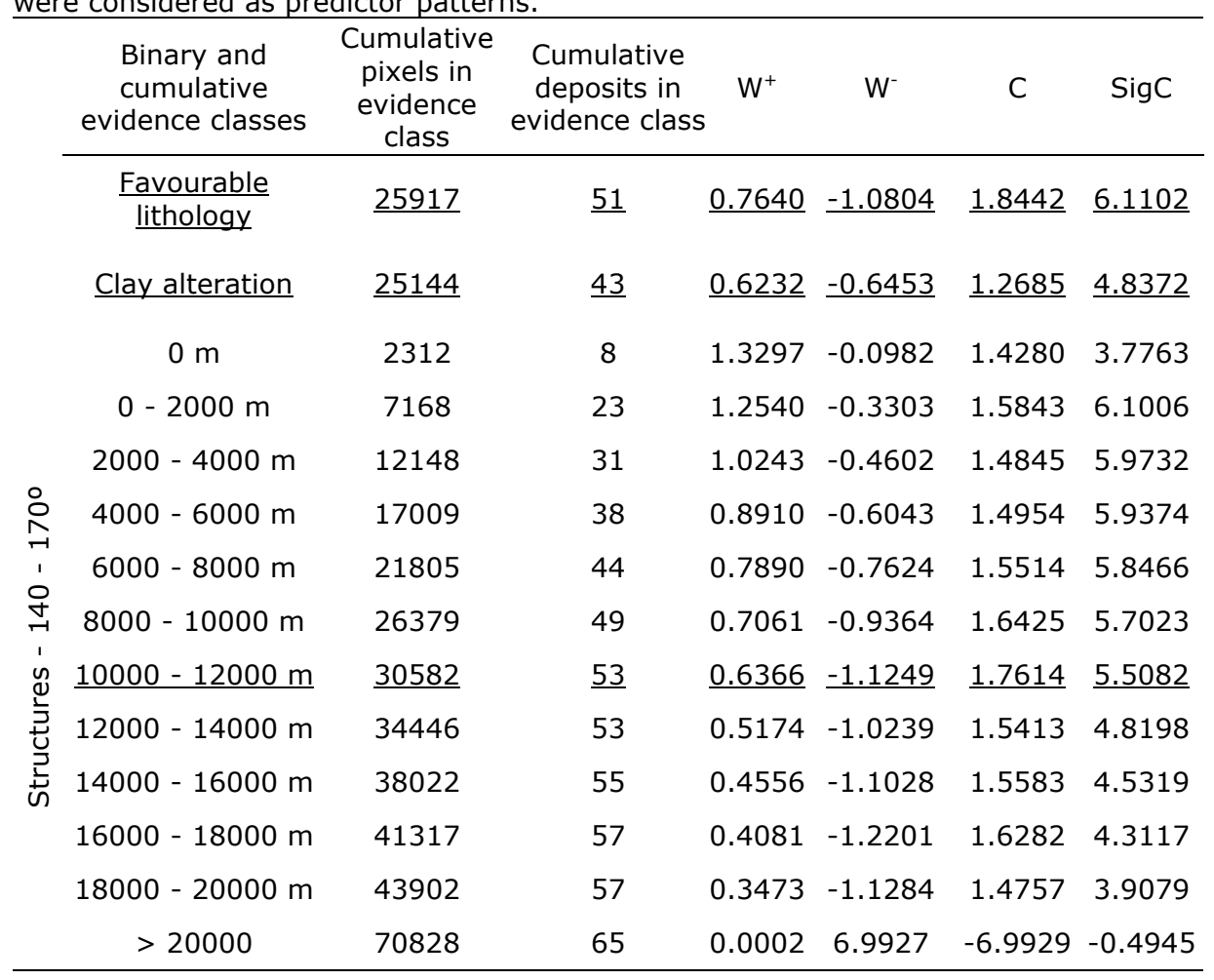


The pairwise test of CI for the regional-scale binary predictor maps (Figure $3.6 a, b, c)$ shows values of $X^{2}$ below the critical value of 3.84 (Figure $3.6 \mathrm{~d}$ ), suggesting that the assumption of $\mathrm{CI}$ is valid, and that the predictor maps can be used for the regional-scale prediction of LISEDs occurrence. This prediction is represented by the regional-scale posterior probability map (Figure 3.7), which includes eight discrete values of posterior probability, and predicts a total of 73 deposits, which is $12 \%$ more than the observed number of deposits.

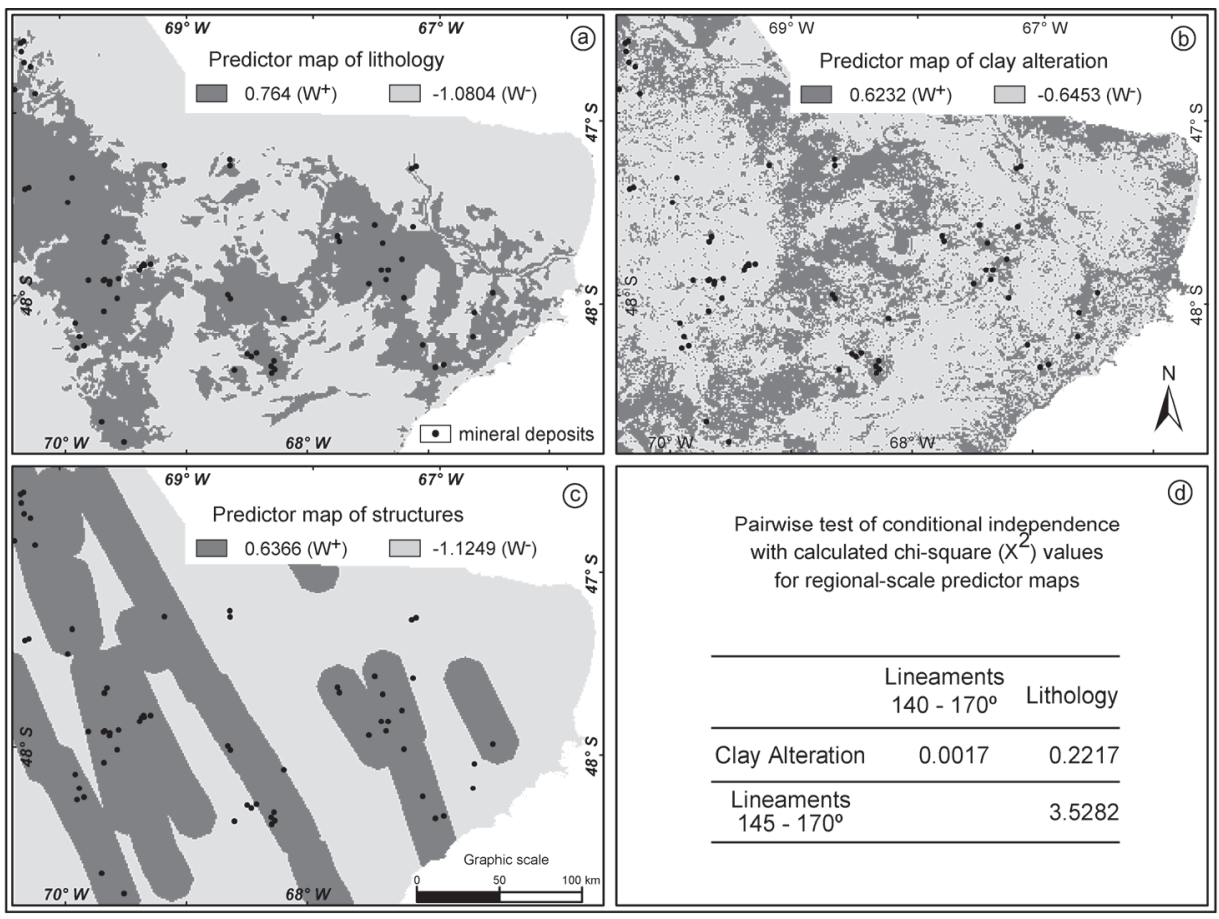

Figure 3.6: a), b), c) Binary predictor maps representing results from the spatial association analysis (Table $3-3$ ) of the regional-scale dataset corresponding to model Reg-1 (Table 3-2). These maps are useful for conditional independence tests and generating posterior probability maps. d) Results of pairwise test of conditional independence for the predictor maps.

Posterior probabilities higher than the prior probability, which is 0.000918 , were considered favourable for LISEDs occurrence, while those lower than the prior probability were considered unfavourable, obtaining the favourability map in Figure 3.8. This favourability map shows that about 35\% of the regional-scale area is favourable for LISEDs discovery. The favourable area contains 54 of the 65 deposits used for training; therefore, the regional scale predictive model has about $83 \%$ success rate. In addition, 54 out of 65 of the predictions resultant from the LOOCV method, predicted as favourable 
the cells corresponding to validation deposits; therefore, the "Prediction Rate" is equal to the "Success Rate" (83\%).

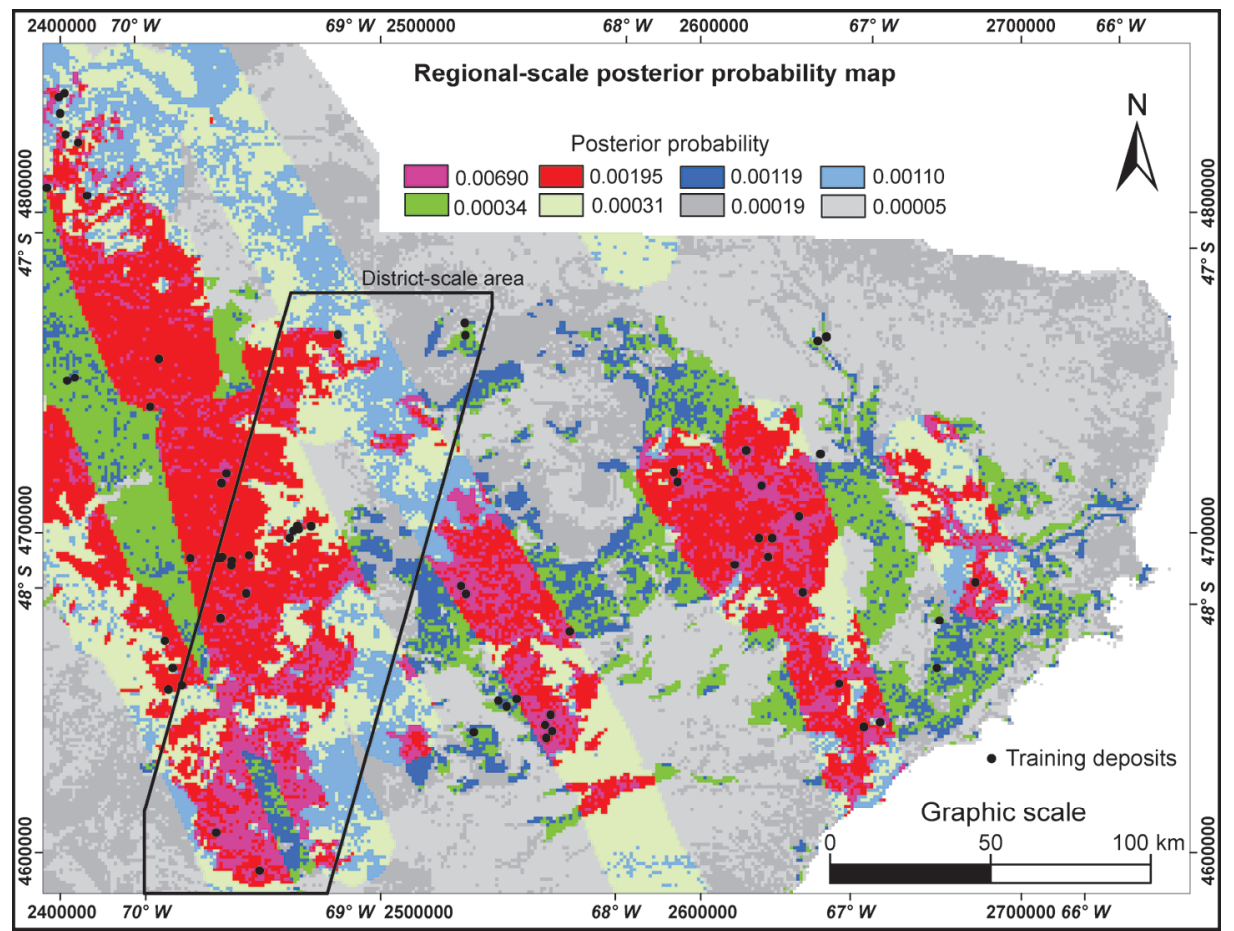

Figure 3.7: Regional-scale posterior probability map. Classes of posterior probability are discrete values produced directly from the WofE calculations.

\subsubsection{Spatial association analysis and predictive mapping in the district-scale area}

The district-scale prospectivity mapping was carried out with the districtscale dataset restricted to the areas of favourable lithology of the detailed lithological map (model Dist-2 in Table 3-2). This restricted area includes 17 training deposits and $5260.54 \mathrm{~km}^{2}$ (526,054 cells), which is $44 \%$ of the total district-scale area. Therefore, the prior probability of LISEDs in the restricted area is 0.000032 .

From the spatial association analysis of the district-scale evidence layers (Table 3-4), the lowest value of $C$ is for the band ratio $4 / 6$, which represents clay alteration; higher values are for the $K_{\text {silica }}$ index, representing silica abundance, and for density of lineaments. The optimum spatial association for band ratio $4 / 6$ occurs in the cumulative percentile class 90-100, which includes only $35 \%$ of the deposits. In contrast, the cumulative classes with optimum spatial association for density of lineaments and $\mathrm{K}_{\text {silica }}$ index include $88 \%$ and $94 \%$ of the deposits respectively. 


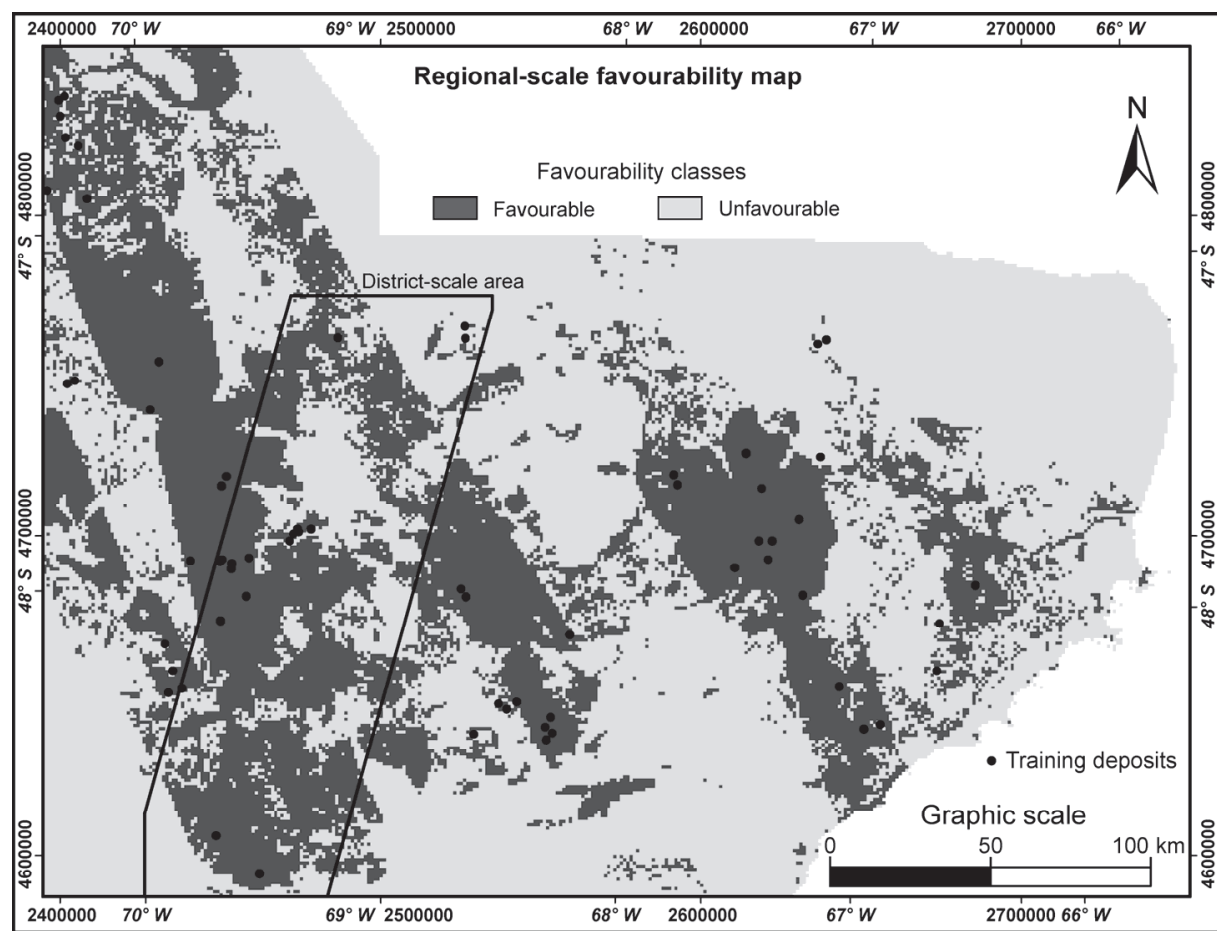

Figure 3.8: Regional-scale favourability map. Favourable areas are those with posterior probabilities higher than the prior probability.

Three predictor maps (Figure 3.9), represent the generalization of cumulative percentile classes of evidence (Table 3-4) into binary maps. These maps show predictor patterns present and absent, which carry respectively the $W^{+}$ and $W^{-}$weights calculated for the classes with optimal spatial association with the training deposits.

The final results from the district-scale prospectivity mapping are a posterior probability map and a favourability map (Figure 3.10a, b). The district-scale posterior probability map (Figure 3.10a) shows all eight discrete classes of posterior probability produced by the WofE calculations. The district-scale favourability map (Figure 3.10b), shows as favourable for LISEDs occurrence, the areas in which the posterior probability is higher than the prior probability.

Using the district-scale geological dataset, the prospective area, initially equivalent to the total district-scale area $\left(11,946.65 \mathrm{~km}^{2}\right)$, was reduced to $44 \%\left(5,260.54 \mathrm{~km}^{2}\right)$ by considering only the favourable lithologies, and it was further reduced to $12.7 \%$ of the total $\left(1,520.68 \mathrm{~km}^{2}\right)$ by applying WofE. This relatively small percentage of the initial area is the area that is favourable for discovery of LISEDs in the district-scale area. 
Table 3-4. Results from the spatial association analysis between LISEDs and districtscale evidence layers inside areas of favourable lithology of the high-resolution lithological map. The spatial association parameters include weights (W), contrast (C), and studentized contrast (SigC). Underlined classes show optimum spatial association and were considered predictor patterns.

\begin{tabular}{|c|c|c|c|c|c|c|c|}
\hline $\begin{array}{l}\text { Evidenc } \\
\text { e maps }\end{array}$ & $\begin{array}{c}\text { Cumulative } \\
\text { evidence } \\
\text { classes } \\
\text { (percentiles) }\end{array}$ & $\begin{array}{c}\text { Cumulative } \\
\text { pixels in } \\
\text { evidence } \\
\text { class } \\
\end{array}$ & $\begin{array}{c}\text { Cumulative } \\
\text { deposits in } \\
\text { evidence } \\
\text { class }\end{array}$ & W+ & W- & C & SigC \\
\hline \multirow{10}{*}{ 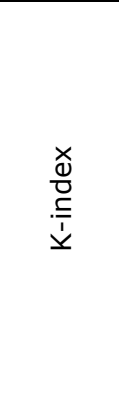 } & $90-100$ & 43382 & 3 & 0.7608 & -0.1081 & 0.8689 & 1.3657 \\
\hline & $80-90$ & 91928 & 7 & 0.8571 & -0.3386 & 1.1957 & 2.4263 \\
\hline & $70-80$ & 143040 & 9 & 0.6663 & -0.4365 & 1.1028 & 2.2694 \\
\hline & $60-70$ & 194299 & 12 & 0.6477 & -0.7628 & 1.4105 & 2.6499 \\
\hline & $50-60$ & 243551 & 14 & 0.5759 & -1.1129 & 1.6889 & 2.6545 \\
\hline & $\underline{40-50}$ & $\underline{302387}$ & $\underline{16}$ & $\underline{0.4931}$ & -1.9780 & $\underline{2.4711}$ & 2.3973 \\
\hline & $30-40$ & 364670 & $\overline{17}$ & 0.3658 & -6.2568 & 6.6226 & 0.6621 \\
\hline & $20-30$ & 421846 & 17 & 0.2202 & -5.8194 & 6.0396 & 0.6038 \\
\hline & $10-20$ & 479139 & 17 & 0.0928 & -5.0213 & 5.1142 & 0.5113 \\
\hline & $0-10$ & 526054 & 17 & -0.0006 & 10.3399 & -10.3405 & -0.7311 \\
\hline \multirow{10}{*}{ 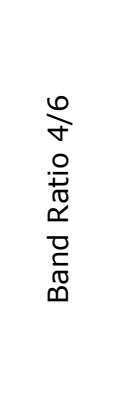 } & $\underline{90-100}$ & $\underline{44909}$ & $\underline{6}$ & $\underline{1.4194}$ & $\underline{-0.3461}$ & $\underline{1.7655}$ & $\underline{3.4785}$ \\
\hline & $80-90$ & 98637 & 9 & 1.0380 & -0.5461 & 1.5842 & 3.2601 \\
\hline & $70-80$ & 148994 & 10 & 0.7309 & -0.5543 & 1.2852 & 2.6079 \\
\hline & $60-70$ & 214013 & 10 & 0.3688 & -0.3650 & 0.7338 & 1.4890 \\
\hline & $50-60$ & 269569 & 10 & 0.1380 & -0.1690 & 0.3069 & 0.6228 \\
\hline & $40-50$ & 326392 & 13 & 0.2090 & -0.4782 & 0.6872 & 1.2019 \\
\hline & $30-40$ & 381592 & 14 & 0.1269 & -0.4422 & 0.5691 & 0.8945 \\
\hline & $20-30$ & 431552 & 15 & 0.0729 & -0.4233 & 0.4961 & 0.6591 \\
\hline & $10-20$ & 482235 & 16 & 0.0263 & -0.3479 & 0.3742 & 0.3631 \\
\hline & $0-10$ & 526054 & 17 & -0.0006 & 10.3399 & -10.3405 & -0.7311 \\
\hline \multirow{11}{*}{ 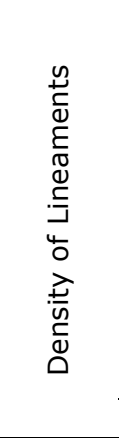 } & $90-100$ & 52489 & 4 & 0.8579 & -0.1632 & 1.0211 & 1.7858 \\
\hline & $80-90$ & 105018 & 10 & 1.0807 & -0.6646 & 1.7453 & 3.5416 \\
\hline & $70-80$ & 157585 & 14 & 1.0113 & -1.3786 & 2.3899 & 3.7565 \\
\hline & $\underline{60-70}$ & $\underline{210164}$ & $\underline{15}$ & $\underline{0.7924}$ & -1.6301 & 2.4225 & $\underline{3.2180}$ \\
\hline & $50-60$ & 262824 & 15 & 0.5688 & -1.4477 & 2.0165 & 2.6787 \\
\hline & $40-50$ & 315400 & 16 & 0.4510 & -1.9181 & 2.3690 & 2.2983 \\
\hline & $30-40$ & 368066 & 17 & 0.3566 & -6.2355 & 6.5921 & 0.6590 \\
\hline & $20-30$ & 420741 & 17 & 0.2228 & -5.8299 & 6.0528 & 0.6051 \\
\hline & $10-20$ & 473388 & 17 & 0.1049 & -5.137 & 5.2419 & 0.5240 \\
\hline & $0-10$ & 526054 & 17 & -0.0006 & 10.3399 & -10.3405 & -0.7311 \\
\hline & \multicolumn{3}{|c|}{ Total pixels $=526054$} & cal pixels & vith depos & sits $=17$ & \\
\hline
\end{tabular}




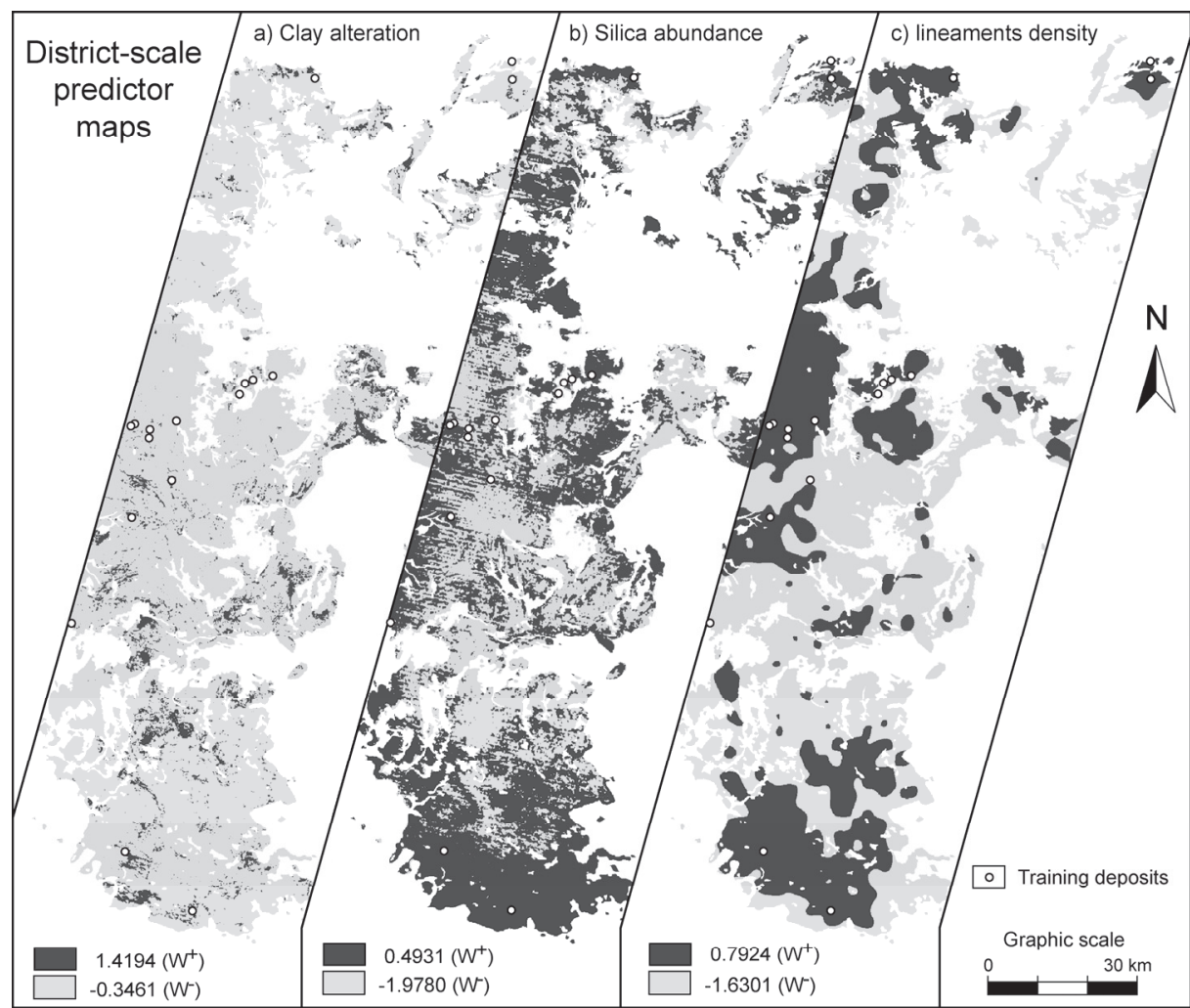

Figure 3.9: Binary predictor maps representing the generalization of cumulative percentile evidence classes (Table 3-4) into two classes with predictor patterns present and absent, which are awarded the values of $\mathrm{W}^{+}$and $\mathrm{W}^{-}$respectively. Dark grey shows the predictor patterns present.

Sixteen out of 17 training deposits are in areas identified as favourable for LISEDs occurrence; therefore, the success rate is $94.12 \%$. In addition, from the LOOCV method, 14 deposits left-out successively for validation were predicted as favourable areas in the 17 predictions; therefore, the prediction rate is $82.35 \%$. 


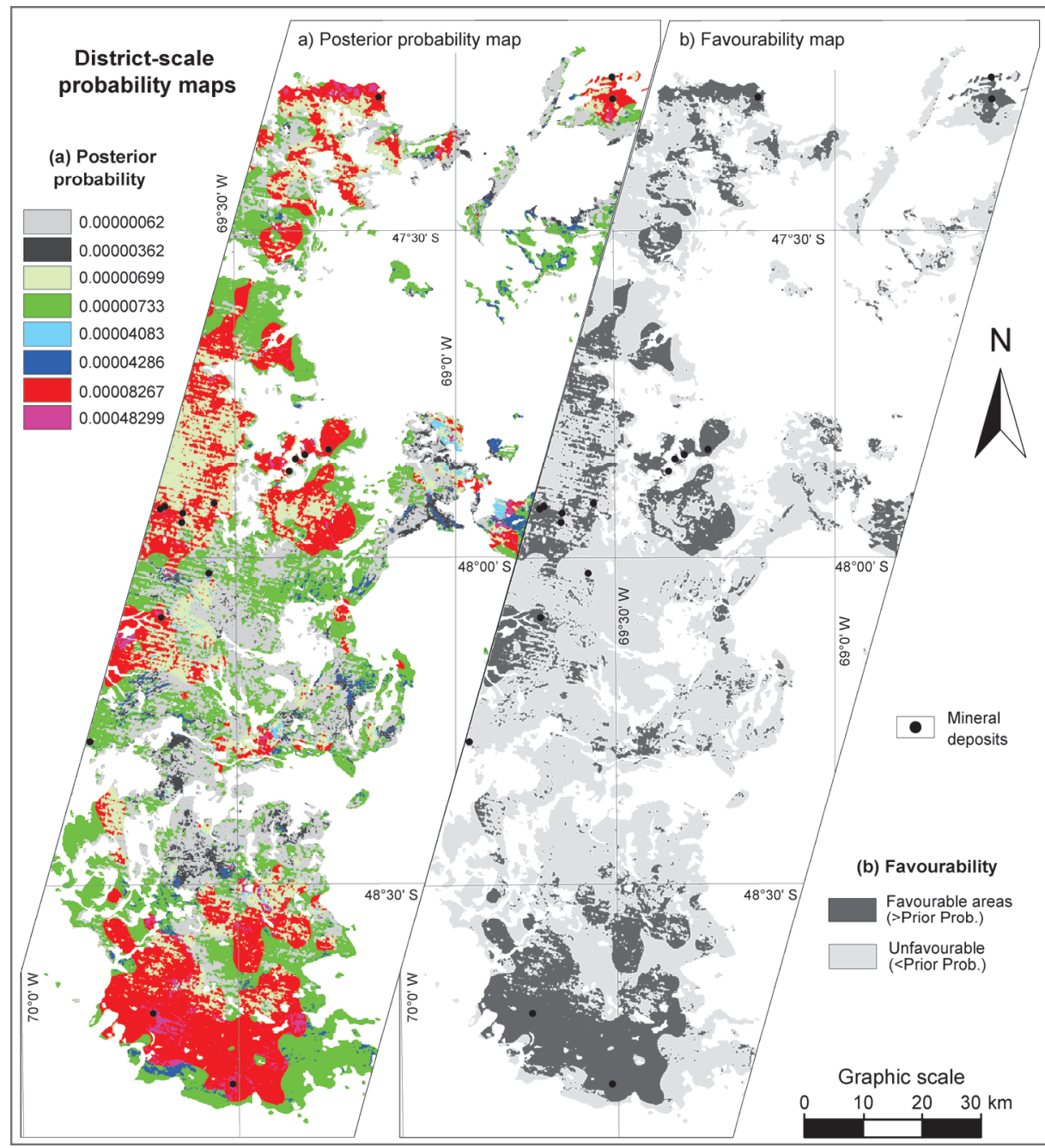

Figure 3.10: District-scale probability maps. (a) Posterior probability map of LISEDs occurrence, showing the eight discrete classes of posterior probability produced by the WofE statistical calculations. (b) Favourability map for LISEDs occurrence.

\subsubsection{Assessment of regional- and district-scale predictions}

The comparison of predictions by the regional- and district-scale models in the district-scale area provided an assessment of the relative effectiveness of the two models for predicting favourable areas for discovering new deposits. The regional-scale model predicted $57.1 \%$ of the district-scale area as favourable, while the district-scale model predicted as favourable only $12.7 \%$ of the same area. In addition, $3.3 \%$ of the areas predicted as unfavourable by the regional-scale dataset in the district-scale area, are predicted as favourable by the district-scale model. Considering only the area of favourable lithology of the detailed lithological map, in the district-scale area, 
a confusion matrix (Table 3-5) shows that: (a) the regional-scale model delineates $83.8 \%$ of the considered area as favourable (i.e., $100 *(440931 / 526054)$, while the district-scale model delineates $28.9 \%$ of the same area as favourable (i.e., $100 *(152068 / 526054)$; (b) only $30.6 \%$ of the area mapped as favourable by the regional-scale model was also mapped as favourable by the district-scale model (i.e., 100*135040/440931); and (c) $20 \%$ of the areas predicted as unfavourable by the regional-scale model are indicated as favourable by the district-scale model (i.e., 100*17028/85123).

Table 3-5. Confusion matrix derived from cross operation of regional and district-scale favourability maps, in areas of favourable lithology of the district-scale area. Values are number of $100 \times 100 \mathrm{~m}$ cells in the maps.

\begin{tabular}{|c|c|c|c|c|c|}
\hline \multirow{4}{*}{ 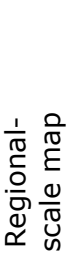 } & & \multicolumn{2}{|c|}{ District-scale map } & \multirow[b]{2}{*}{ Total } & \multirow[b]{3}{*}{$83.8 \%$} \\
\hline & & Favourable & Unfavourable & & \\
\hline & Favourable & 135040 & 305891 & 440931 & \\
\hline & Unfavourable & 17028 & 68095 & 85123 & $16.2 \%$ \\
\hline \multirow{2}{*}{\multicolumn{2}{|c|}{ Total }} & 152068 & 373986 & \multirow[t]{2}{*}{526054} & \\
\hline & & $28.9 \%$ & $71.1 \%$ & & \\
\hline
\end{tabular}

\subsection{Discussion}

\subsubsection{Prospectivity mapping for LISEDs in the Deseado Massif}

The relatively high success-rate and prediction-rate of the favourability maps imply that both the regional and district-scale predictive models are effective and useful guides for exploration of LISEDs in the Deseado Massif. However, the equal values for success-rate and prediction-rate for the regional-scale model is unexpected because, as expressed by Chung and Fabbri (2003), we assume that the predictive model is correct and therefore, the success rate should be higher than the prediction rate. This may indicate problems with the regional-scale predictive model or with the data from which the model derives. Although difficult to compare exhaustively, the success-rate (83\%) for our regional-scale model, is slightly higher than the $80 \%$ obtained for the same region by Carranza and Andrada de Palomera (2005) for areas with moderate and high potential for epithermal deposits. On the other hand, our prediction rate $(83 \%)$ is lower than their prediction rate $(97.91 \%)$. Although this gives the impression of a better validation for the model produced by Carranza and Andrada de Palomera (2005), it is more likely that their prediction rate, noticeable higher than their success rate, indicates problems with their predictive model. These problems may have been partially solved with the regional-scale model we produced, because of the use of different 
methods of mapping and validation, allowing us to use more training deposits.

Results of CI tests obtained by using different layers of evidence in various combinations for prospectivity mapping, show that the lithological evidence layers produce relatively high conditional dependence with other layers (mainly structural evidence), regardless of the accuracy of the lithological map. This is expected because styles and density of fractures, and partially the alteration style, depend on rock type. To avoid this dependency and produce statistically robust WofE analyses, the lithological layer should be modified or used in a different way. Our results suggest that lithology should be used as restrictor instead of predictor layer, because as such, the information conveyed by that layer would be used for the prospectivity mapping but not in the statistical analysis. In addition, this practice proved to have strong influence in the area reduction. The restriction by favourable lithology is a reasonable practice because it is known a priori that lithologies deposited after the events of epithermal mineralization cannot host this type of mineralization.

However, there are two caveats for using the lithological layer to restrict the study area. Favourable lithologies and mineralized rocks are sometimes masked by thin layers of unfavourable lithology (young gravels or basalts) like in the San José district (Dietrich et al., 2012; Shatwell et al., 2011). Therefore, some areas discarded based on lithology alone may still contain mineralization beneath unfavourable lithologies. Other than field evidence, large (reactivated) structures may be the only indication of prospective ground underneath unfavourable lithologies. The regional-scale structural zones used for regional-scale mapping may provide that indication when the structures were reactivated or their detection is not totally hindered by younger deposits. The other caveat is that low accuracy of the lithological maps may lead to erroneous determinations. This may result in discarding areas that otherwise may be favourable, or may cause training deposits to be erroneously left out of the WofE calculations. This modifies the spatial associations between deposits and the other evidence layers.

Our results suggest that predictive mapping with the district-scale model in favourable areas, already delineated by our regional-scale predictive model, seems a reasonable practice to sequentially concentrate exploration efforts, mainly if the initial prospective areas have regional-scale dimensions. This is consistent with the sequential approach commonly carried out during mineral exploration. In addition, this approach is logical and feasible if we consider the differences in area reduction produced by the regional and district-scale models. In the district-scale area however, $3.3 \%$ of the areas predicted as unfavourable by the regional-scale dataset, are predicted as favourable by 
the district-scale model. This suggests a percentage of potentially mineralized areas that could be discarded if the predictive mapping is applied sequentially, or if the district-scale model is not applied at all. Therefore, the more effective approach may include the use of both mapping models in parallel, as independent tools.

\subsubsection{Regional-scale vs. district-scale prospectivity mapping}

Some advantages of the district-scale model over the regional-scale model for mapping districts or smaller areas include: a) its higher efficiency, which is suggested by the success-rate and prediction-rate of the favourability maps; b) the stronger spatial associations of LISEDs with the district-scale evidence layers, interpreted from slightly higher values of $C$ in the districtscale model; c) higher conditional independence for district-scale evidence layers, which indicates that the absolute posterior probabilities yielded by the district-scale model are more reliable than those from the regional-scale model; d) the higher levels of detail and spatial resolution; and e) the much higher reduction of favourable area. While the district-scale model indicates as favourable only $12.7 \%$ of the district-scale area, the regional-scale model indicates as favourable $57.1 \%$ of the same area. The latter is even larger than the area covered by only the favourable lithology of the detailed lithological map ( $44 \%$ of the district-scale area). Considering only the area of favourable lithology in the detailed lithological map $\left(5,260.54 \mathrm{~km}^{2}\right)$, the regional-scale model reduced the potentially favourable areas to $83.8 \%$ of the initial area, while the district-scale model reduced it to only $28.9 \%$ of the same area. This indicates a higher usefulness of the district-scale model, because the aim of prospectivity mapping is to focus on favourable areas for follow up exploration.

These slightly more useful and efficient results of the district-scale model may be a consequence of using ASTER instead of Landsat, more accurate and detailed geological maps, and therefore higher resolution predictor maps. ASTER allowed including silica abundance as evidence, which had a beneficial influence in prospectivity mapping because silicification is one of the predominant alterations in these types of deposits in the Deseado Massif. In addition, the higher spectral resolution of ASTER may help to detect only the clay alteration minerals that predominate close to the mineralization. The higher spatial resolution of predictor maps in the district-scale model, permits higher details in the final maps, and the inclusion of small areas with favourable lithologies in the calculations. This avoids losing prospective ground and assures that most of the available deposits are used in the analysis. In the regional-scale model, the coarser spatial resolution of predictor maps and lower detail and accuracy of lithological evidence causes the areal extent of some formations (e.g., La Modesta) to become almost 
negligible in the calculations at regional-scale, because of the restricted size of their outcrops.

Potential disadvantages of district-scale models in the Deseado Massif are the limited availability of some data, the limited quality of available data, and the more demanding data processing. As well as in other regions of the world (Ford and Hart, 2013), data availability and quality are restricted in the Deseado Massif; the relatively low accuracy of available geological maps is an example of that. Positioning errors estimated for the geological maps used in this research are well above those recommended by the National Map Accuracy Standards of 1947 (U.S. Bureau of the Budget, 1947). This standard recommends that no more than $10 \%$ of the tested points should exceed an error of $\sim 127 \mathrm{~m}$ for $1: 250,000$ scale maps and $\sim 381 \mathrm{~m}$ for $1: 750,000$ scale maps, while the medians of errors for our geological maps are 268 and $1,249 \mathrm{~m}$ for the respective scales. The use of ASTER involves a more demanding data processing and the difficulty of combining several scenes because of calibration differences.

\subsubsection{Assessing the usefulness of evidence layers and improving the prospectivity mapping}

Results of the predictive modelling procedures helped to assess the usefulness of the different types of evidence used in this research, and to infer which of them should be further investigated for improving the predictive models. Those investigations may include new exercises of prospectivity mapping as well as studies in specific subjects related to ore deposits geology.

The results of the spatial association analyses indicate that lithology, structures and silica abundance are effective spatial predictors. At regionalscale, both the lithological and the structural evidence show strong spatial associations with LISEDs. At district-scale, density of lineaments (indicative of fracturing and overall permeability), and $\mathrm{K}_{\text {silica }}$ index (indicative of silica abundance), showed strong spatial association and low $W$ values. This suggested that most district-scale fractures mapped in this study were probably contemporaneous or older than the mineralization, and that areas with low density of fractures and no silicic alteration are less favourable to find LISEDs. In addition, the relatively large distance from regional structures $(12,000 \mathrm{~m})$ to reach the optimal spatial association with the LISEDs, may indicate that at least part of the mineralized rocks are hosted in secondary structures around the regional structures. This may have been a consequence of the interaction of regional NNW-NW structures, which may have acted as fluid pathways, with other sets of structures (Giacosa et al., 2010), or with strongly fractured (permeable) rocks. 
These strong associations confirm the importance of structural controls on the emplacement of LISEDs in the Deseado Massif, as indicated by field studies of several authors (e.g., Dietrich et al., 2012; Echavarría et al., 2005; Fernández et al., 2008; Moreira et al., 2008; Schalamuk et al., 1997). It was also observed that siliceous alterations were strongly related with the mineralizing processes, and that these zones formed excellent features for deposit recognition in the area, as stated by Schalamuk et al. (2002).

Clay alteration layers used in this research are the weakest layers of evidence, which is consistent with results of Carranza and Andrada de Palomera (2005), but is contrasting with the conspicuous presence of clay alterations described in epithermal systems (Andrada de Palomera et al., 2012; Gemmell, 2007; Hedenquist et al., 2000; Simmons and Browne, 2000; Simmons et al., 2005; Simpson and Mauk, 2011; Zhai et al., 2009). Presence of clay alteration was amongst the best predictors in studies by other authors (e.g., Raines, 1999). These layers show the lowest contrasts in the spatial association analysis at regional- and district-scales. At district-scale, only about $35 \%$ of the deposits are located in areas with optimum spatial association of the clay alteration predictor map, and about $41 \%$ of the deposits are in cumulative classes with low $C$, suggesting that many deposits are located in areas where clay alteration was either absent or not detected. A possible explanation is that clay alteration haloes related to these deposits are restricted in size. This has been confirmed in extensively altered areas where the spatial extent of clay alteration is very small.

This weak spatial association between deposits and clay alteration may also be due to: (a) clay occurrences in the study area that are genetically unrelated to hydrothermal alteration (e.g., transported or produced by weathering); (b) the kind of methods that were used to produce the clay alteration evidence and predictor maps, including filtering and resampling to relatively large cells (mainly at regional-scale). They may have caused removal of small alteration anomalies, weakening the spatial association with the deposits; and (c) predominance of siliceous alteration in the centre of the deposits (where training points are located), which may have obscured clay alteration. This is likely since most deposits include silicification and stockworks, and some of them (e.g., Bacon-Mina Martha and Bajo Pobre) are located in areas with low $C$ of the $4 / 6$ band ratio image and with relatively high silica content (in the $\mathrm{K}_{\text {silica }}$ image).

Therefore, the geological evidence representing hydrothermal clay alteration should be studied in more detail in the Deseado Massif in order to obtain better results in the prospectivity mapping. 
The lack of detailed knowledge about the relationship between LISEDs and the composition and spatial configuration of alteration envelopes, the lack of alteration ground-truth to calibrate remote sensing data, and the relatively coarse spatial and spectral resolutions of the available remote sensing data are limiting factors for mineral prospectivity mapping of districts and smaller areas in the Deseado Massif.

Customization of exploration models for different parts of the Deseado Massif may lead to improve the prospectivity mapping at district or larger scales. The structural differences amongst different sectors of the Deseado Massif, which were already suggested by Giacosa et al. (2010) and Japas et al. (2013), and the differences of structural controls on mineralization inferred by Andrada de Palomera and Carranza (2005), support the idea of predominant structural controls with slightly different directions in different sectors of the Deseado Massif. Although the structural evidence is probably the clearer example of the need for local customization, considering differences in patterns and types of alterations, and determining in detail the ages of mineralization and volcanic rocks would probably help improving the predictions.

The determination of the temporal limit between favourable and unfavourable lithologies with higher resolution than that of a formation can improve the prospectivity mapping in districts or smaller areas. This is possible because of the short lifespan of hydrothermal systems, which allows placing the upper limit of the mineralizing events between members of a formation in the stratigraphic sequence, as it has been done in some areas of the Deseado Massif (Andrada de Palomera et al., 2012; Permuy Vidal et al., 2014). Then, this can be used for constraining more accurately the initial areas to be assessed with WofE or similar techniques.

Accuracy and spatial detail of the evidence maps, which depend partially on spatial resolution, impact on the quality of the prospectivity mapping. Because geographic data is scale-dependant (Goodchild, 2011), excessive detail in regional-scale evidence maps (i.e., showing features hardly distinguishable at that scale) may result in problems, such as: a) cluttering of maps by fragmentation of areas that would show homogeneous probabilities at lower resolutions; b) difficulties with handling of more voluminous data of higher resolution maps; and $c$ ) inefficient use of resources related to the acquisition of more detailed data (during field campaigns) if the prospectivity maps result from up-scaling of evidence maps. On the other hand, more detailed evidence maps are advantageous because they allow increased map accuracy and a more precise delineation of areas of favourable evidence. Thus, the necessary detail of the input data 
depends on the scale at which the final predictive map will be displayed, and should be in accordance with the size of the area to be prospected.

In addition to spatial resolution, the spectral resolution of the optical satellite data affects the modelling results. In the current study, the clay alteration evidence layer from Landsat ETM+ was produced at lower spectral resolution than that derived from ASTER data. The lower spectral resolution of Landsat ETM+ data causes less detail in the reflectance spectra that were used for the mapping of alteration mineralogy. Absorption in Landsat band 7 can be caused by a variety of alteration minerals, including illite, smectite, kaolinite, alunite and chlorite. Since ASTER imagery has a higher spectral resolution in the wavelength range of Landsat band 7, the ASTER imagery can be used to discriminate better between alteration minerals and map more accurately illite, smectite and kaolinite. Therefore, the use of Landsat data seems adequate for the regional-scale mapping, with $1000 \mathrm{~m}$ spatial resolution, but for the district-scale mapping with $100 \mathrm{~m}$ spatial resolution, ASTER is more suitable because it may focus alteration mapping to mainly the illite-kaolinitesmectite richer areas, which are better indicators of mineralisation than for instance chlorite.

Finally, although not tested in this research, geochemical and geophysical evidence are other layers that could be investigated and included in the predictive mapping models. Magnetic and radiometric data are potentially useful for detection of hidden structures and areas containing strongly altered rocks.

\subsection{Conclusions}

Prospectivity for low- and intermediate-sulfidation epithermal deposits was mapped successfully in most of the Deseado Massif, by using easily obtainable datasets, and applying the weights of evidence and the leave-oneout cross-validation methods, which allowed using all available deposits for training the model, as well as for validating it.

Prospecting for low- and intermediate-sulfidation epithermal deposits in districts or smaller areas with our district-scale model was more useful, effective and reliable than using the regional-scale model. That reflects the efficiency of using more accurate and detailed lithological maps, the incorporation of silica abundance layer of evidence, the higher spectral resolution of ASTER, and the use of lithology as restrictor evidence instead of as predictor evidence. It likely also reflects the higher resolution of the district-scale predictor maps in contrast to the regional-scale predictor maps $(100 \mathrm{~m}$ vs. $1000 \mathrm{~m})$. Therefore, it seems worthwhile to use the district-scale 
datasets for prospectivity mapping in districts or smaller areas in the Deseado Massif.

The most efficient practice to map mineral prospectivity for low- and intermediate-sulfidation epithermal deposits in the Deseado Massif, and probably other regions, is to sequentially apply a district-scale prospectivity model in areas already indicated as favourable by a regional-scale prospectivity model. It seems more effective, however, to apply both models as independent and additive prospective tools, to avoid dismissing prospective ground that may be discarded by the regional-scale model.

The district-scale prospectivity models can be improved by investigating, in every district, the relationships between predominant deposit styles and different types of geological evidence. Most of these investigations should probably focus on hydrothermal alterations and the ways they can be detected. However, the study of pathfinder elements, structural controls, and relative age between mineralization and host rocks, should also be helpful for improving our predictions.

In addition, the accuracy and detail of the geological maps are key factors for improving the prospectivity mapping in the Deseado Massif and probably other areas where low and intermediate-sulfidation epithermal deposits are sought. 


\section{Chapter 4}

\section{Geology and mineralization of the La Josefina deposit}

\footnotetext{
* This chapter is partially based on: Andrada de Palomera, P., van Ruitenbeek, F.J.A., van der Meer, F.D. and Fernández, R., 2012. Geochemical indicators of gold-rich zones in the La Josefina epithermal deposit, Deseado Massif, Argentina. Ore Geology

Reviews, 45: 61-80.
} 


\subsection{Introduction}

The recognition of different portions of epithermal paleo-systems, including determining the approximate vertical (and lateral) position in the paleosystem that an explored area represents, is a valuable tool to help infer the possible presence and location of ore. This recognition is often done by interpreting general lithological and geochemical data in the frame of a conceptual model of the deposit type being sought. Detailed geochemical composition of rocks, and the distribution of hydrothermal alteration minerals, can help in these determinations.

The La Josefina deposit, located in the central part of the Deseado Massif (Figure 4.1), includes several lithologies from the Precambrian basement to younger basalts, although the predominant rocks are Jurassic volcanics from the Bahía Laura Group. This area shows gold and silver epithermal mineralization distributed along a $10 \times 3 \mathrm{~km}$ belt of hydrothermally altered rocks. Along this alteration belt (Figure 4.1), mineralization has been detected in seven areas with different geological and geochemical characteristics, showing that they were formed at different positions in an epithermal paleo-system. While the northern areas seem to represent the upper parts of the epithermal paleo-system, the other areas were formed at deeper levels. The mineralization in the area is strongly structurally controlled and disposed in quartz veins, veinlets and hydrothermal breccias, which are mainly hosted in the Chon Aike Formation, although there are indications that the metamorphic basement (La Modesta Formation) might also be mineralized (Moreira et al., 2001).

The primary objectives of this chapter are to construct a geological conceptual model of the La Josefina epithermal deposit by interpreting geological and some geochemical information, available mainly from literature, and to set up the geological basis for studying and interpreting new geochemical and hydrothermal alteration data obtained from different parts of this epithermal paleo-system. The La Josefina LISED (Figure 4.1) was selected to carry out this study, because it shows features indicative of different portions of a likely complete epithermal paleo-system, some of which are mineralized with $\mathrm{Au}$ and $\mathrm{Ag}$.

\subsection{Method}

Geological and geochemical data from the La Josefina deposit were interpreted for determining the approximate position of each explored area in the epithermal paleo-system. To aid in these interpretations, four schematic cross sections were constructed for different areas, using available lithological, alteration and geochemical data. The cross sections were constructed along directions that show the most relevant geological features 
in each represented area. Then a general and hypothetical conceptual model of the paleo-system was drafted and the positions of the explored areas were indicated in the graphical model.

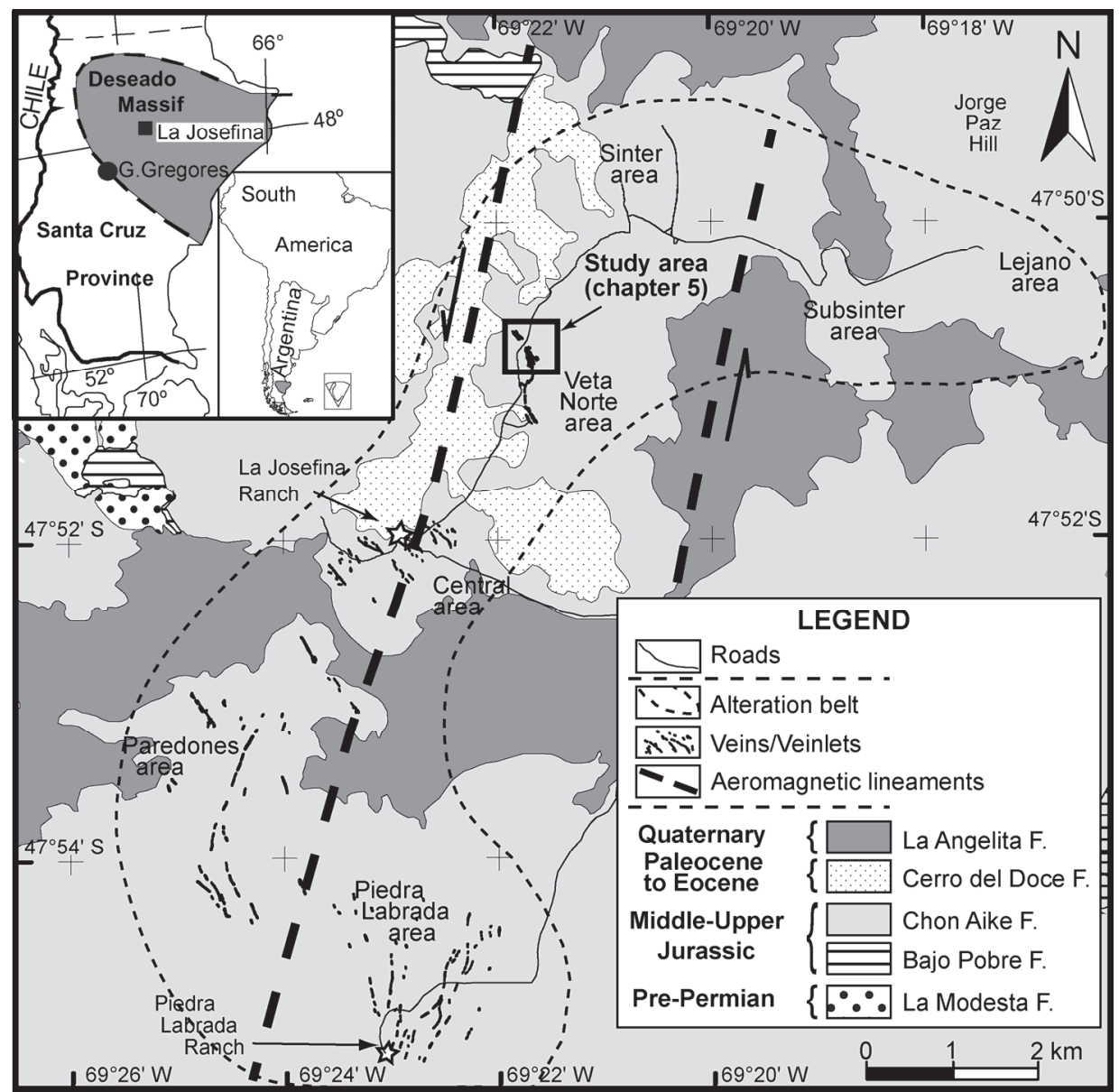

Figure 4.1: Location and general geology of the La Josefina deposit. Lithology modified from Moreira (2005). Magnetic lineaments extracted from Peñalva et al. (2005).

Most of the geological information used for this chapter is available in publications, but other is unpublished material produced by Fomicruz S.E., and Hunt Mining Corp. The available literature relative to the La Josefina deposit was studied and the most relevant information was summarized and interpreted. In addition, some information known by the author was also used for the interpretations.

The interpretations and the final hypothetical conceptual model of the complete paleo-system were carried out by using as basis the currently accepted conceptual models for low-sulfidation epithermal deposits published 
in relevant journals, but slightly adjusting them to the geology and configuration of the La Josefina deposit.

\subsection{Stratigraphy of the La Josefina district}

The oldest rocks in the district are metamorphic rocks of the La Modesta Formation. They crop out in an area of approximately $20 \mathrm{~km}^{2}$ located at ca. $1.5 \mathrm{~km}$ to the $W$ of the Central area (Figure 4.1 and Figure 4.2). It is composed of alternating pelitic and psammitic muscovite-chlorite schists and meta-quarzites, with minor calc-silicate rocks, basic metavolcanics and tourmaline-bearing schists (Moreira et al., 2013). The age of this Formation is still not precisely determined; but Moreira et al. (2013) interpreted that the maximum age of sedimentation of its protolith is about $446 \pm 6 \mathrm{Ma}$, while the age of metamorphism must be older than the Permian and could be Late Carboniferous.

The Bajo Pobre Formation is present in the La Josefina district in restricted outcrops. Some of them are in contact with the La Modesta Formation, others are located at ca. $2 \mathrm{~km}$ to the NW and $8 \mathrm{~km}$ to the SE of mineralized areas (Figure 4.1).

The predominant rocks in the district are from the Chon Aike Formation (Figure 4.1) that consists of several Members (Figure 4.2) (Fernández et al., 1996; INREMI, 1996; Moreira, 2005; Moreira et al., 2009; Peñalva et al., 2005). Those members include magmatic and volcaniclastic lithofacies (lava domes and flows, ignimbrites, minor tuffs, tuffites, volcanic breccias and pyroclastic surges). The most important members related with the belt of hydrothermal alteration in the La Josefina deposit are the Piedra Labrada, Mogote Hormigas, Cerro Jorge Paz, and La Josefina Members (Figure 4.2).

The Piedra Labrada Member consists of crystal-rich ignimbrites with quartz, sanidine, plagioclase and biotite crystals, and locally with fiammes. It is the oldest member in the area and was dated in $156.4-150.5 \mathrm{Ma}$ by U-Pb SHRIMP analyses of zircons (Moreira et al., 2009). This member predominates in the Piedra Labrada, Paredones and Central areas (Figure 4.2).

The La Josefina Member includes lava flows and domes outcropping along the north-western border of the alteration belt. The lavas have aphanitic textures and less than $10 \%$ of microphenocrysts (Moreira, 2005); their groundmass is composed of quartz, potassic feldspars and scarce plagioclase, and their phenocrysts are mainly plagioclase, biotite and scarce quartz and sanidine. Some fragments of a breccia present in the subsurface and likely pertaining to the Mogote Hormigas Member may have come from these lavas. 


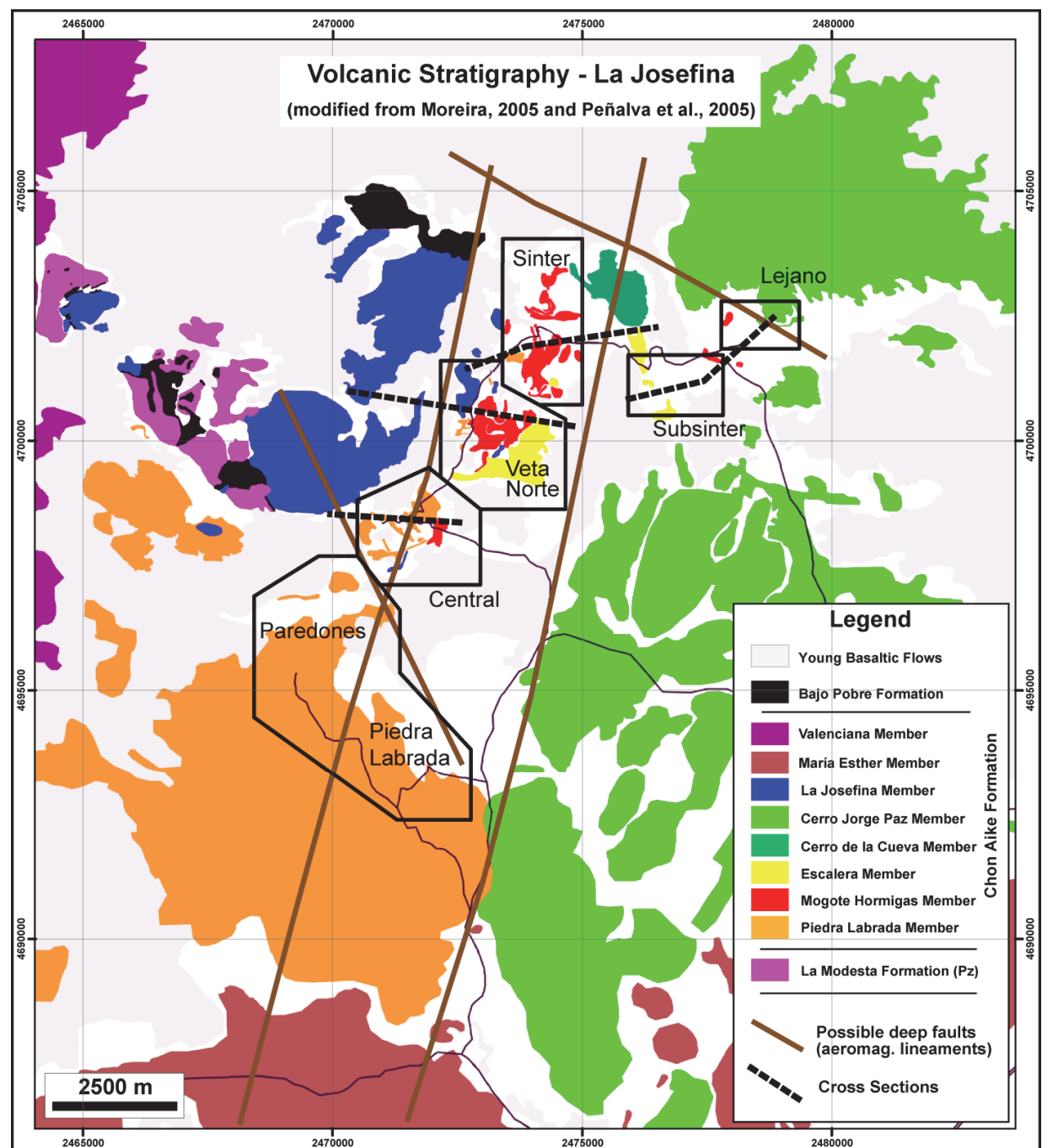

Figure 4.2: Volcanic stratigraphy in the La Josefina district. The Chon Aike Formation is divided in Members. Summarized from Moreira (2005), Moreira et al. (2009) and Peñalva et al. (2005). A belt of hydrothermally altered rocks is defined by the location of the seven indicated areas.

Moreira (2005) and Moreira and Fernández (2015) mentioned the presence of the La Josefina Member as host of the Flaca East and Flaca West veins in the northern part of the Veta Norte area. However, the lavas have not been detected in trenches and a borehole drilled there, and it is more likely that fragments of these lavas are only present at the surface in the form of debris covering the underlying lithology. Instead, the predominant rocks hosting the two mentioned veins in the subsurface are volcanic polymictic breccias alternating with layers of fine grained tuffs. The breccia fragments are mainly from crystal-rich tuffs, some of which are fine grained and showing 
laminations or fluidal textures (probably lavas); a few fragments may be from the metamorphic basement. These rocks are probably part of the Escalera or Mogote Hormigas Members.

The Mogote Hormigas Member predominates in the Veta Norte and Sinter areas. It temporary follows the Piedra Labrada and probably the La Josefina Members in the sequence. It is composed mainly of lithic and pumice-rich ignimbrites with abundant matrix and fiammes, showing low percentage of crystals and moderate to high degree of welding (Moreira, 2005).

The Escalera Member (Moreira, 2005) is composed of crystal-rich ignimbrites, breccias and pyroclastic surges, and it lays over the Mogote Hormigas Member. It predominates in the SE part of the Veta Norte area and the western part of the Subsinter area (Figure 4.2), but is also present in the Sinter area, where it has been detected over the Mogote Hormigas Member in a diamond borehole.

The Cerro Jorge Paz Member appears bordering the alteration belt to the east (Figure 4.2). It is highly variable in lithology, including different types of ignimbrites, breccias, and surges (Moreira, 2005). Regardless of their grain size and fragment shapes, they seem to be crystal-poor rocks, and may have pumice (sometimes fiammes) and lithic fragments. They can have some crystals of quartz, biotite, feldspars, plagioclase and sanidine. The Cerro Jorge Paz was interpreted as the youngest member of the Chon Aike Formation in the area (Moreira, 2005).

Lava flows of the Cerro del Doce basalts and the La Angelita Formation cover large portions of the La Josefina district (Figure 4.1 and Figure 4.2).

\subsection{Mineralization in the La Josefina deposit}

Most features of the La Josefina deposit are of the low-sulfidation epithermal style (Rios et al., 2000; Schalamuk et al., 1998). The elements of economic significance are $\mathrm{Au}$ and $\mathrm{Ag}$, and are contained in quartz veins, veinlets and hydrothermal breccias, which often include adularia. The veins show mainly open-space textures, predominantly comb and saccharoidal, but also colloform-crustiform and bladed. Other typical features of low-sulfidation deposits present in La Josefina, are siliceous and calcareous sinter deposits. However, the presence of tetrahedrite, the common barite in the veins, the salinity of fluid inclusions, reaching 15 wt\% $\mathrm{NaCl}$ eq. (Rios et al., 2000), and the FeS content of sphalerite, from 2.72 to $5.2 \mathrm{~mol} \%$ (Moreira et al., 2004a) are probably more typical features of intermediate-sulfidation deposits. 
The Au-Ag-rich veins and associated hydrothermal alterations in the La Josefina deposit are genetically related to the Jurassic volcanism, which is inferred from different pieces of evidence. One of them is the overlap of the age of the Chon Aike Formation, dated in $153 \pm 3.6 \mathrm{Ma}$ to $148.8 \pm 3.6 \mathrm{Ma}$ (Arribas et al., 1996; Moreira et al., 2009), with the age of the hydrothermal alterations, dated in $156 \pm 2 \mathrm{Ma}$ (Fernández et al., 1999). Other evidence is based on the position of veins in the volcanic sequence; most of the veins and veinlets are hosted in the older units of the Chon Aike Formation (Piedra Labrada and Mogote Hormigas Members), while siliceous and calcareous deposits, interpreted as the upper part of the epithermal paleo-system, seem to rest below the youngest portions of this formation (upper part of Cerro Jorge Paz Member). This implies that the La Josefina hydrothermal system was temporally constrained in the Chon Aike Formation. Finally, the similar $\mathrm{Pb}$ isotopes ratios calculated for the volcanic rocks and for sulfides in the epithermal veins also indicate a genetic link between the Jurassic volcanic rocks and the mineralization (Moreira et al., 2005).

The development of the vein system in the La Josefina epithermal deposit was strongly structurally controlled. The controlling structures were two main NNE oriented fractures, one of which is located at ca. $300 \mathrm{~m}$ to the west of the Veta Norte area (Figure 4.1 and Figure 4.2). The locations of these two fractures were inferred from the analysis of two regional aeromagnetic lineaments (Peñalva et al., 2005). These two lineaments were interpreted as part of a shear zone with sinistral displacements produced by a principal stress $(\sigma 1)$ directed at ca. $340^{\circ}$ and an extensional direction $(\sigma 3)$ with azimuth of $70-80^{\circ}$ (Moreira et al., 2008). Within this framework of stress and under the Jurassic general extensional environment, NNW and NW trending veins were developed in dextral-slip faults (Moreira et al., 2008). Those veins were later dissected by WNW trending dextral-slip faults.

Different levels of an epithermal paleo-system are represented by different explored areas in the La Josefina deposit. The Veta Norte, Central, Paredones and Piedra Labrada areas (Figure 4.1) are interpreted as relatively deep levels of the paleo-system because they include veins of predominantly coarse crystalline quartz, some calcite and adularia, and temperatures of homogenization in fluid inclusions reaching up to $290^{\circ} \mathrm{C}$ (Rios et al., 2000). In contrast, the Sinter, Subsinter and Lejano areas (Figure 4.1) are interpreted as the upper levels of the paleo-system. In the last three areas, quartz veinlets are scarce and there are siliceous and calcareous deposits considered as evidence of paleo-surface (Moreira et al., 2002). Pervasive silicification and abundant kaolinite, typically produced by steam-heated waters in the upper parts of epithermal paleo-systems, are also present in the Sinter, Subsinter and Lejano areas. The spatial association of the veins with the hydrothermal products indicative of upper levels in the paleo-system 
(Moreira et al., 2009) suggest that all those features pertain to the same epithermal paleo-system.

\subsection{Rock alterations and other hydrothermal products}

Two general environments of alteration are recognized in the La Josefina district. The first one is localized around veins and veinlets; it consists of areas with predominant clay alteration (locally with adularia) and silicification. In those areas, the alteration (other than silicification) did not destroy the original texture and mineralogy of the rocks. The second environment is not directly related to veins and was probably produced by acid steam-heated waters in or close to paleo-surface; it includes rocks with different degrees of silicification and leaching, and areas with predominant kaolinite and illite. The hydrothermal alterations can be classified in four general types (Table 4-1), including: (1) Siliceous, (2) Argillic, (3) Propylitic, and (4) Potassic. In addition, other hydrothermal products were deposited at the paleo-surface, forming calcareous and siliceous rocks. 
Table 4-1. Hydrothermal alterations observed in the La Josefina deposit.

\begin{tabular}{|c|c|c|}
\hline \multicolumn{2}{|c|}{ Alteration Type } & Relevant Characteristics \\
\hline \multirow{4}{*}{ 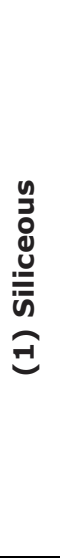 } & $\begin{array}{l}\quad(1 a) \\
\text { Vein-related } \\
\text { siliceous } \\
\text { alteration }\end{array}$ & $\begin{array}{l}\text { Restricted to up to } 1 \mathrm{~m} \text { (occasionally } 5 \mathrm{~m} \text { ) from the veins } \\
\text { (Andrada de Palomera et al., 2012). It consists of patches or } \\
\text { strips with silica replacing matrix and different minerals; often } \\
\text { with quartz, chalcedony and opal thin veinlets. It passes } \\
\text { transitionally to argillic alteration. }\end{array}$ \\
\hline & $\begin{array}{l}(1 \mathrm{~b}) \\
\text { Pervasive } \\
\text { silicification }\end{array}$ & $\begin{array}{l}\text { Homogeneous massive replacement of rocks by chalcedony, } \\
\text { irregular quartz crystals, and some Fe-oxides and clays. The } \\
\text { original rocks lost most of their characteristics except for some } \\
\text { laminar stratification. Present in the Lejano and Subsinter } \\
\text { areas. Crystal-and fiamme-rich ignimbrites of the Cerro Jorge } \\
\text { Paz Member may be the protolith. }\end{array}$ \\
\hline & (1c) & $\begin{array}{l}\text { Silicified rock with abundant cavities covered by saccharoidal } \\
\text { quartz and calcite. Microscopically, a quartz crystals aggregate }\end{array}$ \\
\hline & $\begin{array}{l}\text { Vuggy } \\
\text { silicification }\end{array}$ & $\begin{array}{l}\text { inter-grown with remaining calcite, abundant Fe-oxides, some } \\
\text { jarosite and possible barite and plumbogummite (Moreira, } \\
\text { 2005). Produced by strong leaching in the Lejano area. }\end{array}$ \\
\hline \multirow{3}{*}{ 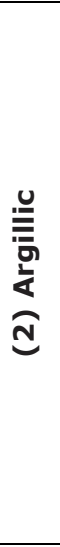 } & $\begin{array}{l}(2 a) \\
\text { Vein-related } \\
\text { argillic } \\
\text { alteration }\end{array}$ & $\begin{array}{l}\text { Restricted to few meters around the veins. Illite, kaolinite and } \\
\text { interstratified illite/smectite totally or partially replacing } \\
\text { feldspars, pumices, lithic fragments and matrix. Also filling } \\
\text { fractures and pumice cavities. Kaolinite may be due to } \\
\text { alteration of illite by acid hydrothermal fluids or weathering } \\
\text { (Moreira et al., 2004b), but it might also be due to kaolinite- } \\
\text { rich steam heated waters drained downwards into the system. }\end{array}$ \\
\hline & $\begin{array}{l}(2 b) \\
\text { kaolinite-rich } \\
\text { argillic } \\
\text { alteration }\end{array}$ & $\begin{array}{l}\text { Kaolinite associated to trydimite and possible dickite, } \\
\text { completely replacing a flow tuff with rounded pumice, mainly in } \\
\text { the Subsinter area, but also in the Lejano area. }\end{array}$ \\
\hline & $\begin{array}{l}(2 \mathrm{c}) \\
\text { Illite-rich } \\
\text { argillic } \\
\text { alteration }\end{array}$ & $\begin{array}{l}\text { Illite with minor kaolinite and jarosite strongly replacing a flow } \\
\text { tuff with fragments of up to few } \mathrm{cm} \text {. Homogeneously silicified } \\
\text { cement (probably glass re-crystallization) also has illite. It } \\
\text { seems to pass in transition to kaolinite rich alteration affecting } \\
\text { the same rock (Moreira, 2005). }\end{array}$ \\
\hline (3) & ic & $\begin{array}{l}\text { Diffuse and weak alteration halo far away from the structures. } \\
\text { Composed by chlorite }+ \text { calcite }+ \text { pyrite } \pm \text { epidote, and partially } \\
\text { restricted to phenocrysts. Probably pre-mineralization by } \\
\text { regional process (Moreira, 2005) }\end{array}$ \\
\hline \multirow{3}{*}{ 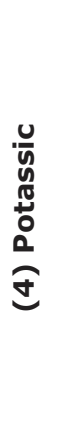 } & $\begin{array}{l}(4 a) \\
\text { Adularia in } \\
\text { veins and } \\
\text { veinlets }\end{array}$ & $\begin{array}{l}\text { Adularia crystals of up to } 1 \mathrm{~cm}(2-3 \mathrm{~mm} \text { mean size), rhombic } \\
\text { or pseudo-rhombic, and frequently twinned. Locally reaching } \\
15 \text { vol \% in the Adularia and Flaca veins, and some veinlets in } \\
\text { Lomas Rojas, south of Sinter area. Also in hydrothermal } \\
\text { eruption breccias in the Sinter area, and in scarce amounts in } \\
\text { the Piedra Labrada and Paredones areas, and at depth in the } \\
\text { Amanda and Cecilia veins. }\end{array}$ \\
\hline & $\begin{array}{c}\text { (4b) } \\
\text { Adularia }\end{array}$ & \\
\hline & $\begin{array}{l}\text { around } \\
\text { veins with } \\
\text { argillic } \\
\text { alteration }\end{array}$ & $\begin{array}{l}\text { Euhedral (rhombic) to anhedral crystals of } 140-180 \mu m \text {, found } \\
\text { locally. More clearly observed in corroded borders and fissures } \\
\text { of the quartz crystals of ignimbrites (Moreira, 2005). }\end{array}$ \\
\hline
\end{tabular}




\subsubsection{Siliceous alterations}

The siliceous alteration consists of siliceous replacements and related thin veinlets. Three types of siliceous alteration were recognized: (1a) veinrelated siliceous alteration, (1b) pervasive silicification and (1c) vuggy silicification (Table 4-1). The vein-related siliceous alteration (1a) is present in the areas with veins (Veta Norte, Central, Paredones and Piedra Labrada areas) and often passes transitionally to argillic alteration. In the Sinter, Subsinter and Lejano areas, scarce quartz veinlets are observed and silicification around them is very restricted, if present.

The pervasive silicification (1b) is present in topographic highs in the Subsinter and Lejano areas (Figure 4.3). It was probably produced by silica oversaturation, either by addition of silica from fluids or by strong leaching of part of the ignimbrites (Rolando and Fernández, 1996). In the Subsinter area, this alteration produced a homogeneous and massive replacement of the rock by aggregates of light-brown to whitish chalcedony, irregular quartz crystals, and some Fe-oxides and clays. Some patinas of plumbogummite $\left(\mathrm{PbAl}_{3}\left(\mathrm{PO}_{4}\right)_{2}(\mathrm{OH})_{5} \cdot \mathrm{H}_{2} \mathrm{O}\right)$ over the massive silica, were also observed and confirmed by XRD (Rolando and Fernández, 1996). In general, the original rocks are not recognizable because they suffered a strong modification, but they might have been crystal-and fiamme-rich ignimbrites of the Cerro Jorge Paz or Mogote Hormigas Members (Moreira, 2005).
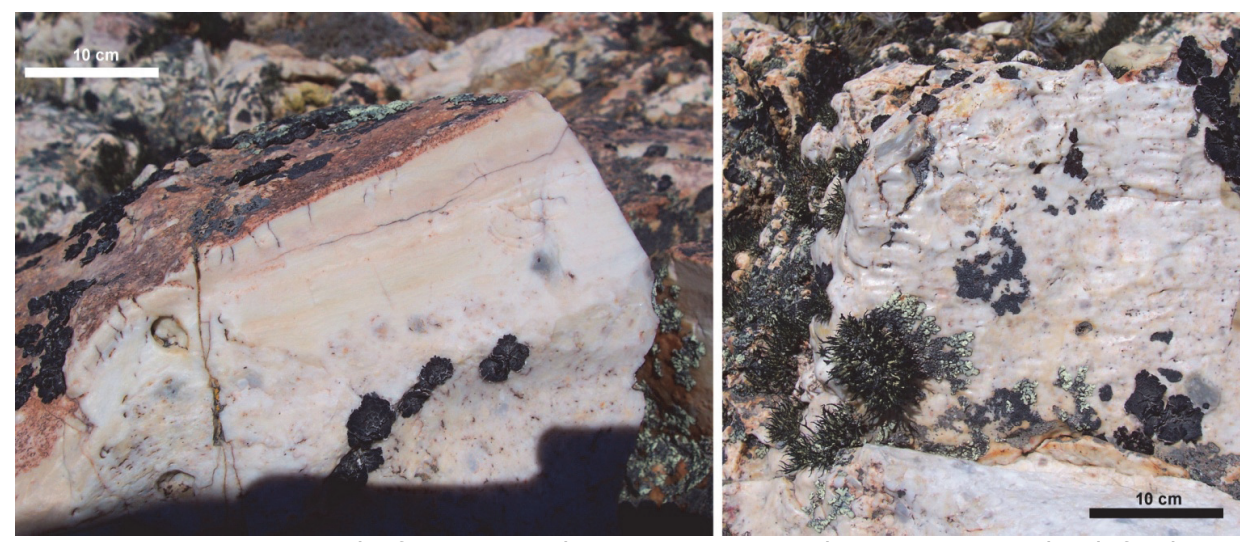

Figure 4.3: Pervasive silicification in the Lejano area. The picture on the left shows preserved laminations.

The vuggy silicification (1c) is only present in a small portion in the NE of the Lejano area. The silicified rocks show white to light gray saccharoidal quartz and abundant cavities covered by quartz crystals and calcite. These rocks may have been produced by strong leaching such as that often produced in relatively high acidity environments resulting from steam-heated waters. 


\subsubsection{Argillic alteration}

The argillic alteration consists mainly of illite, kaolinite and interstratified illite/smectite (I/S); it is sometimes associated to adularia, quartz, and other minerals (like dickite in minor amounts). This alteration consists of fracture fillings or partial replacements of phenocrysts, lithic and pumice fragments, and matrix. Three types of argillic alteration can be recognized: (2a) veinrelated argillic alteration, (2b) kaolinite-rich argillic alteration and (2c) illiterich argillic alteration.

The vein-related argillic alteration $(2 a)$ is restricted to only a few meters around the veins. Two samples from interstratified I/S in the vein related argillic alteration showed (by XRD analyses) that $75 \%$ of the layers are of illite, and suggest that those minerals were probably formed from a neutral $\mathrm{pH}$ fluid at $190-225^{\circ} \mathrm{C}$ (Moreira et al., 2004b).

The kaolinite-rich argillic alteration (2b), affected a slightly welded flow tuff with rounded pumice fragments that were completely replaced by kaolinite associated to tridymite (Rolando and Fernández, 1996), and there may be dickite. The kaolinitic alteration in those rocks predominates over the siliceous alteration, which is scarce and mainly restricted to the matrix (Rolando and Fernández, 1996). This alteration predominates in the Subsinter area, where kaolinite has been confirmed by XRD (Rolando and Fernández, 1996), but it has also been detected, although visually, in several trenches along the Lejano area.

The illite-rich argillic alteration (2c) consists of illite with minor kaolinite and jarosite that completely replaced the coarse lithic and glassy fragments of a flow tuff (Rolando and Fernández, 1996), while its matrix was predominantly silicified. Homogeneously silicified cement (probably from glass recrystallization) also includes illite.

\subsubsection{Propylitic alteration}

The propylitic alteration consists mainly of chlorite with variable amounts of pyrite and calcite, an locally scarce epidote While chlorite replaced biotite and amphiboles, calcite replaced plagioclases (Moreira et al., 2004b). Although a limited amount of epidote has been locally detected, it seems to be restricted to the central part of the project (Schalamuk et al., 1998). Scarce epidote has been observed in some boreholes in the Central area. The propylitic alteration has been described as producing diffused halos far away from the mineralized veins (Moreira et al., 2004b), and interpreted as due to regional alteration, prior to mineralization. However, Andrada de Palomera et al. (2012) found it in cross sections at depth, in direct spatial contact with veins and silicification around the veins. In addition, the silicic, argillic and 
propylitic hydrothermal alterations observed in cross sections of the Veta Norte area often overlap.

\subsubsection{Potassic alteration}

The potassic alteration is represented by adularia that is recognized in two positions: $a$ ) in the veins and veinlets; and b) associated to argillic alteration and quartz around the veins. Adularia in some cases seems to be altered to kaolinite or illite.

The adularia crystals in veins and veinlets (4a) are white or translucent when fresh and pinkish to orange when argillized or stained with Fe-oxides. In the northern portion of the Veta Norte area, adularia was observed in outcrops of the Flaca East and West veins; and at 75 and $250 \mathrm{~m}$ vertical depth in the Amanda and Cecilia veins (Andrada de Palomera et al., 2012). In these two veins, there is probably fine grained adularia altered to illite or kaolinite. In Lomas Rojas (Sinter area) adularia is associated to quartz veinlets and hosted in the Piedra Labrada Member; in hydrothermal eruption breccias, a few hundred metres to the north, it is associated to at least two generations of quartz veinlets (Moreira, 2005). Some crystals are associated to early grey quartz and have a mean size of $250 \mu \mathrm{m}$. Others are associated with a second quartz generation, are pseudo-rhombic, more abundant and with mean sizes of 50-75 $\mu \mathrm{m}$. There are also abundant tabular adularia crystals of up to 100 $\mu \mathrm{m}$.

The pervasive silicification, vuggy silicification, and kaolinite-rich argillic alteration were mainly formed in a steam-heated waters environment (Moreira, 2005; Rolando and Fernández, 1996), while the rest of the alteration types were probably formed at higher depth and closer to feeder conduits.

\subsubsection{Other epithermal products}

Calcareous deposits are present only in the Lejano area. Some show massive, brecciated or laminated structures, and were interpreted as due to inorganic precipitation; others show wavy (sub-circular) stromatolitic laminations, or tubular structures, and were interpreted as produced by organic precipitation (Moreira et al., 2002). The calcareous rocks are locally replaced by silica and often crosscut by chalcedony and quartz veinlets (Moreira et al., 2002). In some places, they show possible algal shapes.

In the Sinter area, siliceous deposits form a discrete layer composed mainly of fine-grained silica (Figure 4.4), which genesis is not clear yet. This siliceous layer seems to be formed by three main rock types: (1) silicified laminated tuffites, with varied degrees of silicification, (2) laminated siliceous 
rocks that are intercalated in rhythmic successions with silicified laminated tuffites, and (3) breccias with fragments of laminated siliceous rocks and siliceous stromatolites, cemented by abundant fine grained silica. The laminated siliceous rocks (2) were interpreted as silica sinter, while the siliceous breccias were interpreted as hydrothermal breccias produced by disruption of silica sinter probably around fluid vents, and will be called herein as "sinter-breccias". These breccias are also present in the east of the Lejano area.

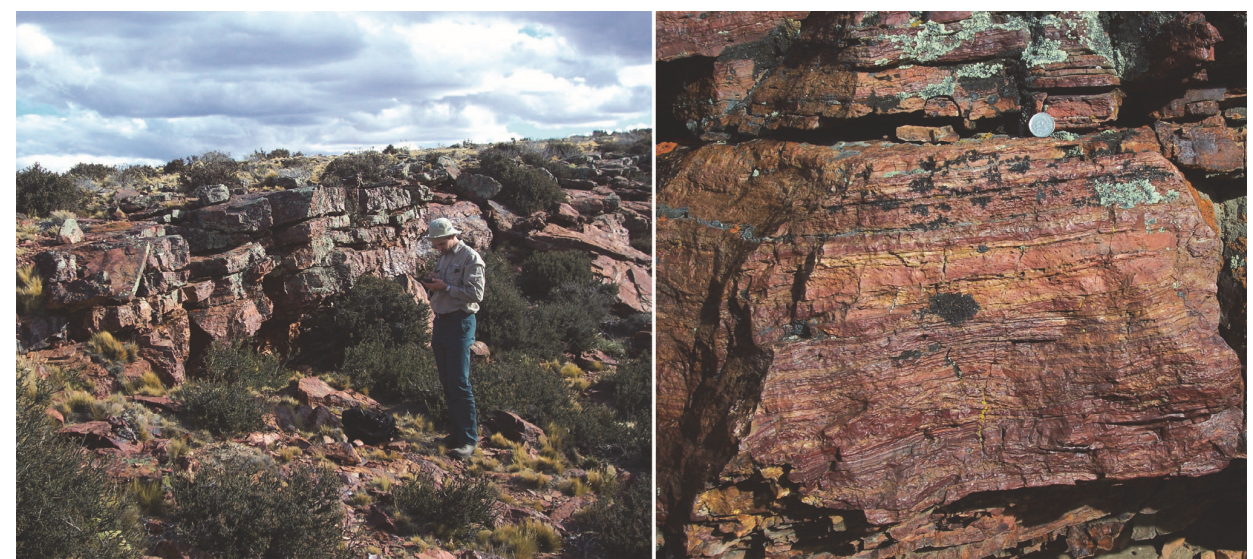

Figure 4.4: Outcrops of the siliceous layer in the north of the Sinter area (Loma del Plato hill).

The laminated tuffites and the silica sinter were probably deposited contemporaneously in shallow lagoons and probably contemporaneous with fracturing, which may have controlled the shape of the small basins and the grain size of their sediments (Fernández et al., 2005). The tuffites and ash deposited in the basins would have been locally replaced by the silica-rich fluids.

In addition to the siliceous layer, the sinter area includes small outcrops of hydrothermal breccias that crosscut the rocks of the Mogote Hormigas Member and the siliceous layer. They have angular to sub-angular fragments of piroclastic rocks, siliceous layer, and schists from the metamorphic basement (La Modesta Formation). The fragments show variable sizes and are in a matrix of fragmented rocks, cemented with scarce silica and some Fe oxides (Moreira et al., 2001). These breccias may represent points of fluids release to the paleo-surface. They are located along the Mogote Hormigas fracture zone (Fernández et al., 2005), which has and Az $345^{\circ}$ and that was probably a fluid feeder conduit. 


\subsection{Results and discussions}

\subsubsection{Conceptual model of the epithermal paleo-system at La Josefina}

Field relationships and some geochemical and mineralogical evidence suggest that the epithermal products in all the explored areas at the La Josefina deposit were produced by the same geothermal system. The veins in spatial association with hydrothermal eruption breccias and silica sinter are showing that field relationship.

The general position of the different areas in the paleo-system, was relatively easy to interpret. The Piedra Labrada, Paredones, Central, and Veta Norte areas, where the predominant products of epithermal activity are veins and veinlets, were interpreted as produced at relatively deep levels in the paleosystem. The Sinter, Subsinter, and Lejano areas, which include silica sinter, siliceous hydrothermal breccias, carbonaceous stromatolitic deposits, hydrothermal eruption breccias, and blankets of steam-heated water alteration, were interpreted as produced at or near paleo-surface. In contrast, detailed relative positions of each area in the paleo-system, were determined with difficulty and relatively high uncertainty.

\subsubsection{The upper portions of the paleo-system}

The Lejano and Subsinter areas (Figure 4.1) include abundant pervasively silicified rocks, hosted in the Mogote Hormigas, Cerro Jorge Paz and Escalera Members of the Chon Aike Formation. They also show relatively abundant and widespread kaolinite, although it seems to predominate in the Subsinter area. The Lejano area in addition, shows some features that are absent in the Subsinter area. Those are vuggy silicified rocks, calcareous deposits, and sinter-breccias. The vuggy silicified rocks are located in small outcrops in the NE of the area (Figure 4.5), adjacent to a NW-trending structural lineament interpreted in satellite images and partly coincident in that area with an aeromagnetic lineament (Figure 4.2) interpreted by Peñalva et al. (2005). This structural lineament is likely showing the location of a main feeder paleo-conduit (Figure 4.5), and it may also be related with the generation of sinter-breccias that are located nearby (Figure 4.6). The vuggy silicified rocks are in contact with the more abundant pervasively silicified rocks. In addition, the vuggy silicified rocks and nearby areas, show a few $\mathrm{Au}, \mathrm{Ag}$ and $\mathrm{Pb}$ anomalies, which are included in a wider area with high concentrations of As and $\mathrm{Sb}$. 


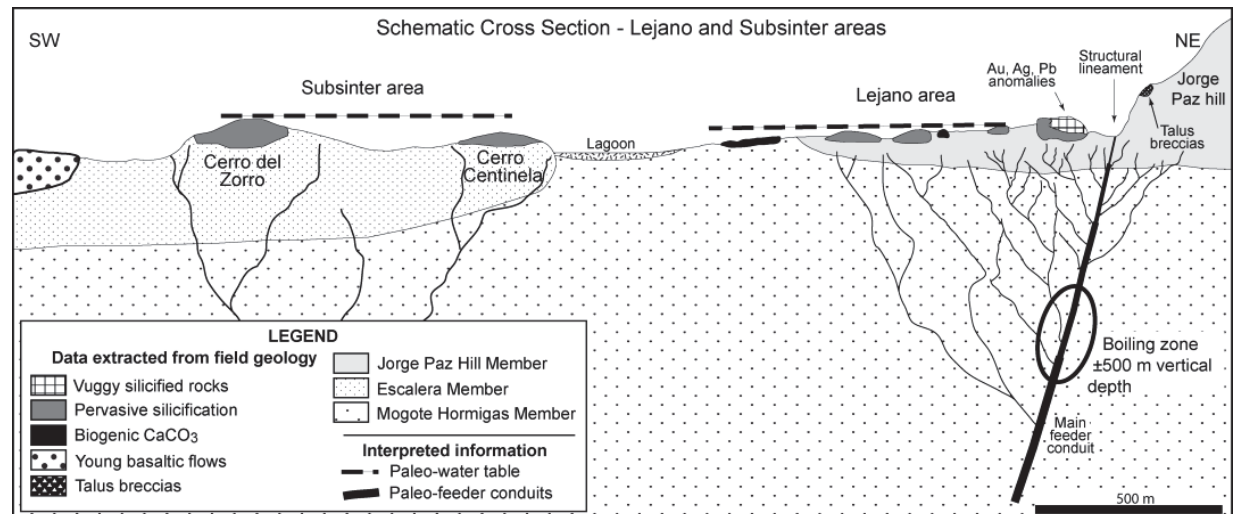

Figure 4.5: Schematic interpreted cross section across the Lejano and Subsinter areas (see location in Figure 4.2).

Scarce quartz and chalcedony veinlets were found in the Lejano and Subsinter areas, mainly in silicified host rocks, and crossing the calcareous deposits. This shows two depositional stages, and two temperatures of formation. While the silicification was produced at low temperature, the veinlets may indicate slightly higher temperatures. Fluid inclusions in some quartz veinlets with temperature of homogenization higher than $170^{\circ} \mathrm{C}$ (Rios et al., 2000) are also indicative of a higher temperatures than those prevailing in the water table. These observations also suggest that there was fracturing after the deposition of the carbonates, which probably means a continuous tectonic activity during the epithermal events.

In low-sulfidation systems, acid solutions can develop in the vadose zone by steam-heated waters that receive volatiles released by boiling of hydrothermal solutions occurring below them. In the vadose zone, the ground pores are filled with water and air, providing an oxidizing environment for volatiles to react and generate acid fluids. Those fluids can produce blankets of advanced argillic alteration, which usually overlay the ore in the hanging wall. Steam-heated waters can travel through aquifers and generate a few meters thick stratiform silicified blankets, even at several kilometres from their source (Sillitoe, 1993). 


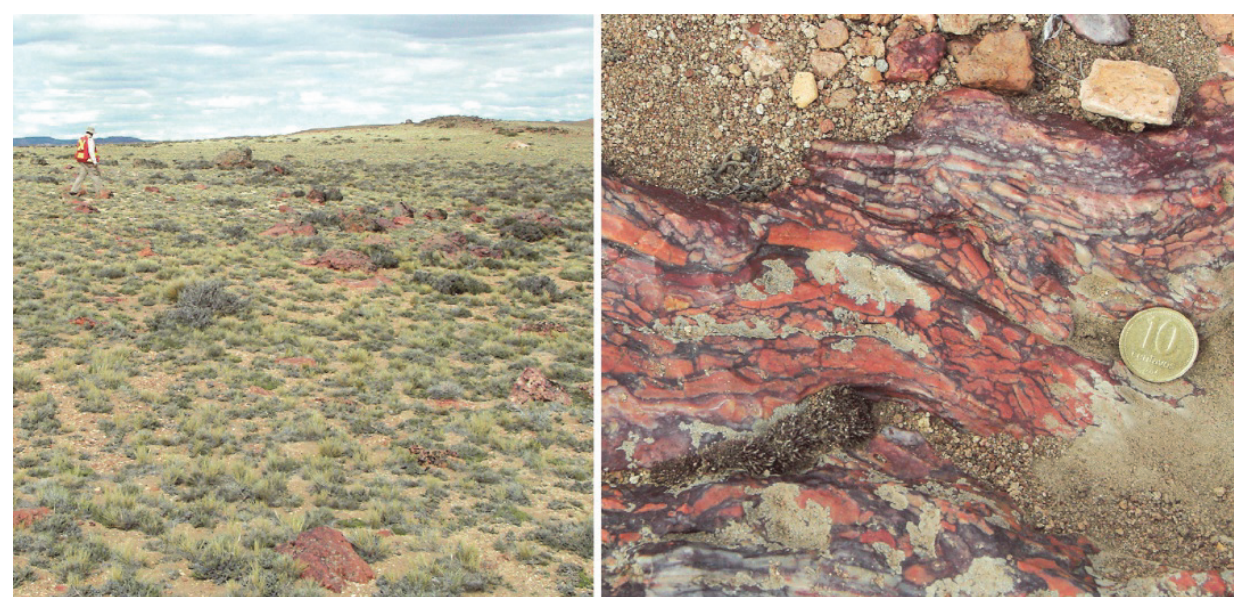

Figure 4.6: Sinter-breccia in the east of Lejano area

The vuggy silicified rocks located in the Lejano area, near the interpreted paleo-conduit, may represent the vadose zone, where low-pH fluids were produced by hot steam derived from a boiling area underneath. These acid fluids would have dissolved and leached pumice fragments and crystals of several minerals (mafic minerals, plagioclases and other feldspars), leaving a silica-rich residue surrounding the cavities. Abundance of $\mathrm{As}$ and $\mathrm{Sb}$ and mainly the $\mathrm{Au}, \mathrm{Ag}$ and $\mathrm{Pb}$ anomalies might indicate contribution of these metals from deep fluids through fluid conduits. Therefore, the vuggy silicified rocks and its surroundings may represent the vertical projection of the boiling zone (Figure 4.5), and of potentially mineralized intervals along the paleoconduit.

The calcareous deposits with stromatolitic structures were formed on the paleo-surface, but this may have occurred in ponds at lower levels than the water table. They were probably deposited from $\mathrm{CO}_{2}$-rich waters discharged at the intersection of the water table with the paleo-surface. Undoubtedly, they represent the upper part of a geothermal paleo-system, and may represent an outer part of it, as occurs in geothermal areas of New Zealand.

The pervasively silicified rocks in the Lejano and Subsinter areas are herein interpreted as parts of a dismembered chalcedony blanket. This blanket may be the product of silica re-mobilized from the steam-heated areas, and may represent levels in the paleo-phreatic aquifer below the vadose zone, and thus a slightly lower level than the area of mineral leaching, represented by the vuggy silicified rocks. The relatively abundant and widespread kaolinite in the Lejano and Subsinter areas was very likely the product of steam-heated waters alteration occurred in the upper part of the epithermal system. 
Summarizing, all of these characteristics suggest that the Lejano and Subsinter areas very likely represent the upper part of the epithermal paleosystem, and probably close to its outer limits. The Lejano area in particular, may represent the paleo-surface level (Figure 4.5), while the Subsinter area may represent slightly deeper levels, probably just below the vadose zone. The pervasively silicified rocks observed in the Lejano and Subsinter areas may have been part of the same dismembered chalcedony blanket that may have had its main fluid feeder conduit in the Lejano area, at the foot of the Jorge Paz hill. That paleo-conduit may be the reason to find $\mathrm{Au}, \mathrm{Ag}$ and $\mathrm{Pb}$ anomalies there, as well as relatively high As. and Sb. The Subsinter area may represent positions similar to those in the Lejano area, but probably away from main feeder conduits. In the Subsinter area, although vuggy silicified rocks may have already been eroded, resistivity and chargeability surveys did not detect evidence of any feeder conduit below the siliceous rocks. Therefore, it is likely that the hydrothermal deposits in the Subsinter area were produced away from the main feeder conduits (Figure 4.5). Probably, they were deposited from fluids very much diluted with underground water. The concentrations of $\mathrm{As}, \mathrm{Sb}, \mathrm{Au}, \mathrm{Ag}$ and base metals are low or very low, agreeing with the last statement.

These interpreted positions in the paleo-system are consistent with the stratigraphic position of the epithermal materials, which are located in the upper units of the Chon Aike Formation (i.e., the Cerro Jorge Paz and probably the Mogote Hormigas and Escalera Members).

\subsubsection{The Sinter area}

The most distinctive feature of the Sinter area is the previously mentioned siliceous layer. Although this layer is relatively thin, it is strongly resistant to erosion, and therefore, it partially gives shape to the topography of the area. Its largest outcrops are located in the north of the area (Loma del Plato site), in the Mogote Hormigas hill, and to the east of the Mogote Divisoria hill (Figure 4.7 and Figure 4.8). In the south of the Sinter area, the siliceous layer (tickness $6 \mathrm{~m}$ ) was detected in a diamond borehole (SI-09) at about $100 \mathrm{~m}$ of vertical depth, which represents a vertical difference of c.a. $150 \mathrm{~m}$ with the outcrops in the Mogote Hormigas hill. The Sinter area also shows locally abundant kaolinite, which is notorious around the Mogote Hormigas fracture zone. 


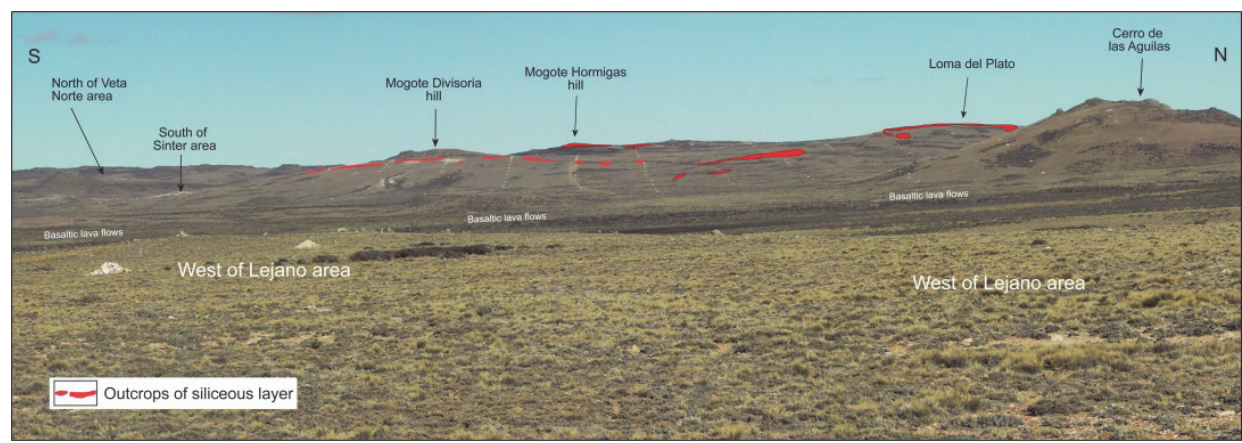

Figure 4.7: View of the Sinter area from the east (Lejano area), showing the siliceous layer's outcrops. The Mogote Hormigas hill is located on a NNW trending branch of the siliceous outcrops, which follows the Mogote Hormigas fracture zone. Other branch of outcrops follows a NE trend and it passes nearby the Mogote Divisoria hill. Aligned white dots are pit-shaped trenches used for geochemical and spectroscopic sampling (see Chapter 6)

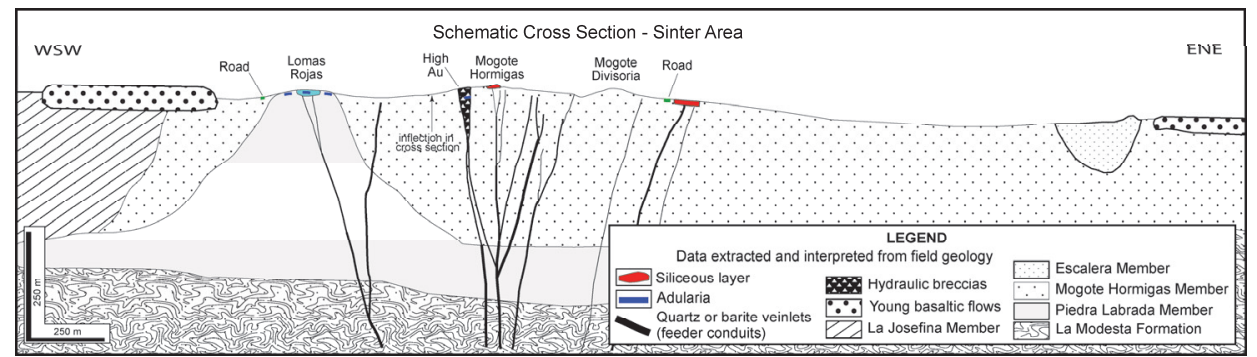

Figure 4.8: Schematic interpreted cross section across the Sinter area (location in Figure 4.2).

The siliceous layer, as well as the underlying rocks of the Mogote Hormigas Member, and the abovementioned hydrothermal eruption breccias are locally mineralized with Au. The most strongly mineralized rocks are hydrothermal breccias located along the Mogote Hormigas fracture zone, in which gold is often visible. Most of that gold is located in Fe oxides, which fills fractures in the breccias, but some of it is in quartz veinlets, and in fragments of the metamorphic basement that contain numerous gold flakes on schistosity and shear planes (Moreira et al., 2001). Low-grade disseminated mineralization was also detected in rocks of the Mogote Hormigas Member, beneath the siliceous layer, and predominantly around the mentioned fracture zone. Gold anomalies were also detected in the Escalera Member, and in a different type of hydrothermal breccias interpreted as formed at deeper levels in the system (Moreira, 2005), which were identified at depth in a diamond borehole $(\mathrm{DDH}-18)$ in the south of the Sinter area. There are also some quartz and scarce barite veinlets, and some adularia, hosted in the Piedra Labrada Member, in the Lomas Rojas site, as well as in hydrothermal eruption breccias around the Mogote Hormigas hill (Figure 4.8). 
The metamorphic rock fragments in hydrothermal eruption breccias may indicate that the metamorphic basement is located at relatively shallow depth below the current ground surface (Figure 4.8). Fragments in those types of breccias may come from up to $300 \mathrm{~m}$ depth (Henley, 1985) and this gives an idea of the possible depth of the basement. This is consistent with the nearby presence of the La Modesta Formation, cropping out $5 \mathrm{~km}$ to the WSW of the Sinter area. Furthermore, the mineralized fragments of the basement suggest that those metamorphic rocks were receptive to gold mineralization.

Despite the lack of clarity about its genesis, the siliceous layer is an indicative that the Sinter area was at a shallow level in the epithermal paleo-system. The predominance of fine grained silica, the fragments of stromatolitic rocks in breccias, the hydrothermal eruption breccias, and the likely presence of silica sinter, coupled with the absence of relevant veins, all suggest an upper position in the paleo-system. However, other features, such as the presence of adularia and the high Au concentrations, indicate a lower level position.

Probably, the Sinter area represents a part of the paleo-system at relatively shallow level, and above the main feeder conduits, although at a level slightly lower than the Lejano area. The presence of features similar to the areas with veins, together with those indicative of upper levels in a geothermal system may have resulted from modifications of the boiling level by pressure changes, probably triggered by sealing the paleo-conduits with abundant silica and subsequent brake of the seal. In any case, while the Lejano area was at the border of the geothermal system, the Sinter area was in a more central position and above the main upflow zone.

\subsubsection{The lower portions of the paleo-system}

Hydrothermal features in the remaining four areas (i.e., Veta Norte, Central, Paredones, and Piedra Labrada), are mainly veins, veinlets and breccias, with distinctive textures of low or intermediate sulfidation epithermal deposits, and locally mineralized. The veins and veinlets are mostly hosted in crystalrich ignimbrites of the older units of the Chon Aike Formation (Piedra Labrada and Mogote Hormigas Members). Most of the veins are sub-vertical or strongly dipping to the northeast, and several episodes of open space vein filling were recognized in them (Andrada de Palomera et al., 2012; Moreira, 2005).

The Veta Norte area includes a set of veins, veinlets and hydrothermal breccias grouped in a NNW-SSE trending sigmoid-shape belt of about $1300 \mathrm{x}$ $300 \mathrm{~m}$. These veins are predominantly hosted in the Mogote Hormigas Member of the Chon Aike Formation, but at least parts of them are hosted at depth in the Piedra Labrada Member (Figure 4.9). The veins thickness is 
variable, reaching occasionally about $3 \mathrm{~m}$; they are mainly composed of crystalline quartz, but also some opal, barite, and sulfides, and a limited amount of adularia. Locally, their gold and silver contents are high. They were produced by fluids at temperatures probably $<270^{\circ} \mathrm{C}$, which is inferred from fluid inclusions. The hydrothermal alterations around the veins are argillic, silicic, and propylitic, in order of abundance; while the argillic alteration seems to prevail at shallow levels, the propylitic alteration prevails at deeper levels (Andrada de Palomera et al., 2012).

The geochemistry from diamond boreholes of the Veta Norte area shows high $\mathrm{Au}, \mathrm{Ag}, \mathrm{Cu}, \mathrm{Pb}$ and $\mathrm{Zn}$ concentrations, of up $71.1 \mathrm{ppm}, 4720$ ppm, 19.7\%, $57.9 \%$ and $11 \%$ respectively (sample lengths of $0.4 \mathrm{~m}$ for $\mathrm{Au}, \mathrm{Ag}, \mathrm{Cu}$ and $\mathrm{Pb}$, and $0.85 \mathrm{~m}$ for $\mathrm{Zn}$ ). The highest $\mathrm{Au}$ concentrations are in the Amanda and Cecilia veins, while the highest $\mathrm{Ag}, \mathrm{Cu}, \mathrm{Pb}$ and $\mathrm{Zn}$ concentrations are in the Sur vein, south of the Veta Norte area.

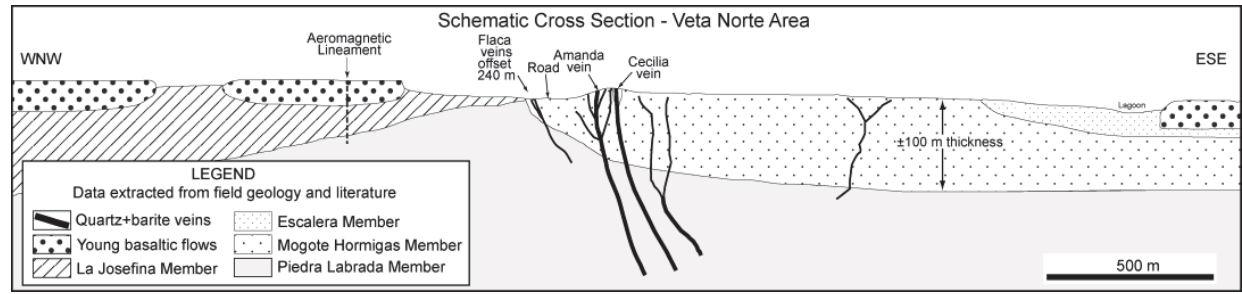

Figure 4.9: Schematic interpreted cross section across the Veta Norte area (location in Figure 4.2).

In general, the Veta Norte area seems to represent a portion of a Au-Ag-rich low-sulfidation epithermal paleo-system, probably located near the boiling level. However, evidence of boiling was not found in fluid inclusions, and the amount of adularia is only relevant in the Flaca East and West veins, in the north of the area. In addition, the concentrations in $\mathrm{Ag}$ and base metals are higher in the Veta Sur, while Au concentrations are higher in Amanda and Cecilia veins. These pieces of evidence seem to suggest that boiling was limited, and probably restricted to the north of the area (Flaca, Amanda and Cecilia veins). Therefore, the north of the Veta Norte area may have been located in and slightly above the boiling zone, as interpreted by Andrada de Palomera et al. (2012), while the south of the area (Sur vein), may have been located in a lower position, probably just in and below the boiling level.

The Central area includes several narrow zones of veins and veinlets with NW-SE general direction, which are hosted in the Piedra Labrada Member (Figure 4.10). Those zones are discontinuous and have widths of less than $3.5 \mathrm{~m}$. Adularia is present in some veins, and scarce epidote was observed in drill holes. Fluid inclusions show temperatures of homogenization of 250$270^{\circ} \mathrm{C}$ in adularia (Moreira, 2005), and of $220-290^{\circ} \mathrm{C}$ in quartz, which also 
show evidence of boiling (Rios et al., 2000). Some intersections in drill holes showed high $\mathrm{Au}$ and $\mathrm{Ag}$ grades, of up to 1,375 and $447 \mathrm{ppm}$ respectively ( $0.46 \mathrm{~m}$ sample length), and generally high $\mathrm{Cu}, \mathrm{Pb}$, and $\mathrm{Zn}$ concentrations, of up to $1.23,29.7$ and $8.9 \%$ respectively (samples lengths of $0.65,0.80$ and $0.60 \mathrm{~m})$.

The vertical level that the Central area represents relative to that in the Veta Norte area is difficult to determine. The Central area shows indications of a deeper level such as generally higher temperatures of homogenization of fluid inclusions, presence of epidote (of relatively high temperature), and absence of barite, which is from a low temperature late stage in the deposit; in addition the veins are hosted in the lower member of the Chon Aike Formation (Piedra Labrada Member). These and other indications are arguably meaningful, and they are likely neither clear nor conclusive evidence because they are not notoriously different between the two areas and because other variables have effects on their comparison. For instance, epidote has been detected at depth and in scarce amounts in the Central area, so it cannot be directly compared with data from surface in other areas; and the temperature of homogenization in fluid inclusions depend on the part of the vein and predominant infill that was sampled. It is also possible that some infills were deposited in some areas but not in others because of structural issues rather than because of different vertical positions in the system.

The geochemical variables are also difficult to compare; a simple average of the concentrations (as often used), do not reliably represent a population with asymmetric distribution, as occur with most element concentrations. Probably is better to use the median or the maximum detected concentrations in every area; but even though, the depths of sampling, the sampled infill, the length of the samples, and thus the different materials (either veins or host rocks) that are sampled, should be assessed for any comparison; as it should also be assessed the effects of weathering. Considering the samples length, the comparison of maximum concentrations mentioned above for Veta Norte and Central areas, only have sense for Au and $\mathrm{Ag}$, which are notoriously different between the two areas. This difference indicates that Ag is clearly lower and Au higher in the Central area, suggesting that the Central area may represent an upper part of the system.

The clearer differences between these two areas however, are in the structural orientation and the host rocks of the veins. While the general orientation of veins in the Veta Norte area is close to NNW, in the Central area is NW. This suggests that regardless of their level in the paleo-system, the two veins systems are hosted in structures with different directions and probably with different histories and origin; unless they have been rotated 
after their formation. The Amanda and Cecilia veins in the Veta Norte area are hosted by the Mogote Hormigas Member at surface and by the Piedra Labrada Member at depth; while the veins in the Central area, are hosted by the Piedra Labrada Member from the ground surface downwards.

The Simona and Upi veins located in transition between the Central and Paredones areas are nearly NW trending and very irregular thin quartz veins which include relatively coarse quartz. The veins are hosted in the Piedra Labrada Member of the Chon Aike Formation.

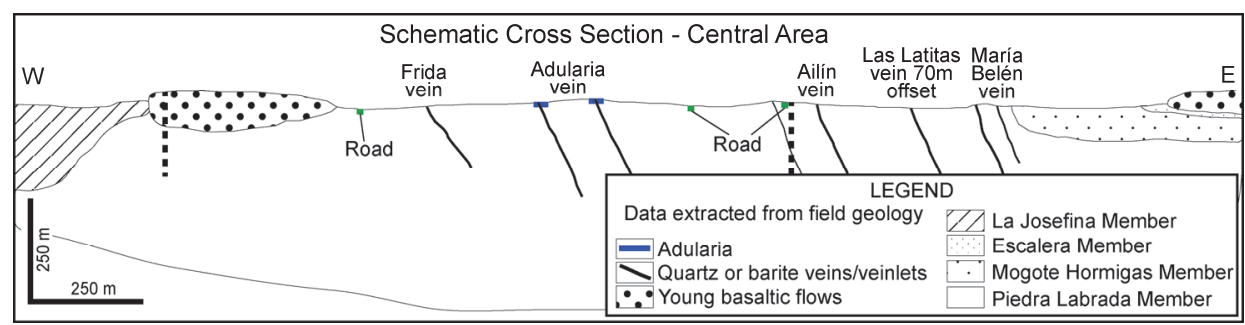

Figure 4.10: Schematic interpreted cross section across the Central area (location in Figure 4.2).

The Paredones and Piedra Labrada areas show a series of stockworks with variable directions from NW-SE to NNE-SSW, formed by veins and veinlets hosted in the Piedra Labrada Member. These veins are composed mainly of coarse crystalline quartz and some chalcedony; adularia and pseudomorphs of calcite were found, but only in one of the veins. Their Au content is relatively low, while $\mathrm{Ag}$ and base metals are relatively high. These indicators suggest that these two areas were located in a low level in the paleo-system.

\subsubsection{Hypothetical model of the epithermal paleo-system}

Using the information of the different explored areas in the deposit, a hypothetical conceptual model of the paleo-system was drafted (Figure 4.11) and the interpreted position that the different areas would have had in the paleo-system were indicated. This was only built to set up a tentative frame for the rest of the research, presented mainly in chapters 5 and 6 .

It seems clear that the Lejano area was the very top of the paleo-system with the calcareous stromatolitic rocks showing evidence of paleo-surface. It is also very likely that the rocks in the Subsinter area were at slightly lower level, but anywise at the upper parts of the system. The Sinter area on the other hand seems to show features indicative of two different environments, including paleo-surface and deeper levels closer to the areas of boiling. While the current erosion level at the southwest portion of the Sinter area (south and south west of the Mogote Hormigas hill) shows indications of levels 
probably close to the level of boiling, the rest of the Sinter area was probably formed in the upper parts of the paleo-system.

The remaining explored areas included in the alteration belt, were formed at deeper levels than the Sinter area, or at least than most of it. However, with the current knowledge it is difficult to assign accurate positions in the paleosystem to every one of these different areas. Most of these areas show similar features, such as indications of boiling. In addition, the Piedra Labrada and Paredones areas have not been much studied yet.

These areas with veins show, however, clear differences in the orientations of their veins, which range from NW to NE. While the main trend of veins in the Veta Norte area is NNW oriented, there are inflections and some veins trend even to the NE. Most veins in the Central area and those in the northwest of the Paredones area show NW orientations. The remaining veins in the Paredones area show NW and NE orientations, while the veins in the Piedra Labrada area are disposed with the shape of a fan, with orientations ranging from NW to NE. It is likely that not all of these orientations may have been under the same stress during the same time; therefore, it is expected that the resulting veins reflect the differences in stress or they were formed at different time and probably different conditions. 


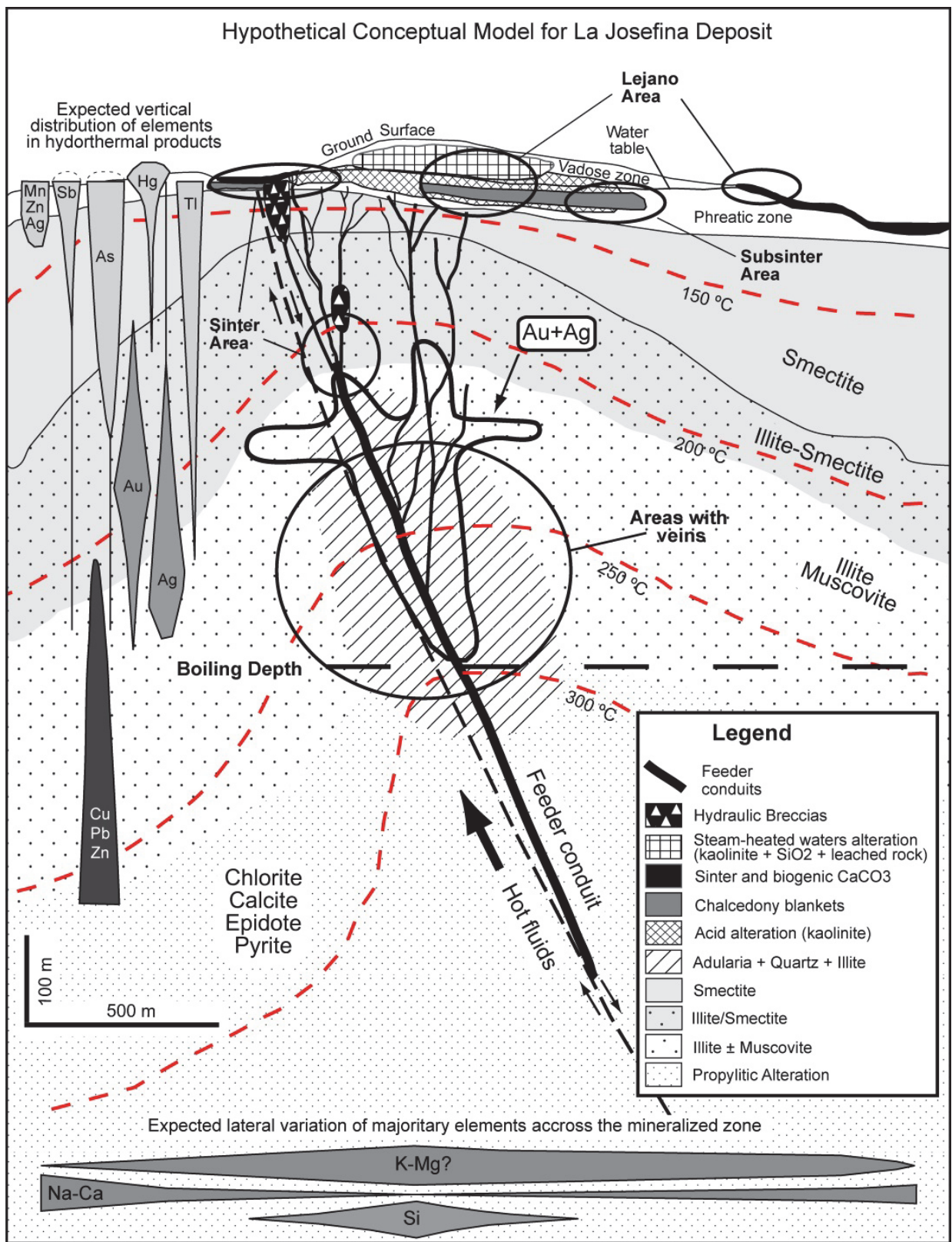

Figure 4.11: Hypothetical conceptual model of the La Josefina deposit. Most information was extracted from literature. The alteration zones represent general areas where the indicated minerals are expected to predominate. The configuration of the system is only conceptual with just some customizations to the La Josefina case. The graph represents a snapshot in time of an ideal paleo-system.

It is possible that all these areas with veins were formed at similar levels in the paleo-system, with only small differences produced by minor level 
differences and by different formation timing, and therefore, slightly different conditions of formation. However, to know this, more data have to be collected and interpreted.

Some structural modifications, moving vertically the different portions of the paleo-system, very likely occurred between different areas or inside the same area. An example is the current vertical difference, of about $150 \mathrm{~m}$, between two portions of the siliceous layer in the Sinter area (one in outcrops and the other in the subsurface).

\subsection{Conclusions}

The Lejano and Subsinter areas represent the upper parts of the paleosystem. The calcareous stromatolites in the Lejano area were deposited at the paleo-surface, while the vuggy silicified rocks were formed in the vadose zone, probably a few metres below paleo-surface, and near the point of fluid discharge of a main paleo-conduit, located in the NE of the Lejano area. The pervasively silicified rocks in the Lejano and Subsinter areas were formed slightly below the vuggy silicified rocks, in a phreatic aquifer, which probably extended from the Lejano to the Subsinter area. The main paleo-conduit may follow a NW trend and may dip towards the SW.

In general, the Sinter area was probably located at a vertical level intermediate between the areas of veins and the upper parts of the paleosystem. Modifications of the boiling depth by sealing of the paleo-conduits with silica and subsequent rupture of that sealing may have helped to produce features indicative of contrasting levels in the system, but also post mineralization faulting may have contributed in a similar way, levelling at the current erosion surface, sectors that were originally at different relative levels. The Mogote Hormigas fracture zone in the Sinter area was located above the main upflow zone of the paleo-system, in contrast to the Lejano and Subsinter areas that were located at its outer limits.

The Veta Norte, Central, Paredones and Piedra Labrada areas represent vertical levels deeper than those in the Sinter area. These four areas show differences amongst them and even between adjacent portions inside them, what suggests that they were formed at slightly different conditions. However, the detected differences are not strong enough for a clear determination of different relative positions in the paleo-system. 


\section{Chapter 5}

Geochemical indicators of gold-rich zones in the La Josefina epithermal deposit ${ }^{*}$

\footnotetext{
* This chapter is based on: "Andrada de Palomera, P., van Ruitenbeek, F.J.A., van der Meer, F.D. and Fernández, R., 2012. Geochemical indicators of gold-rich zones in the La Josefina epithermal deposit, Deseado Massif, Argentina. Ore Geology Reviews, 45: 61-80.
} 


\subsection{Introduction}

Several Au deposits in the Deseado Massif, including the La Josefina epithermal low-sulfidation deposit (Figure 4.1), are currently under exploration using abundant geochemical data. Surface geochemical data are used to interpret and map near-surface Au-rich zones with possible extensions at depth. Subsequently, subsurface geochemistry is used to confirm the presence and size of the Au-rich zones at different depths. The $\mathrm{Au}$ in these zones usually occurs in breccias and veins, which are mainly composed of quartz and minor adularia, calcite, barite and sulfides. Some mineralized veins and breccias are small or covered by debris and, thus, difficult to detect at the surface. In these cases, geochemical haloes around veins can be used over areas of few hundreds of metres wide (deposit-scale) to indicate the presence and location of mineralized veins. If mineralized veins are detected at the surface or their presence at depth is inferred, areas of tens of metres wide (detailed-scale) around veins are investigated by drilling. The aim of drilling is to cross the mineralized veins at different vertical levels; but often, drilling fails in finding the veins at the expected depths because they either pinched-out or were displaced by faults. However, the drillhole lithogeochemical data can help to determine if veins may be located nearby or if that is unlikely.

For any one of the above-mentioned applications of exploration geochemical data in the Deseado Massif, variations of element concentrations around mineralized rocks should be well known. Such variations in element concentrations have been studied in several low-sulfidation deposits (Berger and Silberman, 1985; John et al., 2003; Mauk and Simpson, 2007; Murakami and Feebrey, 2001; Warren et al., 2007) and general guidelines have been summarized for such deposits (Cooke and Simmons, 2000; Hayba et al., 1985; Hedenquist et al., 2000; Pirajno, 1992). However, as pointed out by some authors and due to the high variability of element contents within the epithermal environment (Hedenquist et al., 2000; Silberman and Berger, 1985), it would be very difficult to establish either a generalized element distribution model applicable to every deposit or a suite of elements that is always anomalous. Therefore, each deposit or district should be studied separately to know which elements to use and how to use them during exploration.

The geochemical indicators of mineralized zones at deposit-scale in the La Josefina and similar deposits in the Deseado Massif are not well known, and variations in element concentrations at detailed-scale in particular are poorly known elsewhere. In addition, if geochemical data are obtained at or close to the ground surface, the likely effects of weathering on element distribution patterns around mineral deposits should be known. This issue is usually 
overlooked during exploration, but is essential for proper interpretation of exploration geochemical data. The effects of chemical weathering on primary element dispersion patterns around mineral deposits are unknown in the Deseado Massif. Several researchers (e.g., Duzgoren-Aydin and Aydin, 2009; Duzgoren-Aydin et al., 2002; Malpas et al., 2001; Scott, 2001) studied the effects of chemical weathering, but only in areas not related to mineral deposits or with deposits and climatic conditions different to those in the Deseado Massif.

This study, carried out in the Veta Norte area of the La Josefina deposit (Figure 4.1), had three objectives. The first was to determine geochemical indicators that can be used to distinguish deposit-scale hydrothermally altered zones hosting Au-rich veins. The general approach used for this objective was to find out the modifications that different hydrothermal alterations produced on the lithogeochemistry, particularly those modifications produced during Au-mineralization. The second objective was to determine geochemical indicators that can be used to estimate proximity to Au-rich veins. For this, we studied detailed-scale variations of element concentrations with proximity to Au-rich veins. The third objective was to find out the effects of chemical weathering on element concentrations, to assess the usefulness of geochemical data extracted from the upper parts of the ground profiles. For this, we compared element concentrations at different depths but at a constant distance from Au-rich veins. The results of this study can increase the efficiency of geochemical surveys for mineral exploration in the La Josefina and similar deposits.

\subsection{Geology of the study area}

The Chon Aike Formation is the only one outcropping in the study area. There, it includes several volcanic lithofacies of similar mineralogical compositions. This formation is mainly composed of ignimbrites, consisting of quartz, sanidine, plagioclase and biotite. In the basal part of the formation, there are crystal-rich ignimbrites with an average of $20 \%$ crystals of quartz, sanidine, plagioclase and biotite, and locally with fiammes (Moreira, 2005). Over these rocks, there are lithic and pumice-rich ignimbrites with abundant matrix and fiammes, showing moderate to high degree of welding (Moreira, 2005). Intercalated with the ignimbrites are scarce layers of laminated finegrained fall tuffs and reworked volcaniclastic rocks; those layers are $<1 \mathrm{~m}$ thick and are composed of quartz, plagioclase, sanidine and biotite. In addition, there are clast-supported volcanic breccias with fragments of up to $40 \mathrm{~cm}$ composed of acid lavas and crystal-rich ignimbrites. These breccias have a light grey matrix with lithic and pumice fragments of up to $5 \mathrm{~mm}$. The Chon Aike Formation includes also lava flows outcropping a few hundred metres to the west outside the study area. Some fragments of the mentioned 
breccias may have come from these lavas. The lavas have aphanitic textures and less than $10 \%$ of microphenocrysts (Moreira, 2005); their groundmass is composed of quartz, potassic feldspars and scarce plagioclase and their phenocrysts are mainly plagioclase, biotite and scarce quartz and sanidine. Moreira (2005) mentioned the presence of lavas in the northern part of the study area, although these rocks have not been detected in trenches and boreholes drilled there.

\subsection{Mineralization in the study area}

In the Veta Norte area, the Au-mineralization is associated mainly with NNW trending quartz veins. These veins are located along a NNW-SSE trending zone measuring ca. $200 \mathrm{~m}$ wide and more than $1300 \mathrm{~m}$ long. In this zone, the activity of faults during the Jurassic, coupled with inflections along them, favoured the formation of the quartz veins and hydrothermal breccias in sectors with local extension, but hindered their formation in sectors with local compression. Thus, the veins are discontinuous, both at the surface and in the subsurface, and show variable widths and directions. These observations support the interpretations of Moreira et al. (2008) about the presence of several WNW-ESE syn-mineralization fractures (Figure 5.1) and the likely arrangement of fractures and veins at depth, which are discontinuous.

The study area is located in the northern part of the Veta Norte area, which includes the Flaca East, Flaca West, Amanda and Cecilia veins (Figure 5.1). The Flaca East and West (FEW) veins are parallel and ca. $30 \mathrm{~m}$ apart. They have thicknesses of up to $0.3 \mathrm{~m}$, strikes of $310-330^{\circ}$ and dips of almost $80^{\circ}$ to the ENE. The FEW veins are hosted in volcanic breccias of the Chon Aike Formation. The Amanda and Cecilia (AC) veins are composed of several subparallel veins, veinlets and hydrothermal breccias. They have variable thicknesses, reaching occasionally $3 \mathrm{~m}$. They have strikes of $315-335^{\circ}$ and dips of $60-90^{\circ}$ to the ENE, although some veinlets dip ca. $70^{\circ}$ to the WSW. The AC veins are hosted by lithic and pumice-rich ignimbrites, crystal-rich ignimbrites and volcanic breccias of the Chon Aike Formation.

In the $A C$ veins, the predominant gangue minerals are quartz and chalcedony, but there is minor adularia, barite, opal and calcite. In the Central area (Figure 4.1), rhombic adularia, probably contemporary with Au precipitation, yielded temperatures of homogenization of $250-270^{\circ} \mathrm{C}$ and salinity of $4.6 \mathrm{wt} \% \mathrm{NaCl}$ eq. (Moreira, 2005). In the AC veins, adularia was identified at $75 \mathrm{~m}$ vertical depth in borehole SVN-D08-198 and at more than $250 \mathrm{~m}$ vertical depth in borehole SVN-D08-190 (Figure 5.1). In several veins and veinlets, adularia co-exists with comb quartz, banded quartz, pyrite and chalcopyrite. Barite mainly occurs in the centre of the AC veins and is often replaced by opal or chalcedony, forming lattice-bladed textures. It is also 
present in fragments of some breccias cemented with opal and iron oxides. Barite was considered a relatively late mineral, deposited at less than $100^{\circ} \mathrm{C}$ and crystallized from a fluid with salinity of $4-5$ wt\% $\mathrm{NaCl}$ eq. (Rios et al., 2000).

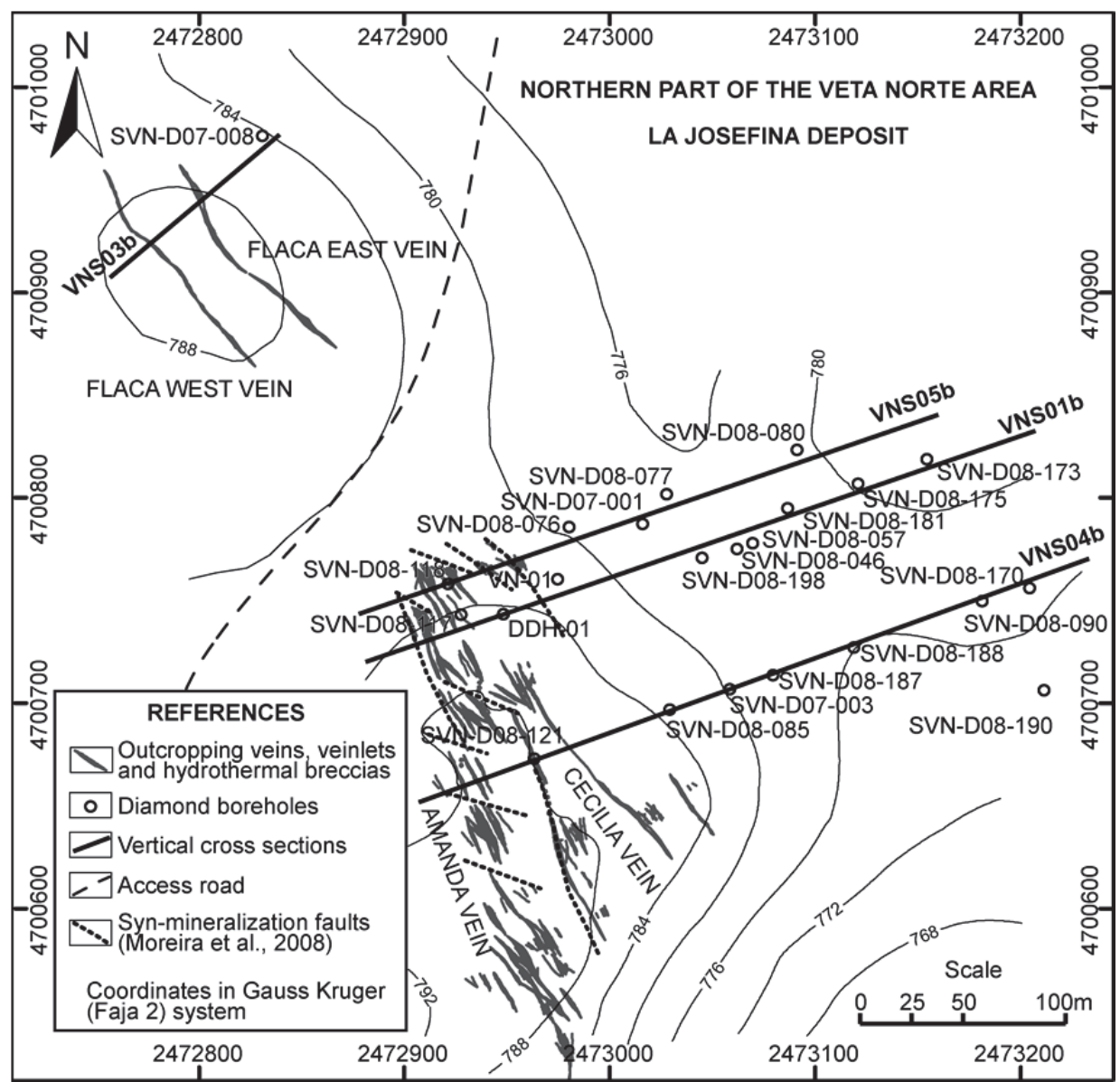

Figure 5.1: Map of the study area in the northern portion of the Veta Norte area (see location in Figure 4.1). Boreholes were drilled sub-parallel to the cross sections, towards SW.

In the $A C$ veins, the ore minerals are mainly native $A u$, electrum and silver sulfosalts. Native $\mathrm{Au}$ occurs as irregular grains in quartz with saccharoidal and comb textures, or as inclusions in oxidized pyrite or disseminated in iron oxides filling fractures. Gold grains have a mean composition of $80.6 \% \mathrm{Au}$, $18.5 \% \mathrm{Ag}$, and traces of $\mathrm{Bi}, \mathrm{Te}$, and As (Schalamuk et al., 1998). Some of the observed Au may have been dissolved and re-deposited by supergene processes (Moreira, 2005; Schalamuk et al., 1998). The Au grains frequently show zonation with yellower colour (higher gold purity) towards their 
boundaries, suggesting the mobilization of $\mathrm{Ag}$ after partial dissolution of $\mathrm{Au}$ grains (Schalamuk et al., 1998). Electrum occurs mostly in coarse quartz; it has no zonation and has concentrations of $48-60 \%$ of $\mathrm{Au}$ and $40-52 \%$ of Ag (Schalamuk et al., 1998).

Pyrite, galena, chalcopyrite, tetrahedrite, sphalerite, bornite and hematite are also present in the $A C$ veins. Pyrite is the most abundant and widespread sulfide; it occurs abundantly as fillings in the AC and FEW veins and as disseminations in the host rocks. Galena is the most abundant base metal sulfide, and it contains up to $0.03 \mathrm{wt} \% \mathrm{Se}$, up to $0.18 \mathrm{wt} \% \mathrm{Ag}, 0.08 \mathrm{wt} \% \mathrm{Cu}$, $0.13 \mathrm{wt} \% \mathrm{Cd}$ and $0.05 \mathrm{wt} \% \mathrm{Au}$ (Schalamuk et al., 1998). Chalcopyrite contains up to 0.01 wt\% Se, some $\mathrm{Te}$, traces of $\mathrm{Ag}$ and $\mathrm{Sb}$, and $0.04 \mathrm{wt} \% \mathrm{Au}$ (Schalamuk et al., 1998). Tetrahedrite was identified as inclusions in pyrite, galena and sphalerite (Moreira, 2005). Sphalerite is in association with pyrite and in paragenesis with galena and chalcopyrite (Moreira et al., 2004a). Fluid inclusions in sphalerite of the AC veins showed salinities of $1.7-3.4 \mathrm{wt} \% \mathrm{NaCl}$ eq. and homogenization temperatures of $190-200^{\circ} \mathrm{C}$ (Moreira et al., 2004a). The FeS content in sphalerite varies from 2.72 to $5.21 \mathrm{FeS}$ mol\% (Moreira et al., 2004a).

Rios et al. (2000) re-interpreted a paragenetic sequence published by Schalamuk et al. (1998). In this reinterpretation, there are three stages (Figure 5.2). The "initial stage" and the "main stage" are hypogene, in contrast to a "supergene" third stage. Adularia was probably the first mineral deposited in the sequence. According to Schalamuk et al. (1998), Au was likely deposited from the end of the initial stage but mainly during the main stage and was later re-mobilized and concentrated during the supergene stage, resulting in high local Au concentrations. Rios et al. (2000) showed that barite precipitated at the end of the main stage, which is consistent with its occurrence in the veins as a late filling material; but those authors also showed that the precipitations of adularia and specularite did not overlap with that of Au. This contrasts with (a) the interpretations of Moreira (2005) that the precipitations of adularia and Au were likely contemporaneous, and with (b) the observations that the specularite is often associated with native Au and high Au contents (Moreira, 2005; Moreira et al., 2004a). Moreover, adularia is often considered as an indication of boiling, which was interpreted as the most likely cause of Au precipitation in the La Josefina deposit (Moreira, 2005; Rios et al., 2000). Therefore, in this research, we adopted a paragenetic sequence modified from that of Rios et al. (2000) considering that precipitations of adularia, $\mathrm{Au}$ and sphalerite were partly contemporaneous (Figure 5.2) (cf. Schalamuk et al., 1998). 


\begin{tabular}{|c|c|c|c|}
\hline Vein minerals & Initial stage & Main stage & Supergene \\
\hline $\begin{array}{l}\text { Pyrite } \\
\text { Quartz } \\
\text { Adularia } \\
\text { Barite } \\
\text { Gold } \\
\text { Specularite } \\
\text { Electrum } \\
\text { Galena } \\
\text { Sphalerite } \\
\text { Tetrahedrite } \\
\text { Chalcopyrite } \\
\text { Opal-Chalcedony } \\
\text { Marcasite } \\
\text { Argentite } \\
\text { Chalcocite } \\
\text { Covellite } \\
\text { Limonite } \\
\text { Cerussite }\end{array}$ & 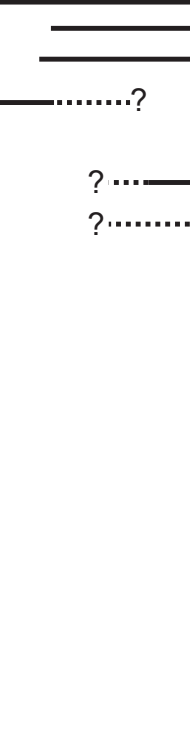 & $\overline{-}$ & \\
\hline Alteration & & & \\
\hline $\begin{array}{l}\text { Propylitic } \\
\text { Sericite-Illite } \\
\text { Kaolinite } \\
\text { Silicification }\end{array}$ & & & \\
\hline
\end{tabular}

Figure 5.2: Paragenetic sequence of the La Josefina deposit (modified from Rios et al. (2000)).

In the AC veins, Moreira (2005) recognized seven types of "vein fillings" but their temporal relationships are unknown. Those types of vein fillings are: (1) quartz with colloform banded, saccharoidal and comb textures, abundant pyrite, and some chalcopyrite, bornite, galena and sphalerite; (2) quartz with colloform banded and saccharoidal textures, banded red opal, and clays; (3) abundant comb quartz (partly amethyst), scarce coarse saccharoidal quartz, some adularia, calcite, native gold, pyrite, chalcopyrite, bornite, specularite, galena, sphalerite, tetrahedrite and silver minerals; (4) veinlets of barite and comb quartz; (5) coarse comb quartz; (6) breccias with opal and oxides of Fe and $\mathrm{Mn}$; and (7) veinlets of coarse comb quartz with up to $90 \%$ sulfides, including pyrite, galena, sphalerite and chalcopyrite.

In the FEW veins, Moreira (2005) recognized a single type of vein filling (at ground surface level) composed of comb and saccharoidal quartz, some specularite and pyrite, abundant rhombic adularia along the contact with the host rocks, and probably native Au. Although not present as vein filling at ground surface level, scarce calcite veinlets were observed in the subsurface. 
The characteristics of vein fillings in the AC and FEW veins suggest that the FEW veins were likely coeval with one of the earliest hydrothermal events observed in the $A C$ veins. Because of their similar quartz textures and mineralogy (including adularia), the vein fillings of the FEW veins are probably temporally correlated with some of type (3) vein fillings of the AC veins, excluding chalcopyrite, bornite, galena, sphalerite, tetrahedrite and silver minerals. Furthermore, the presence of adularia, which is an early mineral (Rios et al., 2000; Schalamuk et al., 1998), suggests that the FEW veins and the type (3) vein fillings in the AC veins were formed during the early stages of formation of the system of veins.

Some general physico-chemical conditions during the formation of type (3) vein fillings in the $A C$ veins can be inferred from data on fluid inclusions in adularia and sphalerite. Those vein fillings were, at least partially, deposited at about $250-270^{\circ} \mathrm{C}$ from fluids with salinities of ca. $4.6 \mathrm{wt} \% \mathrm{NaCl}$ eq. The fluid salinities, the FeS content in sphalerite, with a mean value of $4.93 \mathrm{~mol} \%$ (Moreira et al., 2004a), and the presence of tetrahedrite suggest that the type (3) vein fillings, and probably the native $\mathrm{Au}$, were deposited from an intermediate sulfidation fluid.

Types (4) and (6) vein fillings in the AC veins were deposited during the latest stages of the formation of veins. Type (4) vein fillings were likely formed at $<100^{\circ} \mathrm{C}$ and salinities of $4-5 \mathrm{wt} \% \mathrm{NaCl}$ eq., which were the conditions prevailing during the precipitation of barite in the centre of the veins as a late stage mineral. However, there was possibly at least one later stage of vein fillings because barite was replaced by low temperature silica and was observed in fragments of breccias cemented with opal, chalcedony and iron oxides. Type (6) vein fillings possibly represent this later stage. In the Piedra Labrada area, barite and red opal were found at a late stage; both were described as cement of breccias formed by fracturing of a vein filling with saccharoidal quartz, pseudomorphs of calcite and oxides of Fe and $\mathrm{Mn}$ (Moreira, 2005). The other vein fillings described for the AC veins must have formed between the deposition of adularia and that of barite.

\subsection{Methods}

In this study, a geological framework for geochemical data analysis and interpretation was established using information from literature and from descriptions of 21 diamond drill cores. The literature was used to establish the general characteristics of the La Josefina deposit and especially those of the study area. The descriptions of the drill cores were used to delineate the location of hydrothermal veins and breccias, and to determine the predominant types of hydrothermal alterations, as well as to represent veins and alterations in four vertical cross sections (VNS01b, VNS03b, VNS04b and 
VNS05b), which are parallel to the directions of the drillholes (Figure 5.1). After setting up the geological framework, geochemical data from the same 21 drill cores were studied, first at deposit-scale (few hundred metres) and then at detailed-scale (tens of metres). Geochemical data from published literature were used to represent the composition of the original fresh rocks; we referred to those fresh rocks as "estimated protolith" (EP).

\subsubsection{Geochemical data}

The geochemical data include assays of samples from the drill cores. The drill cores were split in two halves with a diamond saw, and one of the halves was sampled at intervals of 0.3-2 m length (average of $1 \mathrm{~m}$ ). The length of the sampled intervals was adjusted to obtain a homogeneous core sample. When possible, veins were sampled separately from their host rocks. For calculations involved in analyses of the data (see below), we represented every sample as a point at the centre of the sampled interval.

The samples were analysed for 28 elements using different techniques. ALSChemex laboratories determined the concentrations of Au by fire assay, $\mathrm{Hg}$ by an aqua regia digestion followed by cold vapour-AAS, and the remaining elements by ICP after digestion with four acids $\left(\mathrm{HF}, \mathrm{HNO}_{3}, \mathrm{HClO}_{4}\right.$, and $\left.\mathrm{HCl}\right)$. Samples with more than $100 \mathrm{ppm} \mathrm{Ag}$ or more than $5 \mathrm{ppm}$ Au were reanalysed for those elements with a gravimetric method. The samples from drillhole DDH-01, and most of the samples from drillhole VN-01 were analysed by Fomicuz S.E. for Au only, using aqua regia and methyl isobutyl ketone (MIBK) extraction. Because the digestion and limit of detection of this method is different from that of the fire assay, the concentrations determined by it were used to indicate the presence of mineralized rocks but not for statistical calculations.

Concentrations of minor and trace elements in the "estimated protolith" (EP) were represented by global average abundances in granites, reported by Levinson (1974), while concentrations of P, Mn and major elements were represented by median concentrations calculated from 28 samples of fresh rhyolitic and rhyodacitic ignimbrites of the Chon Aike Formation, collected near the study area by Alperin et al. (2007).

In addition to the individual elements, the $\mathrm{K}_{2} \mathrm{O} / \mathrm{Na}_{2} \mathrm{O}$ ratio, the alteration index (AI) of Ishikawa et al. (1976) and the chlorite-carbonate-pyrite index (CCPI) of Large et al. (2001) were calculated. The AI $\left(100\left(\mathrm{MgO}+\mathrm{K}_{2} \mathrm{O}\right) /\left(\mathrm{MgO}+\mathrm{K}_{2} \mathrm{O}+\mathrm{CaO}+\mathrm{Na}_{2} \mathrm{O}\right)\right)$ indicates the breakdown of sodic plagioclase and volcanic glass and their replacement by sericite and chlorite, through losses of $\mathrm{Na}$ and $\mathrm{Ca}$ and gains in $\mathrm{K}$ and $\mathrm{Mg}$. An increase in $\mathrm{CCPI}\left(100(\mathrm{MgO}+\mathrm{FeO}) /\left(\mathrm{MgO}+\mathrm{FeO}+\mathrm{K}_{2} \mathrm{O}+\mathrm{Na}_{2} \mathrm{O}\right)\right)$ may indicate the formation of 
chlorite, Mg-Fe carbonates, pyrite, magnetite or hematite (Large et al., 2001).

The $\mathrm{K}_{2} \mathrm{O} / \mathrm{Na}_{2} \mathrm{O}$, AI and CCPI were used for two objectives. The first objective was to verify that the 28 samples from Alperin et al. (2007), used for calculating concentrations in the EP, represented fresh rocks. The calculated values of $\mathrm{K}_{2} \mathrm{O} / \mathrm{Na}_{2} \mathrm{O}, \mathrm{AI}$ and CCPI for each of those samples are within ranges for unaltered rhyolitic-dacitic rocks, which are of $<2.5$ for $\mathrm{K}_{2} \mathrm{O} / \mathrm{Na}_{2} \mathrm{O}$ (Páez et al., 2010), 20-60 for AI and 10-60 for CCPI (Gifkins et al., 2005; Large et al., 2001). The second objective was to test these three variables as possible geochemical indicators of proximity to mineralized rocks.

\subsubsection{Subdivision of datasets}

Based on various criteria (i.e., Au contents, degree of oxidation of rocks, predominant hydrothermal alterations, position relative to the system of veins and distance to mineralized paleo-conduits), an initial geochemical dataset of 1426 samples, assayed for 28 elements, was divided into several datasets used for different parts of the research.

Based on overall Au contents, a mineralized zone (MZ) and a non-mineralized zone (NMZ) were distinguished in the study area. The $M Z$, which includes the Amanda and Cecilia (AC) veins (Figure 5.1); shows a Au-rich vertical interval extending from ground surface to at least $250 \mathrm{~m}$ depth, with up to $71.1 \mathrm{ppm}$ $\mathrm{Au}$ at $120 \mathrm{~m}$ depth. The NMZ, which includes the Flaca East and Flaca West (FEW) veins (Figure 5.1), shows low Au concentrations, reaching only 0.19 $\mathrm{ppm}$ at ground surface and $0.038 \mathrm{ppm}$ in drillholes. In addition, more than $70 \%$ of the samples collected in the NMZ yielded $\mathrm{Au}$ concentrations of $<0.005 \mathrm{ppm}$, which is the detection limit (DL) for Au. The absence of high Au contents in the NMZ extends from ground surface to at least $50 \mathrm{~m}$ vertical depth.

Regarding the degree of oxidation of the rocks, the vertical interval in which the sulfides (predominantly pyrite) have been completely destroyed and which has abundant Fe-oxides or oxyhydroxides was considered an interval of strong oxidation. This interval has its base at $750 \mathrm{~m}$ above sea level (Figure 5.3) and extends upwards, for 25-30 m, up to the ground surface. Rocks in the interval of strong oxidation were classified as "strongly oxidized", while those located below were classified as "weakly oxidized". Because oxidation is one of the processes that contribute to chemical weathering, the degree of oxidation was considered a proxy for the degree of weathering. It was not possible to estimate the absolute degree of weathering and its maximum depth because of the lack of specific studies. 
Considering the predominant types of hydrothermal alteration of the rocks in the MZ, samples located in the footwall of the system of veins were discarded because hydrothermal alterations in that sector are different from those in the system of veins and its hanging wall, and thus their geochemistry is expected to be different. The small number of samples in the footwall prevented their evaluation as a separate group. The samples from the NMZ were used irrespective of their location relative to the veins because the same types of alteration predominate in the whole cross section.

For the distance to mineralized paleo-conduits criterion, quartz veinlets, siliceous hydrothermal breccias and sulfide veinlets with Au concentrations $>0.5 \mathrm{ppm}$ were interpreted as "mineralized paleo-conduits" (MPCs) of epithermal fluids. They were traced in each cross section based on the descriptions of the drill cores. Then, the distance from each sample to the nearest MPC in every cross section was calculated using $10 \mathrm{~m}$ wide buffer polygons generated around and perpendicular to the borders of the MPCs (Figure 5.3). Only samples up to $60 \mathrm{~m}$ from the MPCs were used because the samples in more distant intervals were scarce. In addition, 32 samples located in the deeper part of borehole SVN-D07-001 were discarded because their positions relative to mineralized veins were uncertain; there may be mineralized veins a few metres beyond the end of that borehole.

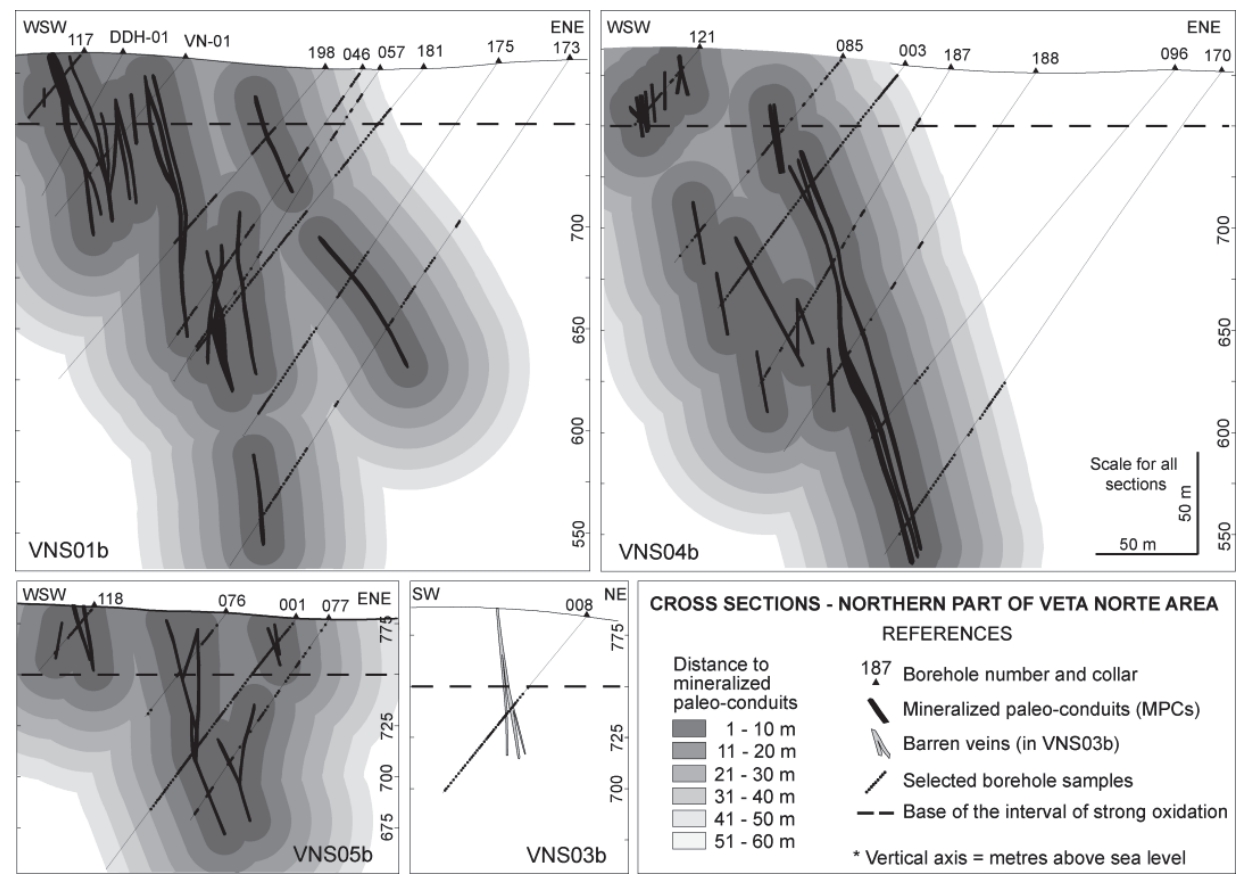

Figure 5.3: Vertical cross sections of the mineralized zone (VNS01b/04b/05b) and nonmineralized zone (VNS03b) showing the drillcore samples used during this research and buffers at every $10 \mathrm{~m}$ from mineralized paleo-conduits. 


\subsubsection{Statistical treatment of the geochemical data}

Because the concentrations of several elements in some subsets of data show asymmetric distributions, which cannot be adequately described by the mean and standard deviation, most of the geochemical data were studied using the median, first and third quartiles. Those statistics, however, were not used to describe the variability of concentrations of the elements that show either concentrations with bimodal distributions or concentrations below DL in $>15 \%$ of the samples from certain datasets, (e.g., $\mathrm{Au}, \mathrm{Ag}, \mathrm{As}$, and $\mathrm{Sb}$ in the $\mathrm{NMZ}$ and $\mathrm{Ag}, \mathrm{Sb}$, and $\mathrm{Bi}$ in the $\mathrm{MZ}$ ). In any of those two situations, the median and quartiles would inadequately represent the element concentrations in the datasets. Therefore, those concentration data were represented by other methods explained in sub-sections 5.4.4 and 5.4.5.

\subsubsection{Geochemical study at deposit-scale}

For the deposit-scale geochemical study, the median element concentrations from three datasets were compared. First, element concentrations in the EP were compared with the concentrations in 35 samples from the NMZ. Then, concentrations in the EP were compared with the concentrations in 704 samples from the MZ. Finally, the element concentrations in the $M Z$ were compared with those in the NMZ. The data from the mineralized and nonmineralized zones were extracted from weakly oxidized host rocks in the system of veins and their hanging wall, avoiding samples from MPCs, for testing only the modifications produced in host rocks around the MPCs.

To help in the interpretation of the data, the differences between datasets were represented as percentages of one of the datasets. Differences between the EP concentrations and the median concentrations in the MZ and NMZ were represented as percentage of the EP concentrations. Similarly, differences between median concentrations in the $N M Z$ and median concentrations in the $M Z$ were represented as percentage of the former. The differences between concentrations in the EP and in the NMZ (or MZ) were not calculated if concentrations in the NMZ (or MZ) were below DL and if the DL was higher than the concentration in the EP (calculated with other analytical method). That is because it was uncertain whether the element concentration increased or decreased, depending on how low the actual concentration (expressed as below $\mathrm{DL}$ ) is. For instance, if the concentrations of $\mathrm{Ag}$ are $0.04 \mathrm{ppm}$ in the EP and $<0.5 \mathrm{ppm}$ in the $\mathrm{NMZ}$, while the $\mathrm{DL}$ is 0.5 $\mathrm{ppm}$, and if the actual $\mathrm{Ag}$ concentration in the $\mathrm{NMZ}$ is between 0.04 and 0.5 $\mathrm{ppm}$, the $\mathrm{Ag}$ concentration would have increased. However, if the actual $\mathrm{Ag}$ concentration in the NMZ is below $0.04 \mathrm{ppm}$, the $\mathrm{Ag}$ concentration would have decreased. 
If the number of samples with element concentrations below DL was $<15 \%$ of the total number of samples in a subset of data, the median was used to represent the overall element concentrations in that subset. For the calculation of the median, data below DL were replaced with half of the DL (Carranza, 2011; Reimann and Filzmoser, 2000). This transformation allowed comparison of median concentrations between datasets.

In contrast, when the number of samples with element concentrations below DL was $>15 \%$ of the total number of samples in a subset of data, or when the element concentrations showed bimodal distributions, the median was not used. The concentrations of elements showing bimodal distributions in some datasets were represented by the concentrations of the two modes observed in the histograms; then, those two mode concentrations were compared with the median concentrations in other datasets. When $>15 \%$ of the samples in a subset of data showed concentrations of an element below $\mathrm{DL}$, a median value was calculated by replacing data below $\mathrm{DL}$ to the value of the DL; the median element concentration in that subset of data should be lower than the calculated median value. Then, that calculated value was compared with median concentrations from other datasets.

In the NMZ, the distributions of several elements were bimodal. For some of those elements, one of the modes was produced by the concentrations in 12 samples from a lithological unit different from those in the rest of the cross section. This lithological unit is composed of polymictic volcanic breccias, containing thin veinlets of calcite or dolomite and fragments with $1-1.5 \%$ disseminated pyrite; it includes abundant black fragments (probably of limestone). These breccias are geochemically different from others in the study area; they show low $\mathrm{K}_{2} \mathrm{O}, \mathrm{Hg}$, Be, relatively high $\mathrm{Al}_{2} \mathrm{O}_{3}, \mathrm{As}, \mathrm{Pb}$ and $\mathrm{Cd}$, and high $\mathrm{Na}_{2} \mathrm{O}, \mathrm{FeO}, \mathrm{CaO}, \mathrm{MgO}, \mathrm{TiO}_{2}, \mathrm{Cu}, \mathrm{Sr}, \mathrm{V}, \mathrm{Co}, \mathrm{Cr}, \mathrm{Ni}, \mathrm{P}$ and $\mathrm{Mn}$. The source of materials composing those breccias are likely different from the Chon Aike Formation (e.g., Bajo Pobre Formation). The samples from those rocks were omitted from this study, leaving 35 samples in the final dataset. In this final dataset, only $\mathrm{Zn}, \mathrm{Na}_{2} \mathrm{O}$ and $\mathrm{CaO}$, and the $\mathrm{AI}$ and $\mathrm{K}_{2} \mathrm{O} / \mathrm{Na}_{2} \mathrm{O}$ showed bimodal distributions.

For cross-validating the comparisons of concentrations between the EP and the $M Z$ and NMZ, the "isocon" method of mass balance (Grant, 1986) was applied. The method is derived from the mass balance equations of Gresens (1967), which can be used to calculate gains and losses of element in altered rocks.(Grant, 1986) combined volume and density into mass, and derived the equation:

$C_{i}^{A}=M^{O} / M^{A}\left(C_{i}{ }^{O}+\Delta C_{i}\right)$ 
where $\mathrm{C}_{\mathrm{i}}^{\mathrm{A}}$ and $\mathrm{C}_{\mathrm{i}}^{\mathrm{O}}$ are the concentrations of element $\mathrm{i}$ in the altered rock and the protolith, respectively; $M^{A}$ is the rock mass of the altered rock, $M^{O}$ is the rock mass in the protolith and $\Delta \mathrm{C}_{\mathrm{i}}$ is the change in concentration of element $\mathrm{i}$.

The equation above means that the evaluation of gains and losses of elements depends on the overall rock-mass change of the studied rocks. The rock-mass change can be calculated using elements that were immobile during the alteration, for which $\Delta \mathrm{C}_{\mathrm{i}}=0$. If the values of $\mathrm{C}_{\mathrm{i}}{ }^{0}$ are plotted against values of $C_{i}^{A}$, the immobile elements plot on a straight line that passes through the origin, and has slope $\mathrm{M}^{\mathrm{O}} / \mathrm{M}^{\mathrm{A}}$; this line is called an "isocon". The slope of the isocon defines the overall rock-mass change (e.g., slope $=1$ if rock-mass change $=0$ ), and is used to calculate mass gains and losses of elements that were mobile during alteration.

Element gains and losses, produced by hydrothermal alteration in the mineralized and non-mineralized zones, were calculated. For that calculation a rearrangement of equation (1) was used (i.e., $\Delta C_{i}=\left(M^{A} / M^{O}\right) C_{i}^{A}-C_{i}{ }^{\circ}$, in which $\left(\mathrm{M}^{\mathrm{A}} / \mathrm{M}^{\mathrm{O}}\right)$ is the inverse of the slope of the isocon.

\subsubsection{Geochemical study at detailed-scale}

Data of element concentrations and alteration indices of samples from the MZ and at different distances from the MPCs were plotted in clustered boxplots. Element concentrations in 801 samples from weakly oxidized rocks and in 263 samples from strongly oxidized rocks were used. These samples were extracted from 20 diamond drillcores and only from the system of veins and its hanging wall. For every element and alteration index, data from strongly oxidized and weakly oxidized rocks were represented in separate boxplots for every distance interval from MPCs. The $0 \mathrm{~m}$ interval includes samples inside the defined MPCs, while the other intervals include samples outside the MPCs and were defined at every $10 \mathrm{~m}$ from the MPCs. In the boxplots, the boxes represent the median, first and third quartiles, while the ends of T-bars represent 1.5 times the inter-quartile range and the values beyond the ends of T-bars are outliers.

The boxplots were used to evaluate (i) the contrast between MPCs and host rocks, (ii) the variations of element concentrations with distance from MPCs, and (iii) the contrast of concentrations between strongly oxidized and weakly oxidized rocks. Curves connecting median concentrations between distance intervals were called "models of compositional variation". Parts of those curves were considered "compositional drifts" when the median concentrations increased or decreased constantly for at least two consecutive intervals. In host-rock dominated materials, the compositional drifts were described by two quantities: "range" and "strength". The range is the 
distance from the MPC up to which the compositional drift is preserved. The strength is a measure of the overall slope of the curve that connects median concentrations along a compositional drift.

Most elements with concentrations showing bimodal distributions or with concentrations below $\mathrm{DL}$ in $>15 \%$ of the samples, were not studied with boxplots. In the $\mathrm{MZ}$, data for $\mathrm{TiO}_{2}, \mathrm{Sr}$ and $\mathrm{Mn}$ exhibit bimodal distributions. The two populations observed for $\mathrm{TiO}_{2}$ and $\mathrm{Sr}$ could not be separated; therefore, these two variables were not represented in the boxplots. In contrast, the two Mn populations were separated; one corresponding to strongly oxidized rocks and the other to weakly oxidized rocks. Because strongly and weakly oxidized rocks are separated in the boxplots, the concentrations of $\mathrm{Mn}$ were represented in those plots. Concentrations of $\mathrm{Ag}$, $\mathrm{Sb}, \mathrm{Bi}, \mathrm{Mo}, \mathrm{W}$ and $\mathrm{Cd}$ were below $\mathrm{DL}$ in $>15 \%$ of the samples; hence, they were not plotted in boxplots.

For $\mathrm{Ag}, \mathrm{Sb}, \mathrm{Bi}, \mathrm{Mo}, \mathrm{W}$ and $\mathrm{Cd}$, some evaluations were still possible, however. They were carried out to find out the overall differences in element concentrations between the MPCs (interval $0 \mathrm{~m}$ ) and adjacent host rocks (interval 1-10 m). For this evaluation, we compared the values of two parameters between these two intervals; one of the parameters was the percentage of cases below $\mathrm{DL}$ and the other was the median concentration in the interval, calculated with data below DL substituted by the DL.

\subsection{Results and Discussion}

\subsubsection{Hydrothermal alteration in the study area}

The hydrothermal alterations (silicic, argillic and propylitic) in the host rocks often overlap along the studied cross sections (Figure 5.4). Pervasive silicification occurs generally in hydrothermal breccias or at $<5 \mathrm{~m}$ from veins and veinlets; less commonly, it occurs in patches farther away from the veins. Argillic alteration includes clays (illite, kaolinite, scarce smectites and interstratified illite/smectite), which replaced fragments and matrix or were directly deposited in fractures. Propylitic alteration includes mainly chlorite and pyrite; locally it includes calcite, predominant in the deeper parts of the profiles, and very scarce epidote. In the studied cross sections, the spatial link between hydrothermal alterations and veins is only clear for silicification. Most of the rocks affected by silicification are close to veins or veinlets. In cross sections VNS01b and VNS04b (Figure 5.4), the pattern of silicification at depth is similar to that of the AC veins. Argillic and propylitic alterations do not show a regular pattern related to the veins; instead they show a slightly different distribution related to depth. In general, argillic alteration predominates in the upper part of the profiles, while propylitic alteration 
predominates in the deeper parts and is absent in the upper parts; both argillic and propylitic alterations are crossed by veins and related silicic alteration (Figure 5.4). However, the limited information from the footwall of the Amanda vein, mainly at shallow depth, hinders a more accurate interpretation of the distribution of hydrothermal alterations.

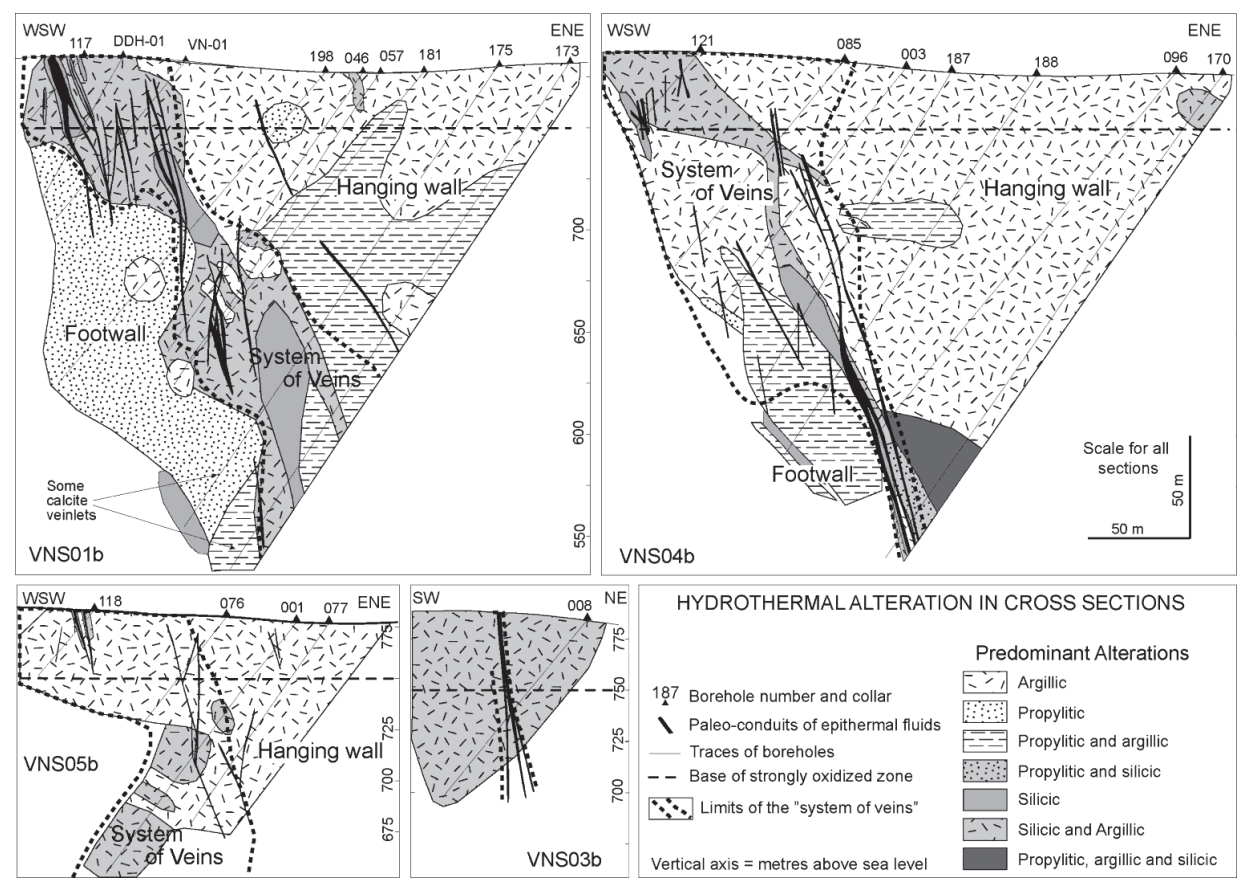

Figure 5.4: Hydrothermal alterations in cross sections synthesized from descriptions of drill cores. The system of veins and its footwall and hanging wall are indicated.

Based on location, predominant hydrothermal alteration and vein mineralogy, three sectors are distinguished in the cross sections of the MZ. The first sector contains the AC veins and surrounding veinlets (Figure 5.4), and is referred to here as the "system of veins". This sector includes hydrothermal breccias, abundant veinlets of crystalline quartz with various textures, abundant pyrite and subordinate chalcopyrite, galena, sphalerite, tetrahedrite and bornite. In the system of veins, the distinctive alteration is silicic, which in most cases is overprinted by argillic alteration. The second sector is the "hanging wall" of the system of veins. In this sector, crystalline quartz is almost absent; abundant pyrite and locally chalcopyrite, galena and sphalerite are disseminated and occasionally form veinlets; in the zone of strong oxidation, $\mathrm{Fe}$ oxides predominate instead of the sulfides. In the hanging wall, the predominant hydrothermal alteration is argillic, but there is subordinate propylitic alteration; chlorite is locally abundant, mainly at deeper locations, and often related to sulfides surrounding veinlets or disseminated in the groundmass. Veinlets with Au concentrations $>0.5 \mathrm{ppm}$ 
are thin and scarce (in VNS01b and VNS05b). The third sector is the "footwall" of the system of veins, wherein there are scarce veinlets of crystalline quartz and propylitic alteration predominates.

In the $\mathrm{NMZ}$, it is apparent that, despite of limited information, the system of veins, footwall and hanging wall are different in character from those in the $M Z$. The system of veins, which includes the FEW veins, is composed of only a few crystalline quartz veinlets with some limonite and $\mathrm{Mn}$ oxides and with adularia at ground surface. The hanging wall includes scarce Fe and $\mathrm{Mn}$ oxides and very scarce veinlets of chalcedony, and it has no sulfides. Finally, the footwall of the veins includes veinlets and disseminations of pyrite and veinlets of calcite. The hydrothermal alteration in the whole profile is a mixture of argillic and silicic alterations. Unlike in the $M Z$, both argillic and silicic alterations around the FEW veins are weak and argillic alteration only includes illite.

In the $M Z$, the hydrothermal alterations of the hanging wall extend at least $200 \mathrm{~m}$ to the NE of the system of veins. The extent of the alteration halo in the footwall of the veins is undefined because of limited information. However, judging from the extents of the alterations (mainly propylitic) in cross section VNS01b, the footwall at ground surface is altered for more than $100 \mathrm{~m}$ to the SW. Therefore, hydrothermal alterations at ground surface cover an area of more than $400 \mathrm{~m}$ wide including the system of veins and its walls.

\subsubsection{Timing and relation between mineralization and hydrothermal alterations}

The vein fillings and related hydrothermal alterations in the $M Z$ occurred during the initial and main stages of the paragenetic sequence (Figure 5.2), while those in the NMZ zone occurred only during the earlier part of the initial stage. The $M Z$ includes the same vein fillings and hydrothermal alterations observed in the NMZ with the addition of several others previously mentioned for the $M Z$, including the ore minerals. This suggests that the hydrothermal products in the $N M Z$ represent part of those observed in the $M Z$. A link between the $M Z$ and $N M Z$ is provided by the correlation of the vein filling in the FEW veins and part of the type (3) vein filling in the AC veins, both containing adularia. The presence of adularia, interpreted as an early mineral, suggests that these two correlated vein fillings are amongst the earliest deposits in the system of veins. In the NMZ, the argillic alterations are devoid of kaolinite, which is common in the MZ. Schalamuk et al. (1998) and Rios et al. (2000) indicated that kaolinite formed only during the main stage of the paragenetic sequence (Figure 5.2), and Moreira et al. (2004b) explained that kaolinite might have been derived from alteration of illite or 
from weathering in a relatively late stage. Therefore, we interpret that the hydrothermal alterations and vein fillings in the NMZ were produced only during the early stages of the veins formation, and that the argillization during these early stages promoted only the formation of illite.

The timing of mineral precipitation in veins and hydrothermal alterations may have been strongly controlled by structural movements during the life of the epithermal system. Dextral movements along curved fractures (Moreira et al., 2008), may have produced local extension in the $M Z$, promoting the opening of fractures, in contrast to what occurred in the NMZ where the movements along the faults may have produced no extension. In this context, adularia and quartz in the NMZ sealed the original fractures, which remained closed, while in the $M Z$, the fractures remained open, at least locally, allowing mineral precipitation and formation of several types of vein fillings in the $A C$ veins.

Some relations between Au-mineralization and hydrothermal alterations can be inferred from the spatial relationship between alterations and MPCs. Goldrich veins and breccias are, up to certain degree, spatially related to silicic alterations; both the high Au concentrations and the silicic alterations are located close to the paleo-conduits. Observed in detail, however, most of the MPCs are partly or completely surrounded by rocks without silicic alteration, but only with argillic or locally propylitic alterations. In addition, silicic alteration alone is often not in contact with the MPCs, although close to them (Figure 5.4). These observations suggest that Au-mineralization and silicification occurred during different stages and, probably, under different physico-chemical conditions of the fluids. Therefore, at the paleo-level of the system represented by the study area, silicic alterations can be used as indicators of nearby paleo-conduits but they cannot be used as direct indications of Au-mineralization.

\subsubsection{Geological Framework}

We consider that the study area represents a portion of a Au-Ag-rich lowsulfidation epithermal paleo-system, located probably in and above the vertical levels of boiling. This portion of the paleo-system includes veins and hydrothermal breccias produced by fluids at temperatures probably $<270^{\circ} \mathrm{C}$ and mainly composed of crystalline quartz, but also some opal, barite and sulfides, and a limited amount of adularia. Those veins and hydrothermal breccias are hosted mainly by (Upper Jurassic) rhyolitic ignimbrites, which represent the silicic part (post-rift) of a bimodal volcanism, deposited during a generalized extensive event coeval with subduction. In the study area, the hydrothermal alterations around the veins are argillic, silicic and propylitic, in 
order of abundance. During this study, however, the areas with abundant propylitic alteration were not evaluated.

\subsubsection{Results of the study at deposit-scale}

Three assumptions were considered to interpret the results of the study at deposit-scale. The first assumption is that the differences in element concentrations between the EP and the NMZ represent geochemical modifications induced by hydrothermal alterations during a period before mineralization, which is referred to as "alteration phase 1 ". The second assumption is that the differences in element concentrations between EP and the $M Z$ represent geochemical modifications induced by hydrothermal alterations before, during and after mineralization. The third assumption is that the differences in element concentrations between the mineralized and non-mineralized zones represent the effects of alterations produced during and after mineralization, a period referred to as "alteration phase 2 ".

\subsubsection{Comparison between estimated protolith (EP) and the non- mineralized zone}

The hydrothermal alterations in the NMZ, which occurred during alteration phase 1 , produced minor geochemical changes in the host rocks. The concentrations of $\mathrm{Sr}, \mathrm{Hg}, \mathrm{V}, \mathrm{P}$ and $\mathrm{Ti}$ in the $\mathrm{NMZ}$ are clearly lower than in the $\mathrm{EP}$, but less clearly in the cases of $\mathrm{Be}, \mathrm{Mo}, \mathrm{Al}_{2} \mathrm{O}_{3}, \mathrm{MgO}$ and $\mathrm{Mn}$ (Table 5-1). The concentrations of $\mathrm{Ba}, \mathrm{Pb}$ and $\mathrm{Fe}$ in the $\mathrm{NMZ}$ are higher than those in the $\mathrm{EP}$, while those of $\mathrm{Co}, \mathrm{Cu}, \mathrm{Cr}$ and $\mathrm{K}_{2} \mathrm{O}$ are similar to those in the EP. The CCPI showed a moderate increase in the NMZ compared to the EP (Table 5-1).

Although with bimodal distributions, the concentrations of $\mathrm{Na2O}$ are clearly lower in the NMZ than in the EP while that of $\mathrm{Zn}$ and the values of $\mathrm{AI}$ and $\mathrm{K}_{2} \mathrm{O} / \mathrm{Na}_{2} \mathrm{O}$ are at least slightly higher in the $\mathrm{NMZ}$ than in the EP (Figure 5.5; Table 5-1). 
Table 5-1. Comparison of median element concentrations and alteration indices of three datasets: estimated protolith, mineralized zone and non-mineralized zone.

\begin{tabular}{|c|c|c|c|c|c|c|c|c|c|}
\hline \multirow[b]{2}{*}{$\begin{array}{l}\text { Elements } \\
\text { and indices }\end{array}$} & \multirow[b]{2}{*}{$\mathrm{DL}^{(\mathrm{a})}$} & \multicolumn{3}{|c|}{ Median Concentrations } & & & \multicolumn{3}{|c|}{ Percentage of Change in Concentrations ${ }^{(9)}$} \\
\hline & & $\mathrm{EP}^{(\mathrm{b})}$ & $\begin{array}{l}\mathrm{NMZ}_{(\mathrm{d})}^{(\mathrm{d})} \\
(\mathrm{n}=35)\end{array}$ & $\begin{array}{c}M Z^{(e)} \\
(n=704)\end{array}$ & \multicolumn{2}{|c|}{$\begin{array}{c}\% \text { of values } \\
B D L(c) \\
N M Z M Z\end{array}$} & $\begin{array}{l}\text { From EP } \\
\text { to NMZ }\end{array}$ & $\begin{array}{l}\text { From } E P \\
\text { to } M Z\end{array}$ & $\begin{array}{l}\text { From } \mathrm{NMZ} \\
\text { to } \mathrm{MZ}\end{array}$ \\
\hline $\mathrm{Au}(\mathrm{ppm})$ & 0.005 & 0.004 & $<0.005$ & 0.0190 & 26 & 14 & $\mathrm{nc}$ & 375 & $>280$ \\
\hline $\mathrm{Ag}(\mathrm{ppm})$ & 0.5 & 0.040 & $<0.5$ & $<0.6$ & 94 & 36 & nc & nc & nc \\
\hline $\mathrm{Cu}(\mathrm{ppm})$ & 1 & 10 & 9 & 15 & 0 & 2 & -10 & 50 & 67 \\
\hline $\mathrm{Pb}(\mathrm{ppm})$ & 2 & 20 & 31 & 110 & 0 & 0 & 55 & 448 & 253 \\
\hline $\mathrm{Zn}(\mathrm{ppm})$ & 2 & 40 & $80 / 300^{(\mathrm{f})}$ & 445 & 0 & 0 & Increased & 1011 & Increased \\
\hline As $(p p m)$ & 5 & 1.5 & $<10$ & 52 & 20 & 2 & $\mathrm{nc}$ & 3367 & $>420$ \\
\hline $\mathrm{Sb}(\mathrm{ppm})$ & 5 & 0.2 & $<5$ & $<5$ & 100 & 37 & nc & nc & nc \\
\hline $\mathrm{Hg}(\mathrm{ppm})$ & 0.01 & 0.08 & $<0.01$ & 0.06 & 51 & 1 & $<-88$ & -25.0 & $>500$ \\
\hline $\mathrm{Bi}(\mathrm{ppm})$ & 2 & 0.1 & $<2$ & $<3$ & 97 & 34 & $\mathrm{nc}$ & $n c$ & $\mathrm{nc}$ \\
\hline Mo (ppm) & 1 & 2 & $<1$ & $<2$ & 100 & 23 & $<-50$ & $<0$ & nc \\
\hline$W(p p m)$ & 10 & 2 & $<10$ & $<10$ & 100 & 44 & $\mathrm{nc}$ & $n c$ & $\mathrm{nc}$ \\
\hline $\mathrm{Ba}(\mathrm{ppm})$ & 10 & 600 & 1170 & 890 & 0 & 0 & 95.0 & 48.0 & -24.0 \\
\hline $\mathrm{Be}(\mathrm{ppm})$ & 0.5 & 5.0 & 2.8 & 1.5 & 0 & 2 & -44 & -70 & -46 \\
\hline $\mathrm{Sr}(\mathrm{ppm})$ & 1 & 285 & 63 & $19 / 80$ & 0 & 0 & -78.0 & Decreased & $n c$ \\
\hline$V(p p m)$ & 1 & 20 & 5 & 44 & 0 & 0 & -75 & 120 & 780 \\
\hline $\mathrm{Cr}(\mathrm{ppm})$ & 1 & 4 & 3 & 7 & 0 & 3 & -25 & 75 & 133 \\
\hline $\mathrm{Ni}(\mathrm{ppm})$ & 1 & 0.5 & $<1$ & 3 & 26 & 12 & $n c$ & 500 & $>200$ \\
\hline $\mathrm{Cd}(\mathrm{ppm})$ & 0.5 & 0.2 & $<0.5$ & $<1.2$ & 86 & 34 & nc & $n c$ & nc \\
\hline Co $(p p m)$ & 1 & 1 & 1 & 8 & 14 & 1 & 0 & 700 & 700 \\
\hline$P(p p m)$ & 10 & 175 & 80 & 120 & 0 & 0 & -54.0 & -31.0 & 50.0 \\
\hline $\mathrm{Mn}(\mathrm{ppm})$ & 5 & 387 & 318 & 1065.0 & 0 & 0 & -18.0 & 175.0 & 235.0 \\
\hline $\mathrm{Al}_{2} \mathrm{O}_{3}(\%)$ & 0.0189 & 14.565 & 12.977 & 13.119 & 0 & 0 & -10.9 & -9.9 & 1.1 \\
\hline $\mathrm{K}_{2} \mathrm{O}(\%)$ & 0.0121 & 4.360 & 4.145 & 4.410 & 0 & 0 & -5 & 1.2 & 6.4 \\
\hline $\mathrm{Na}_{2} \mathrm{O}(\%)$ & 0.0135 & 2.990 & $0.08 / 1.30$ & 0.094 & 0 & 1 & Decreased & -97.0 & $\mathrm{nc}$ \\
\hline $\mathrm{CaO}(\%)$ & 0.014 & 1.675 & $0.09 / 1.20$ & 0.056 & 0 & 0 & Decreased & -97.0 & Decreased \\
\hline $\mathrm{MgO}(\%)$ & 0.0166 & 0.400 & 0.282 & 0.365 & 0 & 0 & -29.5 & -8.8 & 29.3 \\
\hline $\mathrm{FeO}(\%)$ & 0.0129 & 1.480 & 1.775 & 5.369 & 0 & 0 & 20.0 & 263.0 & 202.0 \\
\hline $\mathrm{TiO}_{2}(\%)$ & 0.0167 & 0.165 & 0.067 & $0.06 / 0.35$ & 0 & 1 & -59.0 & nc & nc \\
\hline Al & & 49.26 & $64 / 96$ & 96.70 & & & nc & 91.00 & nc \\
\hline $\mathrm{CCPI}$ & & 19.97 & 29.15 & 55.27 & & & 46.00 & 171.00 & 90.00 \\
\hline $\mathrm{K}_{2} \mathrm{O} / \mathrm{Na}_{2} \mathrm{O}$ & & 1.49 & $4.2 / 57$ & 46.34 & & & nc & 3078.00 & 684.00 \\
\hline
\end{tabular}

(a) $\mathrm{DL}=$ detection limit of the analytical methods. (b) $\mathrm{EP}=$ estimated protolith. Concentrations of $\mathrm{P}, \mathrm{Mn}, \mathrm{Al}_{2} \mathrm{O}, \mathrm{K}, \mathrm{O}, \mathrm{CaO}, \mathrm{MgO}, \mathrm{FeO}$ and $\mathrm{TiO}_{2}$ in EP, were calculated with 28 samples from Alperin $\mathrm{Et}$ al. (2007); for other elements they are average abundances in granites (Levinson, 1974). (c) BDL=below DL. (d) NMZ=Non-mineralized zone. (e) MZ=Mineralized zone. Symbol "«" indicates that more than $15 \%$ of the samples yielded concentrations BDL. (f) In bimodal distributions, aproximate concentrations of both modes are indicated in italic characters. ${ }^{(9)}$ Negative percentages of change indicate depletion; positive indicate enrichment. When concentrations in the $\mathrm{NMZ}$ (or MZ) are $\mathrm{BDL}$, and the $\mathrm{DL}$ is higher than the concentration in the $\mathrm{EP}$, percentages of change between the EP and the NMZ (or MZ) were not calculated ("nc"), because there may have been either a gain or a loss, depending on the actual concentration (expron as change were not calculated because a median concentration for that element was not available. If both modes in the bimodal distribution showed a different result (gain/loss) we displayed "nc"; if both modes showed the same result, we indicated it as "Decreased" or "Increased".

\subsubsection{Comparison between estimated protolith (EP) and the mineralized zone}

Most geochemical studies of low and intermediate sulfidation epithermal deposits only considered overall effects produced by several alteration stages on lithogeochemistry (e.g., Booden et al., 2011; Herrera et al., 1993; Mauk and Simpson, 2007; Warren et al., 2007). The overall effects of alterations that affected the study area in the La Josefina deposit were inferred by comparing the composition of the EP with that of the MZ. 


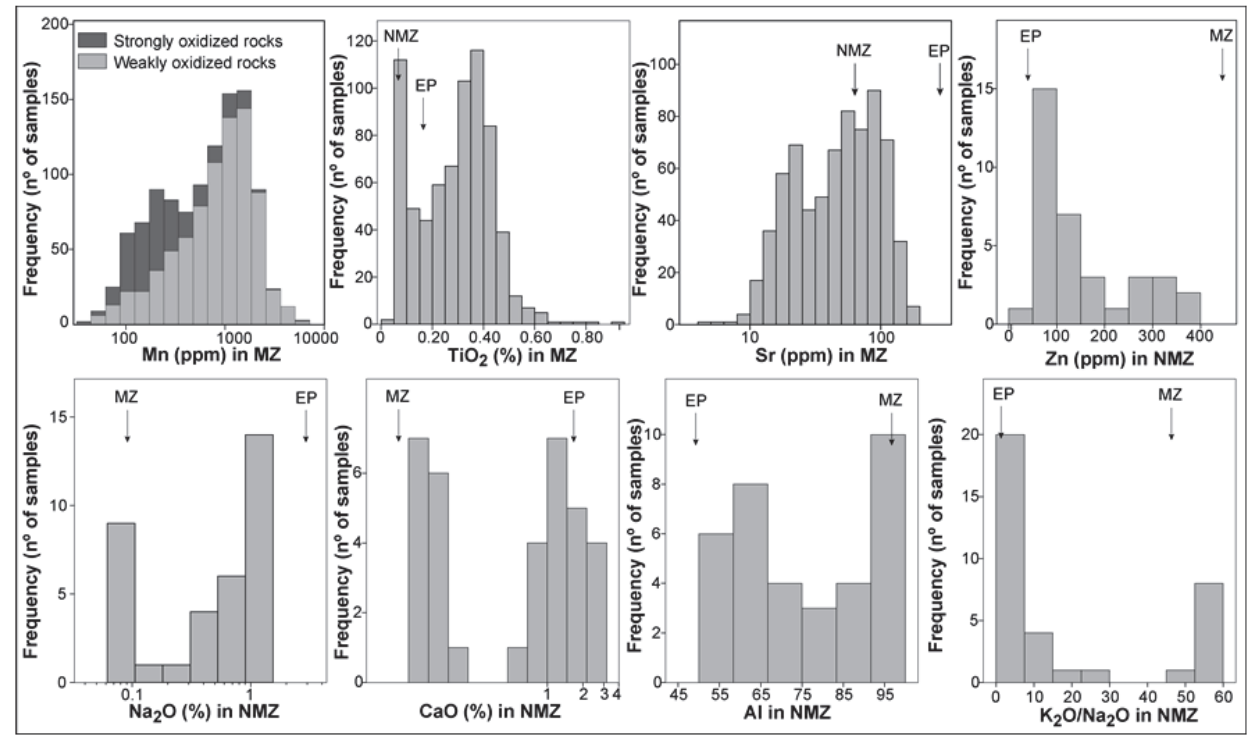

Figure 5.5: Histograms showing bimodal distributions of $\mathrm{Mn}, \mathrm{TiO} 2$ and $\mathrm{Sr}$ in the mineralized zone (MZ), and of $\mathrm{Zn}, \mathrm{Na} 2 \mathrm{O}, \mathrm{CaO}, \mathrm{AI}$ and $\mathrm{K} 2 \mathrm{O} / \mathrm{Na} 2 \mathrm{O}$ in the nonmineralized zone (NMZ).EP $=$ estimated protolith. Arrows indicate median concentrations in the other datasets.

In the $M Z$, the hydrothermal alterations produced an overall stronger geochemical change (i.e., predominant enrichment of elements) than in the NMZ. In comparison to the EP, the concentrations of $\mathrm{As}, \mathrm{Zn}, \mathrm{Pb}, \mathrm{Co}, \mathrm{FeO}, \mathrm{Mn}$, $\mathrm{Au}, \mathrm{V}, \mathrm{Ba}, \mathrm{Cu}, \mathrm{Cr}$ and $\mathrm{Ni}$ are clearly higher in the $\mathrm{MZ}$; those of $\mathrm{Na}_{2} \mathrm{O}, \mathrm{CaO}$ and $\mathrm{Be}$ are notably lower and those of $\mathrm{Hg}$ and $\mathrm{P}$ are slightly lower. The concentrations of $\mathrm{MgO}, \mathrm{Al}_{2} \mathrm{O}_{3}$ and $\mathrm{K}_{2} \mathrm{O}$ in the $\mathrm{MZ}$ are similar to those in the EP. Although the concentrations of $\mathrm{Sr}$ in the MZ show bimodal distribution, almost all samples from that zone show that the $\mathrm{Sr}$ concentrations are lower than in the EP (Figure 5.5).

The values of $\mathrm{AI}$ and CCPI are higher and $\mathrm{K}_{2} \mathrm{O} / \mathrm{Na}_{2} \mathrm{O}$ is much higher in the $\mathrm{MZ}$ than in the EP (Table 5-1). These changes were mainly a function of the leaching of $\mathrm{Na}$ and $\mathrm{Ca}$, rather than addition of $\mathrm{K}$. Therefore, the $\mathrm{K}_{2} \mathrm{O} / \mathrm{Na}_{2} \mathrm{O}$, as used by other authors to evaluate the intensity of potassium metasomatism in other deposits (e.g., Echavarría et al., 2005; Páez et al., 2010), does not seem to be a reliable indicator of potassium metasomatism in the La Josefina deposit.

The overall concentrations of $\mathrm{K}_{2} \mathrm{O}$ in the $\mathrm{EP}, \mathrm{MZ}$ and $\mathrm{NMZ}$ are similar, suggesting that hydrothermal alterations did not add much $\mathrm{K}$ to the rocks, even during the stages of deposition of adularia. In addition, the median concentration of $\mathrm{K}_{2} \mathrm{O}$ in the study area (around $4 \%$ ) is close to those reported by other authors (e.g., Warren et al., 2007) for fresh rhyolites and dacites in 
contrast to higher values reported for $\mathrm{K}$ - metasomatized rocks. Even the median concentration of $\mathrm{K}$ (ca. $6 \% \mathrm{~K}_{2} \mathrm{O}$ ) in the Chon Aike Formation calculated by Peñalva et al. (2005) is higher than the median concentration of $\mathrm{K}_{2} \mathrm{O}$ calculated in this study for either the $\mathrm{MZ}$ or the NMZ (Table 5-1).

In other deposits similar to La Josefina, the overall gains and losses of some elements agree with those inferred for the study area (alteration phases $1+$ 2), while gains and losses of other elements are substantially different. The behavior of $\mathrm{Na}, \mathrm{Ca}, \mathrm{Sr}, \mathrm{Au}, \mathrm{As}, \mathrm{Ba}, \mathrm{Cu}, \mathrm{Pb}, \mathrm{Zn}$ and $\mathrm{Al}_{2} \mathrm{O}_{3}$ in the La Josefina deposit, are mostly consistent with those described in the literature. General depletions in $\mathrm{Na}, \mathrm{Ca}$ and $\mathrm{Sr}$ agree with the results of several studies (Gemmell, 2007; Mauk and Simpson, 2007; Murakami and Feebrey, 2001; Silberman and Berger, 1985). Gains of $\mathrm{Au}$ and As were observed in the Round Mountain, Harsbrouk Mountain, Gosowong, Golden Cross, Yamagano and Axi deposits, and in some deposits in the northern Great Basin of the United States (Berger and Silberman, 1985; Gemmell, 2007; John, 2001; Mauk and Simpson, 2007; Murakami and Feebrey, 2001; Zhai et al., 2009), while gains of $\mathrm{Ba}$ were registered by Darce et al. (1991) and Booden et al. (2011); although $\mathrm{Ba}$ concentrations are considered to have increased particularly in intermediate sulfidation deposits (John, 2001). As in the La Josefina, gains of $\mathrm{Cu}, \mathrm{Pb}$ and $\mathrm{Zn}$ were observed in the Gosowong deposit (Gemmell, 2007) and some deposits in the Great Basin (John, 2001); but, losses of these elements were reported in the Axi deposit (Zhai et al., 2009). Several authors considered Al2O3 as immobile or weakly mobile (Booden et al., 2011; Darce et al., 1991; Mauk and Simpson, 2007; Silberman and Berger, 1985); this is also apparently the case in the La Josefina deposit.

The behaviour of $\mathrm{MgO}, \mathrm{FeO}, \mathrm{Co}, \mathrm{Ni}$ and $\mathrm{K}_{2} \mathrm{O}$ in the La Josefina deposit are different from those described in the literature. Unlike in La Josefina where $\mathrm{MgO}$ is rather immobile, $\mathrm{MgO}$ is quite mobile in other deposits (Booden et al., 2011; Gemmell, 2007; Silberman and Berger, 1985). Iron was gained in the La Josefina deposit, it was lost in the Waitekauri Area (Booden et al., 2011), locally lost in the Golden Cross deposit (Mauk and Simpson, 2007), and slight mobile in the La Libertad deposit (Darce et al., 1991). Cobalt and $\mathrm{Ni}$ were gained in the La Josefina deposit, but were immobile in the Golden Cross deposit (Mauk and Simpson, 2007). Potassium, which exhibits weak mobility in the study area, was gained in altered rocks around many other deposits of this type (Booden et al., 2011; Darce et al., 1991; Gemmell, 2007; Mauk and Simpson, 2007; Murakami and Feebrey, 2001; Silberman and Berger, 1985).

Differences between deposits show the geochemical variability amongst them, as pointed out by Hedenquist et al. (2000) and Silberman and Berger (1985). The geochemical variability may be attributed to genetic differences amongst deposits, differences that eventually may deserve a more detailed 
deposit classification. However, geochemical variability amongst deposits may also be attributed to different compositions of the protolith, and different types of alteration. Gains of $\mathrm{K}_{2} \mathrm{O}$, for instance, are not so noticeable when the protolith is a rhyolitic rock because of the relatively high initial $\mathrm{K}_{2} \mathrm{O}$ content (in K-feldspars); in addition, the gains may be higher in adularia-rich rocks than in illite and illite/smectite-rich rocks, as was observed by Booden et al. (2011). In the study area of the La Josefina deposit, the rhyolitic protolith and the hydrothermal alterations with predominant illite and abundant chlorite probably explain why $\mathrm{K}_{2} \mathrm{O}$ exhibits only weak mobility. Because most studied deposits are hosted by andesitic or dacitic rocks, the results from those studies are probably not directly comparable to the La Josefina and similar deposits hosted in rhyolitic rocks (e.g., Round Mountain and Harsbrouk Mountain).

\subsubsection{Isocon method of mass balance}

In the application of the isocon method, aluminum was selected as immobile element. This was the most reasonable choice because aluminum is relatively immobile in hydrothermal deposits (Booden et al., 2011; Darce et al., 1991; Mauk and Simpson, 2007; Silberman and Berger, 1985), and other potential immobile elements, such as $\mathrm{Zr}$, Th and some REEs are not available in the dataset, while $\mathrm{TiO} 2$ showed a bimodal distribution. The isocon, which has a slope of 0.89 (Table 5-1), was traced using only the median concentration of $\mathrm{Al}_{2} \mathrm{O}_{3}$ from the $\mathrm{NMZ}$. According to the slope of the isocon, and in comparison to the EP, the overall rock-mass increased by about $12 \%$ due to alteration. This is likely due to the addition of sulfides and silica into the host rocks, which probably occupied original pores of the rock.

The results of applying the isocon method to the datasets (Figure 5.6) show that in the $\mathrm{NMZ}, \mathrm{Cu}, \mathrm{Mn}, \mathrm{K}_{2} \mathrm{O}, \mathrm{Co}$ and $\mathrm{Al}_{2} \mathrm{O}_{3}$ are close to (or on) the isocon, while in the $\mathrm{MZ}, \mathrm{Al}_{2} \mathrm{O}_{3}, \mathrm{MgO}$ and $\mathrm{K}_{2} \mathrm{O}$ are close to the isocon. Because $\mathrm{Al}_{2} \mathrm{O}_{3}$ and $\mathrm{K}_{2} \mathrm{O}$ are close to the isocon in both zones, we interpret that they were relatively immobile or that, in general, the host rocks did not gain or lost considerable amounts of those substances during interaction with the hydrothermal fluids. 


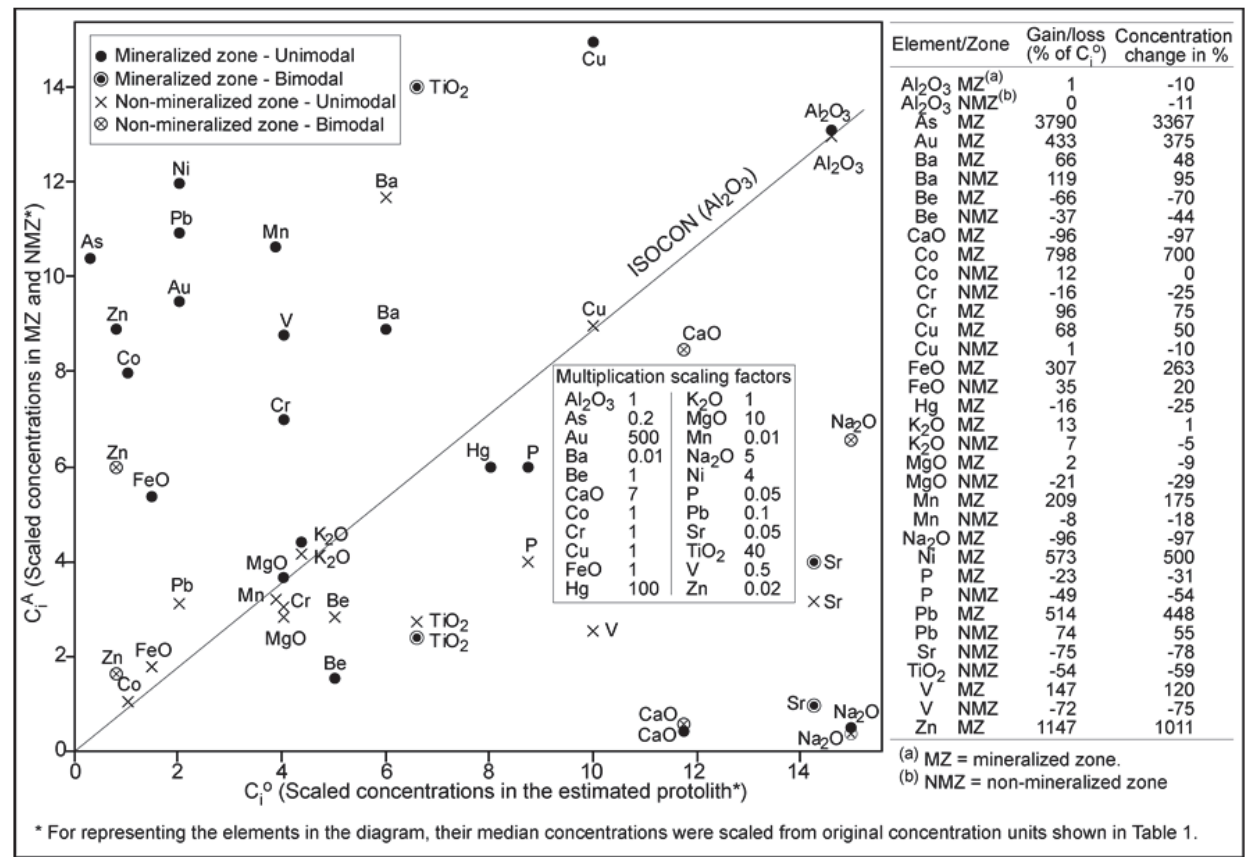

Figure 5.6: Isocon diagram and table based on median concentrations for the mineralized and non-mineralized zones. The isocon line (slope $=0.89$ ) is based on the concentrations of aluminum as immobile element. The median concentrations of elements were scaled to represent them in the same diagram. The table shows a comparison between the gains and losses of elements calculated with the isocon method of mass balance and the change in concentration calculated without mass balance (from Table 5-1); both are represented in percentages of the concentrations in the estimated protolith $\left(\mathrm{C}_{\mathrm{i}}{ }^{\circ}\right)$. Zinc, $\mathrm{Sr}, \mathrm{Na}_{2} \mathrm{O}, \mathrm{CaO}$ and $\mathrm{TiO}_{2}$ show bimodal distributions in one of the zones; thus, the approximate values of both modes were plotted with distinct symbols but were not shown in the table. Elements that show concentrations below $\mathrm{DL}$ in $>15 \%$ of the samples from one or both zones are not shown in the figure.

In general terms and considering some margin of error, the differences in element concentrations obtained by comparing the concentrations in the EP with those in the MZ and NMZ are coincident with the results produced by the mass balance using the isocon method (Figure 5.6). Therefore, the general tendencies obtained from the comparisons without using mass balance analysis are considered reliable, and can be used to draw conclusions about the effects of hydrothermal alterations on the geochemistry. However, the amount of overall rock-mass increase gives an idea of the possible error that should be considered when using the geochemical data without mass balance analysis.

\subsubsection{Comparison between the mineralized and non-mineralized zones}

The median concentrations of $\mathrm{As}, \mathrm{V}, \mathrm{Co}, \mathrm{Mn}, \mathrm{FeO}, \mathrm{Au}, \mathrm{Pb}, \mathrm{Cu}, \mathrm{Hg}, \mathrm{Cr}, \mathrm{Ni}, \mathrm{P}$ and $\mathrm{MgO}$ in the $\mathrm{MZ}$ are higher than in the $\mathrm{NMZ}$, while those of $\mathrm{Ba}$ and $\mathrm{Be}$ are lower, and those of $\mathrm{Al}_{2} \mathrm{O}_{3}$ and $\mathrm{K}_{2} \mathrm{O}$ are similar. Despite showing bimodal 
distributions in the $\mathrm{NMZ}$, the concentrations of $\mathrm{Zn}$ in the $\mathrm{MZ}$ are clearly higher than in the NMZ, while those of $\mathrm{CaO}$ are clearly lower (Figure 5.5; Table 5-1). In contrast, concentrations of $\mathrm{Sb}, \mathrm{Bi}, \mathrm{Mo}, \mathrm{W}$ and $\mathrm{Cd}$ in the $\mathrm{MZ}$ could not be compared with those in the NMZ because they are below DL in $>15 \%$ of the samples from both zones. Concentrations of $\mathrm{Sr}, \mathrm{Na}_{2} \mathrm{O}$ and $\mathrm{TiO}_{2}$, and values of $\mathrm{AI}$ and $\mathrm{K}_{2} \mathrm{O} / \mathrm{Na}_{2} \mathrm{O}$ could not be compared because they show bimodal distributions in one of the datasets, and the modes in the histogram from that dataset are not clearly different from the median of the other dataset (Figure 5.5).

\subsubsection{Result of the study at detailed-scale}

Detailed-scale variations in element concentrations with distance to mineralized veins, are not well documented for low and intermediate sulfidation deposits. In the Bodie Bluff district, Silberman and Berger (1985) investigated variations in concentrations of $\mathrm{Au}, \mathrm{K}, \mathrm{Sr}, \mathrm{Ag}, \mathrm{Zn}, \mathrm{As}, \mathrm{Hg}, \mathrm{Sb}, \mathrm{Mn}$ and $\mathrm{Cu}$ with distance from three mineralized veins, but only up to $7.5 \mathrm{~m}$ from the veins, using a limited number of samples, and considering, along the investigated distance interval, concentrations of individual samples. For most investigated elements, this approach produced strongly irregular variations, which cannot be used to indicate proximity to mineralized veins. In contrast, we plotted element concentrations as median values of several samples within distance intervals from MPCs, showing a more continuous and consistent variation with distance from veins.

Along the studied intervals from MPCs, the boxplots and models of compositional variation clearly represent the continuous compositional variations of the rocks. For most of the elements, these models show increasing or decreasing compositional drifts along a few distance intervals (Figure 5.7; Table 5-2), but the boxplots show strong overlap between adjacent distance intervals. This shows the strong dispersion of element concentrations in every interval, which produces relatively large interquartile ranges. 

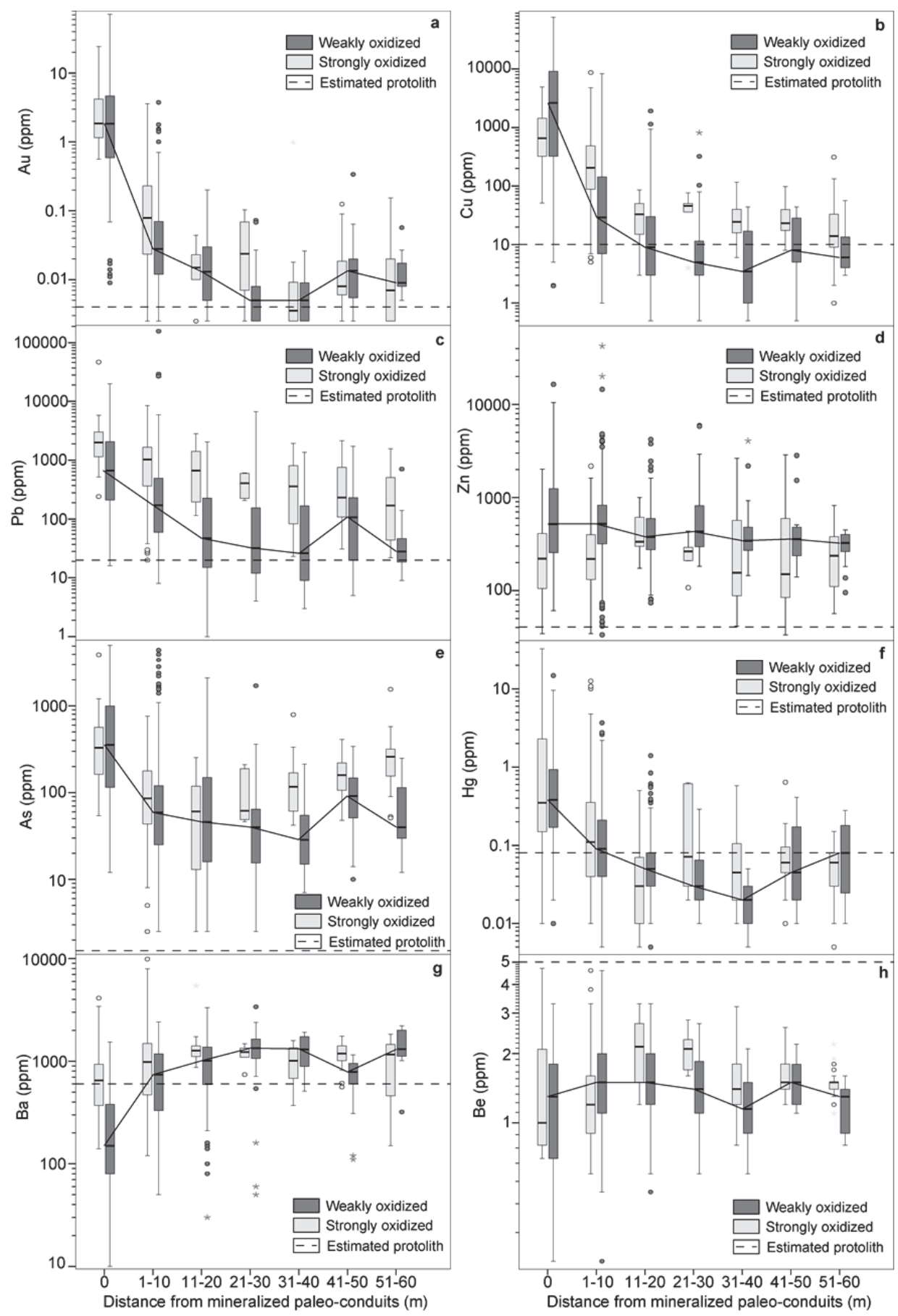

Figure 5.7: Boxplots and models of compositional variation with data from the mineralized zone. Distance 0 coincides with the mineralized paleo-conduits. Small circles are regular outliers; asterisks are extreme outliers. 

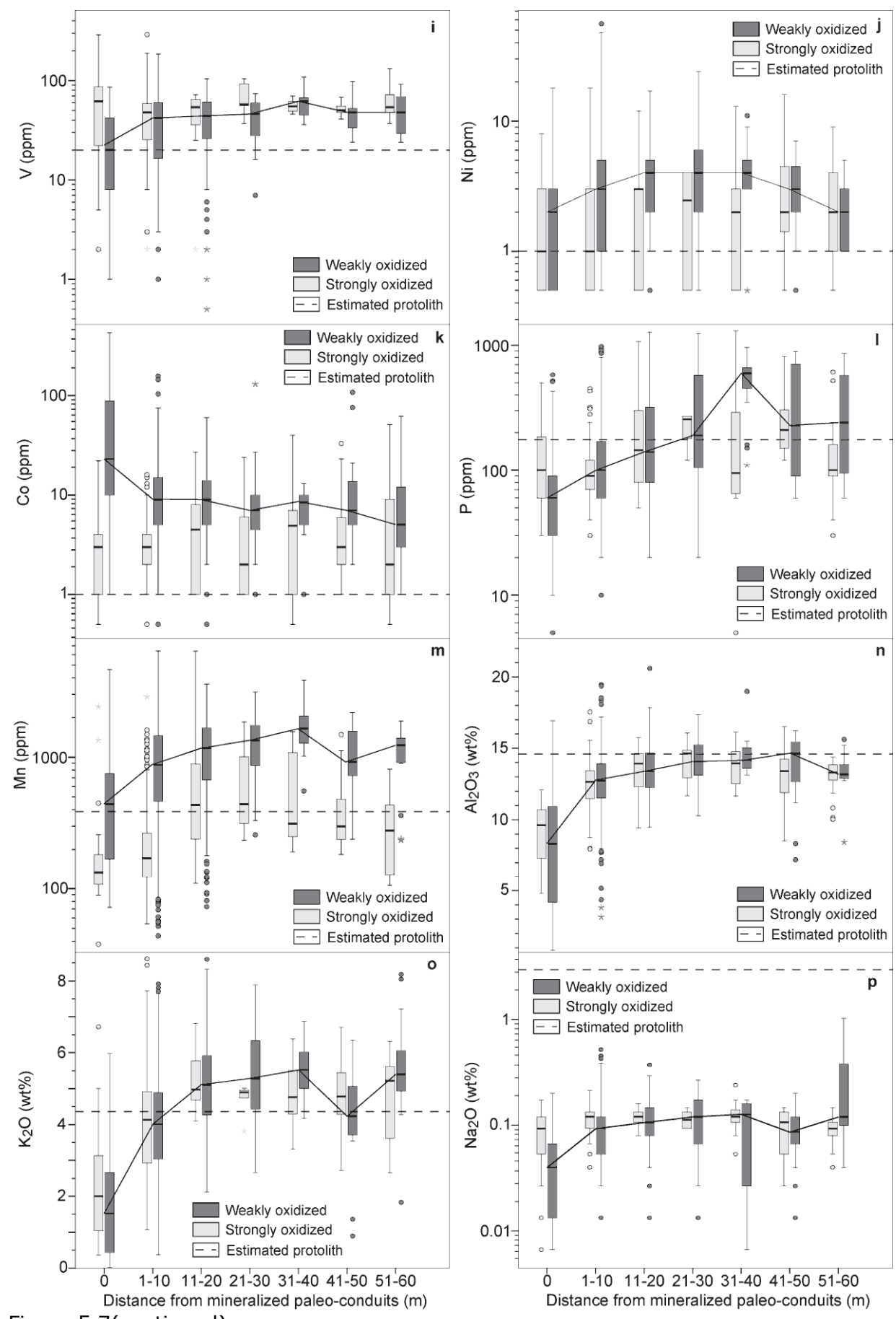

Figure 5.7(continued) 

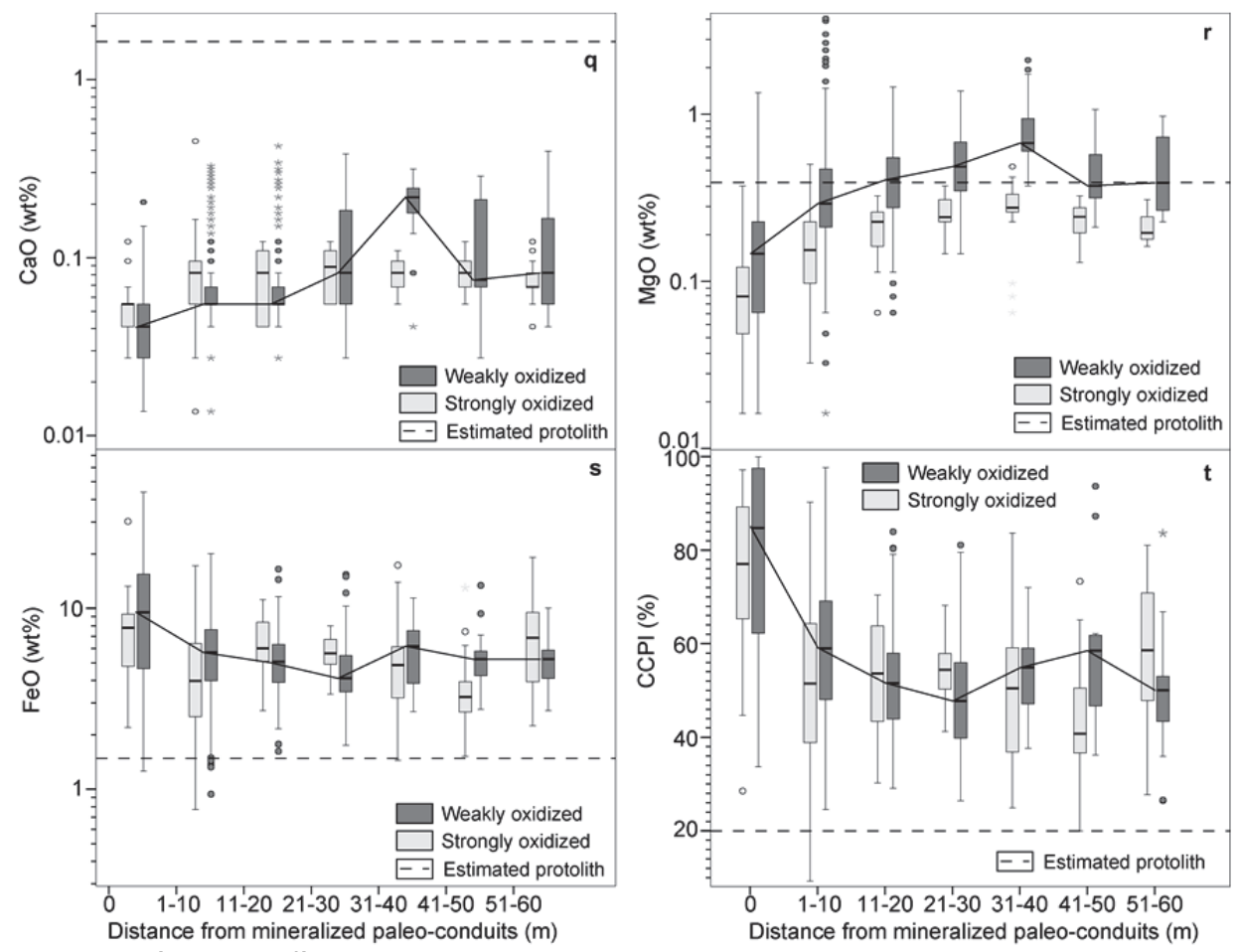

Figure 5.7(continued)

The behaviour of the elements during the formation of MPCs can be inferred from the geochemical contrast between the $0 \mathrm{~m}$ interval, which represents materials deposited from the hydrothermal fluids, and the 1-10 m interval, which represents the host rocks. Relative to their adjacent host rocks, the MPCs (0 m interval) show much higher concentrations of $\mathrm{Au}, \mathrm{Cu}, \mathrm{As}, \mathrm{Hg}, \mathrm{Pb}$ and $\mathrm{Co}$, much lower concentrations of $\mathrm{Al}_{2} \mathrm{O}_{3}, \mathrm{~K}_{2} \mathrm{O}, \mathrm{Na}_{2} \mathrm{O}, \mathrm{CaO}, \mathrm{MgO}$ and $\mathrm{Ba}$, and slightly lower concentrations of $\mathrm{Mn}$ and $\mathrm{P}$. Despite the high number of samples with element concentrations below $\mathrm{DL}$, the concentrations of $\mathrm{Ag}, \mathrm{Sb}$, and $\mathrm{Bi}$ are clearly higher in the MPCs, where they show a low percentage of samples with element concentrations below DL (Table 5-3). The concentrations of Mo and $\mathrm{Cr}$ seem to be similar in the MPCs and its immediate host rocks, while those of $\mathrm{Cd}$ and $\mathrm{W}$ seem to be higher in the MPCs, although they are difficult to evaluate because of their small differences and the high number of undetermined values (Table 5-3). In addition, $\mathrm{Ag}, \mathrm{Cu}, \mathrm{Pb}, \mathrm{As}, \mathrm{Sb}, \mathrm{Bi}$ and $\mathrm{Cd}$ are associated with $\mathrm{Au}$ in native gold, electrum, pyrite, chalcopyrite and galena. These observations suggest that the processes that formed the mineralized veins and hydrothermal breccias were accompanied by precipitation of $\mathrm{Au}, \mathrm{Ag}, \mathrm{Cu}, \mathrm{As}, \mathrm{Hg}, \mathrm{Pb}, \mathrm{Co}, \mathrm{Sb}$ and $\mathrm{Bi}$, and probably $\mathrm{Cd}$ and $\mathrm{W}$. 
Chapter 5

Table 5-2. Statistics for element concentrations in distance intervals from mineralized paleo-conduits, using separate datasets for strongly oxidized and weakly oxidized rocks.

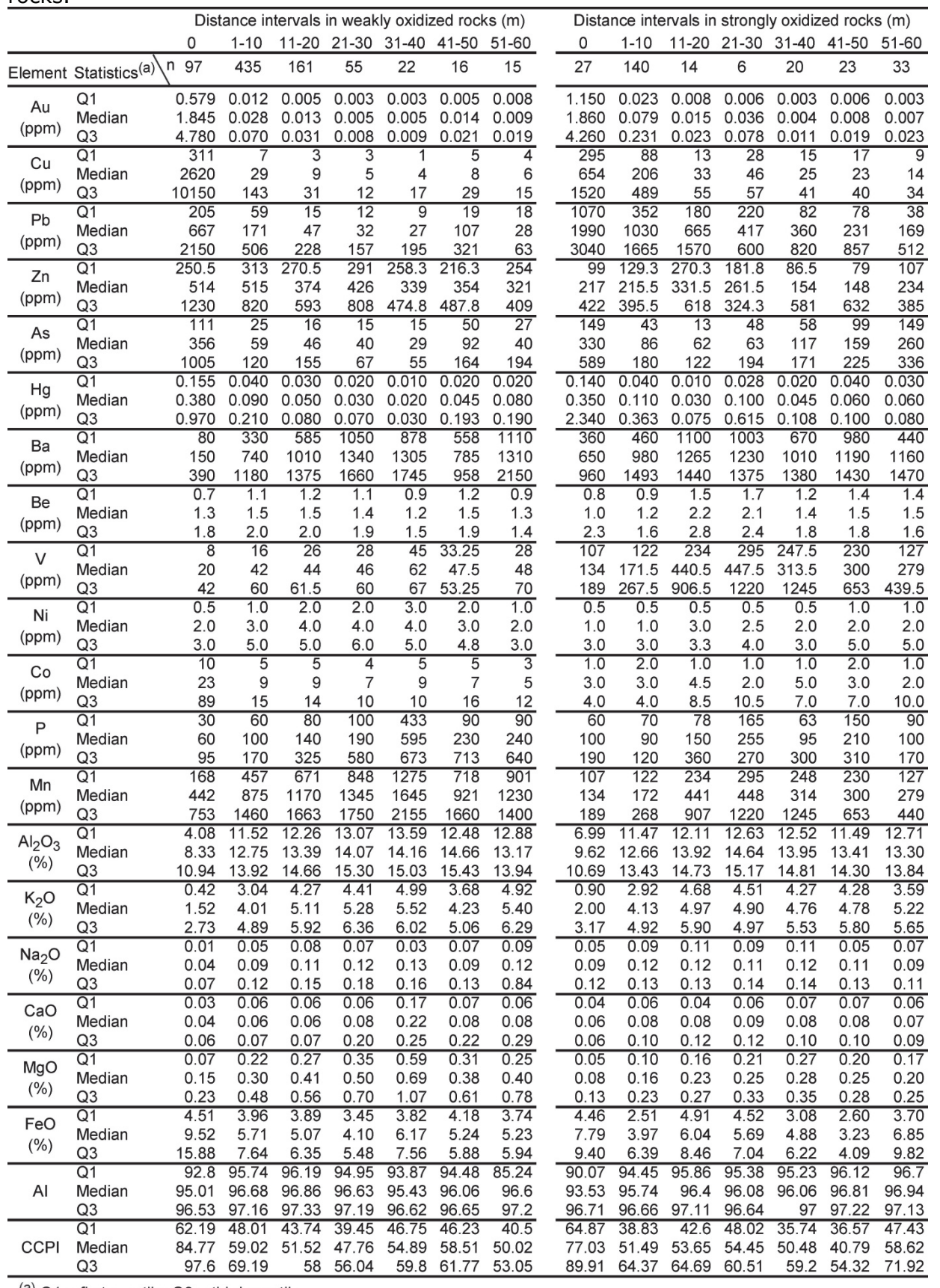

(a) $\mathrm{Q} 1$ = first quartile; $\mathrm{Q} 3=$ third quartile. 
The studied elements generally show either enrichment or depletion relative to the EP along the entire $60 \mathrm{~m}$ interval from the MPCs. For some elements, however, both enrichment and depletion occur at different distances from the MPCs; $\mathrm{K}_{2} \mathrm{O}, \mathrm{MgO}, \mathrm{Cu}, \mathrm{Hg}, \mathrm{Ba}$ and $\mathrm{P}$ (Figure 5.7) show both enrichment and depletion in different parts of that interval. This is important because geochemical data in the proximity of a MPC may indicate either depletion or enrichment, depending on the distance from the MPC. The variations of element concentrations beyond the MPCs represent compositional changes produced by hydrothermal alterations in the host rocks, and are more subtle than the changes that include the MPCs. The strongest overall compositional drifts in host-rock dominated materials are those of $\mathrm{P}, \mathrm{Au}, \mathrm{Cu}, \mathrm{Pb}, \mathrm{Hg}, \mathrm{Ba}$ and $\mathrm{MgO}$, which reach up to $40 \mathrm{~m}$ from the MPCs, except for Au (Table 5-4; Figure 5.7). Concentrations of $\mathrm{Mn}, \mathrm{As}, \mathrm{FeO}, \mathrm{K}_{2} \mathrm{O}, \mathrm{Na}_{2} \mathrm{O}, \mathrm{Al}_{2} \mathrm{O}_{3}$ and $\mathrm{Ni}$ show weaker compositional drifts. Calcium, $\mathrm{Co}, \mathrm{Be}, \mathrm{V}$ and $\mathrm{Zn}$ show no clear compositional drifts in the host rock.

Table 5-3. Median concentrations, and percentage of samples with element concentrations below detection limit $(\mathrm{DL})$ in weakly oxidized mineralized paleo-conduits and their immediate host-rocks, for elements that show concentrations below DL in $>15 \%$ of the samples of the mineralized zone (not included in Table 5-2).

\begin{tabular}{ccccc}
\hline \multirow{2}{*}{ Elements } & \multicolumn{2}{c}{ Median Concentration (ppm) } & \multicolumn{2}{c}{$\% \mathrm{BDL}^{\text {(a) }}$} \\
& $\mathrm{HR}(\mathbf{n = 4 3 5 )}$ & $\mathrm{MPC}(\mathrm{n}=97)$ & $\mathrm{HR}^{\text {(b) }}$ & $\mathbf{M P C}^{(\mathbf{c})}$ \\
\hline $\mathrm{Ag}$ & 0.8 & 36 & 30 & 3 \\
$\mathrm{Sb}$ & 6 & 21 & 36 & 7 \\
$\mathrm{Bi}$ & 3 & 107 & 35 & 3 \\
$\mathrm{Mo}$ & 2 & 2 & 23 & 21 \\
$\mathrm{~W}$ & 10 & 30 & 37 & 22 \\
$\mathrm{Cr}$ & 7 & 6 & 2 & 3 \\
$\mathrm{Cd}$ & 2.2 & 3 & 25 & 9 \\
\hline
\end{tabular}

(a) \% BDL: percentage of samples with values below detection limit.

(b) HR: host-rock dominated materials (interval $1-10 \mathrm{~m}$ ).

(c) MPC: mineralized paleo-conduits dominated materials (interval=0m).

\subsubsection{Geochemical indicators}

At deposit-scale, comparison of the $M Z$ with the $N M Z$, which are both hydrothermally altered, shows that the concentrations of As, $\mathrm{V}, \mathrm{Co}, \mathrm{Mn}, \mathrm{FeO}$, $\mathrm{Au}, \mathrm{Pb}, \mathrm{Cu}, \mathrm{Hg}, \mathrm{Cr}, \mathrm{Ni}, \mathrm{P}, \mathrm{MgO}$ and $\mathrm{Zn}$ (and values of CCPI) are higher in the $\mathrm{MZ}$ than in the $\mathrm{NMZ}$, while those of $\mathrm{Ba}, \mathrm{Be}$ and $\mathrm{CaO}$ are lower in the $\mathrm{MZ}$ than in the NMZ. These 18 variables are therefore, geochemical indicators of the mineralized altered zone.

At detailed-scale, $\mathrm{P}, \mathrm{Au}, \mathrm{Cu}, \mathrm{Pb}, \mathrm{Hg}, \mathrm{Ba}$ and $\mathrm{MgO}$ display the strongest compositional drifts, and thus are the best geochemical indicators of proximity to mineralized rocks. Manganese, As, $\mathrm{FeO}, \mathrm{K}_{2} \mathrm{O}, \mathrm{Na}_{2} \mathrm{O}, \mathrm{Al}_{2} \mathrm{O}_{3}$ and $\mathrm{Ni}$, show weaker compositional drifts, and therefore are poor indicators of proximity to mineralized rocks. 
Table 5-4. Strengths and ranges of elements that show compositional drifts in weakly oxidized rocks. The range is the distance from mineralized paleo-conduits, up to which the compositional drifts of the median concentration is preserved. Changes in median concentrations between every two consecutive distance intervals along the curves were calculated as percentage of the shorter-range interval. The "strength" is the average of all the percentages of change between pairs of intervals up to the considered range.

\begin{tabular}{|c|c|c|c|}
\hline \multirow[b]{2}{*}{ Elements } & \multirow[b]{2}{*}{ Strength $^{(a)}$} & \multicolumn{2}{|c|}{ Maximum Range (m) } \\
\hline & & Weakly oxidized & Strongly oxidized \\
\hline $\mathrm{Au}$ & -57.55 & 30 & 20 \\
\hline $\mathrm{Cu}$ & -47.80 & 40 & 20 \\
\hline $\mathrm{Pb}$ & -40.02 & 40 & 60 \\
\hline As & -21.28 & 40 & 20 \\
\hline $\mathrm{Hg}$ & -39.26 & 40 & 20 \\
\hline $\mathrm{Ba}$ & 34.58 & 30 & 20 \\
\hline V & 14.70 & 40 & No drift \\
\hline $\mathrm{Ni}$ & 33.33 & 20 & No drift \\
\hline$P$ & 96.29 & 40 & 30 \\
\hline $\mathrm{Mn}$ & 23.66 & 40 & 30 \\
\hline $\mathrm{Al}_{2} \mathrm{O}_{3}$ & 3.56 & 50 & 30 \\
\hline $\mathrm{K}_{2} \mathrm{O}$ & 11.73 & 40 & 20 \\
\hline $\mathrm{Na}_{2} \mathrm{O}$ & 10.78 & 40 & No drift \\
\hline $\mathrm{MgO}$ & 32.41 & 40 & 40 \\
\hline $\mathrm{FeO}$ & -15.15 & 30 & No drift \\
\hline CCPI & -10.00 & 30 & No drift \\
\hline
\end{tabular}

(a) Strength calculated up to maximum range. Negative values indicate that mean concentrations increase towards MPC

\subsubsection{Effects of weathering}

Weathering has affected the concentrations of $\mathrm{Cu}, \mathrm{Na}_{2} \mathrm{O}, \mathrm{MgO}, \mathrm{FeO}, \mathrm{As}, \mathrm{Pb}$, $\mathrm{Co}, \mathrm{Ba}, \mathrm{Mn}$ and $\mathrm{Zn}$. The most affected elements were $\mathrm{Cu}, \mathrm{Pb}, \mathrm{Co}, \mathrm{Mn}, \mathrm{MgO}$ and $\mathrm{Zn}$. The concentrations of these elements in weakly oxidized and strongly oxidized rocks are clearly different (Figure 5.7). The median concentration of $\mathrm{Cu}$ in the strongly oxidized samples of the MPCs $(654 \mathrm{ppm})$ is notably lower than in the weakly oxidized samples (2620 ppm). In the host rocks, the opposite occurs (Table 5-2; Figure 5.7). This suggests that some $\mathrm{Cu}$ in the MPCs became mobile and was re-deposited at a distance. In strongly oxidized rocks, the median concentrations of $\mathrm{MgO}, \mathrm{Co}, \mathrm{Mn}$ and $\mathrm{Zn}$ are lower than in the weakly oxidized rocks along the whole $60 \mathrm{~m}$ interval. In contrast, concentrations of $\mathrm{Pb}$ in the strongly oxidized rocks are higher along the whole interval (Figure 5.7). The concentrations of $\mathrm{Na}_{2} \mathrm{O}, \mathrm{Ba}, \mathrm{As}$ and $\mathrm{FeO}$ were slightly affected by weathering; those of $\mathrm{Na}_{2} \mathrm{O}$ and $\mathrm{Ba}$ show the effects of weathering only in the MPCs, while those of As show the effects of weathering only far away from the MPCs. The other studied elements were not considerably affected by weathering.

Near the surface where weathering is stronger, the usefulness of several elements as geochemical indicators of mineralized rocks is a function of the 
scale of study. From a deposit-scale perspective, weathering did not modify considerably the usefulness of the geochemical indicators of mineralized zones because increases in their concentrations at certain distances from MPCs were compensated with decreases in their concentrations at other distances. Most elements show similar overall median concentrations in the strongly oxidized and in the weakly oxidized rocks, and thus they can be used as geochemical indicators of mineralized zones at deposit-scale. From a detailed-scale perspective, in contrast, weathering decreased the usefulness of several elements as geochemical indicators of proximity to MPCs. Compositional drifts defined by the concentrations of $\mathrm{Pb}, \mathrm{Na}_{2} \mathrm{O}, \mathrm{FeO}$ and $\mathrm{Ba}$, and the values of CCPI in the weakly oxidized rocks disappear or become irregular and weaker in the strongly oxidized rocks (Table 5-4). Therefore, these geochemical variables are unsuitable indicators of proximity to MPCs in weathered rocks.

Other authors have studied the effects of weathering on the concentrations of $\mathrm{Ca}, \mathrm{Na}, \mathrm{K}, \mathrm{Fe}, \mathrm{Mg}$ and aluminum in rocks that are similar to those in $\mathrm{La}$ Josefina, although in areas not related to mineral deposits. In most cases, their results do not agree with ours, except those showing strong leaching of Mg (Guan et al., 2001; Selby, 1993), which also occurred by weathering in the La Josefina deposit. In contrast to our results, which show that $\mathrm{Fe}$ and aluminum were almost not modified by weathering, Malpas et al. (2001) found that the concentrations of these elements were increased by weathering. In the La Josefina and other areas related to similar mineral deposits it is plausible that concentrations of $\mathrm{FeO}$ were not increased by weathering because of the likely oxidation and subsequent partial leaching of relatively abundant Fe-sulfides, introduced into the host rocks by previous hydrothermal alteration; although part of the iron is fixated in Fe-oxides. Regarding aluminum, we consider it as nearly immobile during hydrothermal alteration and weathering in the La Josefina and likely in areas with similar conditions, although it is possible that minor amounts of aluminum were moved locally by eluvial processes from the surface to lower soil horizons (Chittleborough, 1991).

Calcium, $\mathrm{Na}$ and $\mathrm{K}$ were invariably leached by weathering in other areas (Chan et al., 2007; Guan et al., 2001; Malpas et al., 2001; Selby, 1993), while in the La Josefina area, those elements were mostly unaffected by weathering. In the study area, weathering likely had no opportunity to leach $\mathrm{Ca}$ and $\mathrm{Na}$ considerably because the concentrations of these elements were already low due to previous hydrothermal alterations. The limited modification of $\mathrm{K}$ concentrations in the La Josefina area in contrast to other studied areas may have also been due to the previous hydrothermal alterations. These alterations probably transferred some $\mathrm{K}$ from $\mathrm{K}$-feldspars of the original host rocks to other K-rich minerals, predominantly illite, which 
are not strongly affected by weathering; this resulted in the overall near immobility of $\mathrm{K}$ during hydrothermal alteration, as well as weathering.

\subsubsection{Implications for exploration}

In the La Josefina epithermal system, hydrothermally altered zones that were mineralized with Au likely show different alteration mineralogy compared to those that were not mineralized. Alterations prior to Au-mineralization (alteration phase 1) included weak silicification and argillization of the host rocks around the veins. Those argillic alterations are mainly composed of illite, while kaolinite is absent. Alterations resulting from the complete hydrothermal process (alteration phases 1 and 2), including the stages of Aumineralization, are silicic and argillic, partially overprinted by propylitic. In contrast to alterations during phase 1 , the alterations during phase 2 seem to have been stronger and included abundant kaolinite as one of the predominant minerals.

In addition to considering the overall effects on lithogeochemistry by all alterations that affected the study area, which only shows net gains and losses (i.e., difference between the initial and final conditions), we attempted to isolate the geochemical modifications of the host rocks produced during the events of mineralization. This was done by inferring the changes produced during the two consecutive alteration phases, 1 and 2, and by integrating data from the detailed-scale part of the study and from previous mineralogical studies. Although that isolation cannot be completely accomplished, because the alterations contemporaneous with mineralization are overprinted by others, we prefer our approach of considering different phases of alteration, rather than the overall effects of all alteration events. This approach gives more flexibility to extrapolate the results to other areas of the deposit or to similar deposits, under slightly different conditions to those in the study area.

Elements that were lost or gained during alteration phase 1 in contrast to alteration phase 2, can be used to effectively distinguish potentially mineralized zones from barren zones. Alteration phase 1 resulted in losses or no modifications for $\mathrm{Au}, \mathrm{Cu}, \mathrm{Hg}, \mathrm{V}, \mathrm{Co}, \mathrm{Mn}, \mathrm{MgO}, \mathrm{Cr}$ and $\mathrm{P}$, while alteration phase 2 resulted in gains of those elements. The concentrations of $\mathrm{Ba}$ increased during alteration phase 1 but decreased during alteration phase 2 . In addition, other elements experience either loss or gain during both alteration phases; while concentrations of $\mathrm{Pb}, \mathrm{Zn}$ and $\mathrm{FeO}$, (and values of $\mathrm{CCPI}$ ) increased, and those of $\mathrm{Be}$ and $\mathrm{CaO}$ decreased. Although it was not possible to assess the effects of alteration phase 1 on As and $\mathrm{Ni}$ because of the high number of samples with concentrations below $D L$, the concentrations of these two elements are higher in the MZ than in the NMZ. Therefore, all 
these 18 geochemical variables are useful geochemical indicators to differentiate between mineralized and non-mineralized zones, but $\mathrm{Au}, \mathrm{Cu}, \mathrm{Hg}$, $\mathrm{V}, \mathrm{Co}, \mathrm{Mn}, \mathrm{MgO}, \mathrm{Cr}, \mathrm{Ba}$ and $\mathrm{P}$ are probably the most effective.

These 18 geochemical variables can be used to distinguish between mineralized and non-mineralized zones in other parts of the deposit, if the sampling procedure and the general geological conditions are similar to those of the study area. The sampling procedure should avoid samples from MPCs and should represent different distances from them. This can be achieved by sampling areas of at least a few tens of metres wide and omitting samples that show values of $\mathrm{Au}$ higher than $0.5 \mathrm{ppm}$. The geological conditions that must be satisfied include the approximate position in the paleo-system; this is difficult to know at the beginning of exploration but, at least, indicators of proximity to paleo-surface such as sinters, blankets of abundant kaolinite or extended pervasive silicification should be absent. The geological conditions should also include relatively homogeneous lithologies of rhyolitic to rhyodacitic compositions, and the absence of abundant propylitic alteration.

In slightly different geological conditions, however, a few elements may be useful indicators of mineralized zones. Some elements added specifically by alterations contemporaneous with mineralization may be identified by integrating the conclusions drawn from the deposit-scale and detailed-scale studies. By comparing the MPCs with their adjacent host rocks, we interpreted that $\mathrm{Au}, \mathrm{Cu}, \mathrm{Pb}, \mathrm{As}, \mathrm{Hg}$ and $\mathrm{Co}$ were deposited preferentially in the MPCs; in addition, these are some of the elements that experienced gains in the host rocks during alteration phase 2, which included Au-mineralization. Moreover, $\mathrm{Cu}, \mathrm{Pb}$ and $\mathrm{As}$ are directly related to $\mathrm{Au}$ in some minerals in the veins. Therefore, these six elements were likely deposited during the mineralizing process in the veins and host rocks. This suggests that a relative increase in the concentrations of $\mathrm{Au}, \mathrm{Cu}, \mathrm{Pb}$ and $\mathrm{As}$, and probably $\mathrm{Hg}$ and $\mathrm{Co}$ are good indicators of mineralized zones, even if the hydrothermal alterations and protolith are slightly different from those in the study area.

In deposit-scale exploration, when geochemical data from ground surface or close to it are evaluated, the effects of weathering should be considered. If samples are collected from strongly oxidized parts of the profile, $\mathrm{Au}, \mathrm{Hg}, \mathrm{V}, \mathrm{P}$, $\mathrm{Cr}, \mathrm{Ni}, \mathrm{Be}, \mathrm{CaO}, \mathrm{Ba}$ and $\mathrm{CCPI}$ can be useful indicators of mineralized zones because they are not considerably affected by weathering. Copper, FeO and As can also be used as indicators, although with caution because they are more affected by weathering. In contrast, $\mathrm{Co}, \mathrm{Mn}, \mathrm{Pb}, \mathrm{Zn}$ and $\mathrm{MgO}$ should not be used because their concentrations may be strongly modified by weathering in the upper part of the ground profile. 
In the La Josefina and in other deposits under similar conditions as the study area, the models of compositional variation can be used for subsurface and surface exploration of relatively well-known zones, when the mineralized target is expected to be close to the sampled areas. In subsurface exploration, after drilling and analysing the drill core samples, the determination of compositional drifts along boreholes may suggest the presence of and proximity to mineralized veins located beyond the borders of the investigated area. The elements with strongest compositional drifts would be the best to indicate proximity to mineralized rocks. The compositional drifts can also be useful during surface exploration when relatively detailed work (e.g., by trenching) is carried out. However, it is probably in the subsurface where the models are more applicable because of the detailed character of the surveys and the absence of weathering.

Because of weathering, some elements decreased their potential as indicators of proximity to MPCs in the study area, while others become unsuitable indicators. In the strongly oxidized rocks, concentrations of $\mathrm{Au}, \mathrm{Cu}, \mathrm{P}, \mathrm{Ba}$, $\mathrm{Hg}, \mathrm{K}_{2} \mathrm{O}, \mathrm{As}, \mathrm{Al}_{2} \mathrm{O}_{3}$ and $\mathrm{Mn}$ show compositional drifts with shorter ranges (20 or $30 \mathrm{~m}$ ) than in the weakly oxidized rocks (Table 5-4; Figure 5.7). Concentrations of $\mathrm{Na}_{2} \mathrm{O}, \mathrm{FeO}, \mathrm{V}$ and $\mathrm{Ni}$ did not show compositional drifts in strongly oxidized rocks.

The use of several elements together to indicate proximity to MPCs and to differentiate between mineralized and non-mineralized zones is beneficial compared to the use of only the best indicator. Gold is probably the best indicator for Au-rich areas, but it has disadvantages like often occurring in low concentrations, showing high variability, and being transported and concentrated by supergene processes, giving the erroneous impression that there is a genetic link with the host rocks and alterations, while there may be only a spatial association. Using several indicators helps to avoid some of the minor changes due to variations in the geological conditions and due to variability in the concentrations of some elements, compensating some of the variations in one element with correct indications from other elements, and finally improving the success in recognizing mineralized areas. In addition, several elements are easier to determine than $\mathrm{Au}$, and some determinations can be done directly in the field, using for instance gamma ray spectrometers for $\mathrm{K}$ or portable $\mathrm{X}$-Ray fluorescence devices for various elements.

\subsection{Conclusions}

For mineral deposits with geological conditions similar to those of the study area, the most effective deposit-scale geochemical indicators of mineralized zones are $\mathrm{Au}, \mathrm{Cu}, \mathrm{Hg}, \mathrm{V}, \mathrm{Co}, \mathrm{Mn}, \mathrm{MgO}, \mathrm{Cr}, \mathrm{Ba}$ and $\mathrm{P}$. Other potential indicators although probably less effective are $\mathrm{Pb}, \mathrm{Zn}, \mathrm{FeO}, \mathrm{CCPI}, \mathrm{Be}, \mathrm{CaO}, \mathrm{As}$ 
and $\mathrm{Ni}$. In addition, it is likely that $\mathrm{Cu}, \mathrm{Pb}, \mathrm{As}, \mathrm{Hg}$ and $\mathrm{Co}$ were deposited in the mineralized veins and host rocks at La Josefina mainly during the Au mineralization stage. Therefore, $\mathrm{Cu}, \mathrm{Pb}, \mathrm{As}, \mathrm{Hg}$ and $\mathrm{Co}$ can be used as good indicators of Au-rich zones even if the geological conditions in those zones are slightly different from those observed during this research.

In detail, the variations in concentrations of several elements in the study area are functions of the distance from paleo-conduits of epithermal fluids. In the system of veins and its hanging wall, where argillic and silicic alterations predominate, the concentrations of 15 elements vary continuously with distance from mineralized paleo-conduits although only the compositional drifts of $\mathrm{P}, \mathrm{Au}, \mathrm{Cu}, \mathrm{Pb}, \mathrm{Hg}, \mathrm{Ba}$ and $\mathrm{MgO}$ are strong, up to 30 or $40 \mathrm{~m}$. Therefore, these variables are useful indicators of proximity to Au-rich veins for detailed-scale geochemical surveys during drilling.

The general effects of weathering on elemental concentrations in the study area were moderate, but their consequences vary according to the scale and objective of the geochemical survey. At deposit-scale, if the objective is to identify potential Au-mineralized zones of a few hundred of metres wide, the effects of weathering are mild, although they prevent the use of $\mathrm{Co}, \mathrm{Mn}, \mathrm{Pb}$, $\mathrm{Zn}$ and $\mathrm{MgO}$ as indicators because their concentrations may be strongly modified. At detailed-scale, if the objective is to estimate proximity to possible Au-rich veins, the effect of weathering is more significant. It can blur the variations of elemental concentrations due to mineralization, turning $\mathrm{Na}_{2} \mathrm{O}, \mathrm{FeO}, \mathrm{V}$ and $\mathrm{Ni}$ into unsuitable indicators of proximity to Au-rich veins, and decreasing the usefulness of $\mathrm{Au}, \mathrm{Cu}, \mathrm{P}, \mathrm{Ba}, \mathrm{Hg}, \mathrm{K}_{2} \mathrm{O}, \mathrm{As}, \mathrm{Al}_{2} \mathrm{O}_{3}$ and $\mathrm{Mn}$.

Previous hydrothermal alterations of original rocks likely have strong influence on the subsequent effects of weathering. This would depend on the composition of the hydrothermal alteration minerals and their susceptibility to be affected by weathering. Therefore, the concepts about effects of weathering developed in areas that have not undergone hydrothermal alteration should not be directly applied in areas surrounding mineralized veins. 


\section{Chapter 6}

\section{Characterizing the hydrothermal alteration system at the La Josefina deposit with reflectance spectroscopy}

\footnotetext{
* This chapter is based on: Andrada de Palomera, P., van Ruitenbeek, F.J.A., van der Meer, F.D. (paper in preparation). Characterizing the epithermal paleo-system with reflectance spectroscopy at the La Josefina Au-Ag deposit, Deseado Massif, Argentina. To be submitted for publication.
} 


\subsection{Introduction}

Hydrothermal alteration minerals in epithermal systems, are often distributed in mineralogical zones around conduits of epithermal fluids and at different vertical levels of the epithermal systems (Cooke and Simmons, 2000). Zonation of hydrothermal minerals and chemical elements occurs around epithermal systems (Browne and Ellis, 1970; Buchanan, 1981; Hedenquist and Henley, 1985; Henley, 1985; Simmons and Browne, 2000; Simmons et al., 2005; Warren et al., 2007; White et al., 1995), both in mineralized and unmineralized systems. The zonation results from progressive modification of the hydrothermal fluids and host rocks either by their mutual interaction or by modifications of the fluids because of mixing or pressure and temperature changes. The fluids are modified as they move through the rocks, losing and gaining elements by boiling, cooling and interacting with the host rocks.

The interactions of hydrothermal fluids with host rocks may produce relatively narrow and well recognizable alteration zones around fluid conduits. The zonation represents a chemical and mineralogical transition or buffer zone from unaltered host rock at distance from the fluid conduit to a vein environment inside (Guilbert and Park, 1986). The variations in fluid composition produced by boiling and cooling occur mainly as the fluids ascend, and their effects are recognizable along vertically oriented intervals in the system, producing relatively large alteration zones. The vertical mineralogical zonation is the result of a decrease in temperature caused by increasing distance from a heat source at depth. It has been observed in active geothermal systems (Battaglia, 2004; Cathelineau and Izquierdo, 1988; Cathelineau et al., 1985; Simmons and Browne, 2000; Yang et al., 2001a; Yang et al., 2000). These mineralogical zonation patterns have also been observed in extinct systems, including those that are associated with epithermal deposits (Simpson et al., 2001; Yang et al., 2001b). Zonation may include propylitic alteration in the deeper parts of the systems, followed by argillic alteration in shallower levels, grading from predominant illite to illite/ smectite to finally smectite in the upper parts and margins of the systems.

This zonation is however an oversimplification of the real situation. The zonation patterns are complicated by the overprinting of alteration caused by variations in fluid chemistry in space and time. Some of them are related to lateral variations produced by the fluid-rock interactions mentioned above. Others are produced by vertical modifications generated by fluid boiling, which strongly affects the fluid chemistry and host rocks above. Boiling is a key process in epithermal systems, because it affects both the characteristics of hydrothermal alterations and the precipitation of precious metals. In addition to this, the positions of the vertical and lateral zones can change 
over time. This may complicate the reconstruction of events in the epithermal systems based on the configuration of hydrothermal alteration mineralogy.

Recognizing zones of alteration minerals at different scales is important for mineral exploration. At deposit and district scales, the recognition of vertical zones can help to infer the current erosion level of the exposed paleo-system and therefore, an approximate depth at which mineralized rocks may be located. At more detailed scales, lateral zonation can help to infer the possible location of paleo-conduits of epithermal fluids. This is favoured by the size of the lateral alteration zones, which are often much wider than the mineralized areas; therefore, they are also easier to detect, either by field mapping or remote sensing.

In this research, the hydrothermal alteration zonation in the La Josefina epithermal paleo-system was studied with reflectance spectroscopy. This was done with three objectives: (a) to determine the spectral characteristics of each of the different levels (portions) of the paleo-system that can be later used to differentiate vertical levels in similar epithermal paleo-systems; (b) to determine the relationship between the mineralogical and spectroscopic characteristics of the different levels of the paleo-system and the location of the ore zones; and (c) to assess the usefulness of spectroscopy to better interpret the configuration of the paleo-system. The hypothetical conceptual geological model of the La Josefina deposit and the schematic cross sections produced in chapter 4 were used as basis for the interpretations and to infer the position that each area in the La Josefina deposit would have had in the epithermal paleo-system. This was aided by the use of geochemistry of samples from surface materials. Reflectance spectroscopic data of surface materials were used for characterizing each of the explored areas in terms of mineralogy and spectral parameters of selected spectral alteration minerals. Finally, the usefulness of spectroscopic data to help determine the different parts of epithermal paleo-systems was evaluated.

\subsection{Hydrothermal alteration in Low- and Intermediate-Sulfidation Epithermal Deposits (LISEDs)}

Hydrothermal alteration minerals that are common in LISEDs include quartz, chalcedony, kaolinite, illite, illite/smectite, smectite, adularia, calcite, chlorite, pyrite, epidote, zeolites, sericite (fine grain muscovite), barite and albite. LISEDs contain scarce siderite and locally, minor amounts of advanced argillic alteration minerals.

In low-sulfidation epithermal deposits (LSEDs), deep-level and regional-scale alterations often consist of propylitic assemblages of quartz, chlorite, illite, 
pyrite, calcite, albite, adularia and epidote (Cooke and Simmons, 2000). This assemblage, which usually surrounds the whole epithermal system (Figure 6.1 ), is in cases deuteric and of questionable direct genetic relationship to epithermal ore-forming systems. Propylitic assemblages are typically chloriterich with epidote occurring only at depth (Hedenquist et al., 2000). In the upper parts of the systems, quartz and adularia generally predominate in the veins within certain intervals and in the immediate vicinity of these veins (Figure 6.1). In those intervals and mainly in the veins, high gold concentrations may be present. Around the quartz and adularia-rich area, clay alteration minerals are often predominant. At levels between the Au-rich intervals and the paleo water table, the host rocks close to the veins are also altered to clays (mainly smectites, illite-smectites, illite, chlorite, kaolinite) and carbonates (Cooke and Simmons, 2000). At the same depths but moving away from the veins, there is often a gradational predominance of illite to illite-smectite, and finally to smectite (Figure 6.1). The latter minerals indicate the presence of reduced and near-neutral pH fluids of low-salinity (Cooke and Simmons, 2000).

In the upper parts of the paleo-systems (Figure 6.1), travertine, silica sinters and kaolinite-rich alteration assemblages are commonly found. Silica sinters may deposit when boiled or boiling epithermal fluids are discharged at the surface; they demarcate the paleo-surface and the paleo-water table (Cooke and Simmons, 2000). Kaolinite-rich alteration forms in the presence of acid sulfate steam-heated waters (Cooke and Simmons, 2000). These acidic conditions are achieved in the vadose zone by condensation of volatiles produced from boiling at deeper levels. Kaolinite-rich alteration, together with illite, minor alunite and opaline rocks, can form blankets of steam-heated origin, commonly underlain by chalcedony blankets (Hedenquist et al., 2000). Kaolinite is therefore, abundant in the upper parts of the systems, in the oxidizing part of the ground profile, directly above the area of boiling of the fluids. However, kaolinite-rich water may drain downwards into the fractures to depths of up to several hundred meters; and therefore, kaolinite may be deposited at lower vertical levels together with vein minerals and may have partially overprinted previous alterations. 


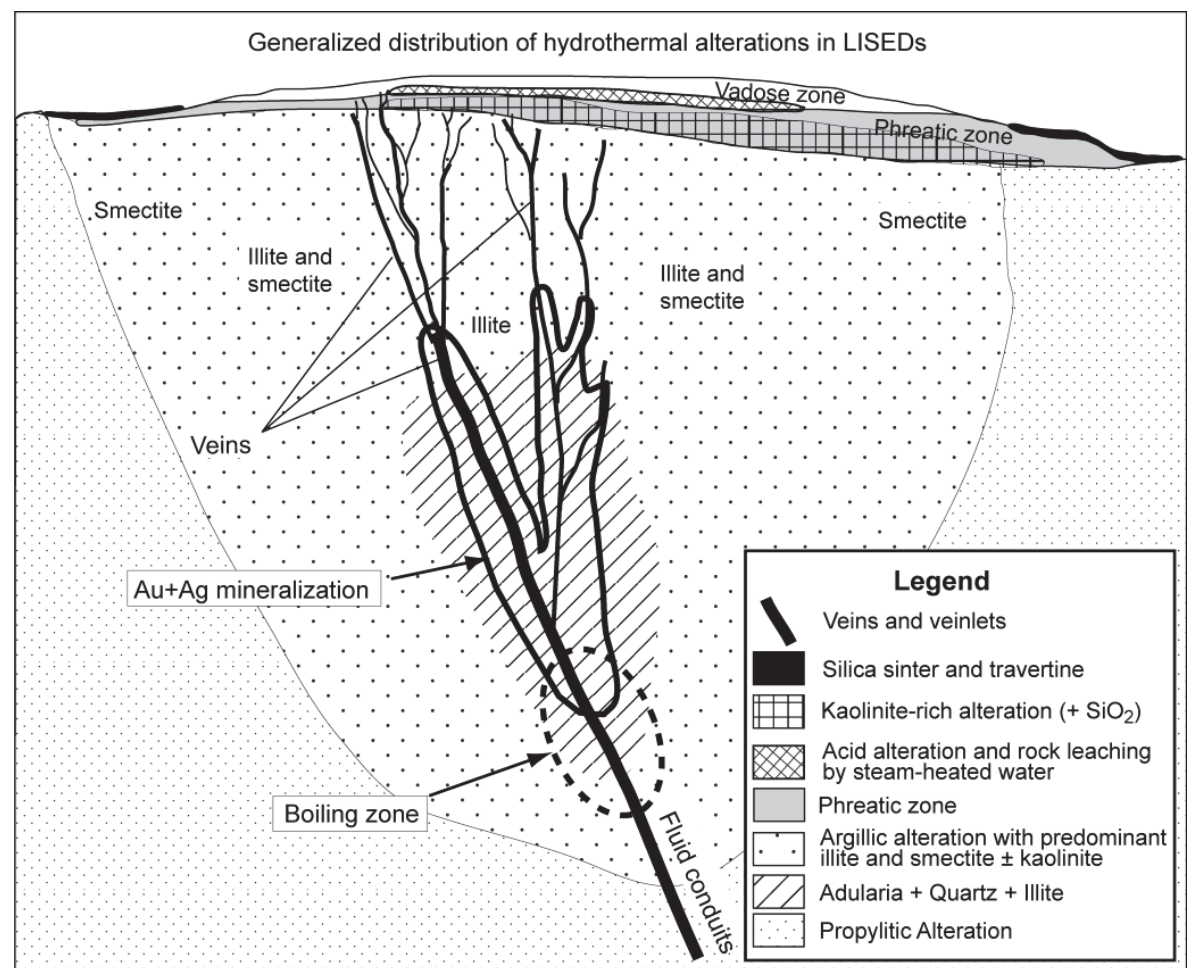

Figure 6.1: Generalized distribution of hydrothermal alterations in LISEDs. Temperature, position of boiling zone, and depth of water table are important controlling factors on distribution of alterations.

\subsection{Background of Reflectance Spectroscopy}

Reflectance spectroscopy has been used for several years for the identification of hydrothermal alteration minerals, as well as compositional variations of some of those minerals (Thompson et al., 1999; Thompson et al., 2009; van Ruitenbeek et al., 2005; van Ruitenbeek et al., 2006; Yang et al., 2001a; Yang et al., 2000; Yang et al., 2001b; Yang et al., 2011). Some of the most common alteration minerals in LISEDs can be recognized by spectroscopy, amongst them the group of white micas (illite and muscovitelike minerals), chlorite, smectites, kaolinite, dickite, jarosite, calcite, hematite and goethite. The compositional variations of some alteration minerals (e.g., white micas, chlorites and smectites) can be inferred from variations of the wavelength of their absorption features (Thompson et al., 1999; Thompson et al., 2009; van Ruitenbeek et al., 2005).

The use of spectroscopy for mapping hydrothermal alteration has become common practice with the availability of portable reflectance spectrometers. The high amount of data that can be collected in short time and the minimal preparation of samples are amongst some advantages of spectroscopy 
(Chang and Yang, 2012), and may help to identify mineral zonation more accurately than conventional methods (i.e., XRD and visual identification). The semi-quantitative nature of spectral parameters derived from the spectral curves is another advantage of spectroscopy, because they can potentially be calculated automatically and used statistically and spatially over relatively large areas. Examples of these parameters are mineral crystallinity (e.g., for white micas and kaolinite), and depth and wavelength position of absorption features, which in some cases can be used to estimate relative mineral abundance.

The precise wavelength position of absorption features in reflectance spectra of some minerals depend on their chemical composition; therefore, variations in the position of those absorption features can be used to estimate mineral compositional variations. In white micas and smectites the wavelength of the $\mathrm{AlOH}$ absorption feature near $2200 \mathrm{~nm}$ is mainly a function of the Al content (Post and Noble, 1993). Because Al can be substituted by other elements such as $\mathrm{Si}, \mathrm{Fe}, \mathrm{Mg}$ and probably $\mathrm{Ti}$ (Duke and Lewis, 2010), the wavelength of the $\mathrm{AlOH}$ absorption feature, indirectly depends on the concentrations of those elements in these minerals (Table 6-1). The position of the feature shifts towards longer wavelengths when Fe or Mg substitutes Al. Duke and Lewis (2010) pointed out that, in metamorphic terrains, a shift in the wavelength of the $\mathrm{AlOH}$ absorption from $2225 \mathrm{~nm}$ to $2194 \mathrm{~nm}$ indicates an increase in total $\mathrm{Al}_{2} \mathrm{O}_{3}$ content in white micas from 2.0 to 2.8 atoms per $11 \mathrm{O}$ atoms. Similar shifts occur with two absorption features in chlorite. One of them $(2235-2255 \mathrm{~nm})$, is produced by $\mathrm{FeOH}$; the other $(2320-2360 \mathrm{~nm})$, is produced by $\mathrm{MgOH}$. Both absorption features shift towards shorter wavelengths in $\mathrm{Mg}$-rich chlorites, and towards longer wavelengths in Fe-rich chlorites (Table 6-1). 
Table 6-1. Changes in spectral features with composition (Compiled from Bierwirth et al., 2002; Huston et al., 1999; McLeod et al., 1987; Pontual et al., 1997; Scott et al., 1998; Thompson et al., 1999).

\begin{tabular}{|c|c|c|c|c|c|c|}
\hline Minerals & Compositions & \multicolumn{4}{|c|}{$\begin{array}{l}\text { Wavelength variation vs } \\
\text { composition }\end{array}$} & $\begin{array}{l}\text { Molecular } \\
\text { bond }\end{array}$ \\
\hline \multirow{4}{*}{$\begin{array}{l}\text { Illite } \\
\text { (white } \\
\text { micas) }\end{array}$} & & $\begin{array}{c}+\mathrm{Al} \\
(+\mathrm{Na})\end{array}$ & \multicolumn{2}{|c|}{$\begin{array}{c}+\mathrm{Al} \\
(+\mathrm{K})\end{array}$} & $\begin{array}{c}-\mathrm{Al}(+\mathrm{K}) \\
(+\mathrm{Fe}+\mathrm{Mg})\end{array}$ & \\
\hline & $\begin{array}{l}\text { Paragonitic: } \\
\mathrm{NaAl}_{2}\left(\mathrm{Si}_{3} \mathrm{Al}\right) \mathrm{O}_{10} \\
(\mathrm{OH})_{2}\end{array}$ & $\begin{array}{c}2180 \\
\mathrm{~nm}\end{array}$ & & & & $\mathrm{Al}-\mathrm{OH}$ \\
\hline & \multicolumn{2}{|c|}{$\begin{array}{l}\text { Muscovitic: } \mathrm{KAl}_{2}\left(\mathrm{AlSi}_{3} \mathrm{O}_{10}\right) \\
(\mathrm{F}, \mathrm{OH})_{2},\end{array}$} & \multicolumn{2}{|c|}{$2200 \mathrm{~nm}$} & & $\mathrm{Al}-\mathrm{OH}$ \\
\hline & \multicolumn{4}{|c|}{$\begin{array}{l}\text { Phengitic: } \quad \mathrm{K}(\mathrm{Mg}, \mathrm{Fe})_{0.5} \mathrm{Al}_{1.5}\left(\mathrm{Si}_{3.5} \mathrm{Al}_{0.5}\right) \mathrm{O}_{10} \\
(\mathrm{OH}, \mathrm{F})_{2}\end{array}$} & $\begin{array}{l}2228(2235) \\
\mathrm{nm}\end{array}$ & $\mathrm{Al}-\mathrm{OH}$ \\
\hline \multirow{5}{*}{ Chlorite } & \multirow{5}{*}{$\begin{array}{l}(\mathrm{Mg}, \mathrm{Fe}, \mathrm{Al})_{3} \\
(\mathrm{Si}, \mathrm{Al})_{4} \mathrm{O}_{10}(\mathrm{OH})_{2}\end{array}$} & \multicolumn{2}{|c|}{$+\mathrm{Mg}$} & \multicolumn{2}{|c|}{$+\mathrm{Fe}$} & \\
\hline & & \multicolumn{2}{|c|}{$\begin{array}{l}2245 \mathrm{~nm} \\
\text { (-intense) }\end{array}$} & \multicolumn{2}{|c|}{$\begin{array}{c}2265 \mathrm{~nm} \\
(+ \text { intense) }\end{array}$} & $\mathrm{Fe}-\mathrm{OH}$ \\
\hline & & \multicolumn{2}{|c|}{$\begin{array}{c}2330 \mathrm{~nm} \\
\begin{array}{c}\text { (broader and }+ \\
\text { intense) }\end{array}\end{array}$} & \multicolumn{2}{|c|}{$\begin{array}{c}2350 \mathrm{~nm} \\
\text { (narrower and - } \\
\text { intense) }\end{array}$} & $\mathrm{Mg}-\mathrm{OH}$ \\
\hline & & \multicolumn{2}{|c|}{$+\mathrm{Mg}$} & \multicolumn{2}{|c|}{$-\mathrm{Mg}$} & \\
\hline & & \multicolumn{2}{|c|}{$1395 \mathrm{~nm}$} & \multicolumn{2}{|c|}{$1410 \mathrm{~nm}$} & $\mathrm{OH}$ \\
\hline \multirow{5}{*}{ Smectite } & & $+\mathbf{A l}$ & \multicolumn{3}{|c|}{-Al } & \\
\hline & $\begin{array}{l}\text { Beidellite: } \\
\mathrm{Na}_{0.5} \mathrm{Al}_{2}\left(\mathrm{Si}_{3.5} \mathrm{Al}_{0.5}\right) \\
\mathrm{O}_{10}(\mathrm{O})_{2} \cdot \mathrm{n}(\mathrm{H} 2 \mathrm{O})\end{array}$ & 2180 & & & & $\mathrm{Al}-\mathrm{OH}$ \\
\hline & \multicolumn{2}{|c|}{$\begin{array}{l}\text { Montmorillonite: }(\mathrm{Na}, \mathrm{Ca})_{0,3}(\mathrm{Al} \\
{ } \mathrm{Mg}_{2} \mathrm{Si}_{4} \mathrm{O}_{10}(\mathrm{OH})_{2} \cdot \mathrm{n}\left(\mathrm{H}_{2} \mathrm{O}\right)\end{array}$} & \multicolumn{2}{|c|}{$2205-2212$} & & $\mathrm{Al}-\mathrm{OH}$ \\
\hline & \multirow{2}{*}{\multicolumn{4}{|c|}{ Nontronite: $\mathrm{Na}_{0.3} \mathrm{Fe}^{3+}{ }_{2}(\mathrm{Si}, \mathrm{Al})_{4} \mathrm{O}_{10}(\mathrm{OH})_{2} \cdot \mathrm{n}\left(\mathrm{H}_{2} \mathrm{O}\right)$}} & $\begin{array}{l}2270- \\
2296\end{array}$ & $\mathrm{Fe}-\mathrm{OH}$ \\
\hline & & & & & $\begin{array}{l}2363- \\
2394 \\
\end{array}$ & $\mathrm{Fe}-\mathrm{OH}$ \\
\hline \multirow{3}{*}{ Alunite } & & \multicolumn{2}{|c|}{$+\mathrm{Na}$} & \multicolumn{2}{|c|}{$+K$} & \\
\hline & $\begin{array}{l}\text { Natroalunite: } \\
\mathrm{NaAl}_{3}\left(\mathrm{SO}_{4}\right)_{2}(\mathrm{OH})_{6}\end{array}$ & \multicolumn{2}{|c|}{$\begin{array}{c}\text { Doublet Close to } \\
1500 \mathrm{~nm}\end{array}$} & & & $\mathrm{OH}$ \\
\hline & $\begin{array}{l}\text { Alunite: } \\
\mathrm{KAl}_{3}\left(\mathrm{SO}_{4}\right)_{2}(\mathrm{OH})_{6}\end{array}$ & & & $\begin{array}{c}\text { Dou } \\
\text { to }\end{array}$ & $\begin{array}{l}\text { t close } \\
30 \mathrm{~nm}\end{array}$ & $\mathrm{OH}$ \\
\hline
\end{tabular}

The relationship between the wavelength position of absorption features and the bulk rock composition is not so clear from the available studies. Duke and Lewis (2010) and van Ruitenbeek et al. (2005) did not find a correlation between the wavelength and the bulk Al content in rocks. van Ruitenbeek et al. (2005) pointed out that, in the Panorama district, the abundance of white micas relative to chlorite, as well as their Al content was a function of several variables, such as temperature, coexisting mineralogy, hydrothermal fluid chemistry and composition of the volcanic host rock. Therefore, the varying physiochemical conditions encountered in different deposits may be a reason for the absence of universal relationships between the Al content and wavelength of the $\mathrm{AlOH}$ feature on the one hand, and the bulk Al content of the host rocks on the other hand. In addition, the modification of the $\mathrm{Al}$ content of white micas may be not enough to produce a clear compositional 
difference in the whole rock, considering that white micas constitute just a small percentage of that rock, mainly if the alteration is weak. The interplay of all these variables is also expected to result in lack of a universal relationship between the compositional variation (and positions of absorption features), and the degrees of alteration and mineralization for different deposit types.

The wavelength position of the $\mathrm{AlOH}$ absorption feature in white micas is potentially useful for exploration of hydrothermal mineral deposits. This usefulness derives from the dependence of the wavelength position on depth, temperature and proximity to fluid conduits. This can be studied with reflectance spectroscopy, which can be an effective field-based exploration tool for determining subtle zonation and quantifying the intensity of alteration associated with orebodies (Biel et al., 2012; Jones et al., 2005). Several attempts have been made to use the compositional variations of white micas, inferred from spectroscopy, as an aid for exploration of mineral deposits and geothermal systems.

The compositional variations of white micas, however, do not follow a universal rule for all hydrothermal deposits. Yang et al. (2001b), compared results from different deposit types and concluded that there is no single uniform trend of compositional variations of white micas in relation to the location of main fluid channels or mineralized areas. That statement may be valid not only for different deposit types but also amongst different deposits of the same general type. However, in each deposit, or probably each district, systematic compositional variations of these minerals can be expected, since in most studied deposits some sort of variations were found. In several cases the variations were not clear or reported as absent (e.g., Yang et al., 2000).

Studies of compositional variations of white micas in hydrothermal deposits produced contrasting results. In the Hellyer massive sulfide $\mathrm{Pb}-\mathrm{Zn}$ deposit (Tasmania), the K-rich white micas become phengitic in more intensely altered rocks and mineralized portions of the deposit (Yang et al., 2001b). In the Arroyo Rojo VMS deposit (southern Argentina), Biel et al. (2012) reached similar conclusions, adding that paragonitic white micas are preferentially located in distal areas; they showed that wavelengths around $2220 \mathrm{~nm}$ for $\mathrm{AlOH}$ features define zones enveloping the massive sulfide mineralization. In contrast, massive sulfide deposits at Myra Falls (Canada) show lower wavelengths of the $\mathrm{AlOH}$ feature in white micas (slightly sodic muscovite) in strongly altered host rocks closer to ore (Jones et al., 2005). A similar trend was observed in the Tuwu Cu-Au deposit (hosted in andesitic rocks), where Al-rich white micas predominate towards the core and most intensely altered part of the system, and relatively Al-poor white micas predominate at the margins and weakly altered parts (Yang et al., 2005). 
The trends determined by Jones et al. (2005) at Myra Falls are similar in rhyolites and andesites, but the absolute wavelengths of the absorption features are slightly different. This suggests that lithology partially controls the results of alteration, including the absolute values of some alteration parameters. The importance of lithology as control on alteration was also inferred by Yang et al. (2005), noting the widespread occurrence of chlorite in andesites and their sporadic presence in acidic or intermediate composition rocks. In areas of contrasting lithologies, the original host rock lithology should be considered to assess the usefulness of spectroscopy.

In geothermal systems, gradations in predominant alteration minerals as well as compositional variations in white micas where correlated with depth and temperature of formation. In the Wairakei and Broadlands-Ohaaki geothermal systems, hosted in felsic volcanics, similar downward gradations in predominant alteration minerals where identified (Yang et al., 2001a; Yang et al., 2000). Both show gradations from predominant smectites to predominant illite to illite+chlorite with increasing depth; the Wairakei system shows also an upper part with predominant mordenite (lowtemperature zeolite). In the Wairakei system, no regular compositional change in white micas and smectites with depth or temperature was found (Yang et al., 2000); but in the Broadlands-Ohaaki systems, a trend of decreasing wavelength position of the $\mathrm{AlOH}$ feature from the surface downward into the underlying illite-dominated zone was found in some drillholes (Yang et al., 2001a). This was interpreted as a reflection of a progressive downward change from the montmorillonite-rich zone $($ AlOH 2208 nm) to the illite-rich zone $(\mathrm{AlOH} 2198 \mathrm{~nm})$. Although this interpretation is arguably from the point of view of the absorption feature wavelength alone, the shift from smectite to illite involves increase in $\mathrm{K}$ content in the clays, such that registered in several geothermal systems with increasing temperature of formation (Battaglia, 2004; Cathelineau, 1988). The increase in potassium is also apparent in orogenic gold deposits at Mount Magnet (Australia) where K-micas are proximal to the Au-rich zones, while Na-micas (paragonitic) are distal (Cudahy et al., 1996; Yang et al., 2001b).

In the Comstock epithermal district (USA), the $\mathrm{AlOH}$ feature is at wavelengths $<2200 \mathrm{~nm}$ predominantly in the upper levels with alunitic-silicic acidic alterations, at $2200-2208 \mathrm{~nm}$ in intermediate level with predominant argillic alteration, and at $>2208 \mathrm{~nm}$ in a lower level with predominant propylitic alteration (Yang et al., 2001b). Those authors concluded that the target for exploration would be the wavelengths between 2200 and $2208 \mathrm{~nm}$ in white micas, which probably include the muscovitic K-rich micas.

The Comstock district, shows similar characteristics to those of the La Josefina deposit, having sulfide assemblages that indicate an intermediate- 
sulfidation state (Hedenquist et al., 2000); however, in Comstock, the deposits are mainly hosted in andesitic volcanic and intrusive rocks, while in La Josefina, they are hosted in rhyolitic volcanic rocks.

\subsection{Method}

\subsubsection{Generalities}

The conceptual model of the La Josefina deposit and the different areas (cross sections) in the deposit that are presented in chapter 4, were used in this chapter as a basis for the spectroscopic interpretations.

The mineralogy of each one of the areas was characterized by acquiring and interpreting reflectance spectroscopic data. Reflectance spectroscopy was selected to study the hydrothermal alterations because of its ability to identify most of the relevant alteration minerals present in LISEDs, and subtle differences related to mineral composition, coupled with its relatively simple collection procedure that allows obtaining abundant data in relatively short time. However, a few samples were also analysed by XRD to validate the interpretation of selected reflectance spectra.

With this characterization, the vertical position of some portions of the paleosystem were reinterpreted, showing the usefulness of spectroscopy for improving the knowledge about LISEDs. Finally, some spectroscopic attributes of each of the different levels of the paleo-system were defined as discriminating features for recognition of similar levels in other paleosystems.

The spectroscopic study included the determination of minerals and the quantification of three spectral parameters. Those parameters are: 1) wavelength position of the $\mathrm{AlOH}$ absorption feature in white micas and smectites (at $\sim 2200 \mathrm{~nm}$ ); 2) white micas crystallinity; and 3) kaolinite crystallinity. These three features were studied spatially, by plotting them on maps of the exposed epithermal system to observe system-scale trends. Plots on more detailed scales of the different areas were used to determine the relationship of these spectral features with veins and areas interpreted as feeder conduits of epithermal fluids or with particular geological features.

The concentrations of $\mathrm{Au}, \mathrm{Ag}, \mathrm{Cu}, \mathrm{Pb}$ and $\mathrm{As}$ in surface samples were compared with the spectroscopic interpretations. Simple point plots were generated, and the distribution of the concentrations were also considered by plotting them in histograms to check if there were more than one population in the plot that could be related to patterns of distribution in the map. The chemical composition of the surface samples were analysed in different 
laboratories using different analytical techniques. ALS-Chemex laboratories analysed most of the samples; they determined $\mathrm{Au}$ concentrations by fire assay and the rest of the elements by ICP of three types; one included a 3acid digestion (IC587), while the other two included a 4-acid digestion (MEMS61 and ME-ICP61). Fomicruz S.E. analysed part of the samples by a wet assay including dissolution with aqua regia and concentration with methyl isobutyl ketone (MIBK). All assay types were used together because only relatively large differences in concentrations were studied.

\subsubsection{Spectroscopic data acquisition and processing}

A total of 1558 reflectance spectra were obtained from surface materials and subsequently used for this study. The spectroscopic data from 1540 of these samples were used for most of the study, while data from 18 samples were used mainly for control purposes, by analysing them with XRD and spectroscopy. The spectroscopic data was acquired with a Terraspec ASD field spectrometer, which measures reflectance in a wavelength range from 350 to $2,500 \mathrm{~nm}$.

The reflectance spectra were acquired from rock chips from outcrops, and rocks extracted from elongated trenches, and from pit-shaped trenches that represent a single sampling point (Figure 6.2). All trenches were opened by a backhoe; their general geological features were logged, and samples were extracted for geochemical analysis. Reflectance spectra were obtained from either the same samples or directly from the material extracted by the backhoe from the lower part of the trench. These samples represent the surface and near surface environments, in which rocks are affected by weathering. The mineralogy resulting of hydrothermal alteration processes is expected to be slightly modified by weathering. However, one of the advantages of studying the surface and near surface materials is based on their potential for remote detections. 

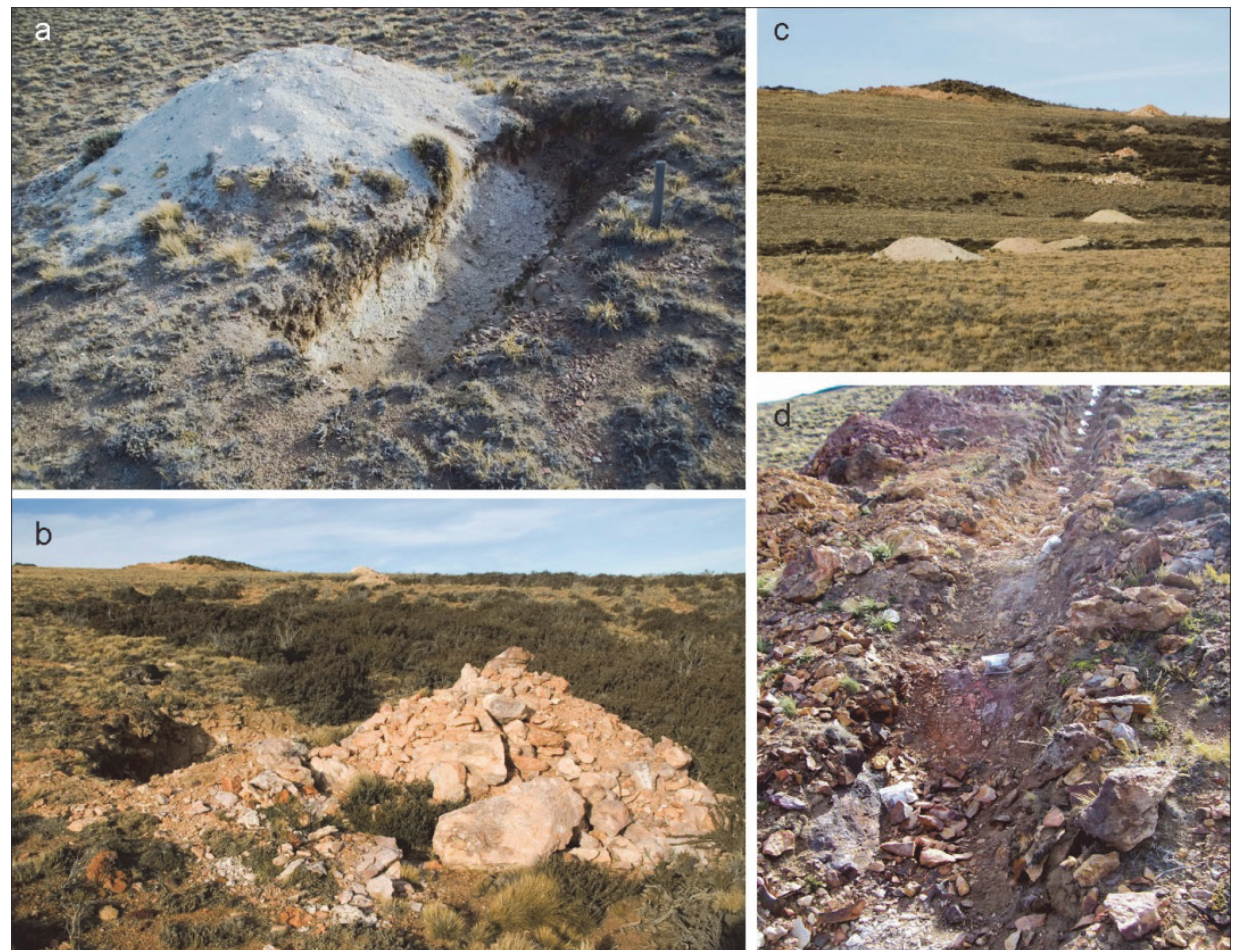

Figure 6.2: Example of trenches in the Sinter area, from which samples were collected. a) and b) pit-shaped trenches representing a sampling point; c) E-W line of pit-shaped trenches; d) regular elongated trench in the Veta Norte area.

The mineralogical interpretation of the reflectance spectra was derived from the comparison of the experimental spectral curves with library spectra. This comparison was done mainly by using "The Spectral Geologist" software (TSG), but with the aids of Specmin Pro version 3.1 and SIMIS Feature Search version.1.6. For this, a spectral library from Spectral International Inc., and the library included in the TSG software, were used. To ensure that all likely minerals were identified, the interpretation was done visually by comparison with the library spectra of laboratory measurements.

The mineral identification included up to four possible minerals, which were organized in their likely order of abundance. The relative abundance of each mineral was determined subjectively, according the depth of the characteristic absorption features of each identified mineral. Most minerals were identified by their absorptions in the SWIR, but a few, mainly chlorite, were also identified by absorptions in the VNIR range, produced by $\mathrm{Fe}^{2+}$. The TSG software was used to apply the normalized hull quotient correction to the raw data, and to calculate the spectral parameters. 
For the assessment of wavelength and crystallinity variations of the white micas and smectites, only samples with predominant white micas or smectites were used (553 samples). Samples with kaolinte, dickite or considerable amounts of minerals that can modify the depth or wavelength of the $\mathrm{AlOH}$ or water absorption features, were avoided, because they would invalidate the calculated values.

Using the parameters shown in Figure 6.3 and the formulas presented by Pontual et al. (1997, volumes 2 and 8), the white micas crystallinity (Wx) and kaolinite crystallinity index $(\mathrm{Kx})$ were calculated as follows:

$\mathrm{Wx}=$ depth of $2200 \mathrm{~nm}$ feature / depth of $1900 \mathrm{~nm}$ feature

$K x=(r 2184 / r 2190)-((r 2160 / r 2177)-(r 2184 / r 2190))$

where, $r=$ reflectance at each specified wavelength (in nanometres); all values were calculated from normalized hull quotient corrected reflectance.

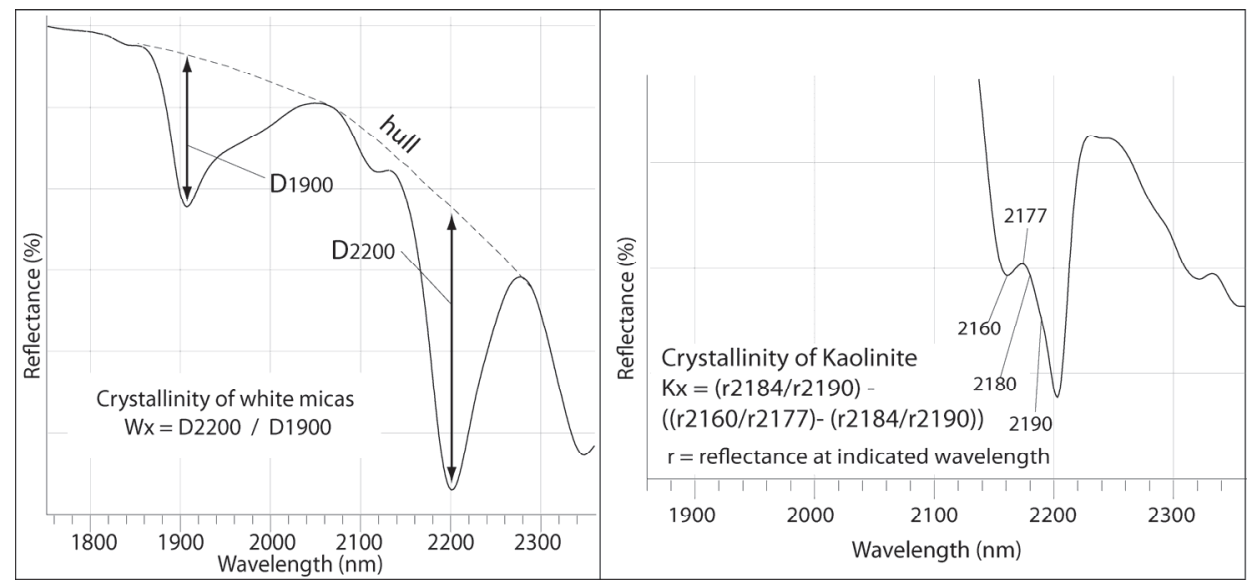

Figure 6.3: Calculation of white micas crystallinity and kaolinite crystallinity. Formulas from Pontual et al. (1997, volumes 2 and 8 )

With decreasing crystallinity, the typical absorption of kaolinite between 2160 and $2180 \mathrm{~nm}$, becomes weaker and tends to shift towards longer wavelengths. The $\mathrm{Kx}$ index is a quantification of that, and its values increases with increasing kaolinite crystallinity (Pontual et al., 1997, volume 8).

In addition, 18 control rock samples were obtained from pit-shaped trenches from the Sinter, Subsinter and Lejano areas. Reflectance spectra were measured from each of these samples at 10 different spots. The same samples were analysed by XRD to validate the minerals determined by spectroscopy, and to help improving the spectroscopic interpretations. The 
samples were analysed with a Bruker D2 XRD equipment. The chemical composition of these samples was measured with a portable XRF Niton XL3t Goldd, with He flush in a lab-mate setup, which gives reasonable results for light rock-forming elements heavier than $\mathrm{Na}$. This was carried out in the Geosciences Laboratory of the Faculty of Geo-Information Science and Earth Observation (ITC) of the University of Twente.

\subsection{Results}

\subsubsection{Spectroscopic determinations in comparison with XRD analyses}

The results of the spectroscopic and XRD analysis of the 18 control rock samples were compared (Table 6-2). In general, there is good correspondence between both analyses; however, there are several minerals that are detected with XRD but cannot be easily detected by spectroscopy, while the opposite is also occurring.

According to the XRD analyses, quartz is present in all 18 samples, and mostly as the predominant mineral. This is consistent with observations from spectroscopy in many samples, in which silica was interpreted as one of the detected minerals, and agrees with the known abundance of silica in the rocks. The precursor rocks contain high proportions of silica in quartz crystals, because they are predominantly of rhyolitic or rhyodacitic compositions; in addition, they were altered by silica-rich fluids, which deposited quartz, chalcedony and opal.

Smectites are either scarce or not easily detected with XRD. Silica is often abundant and may enhance the water absorption around $1900 \mathrm{~nm}$, inducing erroneous identification of smectites. In other cases, spectroscopy indicates smectites clearly, although mainly in samples that were not analysed by XRD, e.g., in Figure 6.4, in which features from montmorillonite are at $963 \mathrm{~nm}$, $1159 \mathrm{~nm}$ and $1912 \mathrm{~nm}$ (relatively sharp). This partially depends on the part of the sample that has been analyzed. 
Table 6-2. Comparison between determinations made by spectroscopy and those made with XRD. Minerals are listed in order of importance.

\begin{tabular}{|c|c|c|}
\hline Sample ID & Minerals interpreted by spectroscopy & $\begin{array}{l}\text { Minerals interpreted } \\
\text { by XRD }\end{array}$ \\
\hline Sample 6 & $\begin{array}{l}\text { Illite (muscovitic-paragonitic), smectite } \\
\text { (montmorillonite?), silica and scarce } \\
\text { hematite, (minor kaolinite?). }\end{array}$ & $\begin{array}{l}\text { Quartz, muscovite, } \\
\text { palygorskite }\end{array}$ \\
\hline Sample 7 & $\begin{array}{l}\text { Illite (tending to paragonitic), silica, } \mathrm{Fe}^{3+} \\
\text { bearing mineral (probably goethite), } \\
\text { smectite. }\end{array}$ & $\begin{array}{l}\text { Quartz, illite, } \\
\text { muscovite }\end{array}$ \\
\hline Sample 11 & $\begin{array}{l}\text { Smectite, illite (probably phengitic), and } \\
\text { minor chlorite. }\end{array}$ & $\begin{array}{l}\text { Quartz, Phengite, } \\
\text { Chlorite }\end{array}$ \\
\hline Sample 12 & dickite and silica & Quartz, dickite, calcite \\
\hline Sample 13 & $\begin{array}{l}\text { Smectite, probably traces of dickite, and } \\
\text { unidentified minerals. }\end{array}$ & $\begin{array}{l}\text { Quartz, sanidite, } \\
\text { oligoclase, phengite, } \\
\text { chlorite }\end{array}$ \\
\hline Sample 14 & $\begin{array}{l}\text { Dickite, silica, gypsum and probably } \\
\text { halloysite. }\end{array}$ & $\begin{array}{l}\text { Quartz, dickite, calcite, } \\
\text { chlorite, gypsum }\end{array}$ \\
\hline Sample 18 & $\begin{array}{l}\text { Illite (tending to paragonitic), hematite } \\
\text { and likely smectite }\end{array}$ & $\begin{array}{l}\text { Quartz, muscovite, } \\
\text { Astrophyllite/kuleskite }\end{array}$ \\
\hline Sample 19 & $\begin{array}{l}\text { Illite, minor smectite, and } \mathrm{Fe}^{3+} \text { bearing } \\
\text { mineral (probably hematite). }\end{array}$ & $\begin{array}{l}\text { Quartz, albite, } \\
\text { muscovite, illite, } \\
\text { gothite? }\end{array}$ \\
\hline Sample 21 & $\begin{array}{l}\text { Illite (tending to paragonitic), and minor } \\
\text { smectite (montmorillonite?). }\end{array}$ & Quartz, illite \\
\hline Sample 25 & Kaolinite and some $\mathrm{Fe}^{3+}$ bearing mineral. & $\begin{array}{l}\text { Quartz, kaolinite, } \\
\text { calcite }\end{array}$ \\
\hline Sample 27 & $\begin{array}{l}\text { predominant kaolinite, minor alunite and } \\
\text { jarosite }\end{array}$ & $\begin{array}{l}\text { Quartz, kaolinite, } \\
\text { albite?, anortoclase, } \\
\text { alunite, calcite }\end{array}$ \\
\hline Sample 28 & $\begin{array}{l}\text { Illite (muscovitic), some smectite, minor } \\
\mathrm{Fe}^{3+} \text { bearing mineral (likely hematite), } \\
\text { probably silica. }\end{array}$ & Quartz, muscovite \\
\hline Sample 29 & $\begin{array}{l}\text { Illite-smectite, probably minor nontronite } \\
\text { and silica. }\end{array}$ & Quartz, albite, illite \\
\hline Sample 32 & $\begin{array}{l}\text { Illite, chlorite, probably smectite and some } \\
\text { silica. }\end{array}$ & $\begin{array}{l}\text { Quartz, illite, phengite, } \\
\text { montmorillonite, } \\
\text { chlorite? }\end{array}$ \\
\hline $\mathrm{T}-217(15)$ & $\begin{array}{l}\text { Kaolinite, } \mathrm{Fe}^{3+} \text { bearing mineral (probably } \\
\text { Goethite) and silica. }\end{array}$ & $\begin{array}{l}\text { Quartz, sanidine, } \\
\text { kaolinite, muscovite, } \\
\text { hallite? }\end{array}$ \\
\hline $\mathrm{T}-215(25)$ & $\begin{array}{l}\text { Illite (composition probably from } \\
\text { muscovitic to phengitic), } \mathrm{Fe}^{3+} \text { bearing } \\
\text { mineral (probably hematite) and silica. }\end{array}$ & $\begin{array}{l}\text { Quartz, } \\
\text { illite/muscovite, } \\
\text { sanidine/microcline }\end{array}$ \\
\hline $\mathrm{T}-219(19.5)$ & $\begin{array}{l}\text { Illite (muscovitic) and } \mathrm{Fe}^{3+} \text { bearing mineral } \\
\text { (probably goethite) }\end{array}$ & $\begin{array}{l}\text { Quartz, } \\
\text { illite/muscovite, barite }\end{array}$ \\
\hline T108(13) & $\begin{array}{l}\text { Kaolinite, } \mathrm{Fe}^{3+} \text { bearing minerals (probably } \\
\text { goethite). }\end{array}$ & $\begin{array}{l}\text { Quartz, kaolinite, } \\
\text { goethite, chlorite }\end{array}$ \\
\hline
\end{tabular}




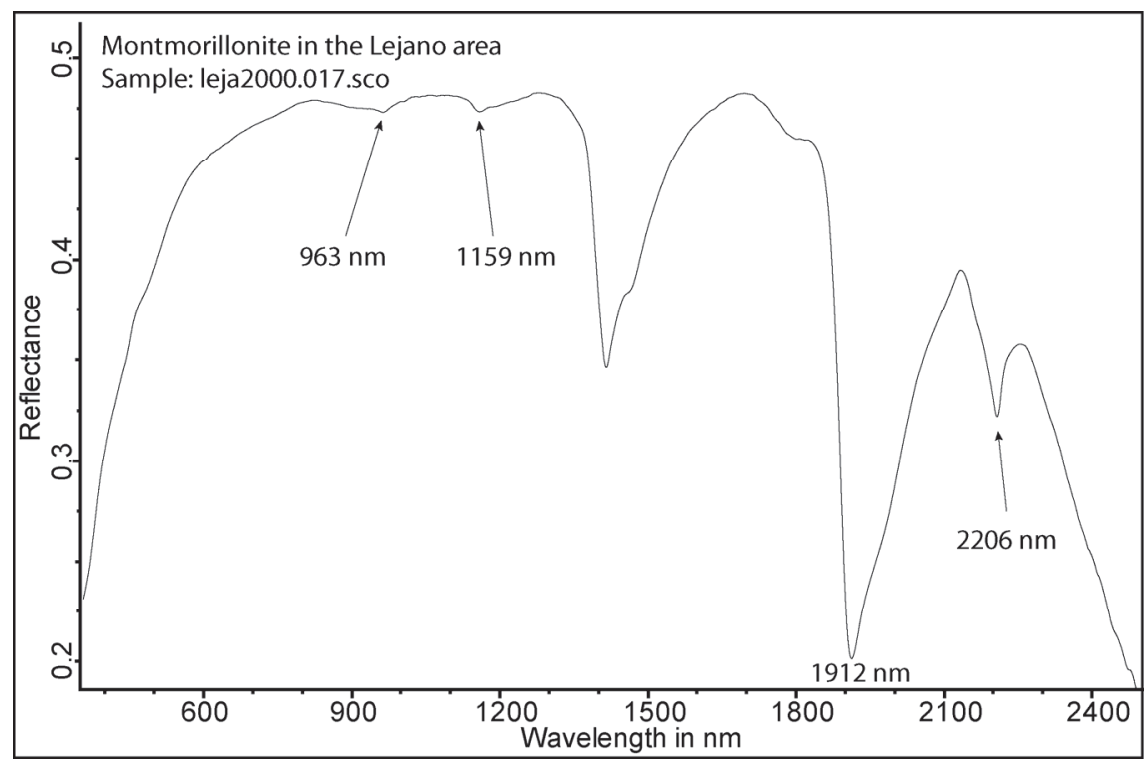

Figure 6.4: Reflectance spectrum of a sample from the east of Lejano area, interpreted as predominant smectite.

In some samples, the $\mathrm{AlOH}$ absorption feature of white micas is positioned between those wavelengths typical of muscovite, and those of paragonite (at shorter wavelengths). In four control samples (Samples 6, 7, 18 and 21), this feature is between 2192 and $2198 \mathrm{~nm}$, indicating possible compositions between muscovite and paragonite. However, the XRD analysis did not confirm paragonite in these samples; instead, muscovite or illite was identified. In other samples, the XRD indicated the presence of phengite, and the spectroscopy shows that the AlOH absorption feature is located at wavelengths from 2208 to $2213 \mathrm{~nm}$, which are higher than those of muscovite, and tending to phengite. The latter observation is in agreement with the XRD data. An example of this is from the reflectance spectra of sample 11 (Figure 6.5), in which the $\mathrm{AlOH}$ absorption feature is positioned at $2211 \mathrm{~nm}$.

In addition, the spectra from sample 11 shows features of chlorite. One of them is a diagnostic absorption near $2250 \mathrm{~nm}$, and was in most cases observed as a subtle inflection. Other features, which are wide and shallow, can be observed in the VNIR range of the spectrum at $~ 700-740 \mathrm{~nm}, \sim 900-$ $940 \mathrm{~nm}$, and $\sim 1090-1130 \mathrm{~nm}$. The presence of chlorite was confirmed by XRD analysis.

The XRD analysis confirmed also calcite in two samples from the Sinter area and two from the Lejano area. In the Sinter area the calcite is associated with kaolinite, in the Lejano area it is associated with dickite. The two 
samples with calcite and kaolinite were sampled in the northern part of the Sinter area from a rock with soft silicification and located at $80 \mathrm{~m}$ from a sample in which calcite was detected by spectroscopy as a subordinated mineral. In the Lejano area calcite was observed in outcrops of calcareous stromatolites and also associated with vuggy silicified rocks (Moreira, 2005).

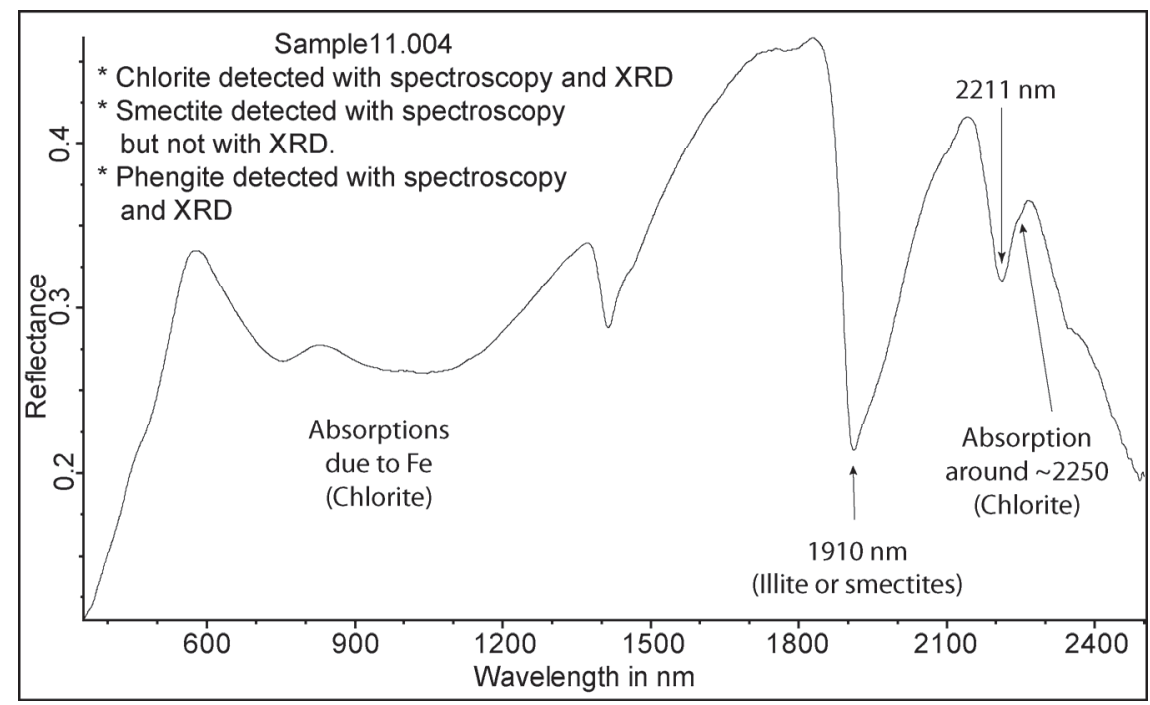

Figure 6.5: Reflectance spectrum of sample 11.004, containing chlorite, phengite and probably smectite.

\subsubsection{Alteration mineralogy}

White micas, kaolinite and smectites are the most abundant minerals in the La Josefina deposit, as revealed by reflectance spectroscopy. The three minerals are widespread, although the reflectance spectra show that their relative proportions vary significantly within the La Josefina system. In most areas, white micas are the predominant minerals (Figure 6.6). The measurements of the wavelengths position of their $\mathrm{AlOH}$ absorption feature, suggest that the composition of the white micas vary between phengitic and paragonitic end members.

Smectites are also widespread, although they are less abundant than white micas (Figure 6.7). Their determination relied partially on the depth of the water absorption feature at around $1900 \mathrm{~nm}$; however, the depth of that feature may also increase because of the presence of silica in the samples. 


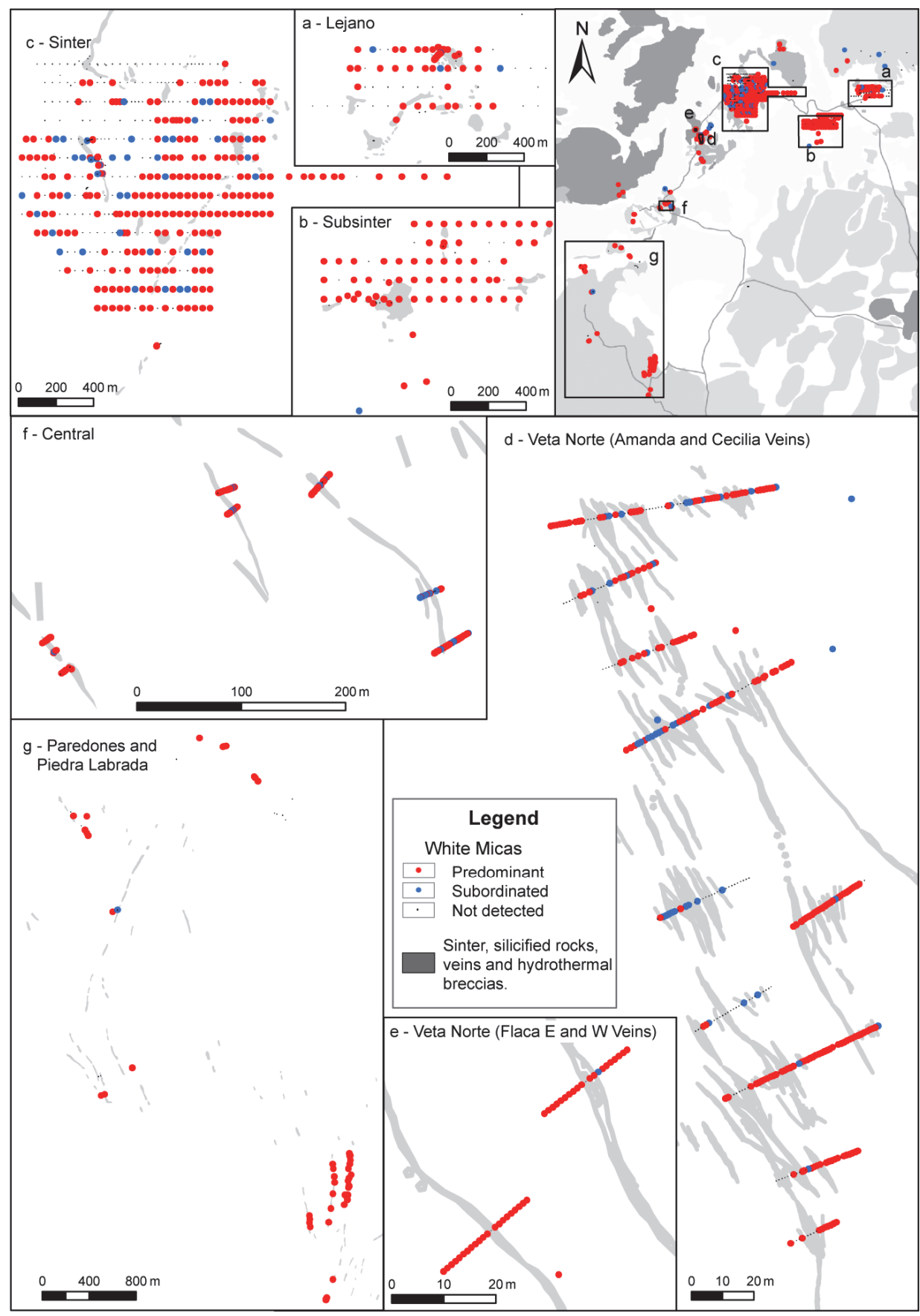

Figure 6.6: Spatial distribution and degree of predominance of white micas in the la Josefina deposit. 


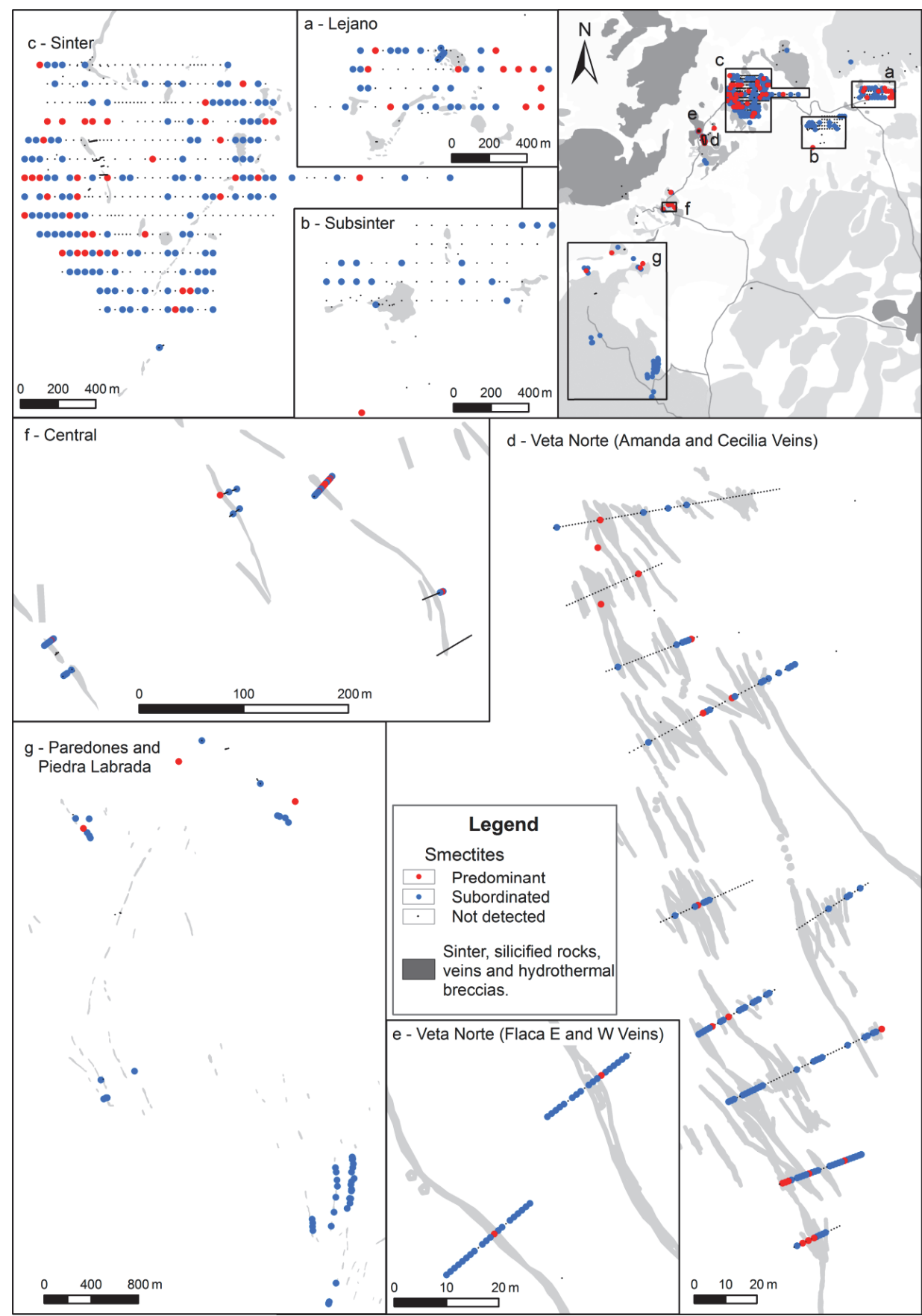

Figure 6.7: Spatial distribution and degree of predominance of smectites in the la Josefina deposit.

Silica is abundant in the area, because of the lithological composition of the precursor rocks and the subsequent silicification by hydrothermal alteration 
processes, and by precipitation of silica in breccias and silica-rich layers. Silica, in general, was recognized by spectroscopy in several samples. Its detection was based on a relatively deep and wide absorption feature around $\sim 1923 \mathrm{~nm}$. Strongly silicified rocks, which were easily recognized in the field, were analysed and their reflectance spectra served as reference for silica-rich rocks in the La Josefina area. These spectra show wide absorption features centred at around $\sim 1923$ and $\sim 1433 \mathrm{~nm}$. Figure 6.8 shows a sample from pervasively silicified rocks from the Subsinter area. Two other samples from strongly silicified rocks, outside the areas of mineralization, show similar spectra. The presence of silica was recognized in the samples to avoid confusion with smectites.

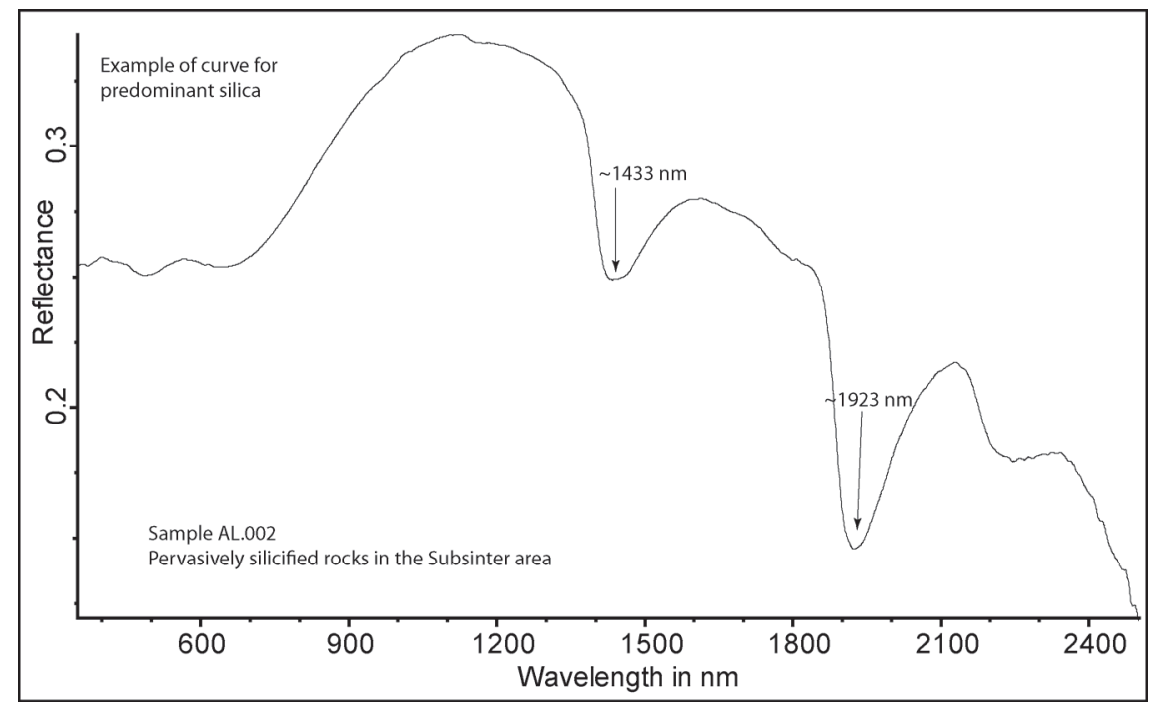

Figure 6.8: Reflectance spectrum of pervasively silicified rock collected from the Subsinter area (sample AL.002)

Kaolinite is present in all areas, and is the dominant mineral in the Sinter and Veta Norte areas (Figure 6.9). Kaolinite has not been detected in samples from the Piedra Labrada area, and is scarce in the Flaca East and West veins, located at the northern limit of Veta Norte area (Figure 6.9).

Kaolinite was also detected as predominant mineral in samples that were collected far from the main feeder conduits, to the north of the Lejano area in the Jorge Paz hill. Those samples were collected from areas where visually, the rocks do not show indications of alteration, representing areas with limited or no hydrothermal alteration. The spectral curves from these samples show relatively low reflectance values and a high degree of noise. Occasionally, they contain minor illite and smectite. Kaolinite in these samples could have been formed by weathering. 
Chlorite is scarce and present as a subordinated mineral. It occurs mainly in the eastern part of the Sinter area, but also in the Piedra Labrada, Lejano and Subsinter areas (Figure 6.10), and in the Ailin vein of the Central area (Figure 6.10). It is especially scarce in the Lejano and Subsinter areas (Figure 6.10). Detection of chlorite was based on four subtle absorption features (Figure 6.11); one at around $2250 \mathrm{~nm}$, and three in the visible and near infrared range ( $\sim 700-740 \mathrm{~nm}, \sim 900-940 \mathrm{~nm}$, and $\sim 1090-1130 \mathrm{~nm})$. 


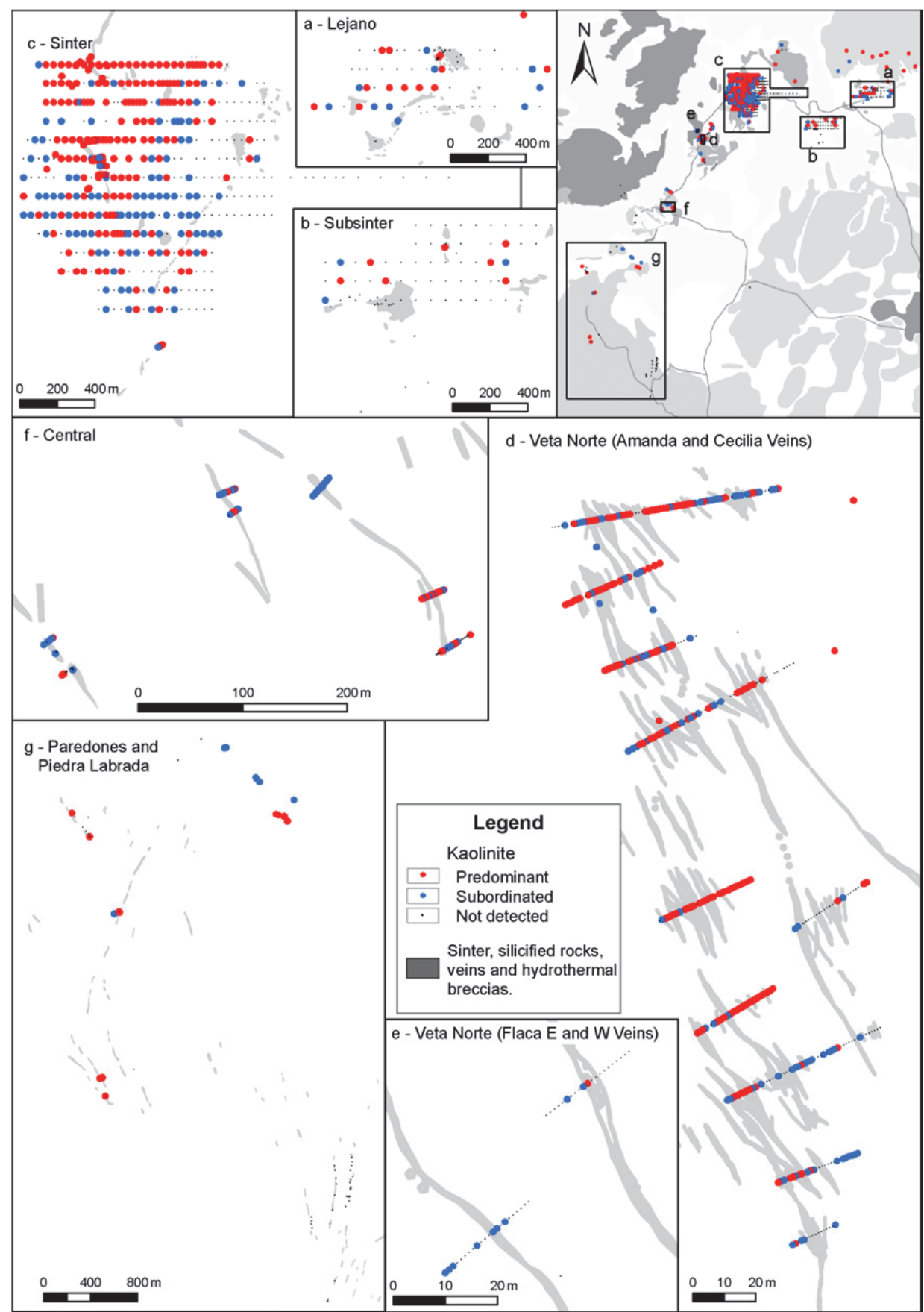

Figure 6.9: Spatial distribution and degree of predominance of kaolinite in the la Josefina deposit. 


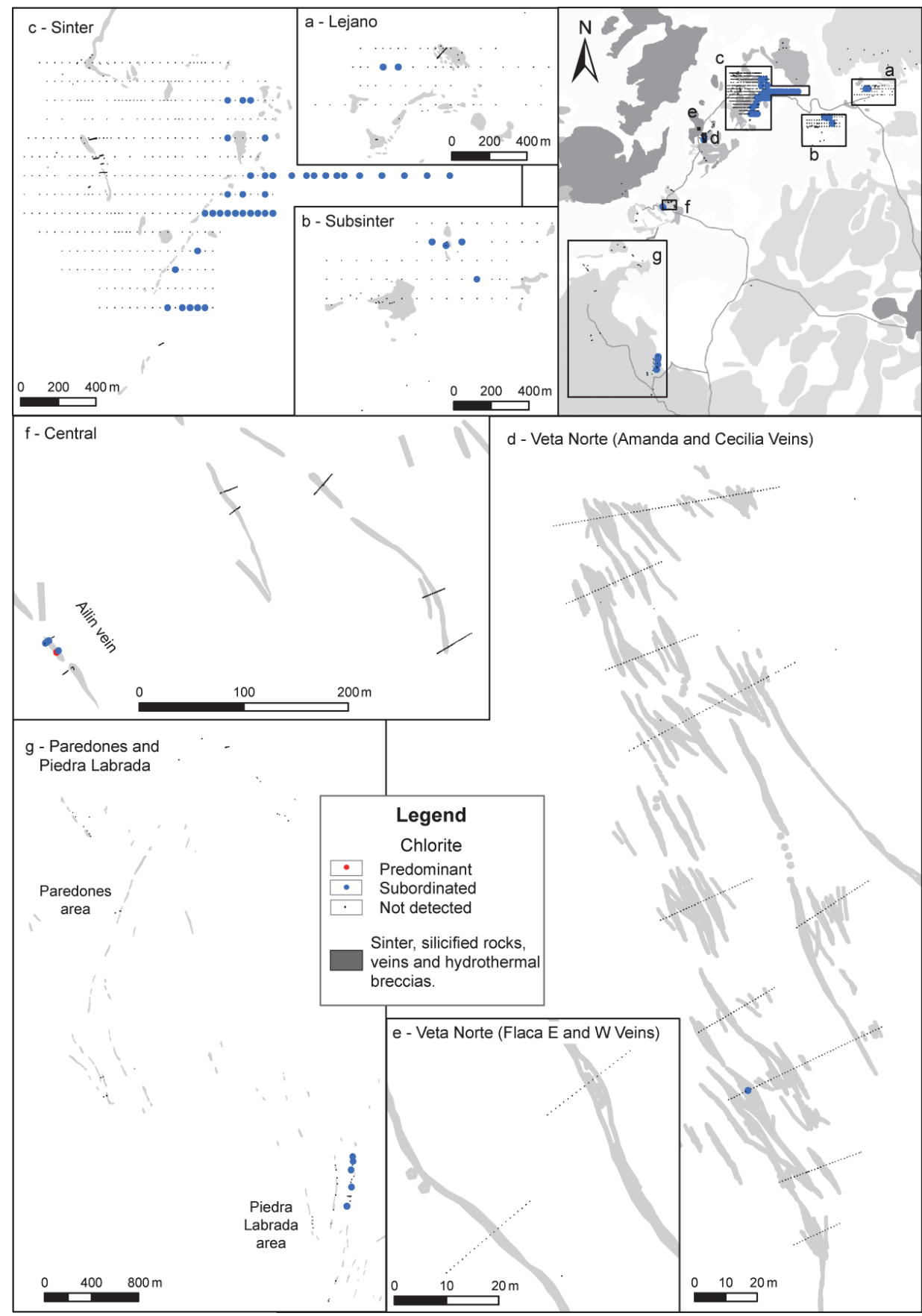

Figure 6.10: Spatial distribution and degree of predominance of chlorite in the la Josefina deposit. 


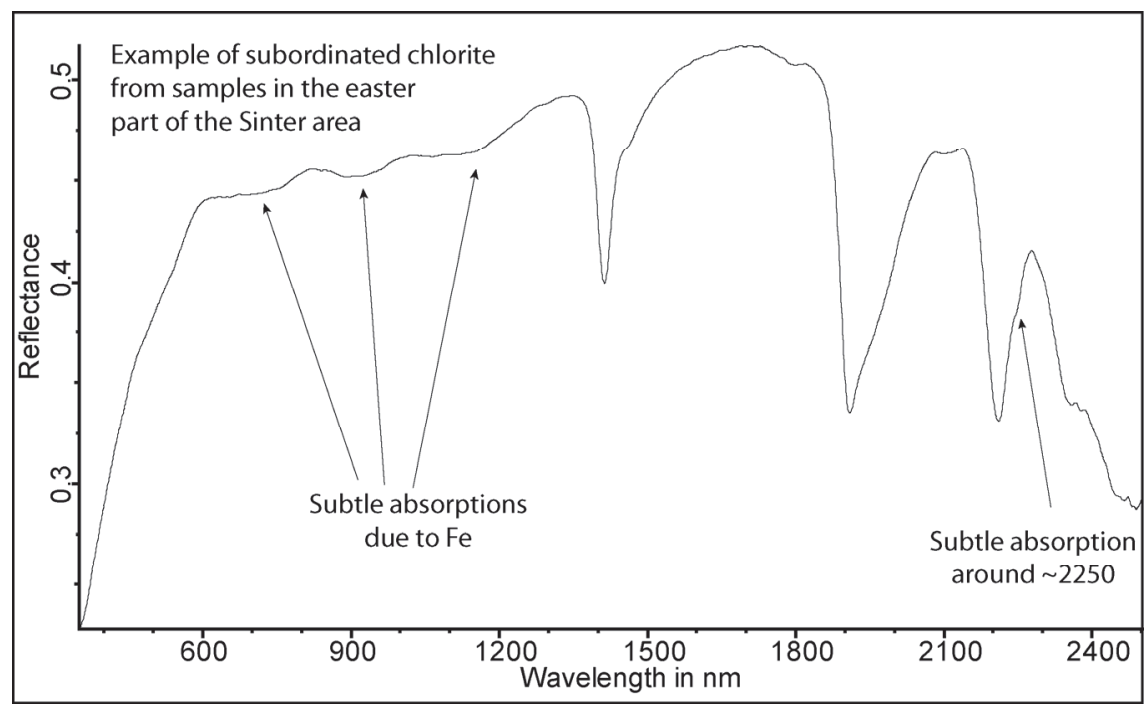

Figure 6.11: Reflectance spectrum of rock that contains minor chlorite from the eastern part of the Sinter area.

Most samples with chlorite from the Sinter area are located to the east of a series of outcrops of a siliceous layer, which follow a NE direction (Figure $6.10 \mathrm{c})$. The samples were collected from pit-shaped trenches that, according to field descriptions, contain disseminated pyrite. In addition, pyrite was also found in association with chlorite at about $900 \mathrm{~m}$ to the east of the outcrops of the siliceous layer in the easternmost part of the Sinter area (Figure 6.10). This association of chlorite with pyrite represents the result of propylitic alteration.

At the surface, the abundance of chlorite is limited. However, at depth in diamond boreholes in the Veta Norte and Central areas chlorite is relatively abundant (Andrada de Palomera et al., 2012), and distinguishable visually. The chlorite abundance at depth was confirmed with reflectance spectroscopy in a separate study, as well as scarce epidote in boreholes in the Central Area.

Several other minerals were detected in limited amounts with reflectance spectroscopy. The sulfates alunite and jarosite were observed in the areas with veins; jarosite is present in samples from the Veta Norte and Central areas. Alunite was mainly observed in the Veta Norte area. The spectra indicate that the alunite is a K-rich variety. Gypsum is also present in most of the areas as a subordinated mineral, although a few samples from the Veta Norte and Lejano areas contain more abundant gypsum. Calcite was detected as predominant mineral in three samples from outcrops of calcareous stromatolites in the Lejano area. It is also present as secondary mineral in 
one sample from the siliceous layer in the Sinter area, a few meters away from a sample in which XRD detected calcite. Dickite was detected only in the Lejano and Subsinter areas, associated with illite, smectite and kaolinite. Zeolites were not detected in any sample.

\subsubsection{Variations of the position of the AlOH absorption feature in white micas and smectites}

The histogram of the wavelength position of the AlOH absorption feature of spectra with predominantly white micas and smectites showed a well-defined bimodal distribution (Figure 6.12). About $89 \%$ of the samples have wavelengths longer than $2197 \mathrm{~nm}$. The upper limit ranges up to of $2216 \mathrm{~nm}$, although the majority of the features are below $2212 \mathrm{~nm}$. The remaining $11 \%$ of these samples contain wavelengths that are shorter than $2197 \mathrm{~nm}$, up to a minimum of $2186 \mathrm{~nm}$. Spatially, the short-wavelength samples are confined to the Lejano and Subsinter areas (Figure 6.14). In those areas, the samples that have short wavelengths positions of the $\mathrm{AlOH}$ feature, are spatially associated with strongly silicified rocks. In the Lejano area, these samples are concentrated on the northeast (Figure 6.14a), and are mainly related to the area of vuggy silicification, where dickite is also present. In the Subsinter area, the short wavelengths are related to pervasively silicified rocks. In both areas, the clusters of samples with low wavelengths (of up to $500 \mathrm{~m}$ diameter) lie within areas with distinctly longer wavelength features.

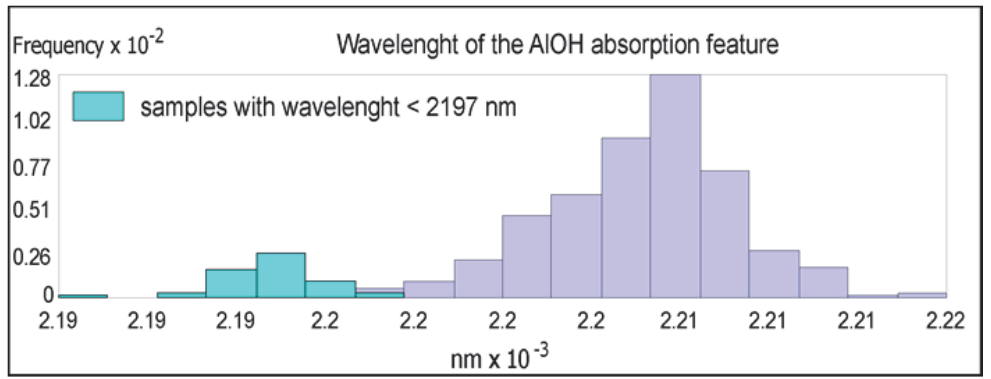

Figure 6.12: Histrogram of wavelengths positions of the $\mathrm{AlOH}$ feature of white micas and smectites.

In addition, the Lejano and Subsinter areas show a wide range of wavelengths that includes samples from both populations shown in the bimodal distribution (Figure 6.12). The other areas, in contrast, show a more limited range of wavelengths and only one population (one mode). Therefore, average wavelengths in each of those areas were described by using the median (Figure 6.13). The samples with longer wavelengths in the Lejano and Subsinter areas are also included in that comparison, because they are part of the same population (wavelengths $>2197 \mathrm{~nm}$ ). 


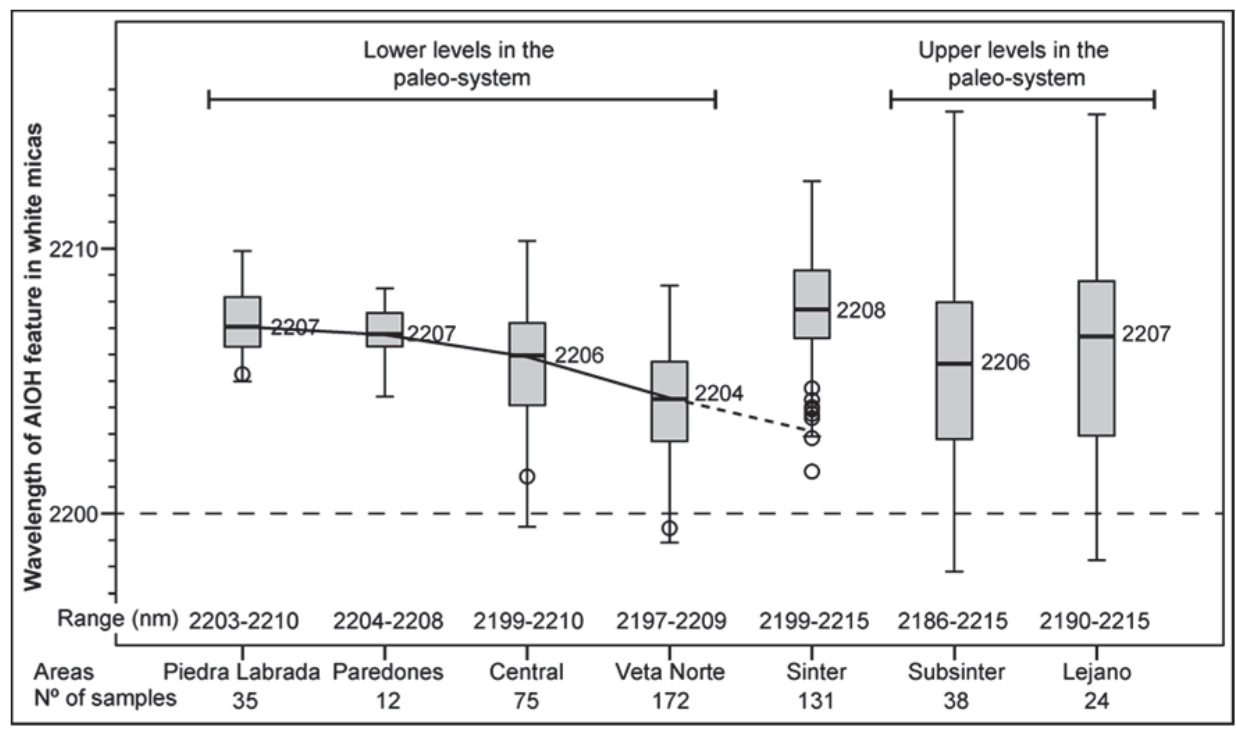

Figure 6.13: Box-and-whisker plots of the variation of wavelength of the $\mathrm{AlOH}$ absorption feature in white micas using only samples showing wavelengths $>2197 \mathrm{~nm}$.

In the Sinter area, there is a clear contrast in wavelength positions between the rocks located to the northwest and those located to the southeast of the outcrops of the siliceous layer that controls the presence of chlorite. The wavelength shifts from shorter than $2209 \mathrm{~nm}$ to longer than $2209 \mathrm{~nm}$ towards the southeast of this line (Figure 6.14c). The Veta Norte, Central, Paredones and Piedra Labrada areas, as well as the western half of the Sinter area, show intermediate median wavelength of the $\mathrm{AlOH}$ feature, mostly around 2204-2207 nm, although there seems to be a tendency of increasing wavelength positions in southerly direction in the latter areas (Figure 6.13). 


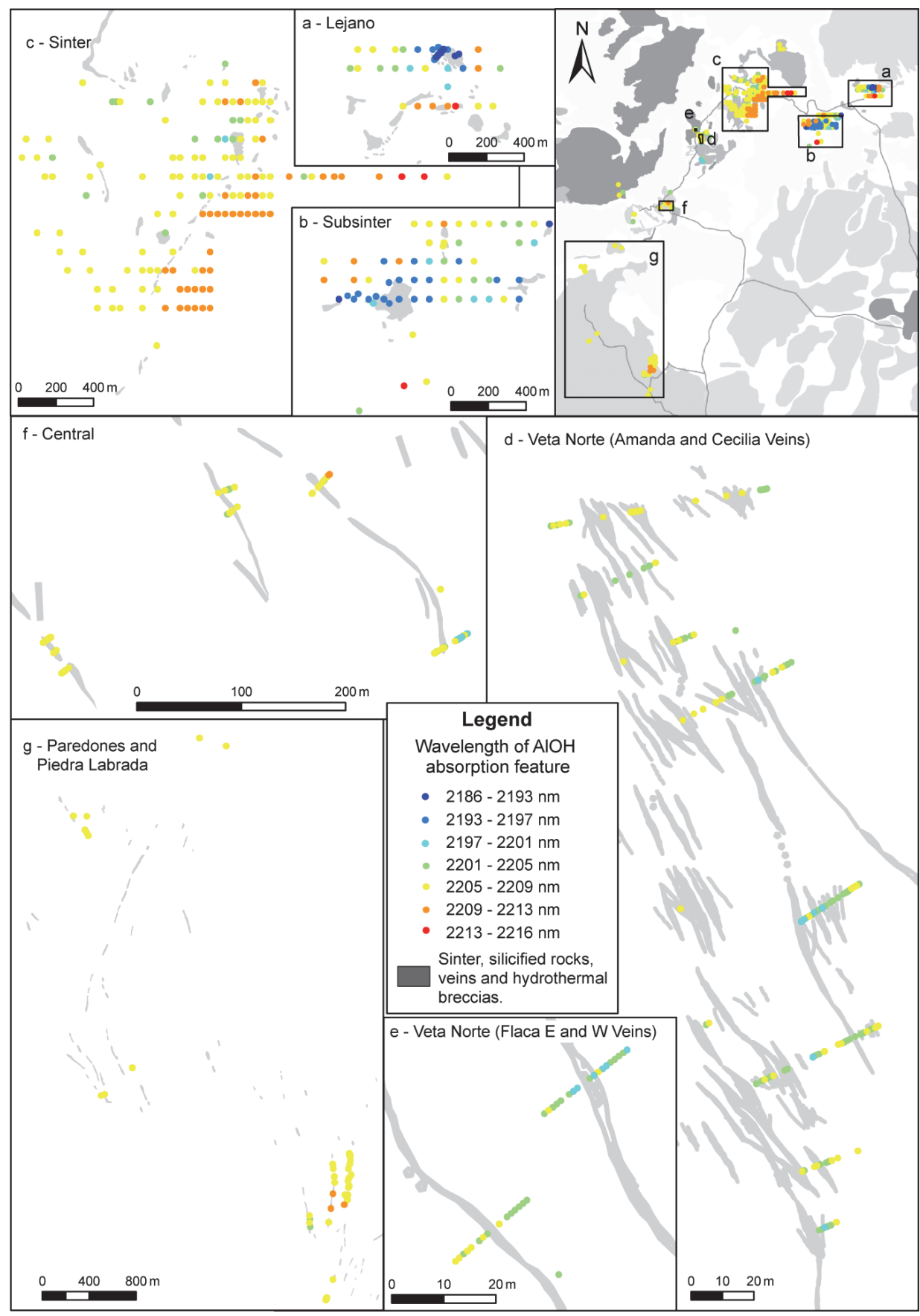

Figure 6.14: Spatial distribution of the wavelength positions of $\mathrm{AlOH}$ absorption feature in white micas and smectites. The Lejano and Subsinter areas show wide ranges of values and include the shortest wavelength positions in La Josefina. Note the sharp contrast in the Sinter area. 


\subsubsection{Variations in white mica crystallinity}

The crystallinity values of the white micas, as calculated from the reflectance spectra, show a normal distribution when the values of all samples from all areas are plotted together. The crystallinity values range from 0.243 to 1.58 . This parameter does not show a clear variation between the different areas.

However, when the areas are studied in detail, systemic variations are observed. The Lejano, Subsinter and Central areas show bimodal distributions (Figure 6.15), while the other areas show unimodal or other distributions. In the Lejano area, the highest crystallinity values are found in rocks with vuggy and pervasive silicification in the northern part (Figure 6.16). These sites coincide with those where white micas show the shortest wavelengths position of the $\mathrm{AlOH}$ absorption feature. The area of high crystallinity and short wavelength positions is surrounded by an area with low crystallinity and longer wavelength positions of the $\mathrm{AlOH}$ feature. In the Sinter area, the crystallinity values are controlled by a northeast trend, parallel to the outcrops of the siliceous layer. Again, this line of siliceous outcrops seems to act as a threshold, separating areas with higher white mica crystallinity to the west, and those with lower crystallinity to the east.

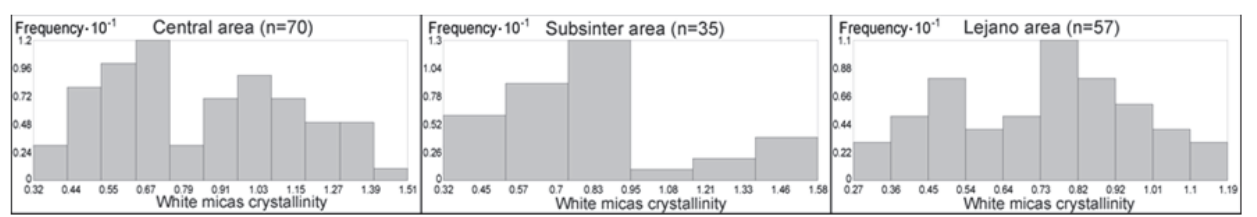

Figure 6.15: White micas crystallinity in three areas that show bimodal distributions. 


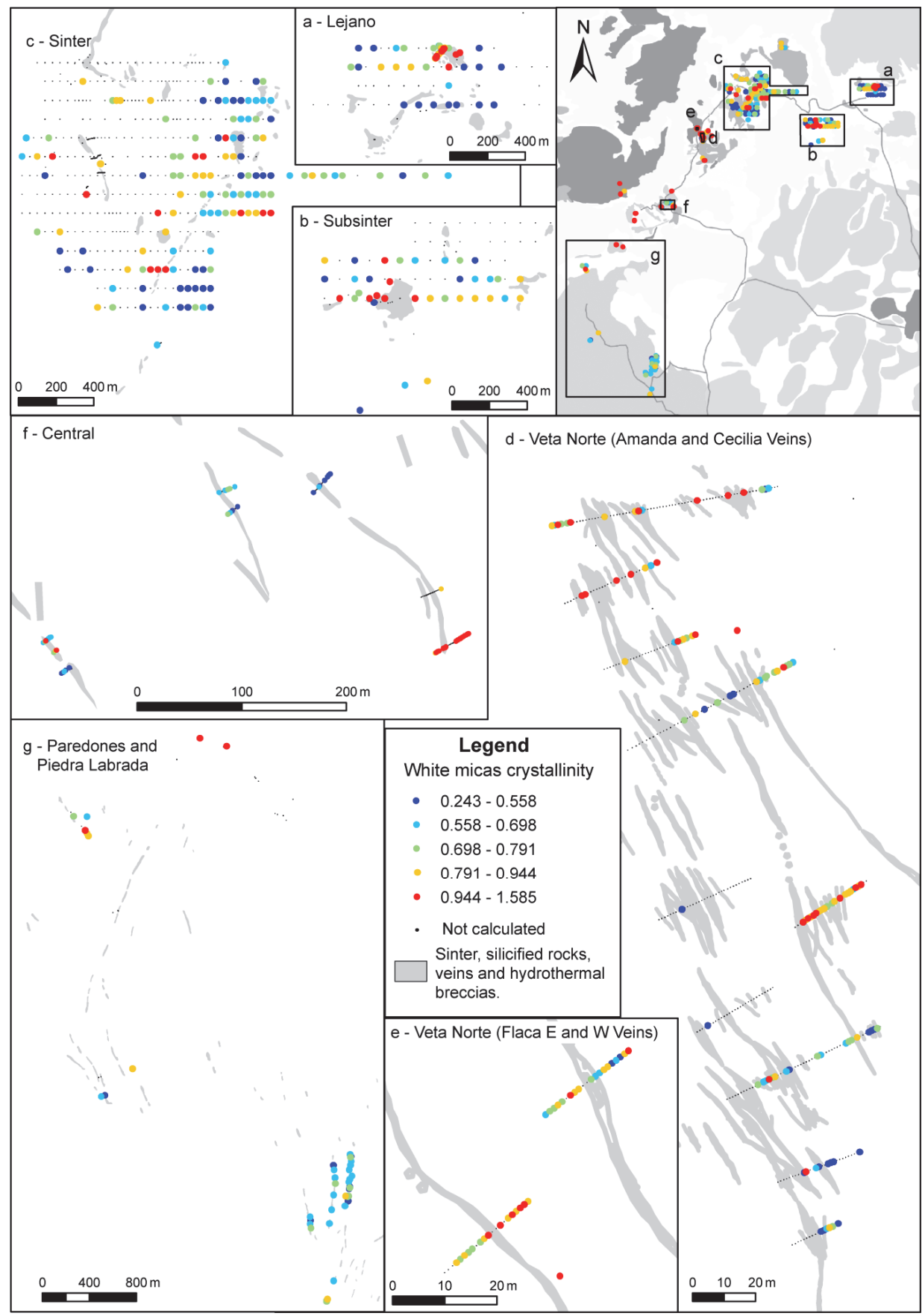

Figure 6.16: Spatial distribution of the crystallinity values of white micas. 


\subsubsection{Variations in kaolinite crystallinity}

Kaolinite crystallinity values range from 0.89 to 1.96 in a distribution that is somewhat bimodal (Figure 6.17). It shows a high variability in each of the areas of the deposit; but there is a noticeable difference between the crystallinity in the areas with veins and that in the Subsinter and Lejano areas (Figure 6.18). In the areas with veins, mainly in Veta Norte and Central, the highest crystallinity values of kaolinite occur in the veins, while the kaolinite around the veins show a lower degree of crystallinity (Figure 6.19). In the Sinter and Lejano areas, the highest crystallinity values are coincident with relatively high gold contents and with paleo-conduits of the epithermal fluids (Figure 6.19). The most obvious mineralized zone is located in the Sinter area and consists of a set of north northwest-trending mineralized rocks (breccias and siliceous layer), either in outcrops or uncovered by trenches that include part of the Mogote Hormigas hill; the higher values of the kaolinite crystallinity parameter are coincident with this and nearby mineralized zones.

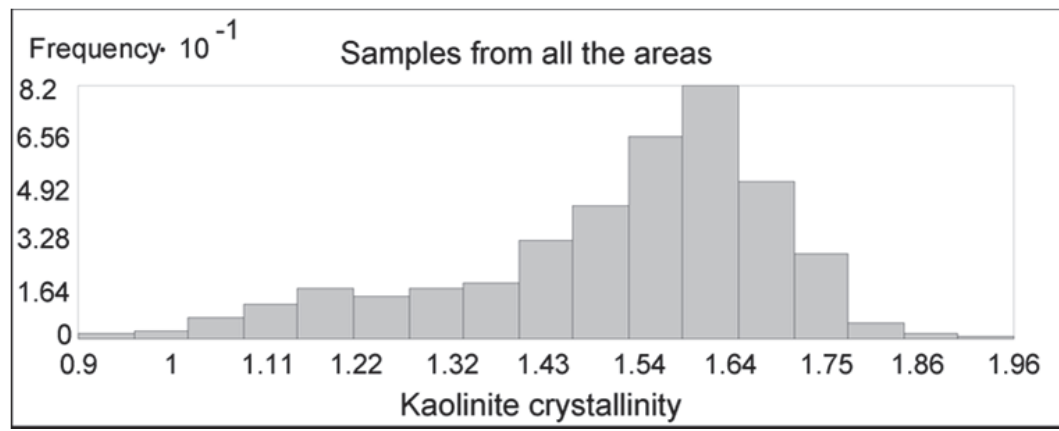

Figure 6.17: Histogram of kaolinite crystallinity values, calculated from all samples with predominant kaolinite (398 samples). 


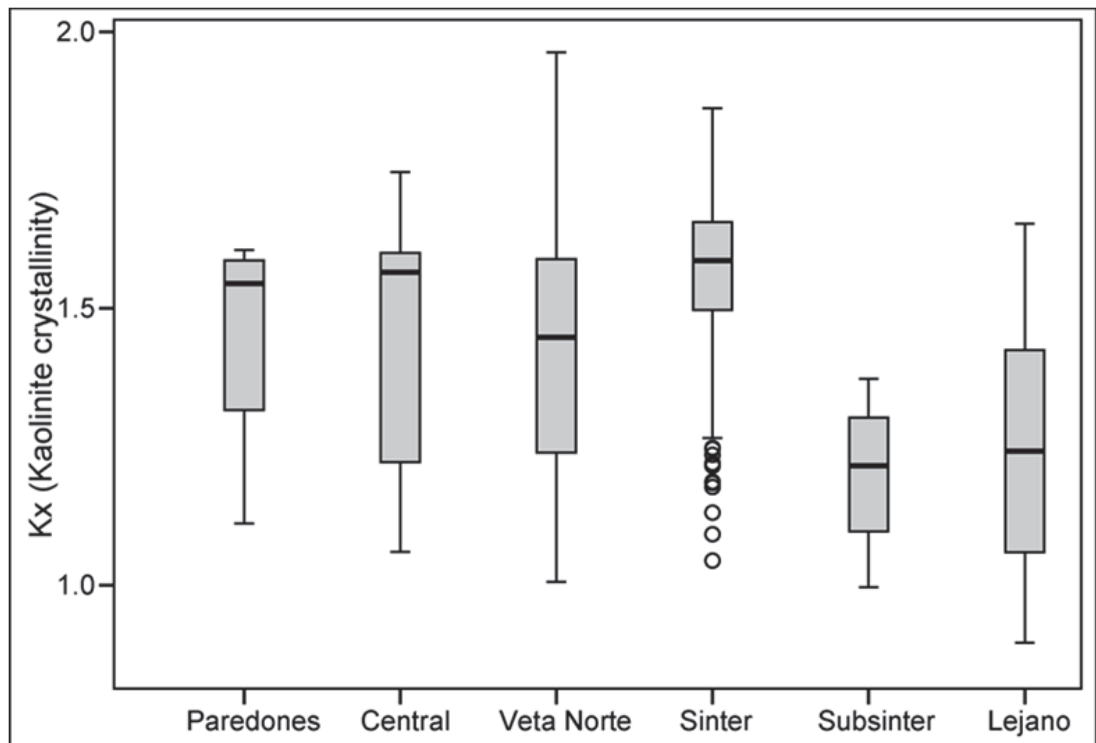

Figure 6.18: Box-and-whisker plots of kaolinite crystallinity values in different areas of the deposit. The Subsinter and Lejano areas show a clear difference with the areas containing veins. Low values in the Sinter area fit with the data from the Subsinter and Lejano areas. 


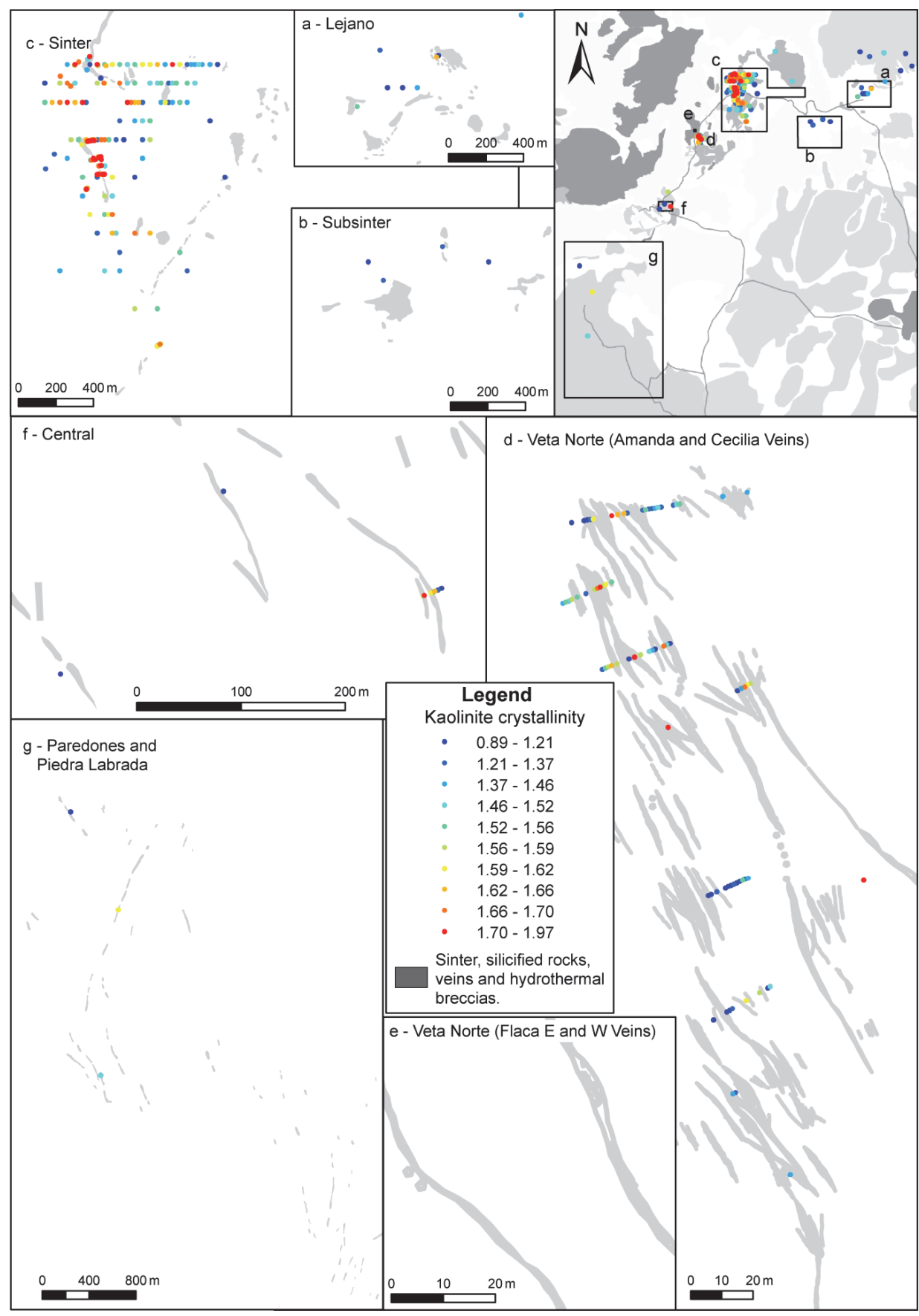

Figure 6.19: Spatial distribution of kaolinite crystallinity values. 
In the Veta Norte and Lejano areas, the distribution of kaolinite crystallinity values is bimodal (Figure 6.20), while in the Sinter area the distribution is unimodal and close to normal.

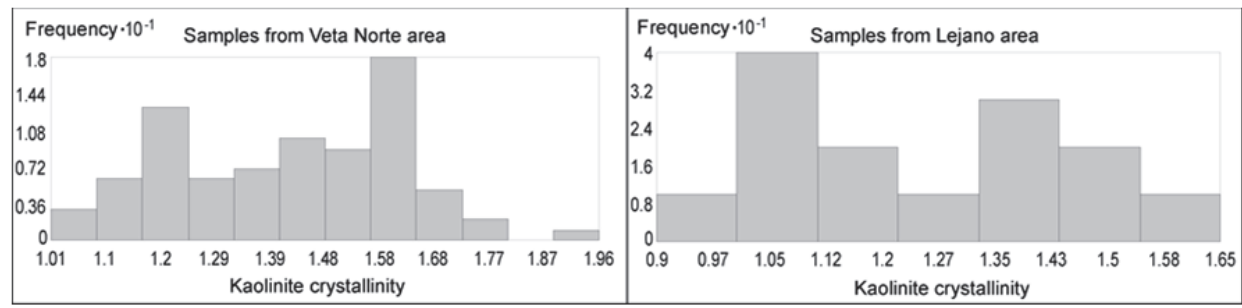

Figure 6.20: Kaolinite crystallinity distributions in Veta Norte and Lejano.

Adjacent to the north of the Lejano area, on the Jorge Paz hill, seven samples collected on rocks at distance from the altered areas, have kaolinite as predominant mineral. The kaolinite in those samples show relatively low crystallinity, with a median value of 1.176 and a range of 1.023-1.482.

\subsubsection{Spatial distribution of selected chemical elements}

The concentrations of five elements, i.e. $\mathrm{Au}, \mathrm{Ag}, \mathrm{Cu}, \mathrm{Pb}$, and $\mathrm{As}$, were plotted as point symbol maps, to facilitate the interpretation of the alteration mineralogy and the epithermal paleo-system.

Gold is anomalous in most areas (Figure 6.22); however, it is specially high in the Amanda and Cecilia veins of the Veta Norte area, in the Ailin and Maria Belen veins in the Central area, and in the western portion of the Sinter area, in a $\sim 500 \mathrm{~m}$ long north northwest-trending zone that includes the Mogote Hormigas hill. A few samples with high Au contents are also present in the Piedra Labrada and Lejano areas. In the Lejano area, Au is anomalous in the northern part, associated to strongly silicified rocks (pervasive and vuggy silicification).

The silver content of rocks in the La Josefina deposit is generally low. The highest values occur in the southern part of the Veta Norte area (Figure 6.23); anomalously high values also occur in the Central and the northern part of Veta Norte area. A few samples with anomalously high silver are located in the Sinter, Lejano and Piedra Labrada areas.

Copper concentrations are low in the Lejano and Subsinter areas, and in the eastern part of the Sinter area (Figure 6.24). The average $\mathrm{Cu}$ contents of samples in the Lejano area, of approximately $9.5 \mathrm{ppm}$, are the lowest in the deposit. The concentrations increase to around $16 \mathrm{ppm}$ in the Subsinter area, and $\sim 34 \mathrm{ppm}$ in the Sinter area. The average concentrations exceed the 200 ppm in the Veta Norte area. Toward the southwest, they decrease to about 
$100 \mathrm{ppm}$ in the Central area, and about $85 \mathrm{ppm}$ in the Paredones area. Finally, in the Piedra Labrada area, the average is approximately $187 \mathrm{ppm}$. These results show a systematic increase in Cu contents from the ENE border of the paleo-system, represented by the Lejano area towards the WSW, reaching the highest values in the Veta Norte area and then decreasing again to the southwest.

Lead shows a bi-modal distribution after log-transforming the concentrations (Figure 6.21). This bimodality is maintained even when using only the assays from only one ICP analysis; therefore we believe that the presence of different assay types do not produce the bimodality and therefore, all types of assays can be used together at least as an indicative of relative concentrations of this element. The mode with lower values in the histogram is from samples of areas located in the northeast of the La Josefina system, including the Lejano and Subsinter areas, and the eastern part of the Sinter area (Figure 6.25).

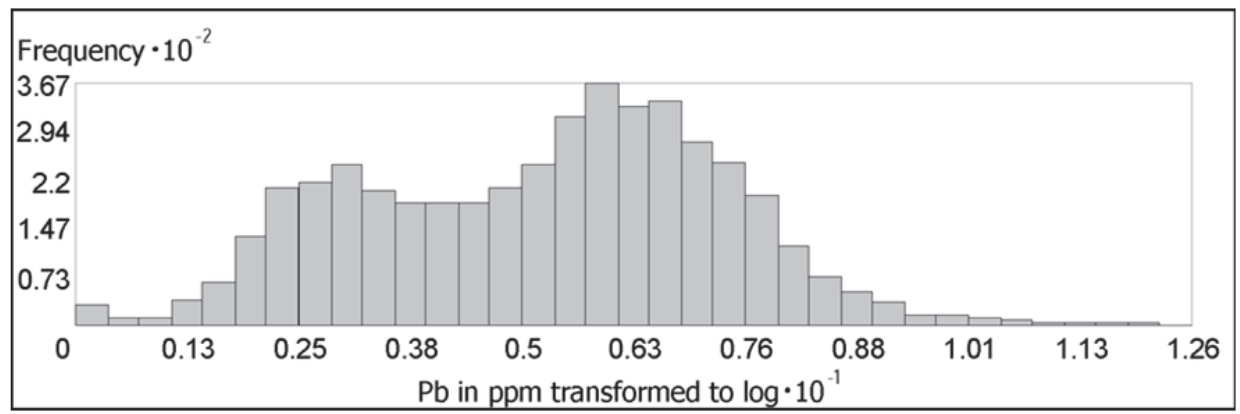

Figure 6.21: Bimodal distribution of log-transformed $\mathrm{Pb}$ concentrations.

Arsenic, which was expected to be abundant in rocks of the upper parts of the paleo-system, is especially high in the veins of Veta Norte, and Central areas (Figure 6.26). In the Sinter area, it forms NNW trending anomalies that surround the areas with most of the $\mathrm{Au}$ mineralization and showing the strongest indications of hydrothermal activity, including hydrothermal breccias. High contents of As in the Sinter area are also present along a northeast direction, sub-parallel to one of the lines with outcrops of the siliceous layer (Figure 6.26c). Samples collected outside the main belt of hydrothermal alteration in the La Josefina deposit, have low As contents. This shows that As is a good indicator of epithermal mineralization and hydrothermal activity, in the area. The Lejano area also contains high concentrations of As, mainly in the northern half, where it is related to elevated Au contents. 


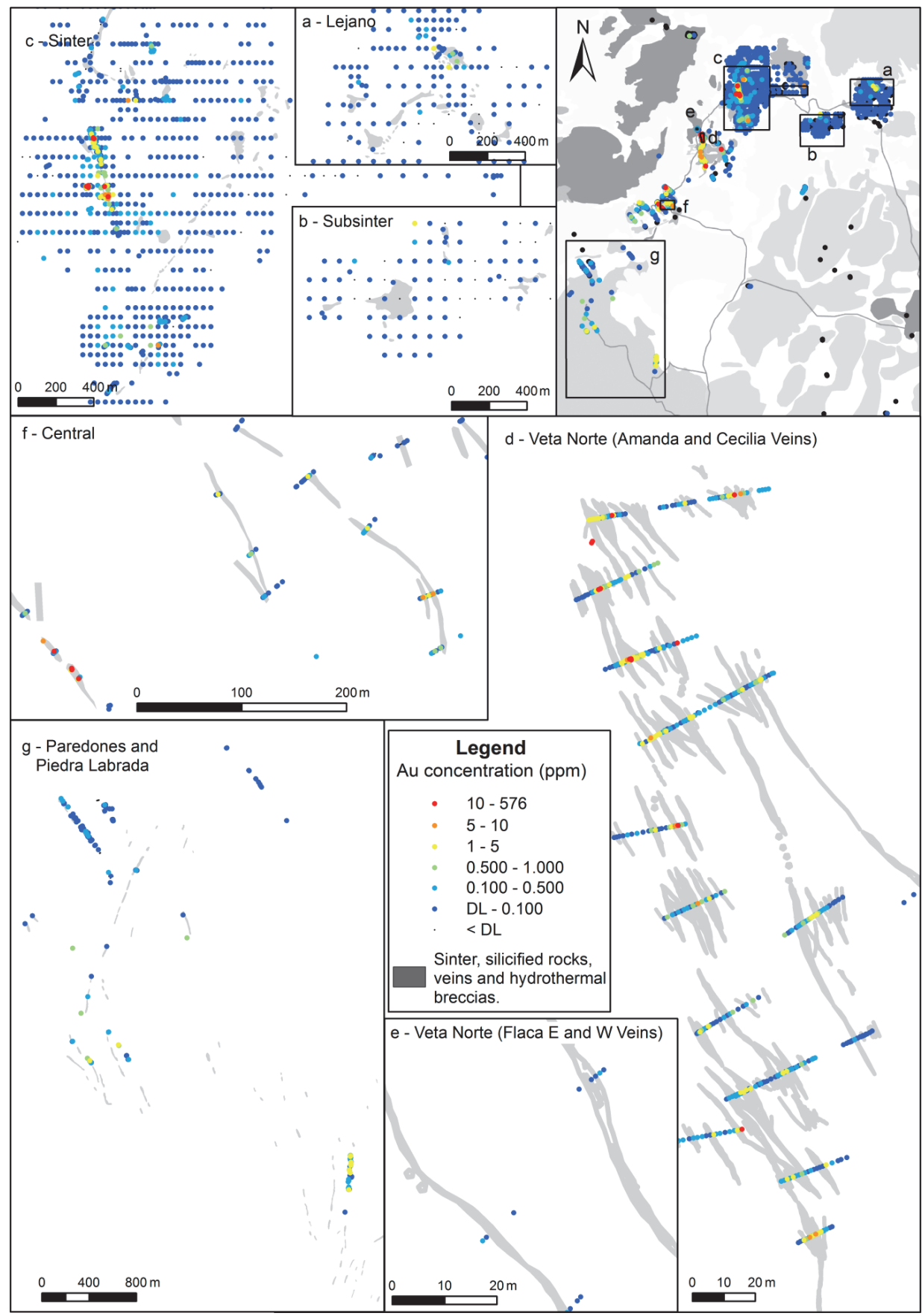

Figure 6.22: Spatial distribution of Au concentrations. 


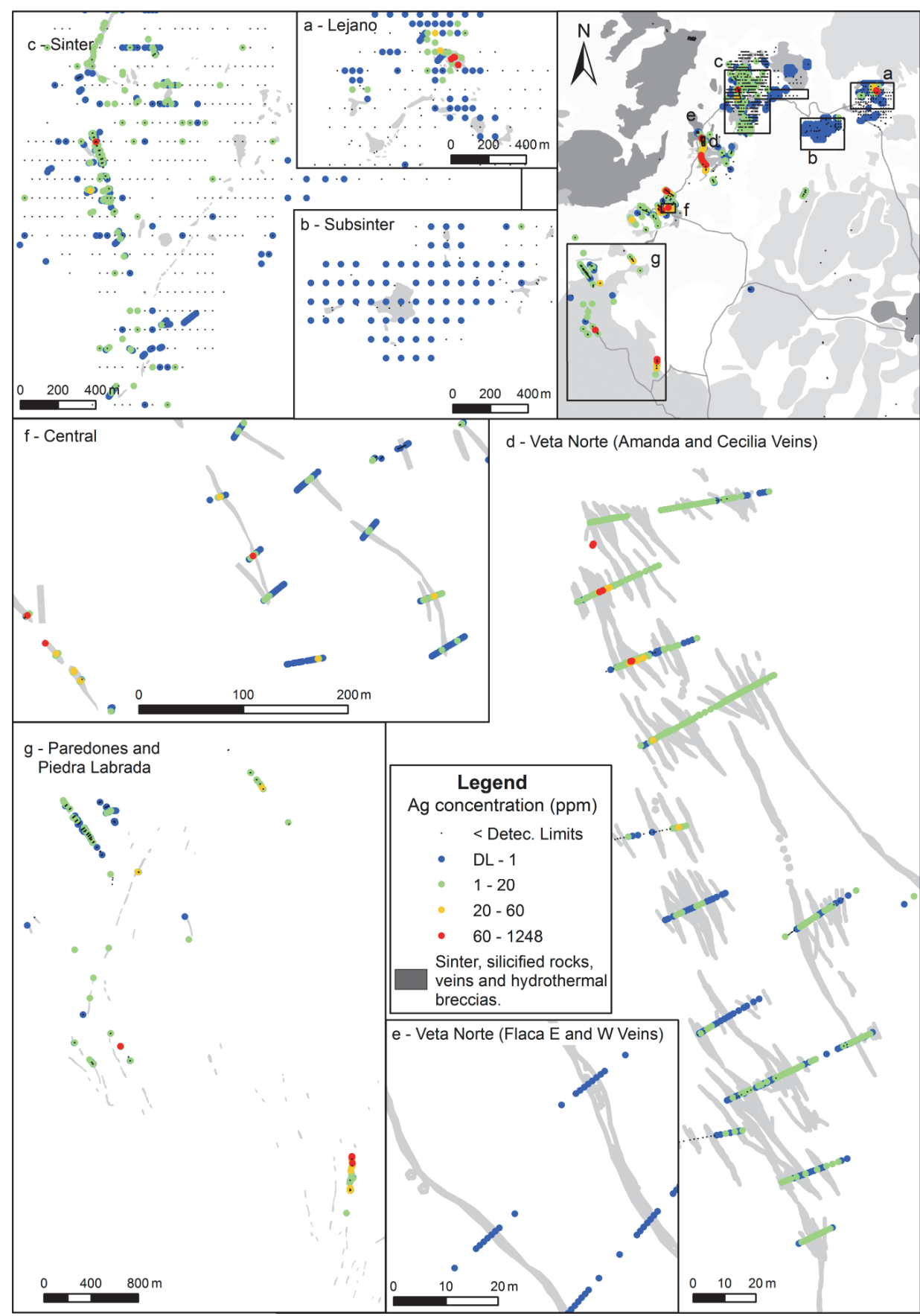

Figure 6.23: Spatial distribution of Ag concentrations. 


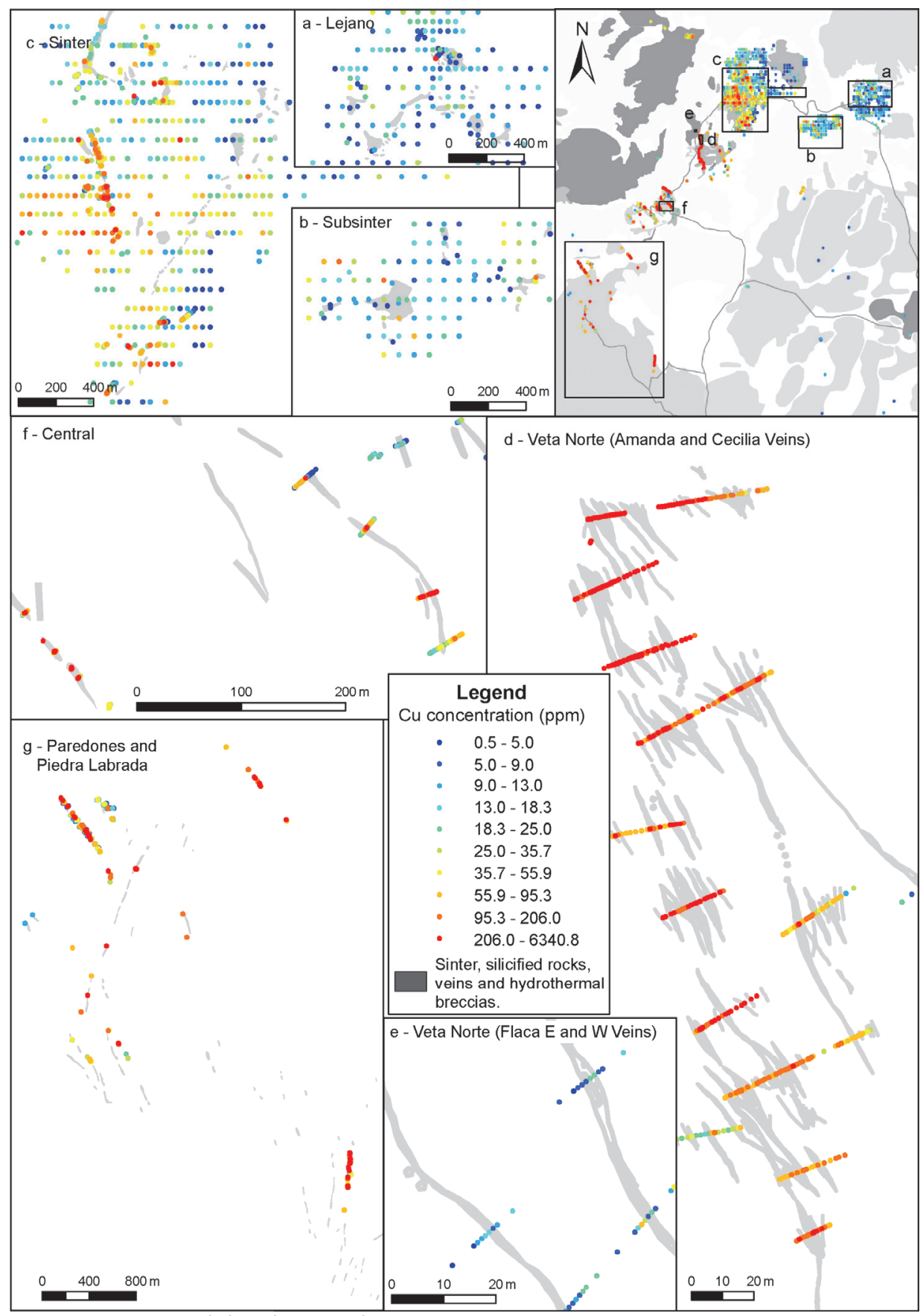

Figure 6.24: Spatial distribution of Cu concentrations. 


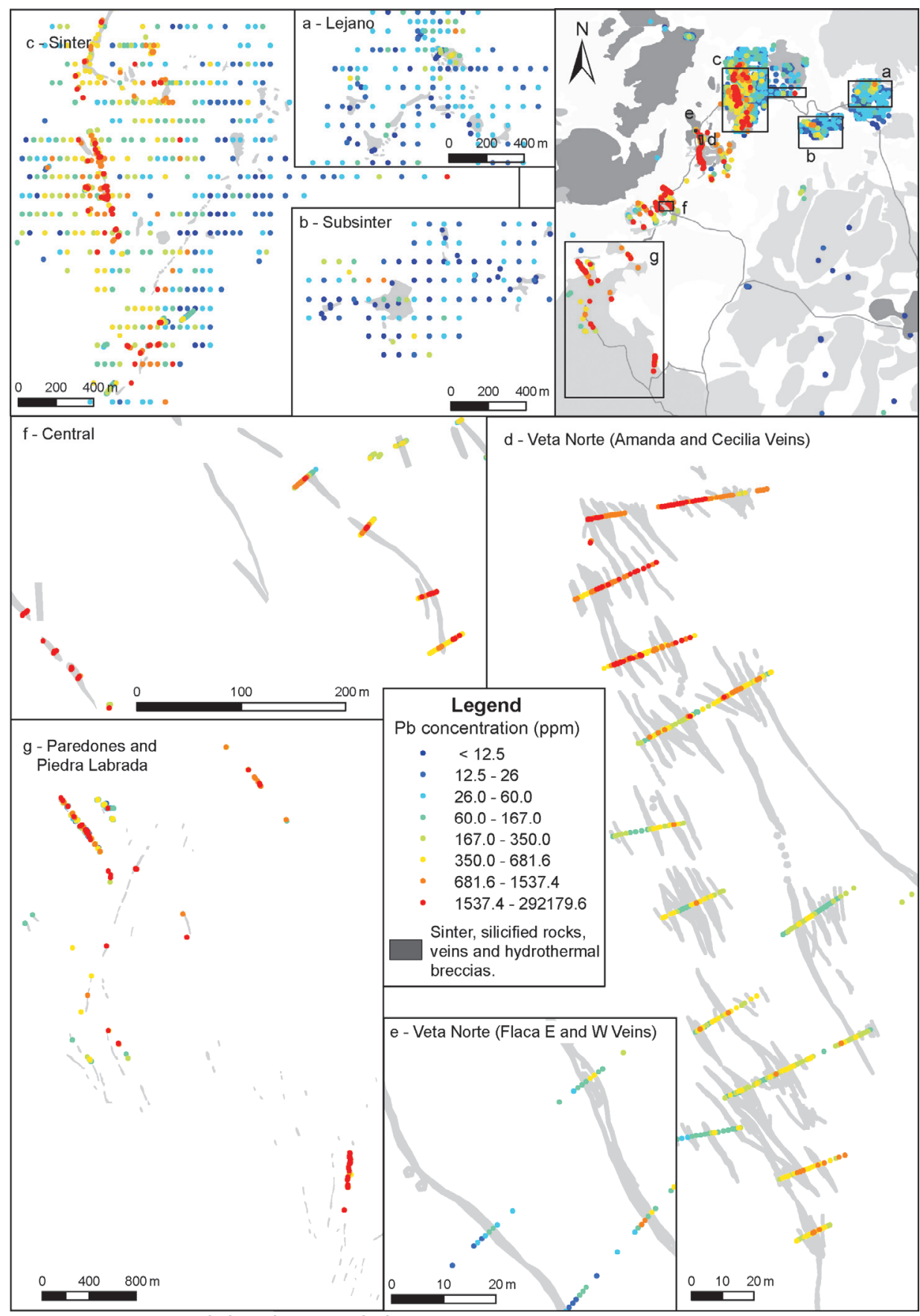

Figure 6.25: Spatial distribution of $\mathrm{Pb}$ concentrations. 


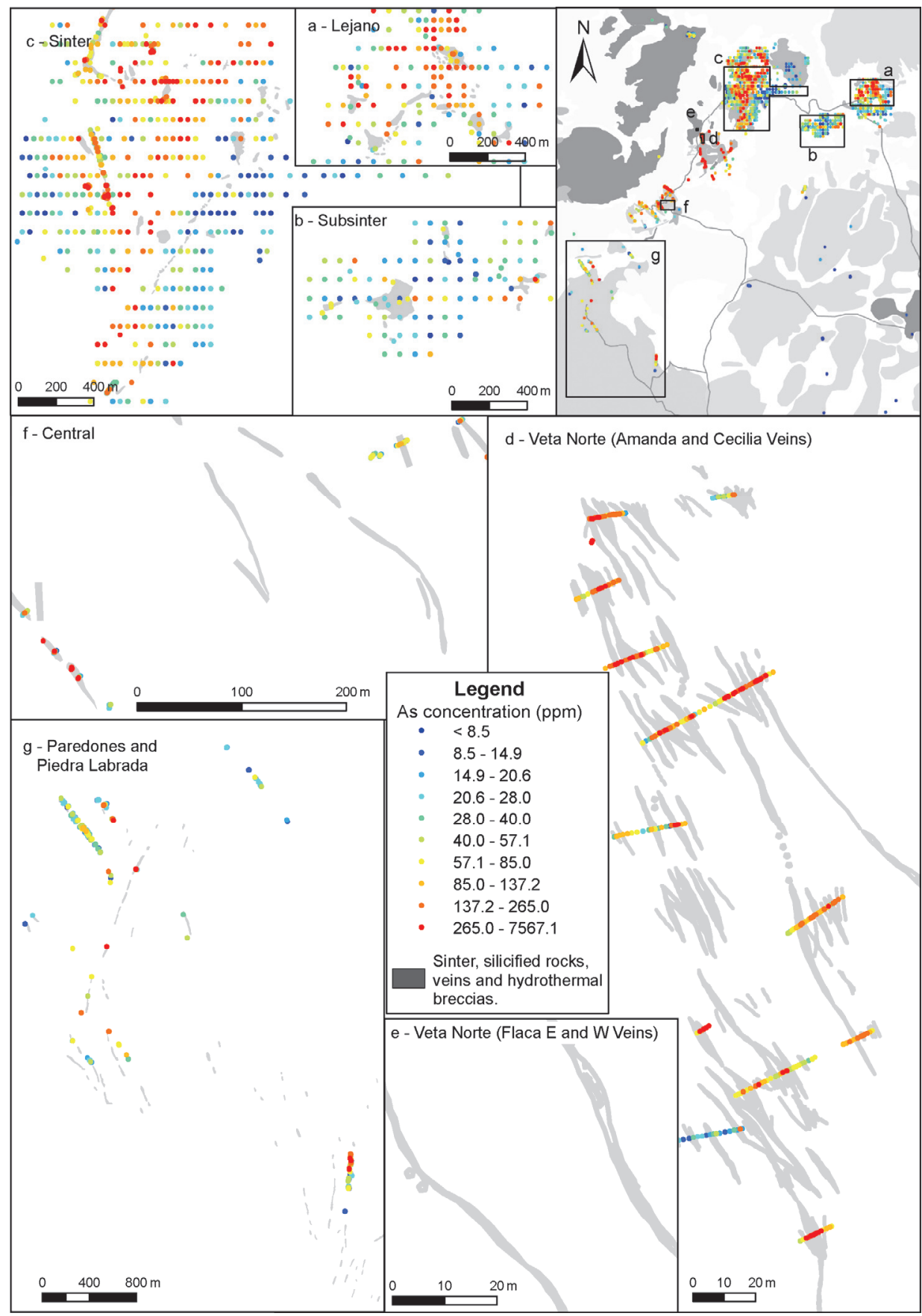

Figure 6.26: Spatial distribution of As concentrations. 


\subsection{Discussion}

The mineralogy detected by spectroscopy shows that white micas, smectites and kaolinite are the predominant minerals and that their occurrences are widespread along the belt of altered rocks that host the La Josefina deposit. The white micas are the predominant minerals in most areas; only in the Sinter area, kaolinite predominates over the white micas and smectites.

The high abundance of kaolinite is not necessarily indicative of an upper position in the paleo-system, as initially thought for the La Josefina deposit. In contrast, kaolinite seems to predominate inside and immediately around the veins or paleo-conducts of epithermal fluids. Lower parts of the system, such as Veta Norte, show even higher proportions of kaolinite than the upper parts. However, this may be slightly influenced by the high sampling density of rocks obtained from relatively narrow zones around the veins (in all areas with veins), which is a common practice during mineral exploration surveys. The possible overprint of the original hydrothermal alterations with kaolinite produced by weathering may also have influenced the proportion of kaolinite and should be considered when using near-surface sampling. Overprinting related to weathering may be favoured by the higher permeability of the veins. Therefore, it is challenging to distinguish weathering kaolinite from hydrothermal kaolinite.

Kaolinite is a common replacement of volcanic glass and plagioclase at temperatures below $200^{\circ} \mathrm{C}$ in advanced argillic alteration blankets that are produced by steam-heated ground water. It can also be deposited in veins and veinlets as late stage minerals because of water collapsing into the system, even up to depths of $300 \mathrm{~m}$ (Hedenquist et al., 2000) or $400 \mathrm{~m}$ (Simpson et al., 2001). Most of the kaolinite in and around veins in the Veta Norte, Central and Sinter areas, is likely to have this origin. This would explain the presence of kaolinite filling fractures as a late stage mineral in the veins; but is partially contrasting with the previously suggested supergene (weathering) origin (Moreira and Fernández, 2015; Moreira et al., 2004b). A supergene origin would probably require an acidic environment caused by high amounts of oxidized pyrite, and that should be represented by ubiquitous jarosite (Hedenquist et al., 2000), which is scarce.

However, kaolinite was also detected with spectroscopy in the Jorge Paz hill, which is relatively far from the main area of alteration and mineralization. In that area, the rocks do neither show much alteration visually, nor are there veins or other obvious indications of hydrothermal activity. In addition, the spectra from these samples show a low reflectance, insinuating that the alteration intensity is low. This suggests that the kaolinite present in those areas was probably produced by weathering. These kaolinites show relatively 
low crystallinity values (although not the lowest). The values of crystallinity for these samples range from 1.023 to 1.482 with a median of 1.176 . This range of values fits one of the two populations observed in the bimodal distribution of crystallinity of all samples in the deposit (Figure 6.17). This agrees with interpretations that the weathering produce low crystallinity kaolinite, such as in the Kuscayiri $\mathrm{Au}(\mathrm{Cu})$ deposit in Turkey (Yilmaz, 2003); and with the knowledge that the conditions in the upper part of lateritic weathering profiles favour precipitation of poorly crystalline kaolinite, even replacing more crystalline kaolinite by less crystalline one (Fritsch et al., 2011).

Therefore, it is very likely that the coexistence of kaolinite from two different origins may be the reason for the bimodal distributions of kaolinite crystallinity in the whole deposit, and in the Veta Norte and Lejano areas. One type of kaolinite may have been produced by steam-heated water related to the hydrothermal activity and shows higher crystallinity, while the other may have been produced later by weathering, and shows lower crystallinity.

Kaolinite crystallinity may potentially differentiate hydrothermal from weathering origin, but also between different levels of the paleo-system. The Lejano and Subsinter areas show noticeably lower crystallinity than the areas with veins. In addition, the highest crystallinity kaolinite can be considered as indicator of epithermal paleo-conduits, since it occurs usually in veins and other interpreted paleo-conduits in the Veta Norte, Central and Sinter areas. Other authors also considered kaolinite crystallinity as likely indicative of depth (and probably temperature). For instance, in the Golden Cross deposit crystallinity seems to increase with depth (Simpson et al., 2001), and in the Broadlands-Ohaaki geothermal system, Yang et al. (2001a) indicated that in the margins of the system, poorly crystalline kaolinite is a low temperature variety of kaolinite.

Most of the white micas have wavelength positions of the $\mathrm{AlOH}$ feature between 2197 and $2206 \mathrm{~nm}$, which suggest that they have a potassic (muscovitic) composition. Other samples however, show relatively low wavelengths (as low as $2186 \mathrm{~nm}$ ), suggesting that they are probably Al-rich white micas, with compositions tending to the more sodium-rich white mica paragonitic; although paragonite was not confirmed by XRD analyses. These short-wavelength samples were obtained from the north of the Lejano area and the southwest of the Subsinter area. The presence of white micas with short wavelength position of the $\mathrm{AlOH}$ absorption feature differentiates the Lejano and Subsinter areas from the other areas in the La Josefina deposit, in which the low wavelengths micas are absent. These two areas also include 
white micas with longer wavelengths, showing the largest range of wavelengths from all areas in the La Josefina deposit.

In detail, the white micas with short wavelengths of the AlOH absorption feature in the Lejano and Subsinter areas also show a relatively high crystallinity, and their occurrences are clearly confined to clusters that are surrounded by white micas with longer wavelength positions of the $\mathrm{AlOH}$ feature and low crystallinity (Figure 6.27). These short-wavelength white micas are associated with pervasively and vuggy silicified rocks. In addition, and in contrast to the Subsinter area, those in the north of the Lejano area are also associated with relatively high kaolinite crystallinity values, and with elevated $\mathrm{Au}, \mathrm{Ag}, \mathrm{Cu}$ and $\mathrm{Pb}$ contents, and higher As contents than those in the Subsinter (Figure 6.27). These features in the Lejano and Subsinter areas support the previous interpretation about the position of these two areas in the paleo-system (Chapter 4 ). The north portion of the Lejano area probably represents an upper part of the paleo-system directly related to a paleoconduit (Figure 6.27), while the Subsinter area, probably represents a location in a similar level, but at distance from the paleo-conduits.

Therefore, spectroscopy can be used to differentiate the upper levels of the paleo-system from lower parts by their large range of wavelengths of the $\mathrm{AlOH}$ absorption feature in white micas, and especially by the presence of high crystallinity white micas with wavelengths below $2197 \mathrm{~nm}$; which are strongly contrasting with the white micas surrounding them (longer wavelength and lower white mica crystallinity). The upper levels of the paleosystem positioned near paleo-conduits would contain kaolinites with relatively high crystallinity values in addition.

The ranges and trend of wavelength positions of the $\mathrm{AlOH}$ absorption feature of white micas, as determined for the different levels of the paleo-system in the La Josefina deposit, show similarities with those detected in the Comstock epithermal district (Yang et al., 2001b), which contains deposits similar to La Josefina. In Comstock, the upper parts of the system, which contain aluniticsilicic acidic alteration, show wavelength positions of the AlOH absorption feature in white micas that are predominantly shorter than $2200 \mathrm{~nm}$. This is consistent with the short wavelengths detected in the Lejano and Subsinter areas; although in those areas, both low and high wavelengths were found. At intermediate levels in the paleo-system, with predominant argillic alteration, white micas in the Comstock district show wavelengths of the $\mathrm{AlOH}$ absorption feature in a range between 2200 and $2208 \mathrm{~nm}$. This range is similar to that occurring in the areas with veins in the La Josefina paleosystem ( 2197 to $2210 \mathrm{~nm}$ ). Finally, lower levels with predominant propylitic alteration in the Comstock district, show the longest wavelengths (>2208 $\mathrm{nm}$ ), which is consistent with the wavelengths above $2210 \mathrm{~nm}$ detected in 
incipient propylitic alteration in the east of the Sinter area and in the Piedra Labrada area.

Chlorite is scarcely present in near-surface rocks, being subordinated to other minerals, mainly white micas. Although it is present in minor quantities in the Ailin vein of the Central area, it is more abundant towards the east of the mineralized areas (Figure 6.10), including the Piedra Labrada area, the east of the Sinter area (Figure 6.27), and in a few samples in the Lejano and Subsinter areas. In the Piedra Labrada area and in the east of the Sinter area chlorite occurs in association with white micas, and some smectite, and in the east of the Sinter it is associated with disseminated pyrite, which is related to incipient propylitic alteration. This association may indicate a transition between the argillic and the propylitic alteration domains. At depth, chloriterich propylitic alteration seems to be relatively abundant in the areas with veins, and coincides with scarce epidote in the Central area. This indicates temperatures of formation higher than $250^{\circ} \mathrm{C}$ for those sites.

The abundant and widespread occurrences of white micas and subordinated smectites at the surface, and propylitic alteration at depth, suggests a depthcontrolled alteration zonation, similar to zonation observed in other epithermal deposits and geothermal systems (Simmons and Browne, 2000; Simpson et al., 2001; Yang et al., 2001a).

It is difficult to subdivide the areas with veins into different vertical levels of the paleo-system. The Central area, with occasional chlorite in the Ailin vein, may represent the lower level which is exposed at the current erosion level. This interpretation would be in agreement with Moreira and Fernández (2015). It is likely that all areas containing epithermal veins represent a similar level in the paleo-system, with only slight vertical differences. 

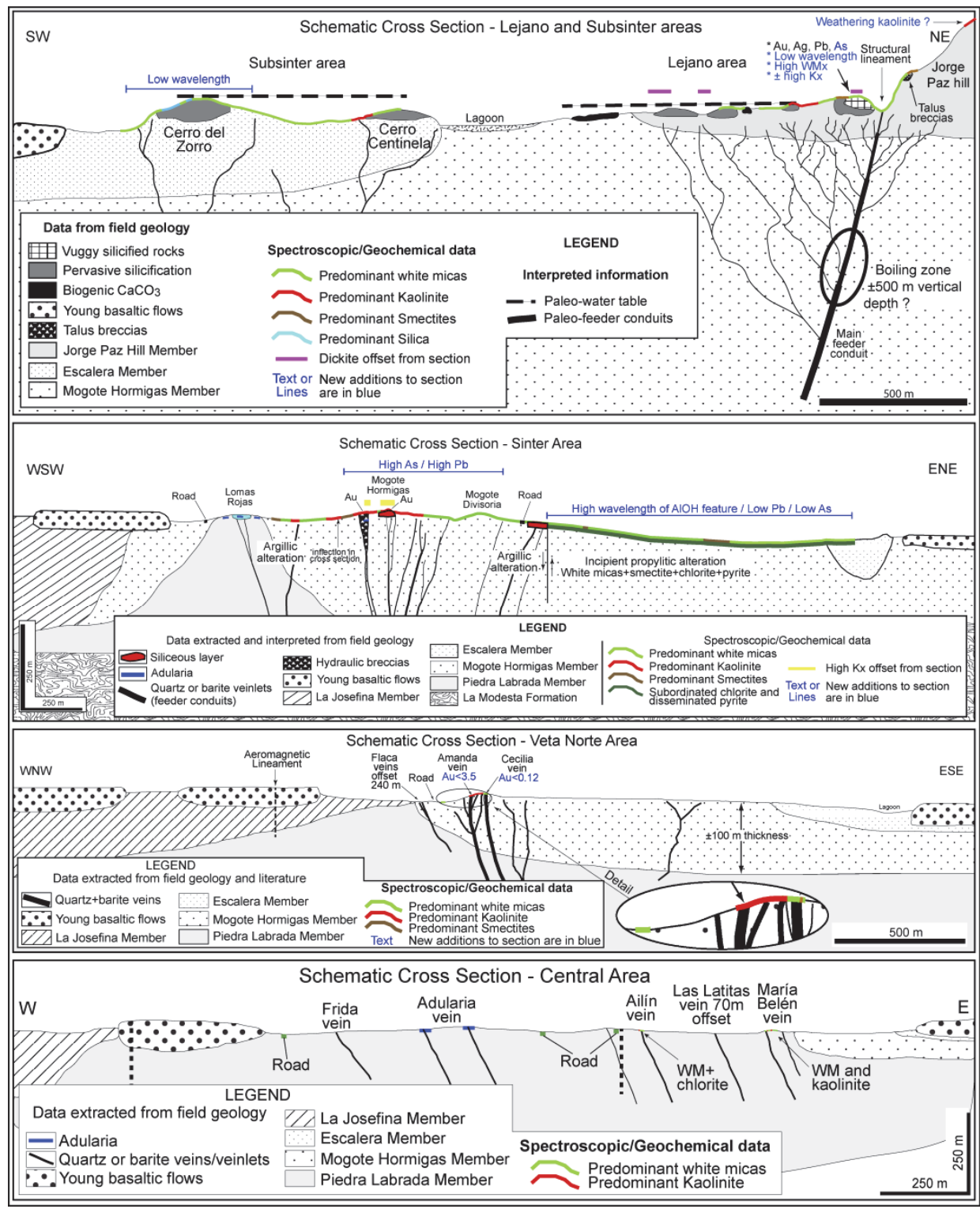

Figure 6.27: Cross sections showed in chapter 4, updated with the incorporation of mineralogical information produced in chapter $6 . \mathrm{WMx}=$ white micas crystallinity; $\mathrm{Kx}=$ kaolinite crystallinity.

However, there are sharp differences in spectral mineralogy and geochemistry between a few adjacent portions of the deposit. Three examples of this are discussed. One is in the north of the Veta Norte area between the Flaca veins, and the Amanda and Cecilia veins (Figure 5.1). The Amanda and Cecilia veins include abundant kaolinite (Figure 6.9) and are mineralized with $\mathrm{Au}, \mathrm{Ag}, \mathrm{Cu}$, and $\mathrm{Pb}$, while the Flaca veins show more 
smectite (Figure 6.7) but very scarce kaolinite, and low concentrations of those elements. Probably the Flaca $W$ and $E$ veins represent early stages in the formation of veins, which may have become sealed afterwards, as proposed by Andrada de Palomera et al. (2012) and in chapter 5 of this thesis. This is consistent with the interpretation that kaolinite is the result of a late stage overprinting deposited in the veins because of their high permeability. Such deposition was not possible in the sealed and therefore less permeable Flaca $\mathrm{W}$ and $\mathrm{E}$ veins. It remains unclear from this whether the metals in the Amanda and Cecilia veins precipitated because of mixing of the hot, near neutral-pH hydrothermal fluid with acidic, relatively cold steamheated water or by other processes.

A second example of sharp spectral and geochemical differences is that between the Piedra Labrada and the adjacent Paredones areas. Some spectral characteristics of the Piedra Labrada area are similar to the eastern part of the Sinter area, while both the spectral and geochemical characteristics differ from those of the Paredones area. The association of white micas, smectites and chlorite, and partially the paucity of kaolinite make the Piedra Labrada area, similar to the east of the Sinter area, while those characteristics and the higher Ag concentrations make it different from the Paredones area. The absence of kaolinite may indicate that the Piedra Labrada area represents a low level in the paleo-system that was not reached by the steam-heated waters drained downwards from the top of the paleosystem.

A third example is from the Sinter area, which shows a linear divide between two zones with clear differences. In the field, this line consists of a NEtrending set of outcrops of the siliceous layer. These outcrops form also the beginning of a topographic slope of decreasing altitude towards the east. The characteristics that differentiate the area to the east of this line from the rest of the Sinter area are: (a) the presence of chlorite as part of an incipient propylitic alteration; (b) an abrupt increase in the wavelength position of the $\mathrm{AlOH}$ absorption feature in white micas; and (c) a general decrease in the white micas crystallinity.

The Sinter area contains characteristics from two types of paleoenvironments: the relatively deep areas with veins, and the shallower levels of the paleo-system. While the western part of the Sinter area show similarities with the areas with veins, the eastern part is similar to the upper parts of the paleo-system represented by the Lejano and Subsinter areas. In addition, the sharp contact between rocks with argillic alteration (white micas+smectites+kaolinite) and those with propylitic alteration in the eastern portion of the Sinter area, suggest that movements by faults have put them in contact. For this to occur, the eastern part of the Sinter area must have 
been moved upwards. In this case, there should have been a subsequent relief inversion due to the competence of the siliceous layer. However, the structural setting is complicated, which makes an acurate reconstruction of the paleo-system in that area, difficult.

Although the Sinter, Subsinter and Lejano areas were probably formed at the upper parts of the paleo-system, they show several differences. This may have resulted because of different composition and temperature of the paleofluids, and different positions relative to the core of the hydrothermal system and main upflow zone. The Sinter area was probably located in a central position relative to the main upflow zone, where the fluids may have been richer in sulphur. In this environment, acid steam-heated waters were produced, which resulted subsequently in abundant kaolinitic alteration. In contrast, the Lejano and Subsinter areas were located at a marginal position at a few thousand metres from the main upflow zone. In that position, $\mathrm{CO}_{2}$ rich fluids may have predominated. These fluids favoured the formation of calcareous rocks at the top of the system. In localized areas near secondary paleo-conduits, e.g. in the northeast of the Lejano area, the fluids were rich in sulfur. This is similar to descriptions of geothermal systems and epithermal deposits, where $\mathrm{CO}_{2}$ steam heated waters form at the margins of the systems (Simpson et al., 2001).

By comparing the data of the La Josefina system with the configuration of geothermal systems in Broadlands and Ohaaki (Simmons and Browne, 2000), it is estimated that the possible paleo-depth of formation of the Central area may have been of nearly $500 \mathrm{~m}$ below paleo-surface. This is consistent with the observation of propylitic alteration with scarce epidote that commonly forms at around $250^{\circ} \mathrm{C}$. The Piedra Labrada area, which contains chlorite and no kaolinite, may have been formed at a depth below the maximum reach of the collapsed steam heated waters ( 300-400 m beneath the paleo-surface), and therefore, it may be similar to that of the Central area.

In addition, with the exception of a few mineralized fragments of the metamorphic basement, all host lithologies in the investigated areas are from the Chon Aike Formation, which thickness is not known with certainty, but according to Panza (1994b), it is between 200-600 m. If those assumptions are correct, and the hydrothermal activity in the area is temporally restricted to the Chon Aike Formation as stated in chapter 4, the whole paleo-system should be mostly accommodated inside that formation. Therefore, the Piedra Labrada and Central areas may be close to the base of the Chon Aike Formation.

Many of the variations in mineralogy and spectral parameters, as well as in geochemistry, presented in this research occur along short distances, and are 
controlled by their proximity to the veins (or paleo-conduits in general). This may occur at different levels of the paleo-system. Therefore, when comparing data from different levels, this issue should be considered to avoid misinterpreting the data when sampling was carried out at different distance from the paleo-conduits, which presence may even be ignored. Otherwise, the variations between different levels of the system may be either obscured or exaggerated.

\subsection{Conclusions}

White micas and smectites are present in every area in the La Josefina epithermal system and the two groups of minerals are usually spatially associated. Although smectites seem to be less abundant in some of the areas, for instance in the north of Amanda and Cecilia veins, none of these minerals alone is a good indicator of any one of the studied parts of the paleo-system.

In contrast to white micas and smectites, kaolinite by itself may be a good indicator of different parts of the paleo-system. The abundance of kaolinite shows an overall decrease from the centre of the system (main upflow zone) towards its periphery, and from the top downwards probably up to around $400 \mathrm{~m}$ below the paleowater table. Since kaolinite is easily detected with remote sensing, it may help as an aid in the exploration for epithermal deposits.

In addition, the highest kaolinite crystallinity values are found associated with the locations of paleo-conduits, which are represented mainly by veins and hydrothermal breccias, but also by strongly silicified rocks with precious metals anomalies and other indications of fluids upflow. Therefore, at different levels of the paleo-system, kaolinite crystallinity is a good indicator for paleo-conduits and potentially mineralized rocks.

The kaolinite crystallinity values vary between different areas. The values are noticeably higher in areas containing veins than in the Subsinter and Lejano areas. This is likely to be influenced by the presence of kaolinite with high degrees of crystallinity occurring in and near the veins. Also minor amounts of kaolinite produced by weathering processes with relatively low crystallinity may be present throughout the areas.

The wavelength position of the $\mathrm{AlOH}$ absorption feature in white micas and smectites can be used as indicator of the depth of their formation within the paleo-system. A wide range of wavelengths (2186-2215 nm), and presence of white micas with wavelengths below $2197 \mathrm{~nm}$, which are absent in other areas, are indicative of the upper portions of the paleo-system. The short 
wavelengths (2186-2197 nm) are typically related to silicified rocks, formed in the paleo-phreatic aquifer by the effects of steam-heated waters; these areas may be located nearby paleo-conduits in the Lejano and in other areas. Samples with short wavelength positions cluster in well-defined areas of up to $500 \mathrm{~m}$ wide. These zones are surrounded by rocks containing white micas of longer wavelengths positions, producing a strong contrast between the two zones. In addition, high crystallinity white micas are coincident with the micas having short wavelength positions, this occurs for instance in the northeast of the Lejano area. Therefore, white micas with high crystallinity and low wavelength position of the $\mathrm{AlOH}$ absorption feature may be good indication of the position of paleo-conduits in the upper parts of the systems.

The areas hosting mineralized rocks, i.e. the areas with abundant veins and the western part of the Sinter area, contain white micas with wavelength positions of the $\mathrm{AlOH}$ absorption feature between 2197 and $2210 \mathrm{~nm}$, being devoid of other wavelengths.

Dickite, which occurs only in the Subsinter and mainly in the Lejano area, is absent in other parts of the deposit. This mineral is another indicator for the shallower parts of the paleo-system. Chlorite is present in low abundances in the near-surface rocks and mostly as subordinated mineral. At depth however, the mineral is more abundant, in particular in the Central and Veta Norte areas (locally with scarce epidote). Chlorite indicates the deeper parts of the epithermal system, especially if associated to veins.

The spectroscopic methods used in this research are useful as exploration tool for epithermal deposits and also to characterize the paleo epithermal system of La Josefina. Reflectance spectroscopy enables the detection of subtle mineralogical differences that are difficult to observe by other means, such as the sharp contrast of alteration mineralogy that is located in the east of the Sinter area, and that seems to indicate the presence of a fault.

The results of the spectral mineralogical interpretation of the Piedra Labrada area also yielded useful information about the system. The paucity of chlorite at surface and its relative abundance at depth in the Veta Norte and Central areas indicates propylitic alteration zones at depth. These zones occur vertically below the argillic alteration widely observed at shallower depths. Following this, the scarce chlorite present at surface in the Piedra Labrada area, which is associated with white micas and smectites, may indicate a relatively deep level, probably transitional between argillic and propylitic alterations. In addition, this area contains quartz veins and stockworks, which represent paleo-conduits. Kaolinite occurrences in veins were deposited from steam-heated water that drained downwards from the upper part of the system after collapse of the system. The absence of kaolinite in 
the Piedra Labrada area suggests that the area was located at a depth beyond the reach of the descendant steam heated fluids $(300-400 \mathrm{~m})$. This is roughly coincident with the depth of transitional zones between argillic and propylitic alterations in geothermal systems. 
Chapter 7

Synthesis and recommendations 


\subsection{Introduction}

The purpose of this research was to obtain tools for better predicting the location of Au-Ag epithermal deposits in the Deseado Massif and geologically similar areas. To help accomplishing this, the three following main objectives were addressed:

1) To determine the geological types of evidence that need to be further investigated for improving the results of prospectivity mapping and mineral exploration for low- and intermediate-sulfidation epithermal deposits in the Deseado Massif.

2) To determine the spatial relationships between mineralized zones and the types of evidence that need to be better understood, and to derive indicators for the different vertical position in the paleo-system and relative proximity to mineralized areas.

3) To increase the knowledge about low- and intermediate-sulfidation epithermal deposits in the Deseado Massif, to better understand their mechanisms of formation, the effects they produce on the host rocks, and the nature of their volcano-tectonic setting.

\subsection{Assessing the efficiency of geological evidence}

Mineral prospectivity mapping of low- and intermediate-sulfidation epithermal deposits (LISEDs) was carried out in the Deseado Massif in order to address the first objective of this research. This was done by using the Weights of Evidence (WofE) data driven method and three general types of geological evidence that are known to be related to these types of deposits. These evidence included lithology, hydrothermal alteration (clay and silica), and structural controls on mineralization. The process of prospectivity mapping produced useful mineral prospectivity maps and contributed to evaluate the relevance of the different types of geological evidence, as well as to infer the need of further investigating some of them.

The results of the prospectivity mapping (chapter 3 ) indicate that clay alteration was the weakest type of evidence used in the process, which is conflicting with the knowledge that the hydrothermal alteration is an integral part of every epithermal system and, as such, is commonly used to infer the presence of epithermal deposits. This suggests that the week associations found in chapter 3 were produced by the way in which the evidence was used, coupled with insufficient understanding of the spatial distribution of hydrothermally altered areas in the LISEDs of the Deseado Massif. 
Geochemistry is another evidence that can be used for prospectivity mapping. Other than geological observations, geochemistry is probably the most widely used tool during mineral exploration, because it provides a direct indication for the occurrence of the elements that are being pursued. However, its proper use needs a good understanding of the spatial distribution of elements around mineralized areas, which is insufficiently known in LISEDs of the Deseado Massif.

Therefore, it was concluded that the distribution of hydrothermal clay occurrences and chemical elements near the epithermal systems require better investigation in the Deseado Massif in order to improve prospectivity mapping of LISEDs and to increase the chances of finding new mineral deposits more efficiently.

In contrast to clay alteration, the evidence layer representing silica abundance, showed a relatively strong spatial association with the mineral deposits at district-scale prospectivity mapping. The incorporation of this type of evidence is likely to have improved the predictions at that scale, which is in agreement with the frequently observed spatial association between siliceous accumulations and LISEDs in the Deseado Massif. Thermal bands of ASTER were used to map the silica abundances.

\subsection{Geochemical and hydrothermal clay alteration evidence}

Considering the results of the prospectivity mapping and the assessment of evidence types presented in chapter 3, geochemistry and hydrothermal clay alteration were studied in a Au-Ag epithermal deposit of the Deseado Massif. The spatial distribution of elements and alteration minerals in the deposit were determined, aiming to derive geochemical and mineralogical indicators of mineralized areas. This was intended for addressing the second objective of this research, and to contribute to new general knowledge about LISEDs of the region; and therefore, helping to better understand their mechanisms of formation and their volcano-tectonic affiliation.

The La Josefina low- to intermediate-sulfidation epithermal deposit was selected for this study because of three reasons. The first is that the deposit contains characteristics of both low- and intermediate-sulfidation deposits. The second is the opportunity to study different vertical levels of the epithermal paleo-system, which are exposed at the current erosion level. Finally, the availability of both detailed geochemical and geological datasets covering the La Josefina deposit. 
The geology and mineralization of the La Josefina deposit were synthesized and presented in chapter 4 . The geological information from seven explored areas, which likely represent different portions of the epithermal paleosystem, was studied, and a hypothetical geological conceptual model was built. This model was used as basis for interpreting the geochemical and mineralogical data.

\subsubsection{Geochemistry of the La Josefina epithermal deposit}

The geochemistry of the northern part of the Veta Norte area in the La Josefina deposit was studied to develop geochemical indicators of Aumineralized zones, and to assess the effects of weathering on these indicators. The results of this part of the research were presented in chapter 5.

The geochemical data were studied at two scales, by comparing a mineralized zone with an adjacent non-mineralized zone and by determining the variations in element concentrations at different distance from the mineralized veins. The interpretation of the observed geochemical distributions in the context of the geological data from the studied area revealed that during epithermal stages, that included the mineralizing events, $\mathrm{Ba}$ was lost, while $\mathrm{Au}, \mathrm{Cu}, \mathrm{Hg}, \mathrm{V}, \mathrm{Co}, \mathrm{Mn}, \mathrm{MgO}, \mathrm{Cr}$, and $\mathrm{P}$ were gained. Also it was inferred that during the whole process of alteration, which included mineralizing and non-mineralizing events, $\mathrm{Pb}, \mathrm{Zn}, \mathrm{FeO}, \mathrm{CCPI}$ (chlorite-calcitepyrite index), were increasingly gained, while $\mathrm{Be}$ and $\mathrm{CaO}$ were increasingly lost. Arsenic and Ni could not be systematically studied but they show higher concentrations in the mineralized zone than in the non-mineralized zone. Therefore, the most effective geochemical indicators of mineralized zones at deposit-scale are the following 10 elements: $\mathrm{Au}, \mathrm{Cu}, \mathrm{Hg}, \mathrm{V}, \mathrm{Co}, \mathrm{Mn}, \mathrm{MgO}, \mathrm{Cr}$, $\mathrm{Ba}$, and $\mathrm{P}$; however, other eight variables (i.e., $\mathrm{Pb}, \mathrm{Zn}, \mathrm{FeO}, \mathrm{CCPI}, \mathrm{Be}, \mathrm{CaO}$, As, and $\mathrm{Ni}$ ), although less effective, are probably still useful indicators of mineralized zones.

From those elements, $\mathrm{Au}, \mathrm{Cu}, \mathrm{Pb}, \mathrm{As}, \mathrm{Hg}$, and $\mathrm{Co}$ were deposited preferentially in the mineralized paleo-conduits besides being anomalous in the mineralized zone, and $\mathrm{Cu}, \mathrm{Pb}$ and $\mathrm{As}$ were found directly related with $\mathrm{Au}$ in native gold, electrum and pyrite. This suggests that these six geochemical indicators are more independent than others of the interactions between fluids and rocks. Therefore, it is expected that $\mathrm{Au}, \mathrm{Cu}, \mathrm{Pb}, \mathrm{As}, \mathrm{Hg}$, and $\mathrm{Co}$ are useful indicators of mineralized zones even if the host rocks and alterations are slightly different than those in the study area.

Weathering modified the concentrations of $\mathrm{Cu}, \mathrm{Na}_{2} \mathrm{O}, \mathrm{MgO}, \mathrm{FeO}, \mathrm{As}, \mathrm{Pb}, \mathrm{Co}$, $\mathrm{Ba}, \mathrm{Mn}$ and $\mathrm{Zn}$, being $\mathrm{Cu}, \mathrm{Pb}, \mathrm{Co}, \mathrm{Mn}, \mathrm{MgO}$ and $\mathrm{Zn}$ the most affected. 
However, the consequences of those modifications vary according to the scale and objective of the geochemical survey, and the position relative to the epithermal paleo-conduits. If the objective is to identify potentially mineralized zones at deposit-scale, the effects of weathering are limited, although they may prevent the use of $\mathrm{Co}, \mathrm{Mn}, \mathrm{Pb}, \mathrm{Zn}$ and $\mathrm{MgO}$ as indicators because they can be strongly affected by weathering. At detailed-scale, if the objective is to indicate the proximity to mineralized veins, the effect of weathering is more significant, hindering the recognition of small variations of concentrations of several indicators $\left(\mathrm{Au}, \mathrm{Cu}, \mathrm{P}, \mathrm{Ba}, \mathrm{Hg}, \mathrm{K}_{2} \mathrm{O}, \mathrm{As}, \mathrm{Al}_{2} \mathrm{O}_{3}\right.$ and $\mathrm{Mn})$.

As a result of weathering, only half (i.e., $\mathrm{Au}, \mathrm{Hg}, \mathrm{V}, \mathrm{Cr}$, and $\mathrm{P}$ ) of the 10 best geochemical indicators of mineralized zones can be used with confidence in surveys that include samples collected at the surface or close to it; while Co, $\mathrm{Mn}, \mathrm{MgO}, \mathrm{Pb}$, and $\mathrm{Zn}$ should directly be avoided in that scenario.

\subsubsection{Hydrothermal alteration mineralogy in the epithermal paleo-system at La Josefina}

The spatial distribution of alteration minerals was studied in seven parts of the epithermal paleo-system in the La Josefina district. This was carried out mainly by means of reflectance spectroscopy of samples collected from outcrops and trenches. During this part of the research (chapter 6), mineralogical indicators of different portions of the paleo-system and of potentially mineralized areas were determined.

White micas and smectites are usually associated, abundant, and present in all studied areas. Because of their widespread distribution, their presence alone is not a useful indicator of level in the paleo-system or proximity to mineralized areas.

However, the wavelength position of the $\mathrm{AlOH}$ absorption feature and the crystallinity of white micas and smectites are good spectroscopic indicators of different parts of the paleo-system. Wavelengths below $2197 \mathrm{~nm}$ are only present in the upper portions of the paleo-system, and are absent in other areas; they are specifically related to silicified rocks formed in the paleophreatic aquifer by the effects of steam-heated waters. High white micas crystallinity is partially coincident with their low wavelengths. In addition, the areas with veins and the western part of the Sinter area, which are the ones that host mineralized rocks, show wavelengths only between 2197 and 2210 $\mathrm{nm}$. Therefore, white micas with wavelength position of their $\mathrm{AlOH}$ absorption feature below $2197 \mathrm{~nm}$ are good indicators of the upper parts of the paleosystem, while those with wavelengths consistently between 2197 and 2210 
$\mathrm{nm}$ may be indicators of paleo-conduits in lower levels of the system, and therefore of potentially mineralized rocks.

Kaolinite is also abundant and present at different levels of the paleo-system, but in contrast to white micas, it constitutes a relatively good indicator by itself. It is more abundant in the upflow zones and their vicinities, mainly in areas with mineralized paleo-conduits. It is also present in broader areas around the upflow zones in the upper portions of the paleo-system. It seems that the amount of kaolinite decreases laterally from the upflow zones and downwards. The spatial distribution of kaolinite is consistent with the interpretation that it was formed in the upper parts of the paleo-system by acid steam-heated waters, which would return downwards into the system, mainly through fractures, and deposit kaolinite in paleo-conduits and partially in the surrounding host rocks. According to some authors, this may happen even up to a depth of $400 \mathrm{~m}$ below the paleo-water table. In addition, there may be another generation of kaolinite, likely produced by weathering, which shows relatively low crystallinity.

In the upper parts of the paleo-system, the distribution of kaolinite occurs in relatively wide areas, but at deeper levels, kaolinite is concentrated only in the paleo-conduits and their immediate host rocks. In addition, the kaolinite crystallinity shows the highest values in vein and other paleo-conduits. Anomalously high crystallinity seems to occur in the paleo-conduits regardless of the level in the paleo-system; that was observed in the areas with veins as well as in the upper part of the paleo-system. Therefore, high crystallinity kaolinite is a very good indicator of the presence of veins and other paleo-conduits, and probably of mineralized areas.

This is in harmony with the previous interpretations, shown in chapter 5, that the alterations that were produced before Au precipitated, do not contain kaolinite; while those that include the period of $\mathrm{Au}$ precipitation contain abundant kaolinite. This may find an explanation in the process of adiabatic boiling that may have produced Au precipitation and contemporaneous steam-heating. It seems feasible that boiling triggered the Au precipitation at depth and generation of steam-heated acid waters and kaolinite in the upper part of the system, which drained downwards and deposited kaolinite in association with the Au-bearing minerals. This kaolinite shows the highest crystallinity in the system, probably reflecting the higher formation temperatures prevailing at depth, in contrast to those close to paleo-surface. Relationships between temperature of formation and crystallinity of kaolinite were already mentioned by other authors. In addition to this, the relatively acid solutions draining downwards into the system, may have contributed to the precipitation of $\mathrm{Au}$, as claimed by some authors for other deposits. 
The alteration zonation presented in cross sections of the Amanda and Cecilia veins, which were studied in chapter 5 , suggests that the cross sections interval between the ground surface and depths of $\sim 150-200 \mathrm{~m}$ represents an area of transition between the argillic alteration, at the upper part, and propylitic alteration at the bottom, where chlorite, some calcite, and scarce epidote are present. At surface, chlorite was only detected with reflectance spectroscopy in a few samples and as a subordinated mineral, but its presence together with the paucity of kaolinite may be an indicator of a low position in the paleo-system, beyond the reach of the acid fluids draining downwards from the vadose zone. This was observed in the Piedra Labrada area.

In chapter 6 , the observation that As is a good indicator of areas affected by hydrothermal alteration, and mainly related to mineralization, is consistent with the determination of As as one of the geochemical indicators of mineralized zones indicated in chapter 5 .

\subsubsection{Comparing the clay alteration evidence maps with field information}

The binary predictor maps of hydrothermal clay alteration, used as input for the prospectivity mapping (chapter 3 ), were compared with the field alteration data that was acquired from the La Josefina deposit (chapter 6). The mineralogy determined from spectroscopy was overlain on those binary maps, and the degree of agreement between the field data and the maps derived from remote sensing was assessed by considering the percentage of samples with certain predominant mineral that were considered altered by the predictor map (Figure 7.1 and Figure 7.2). For this, three groups of minerals were used: kandites, white micas, and smectites. For testing the district-scale predictor map, the samples located over unfavourable lithology of the district-scale area, were filtered out because the district-scale predictor map did not consider areas of unfavourable lithology.

It is clear that the predictor maps did not fully capture the alteration minerals detected in the field. This is consistent with the determinations from the spatial association analysis carried out for the prospectivity mapping, which indicate that the clay alteration evidence was a weak predictor map. The district-scale predictor map indicated alteration for $39 \%$ of the samples with predominant white micas, $50 \%$ of the samples with predominant kandites (kaolinite or dickite), and $37 \%$ of those with predominant smectites. Finally, it indicated alteration for only $42 \%$ of the samples with any one of those minerals as predominant (Figure 7.1). The regional-scale predictor map indicated alteration for $49 \%$ of the samples with predominant white micas, $80 \%$ of those with predominant kandites, $50 \%$ of those with predominant 
smectites, and $62 \%$ of the samples with any one of those minerals as predominant (Figure 7.2 ).

Table 7-1. Comparison of the field alteration data that was acquired from the La Josefina deposit with the binary predictor maps of hydrothermal clay alteration that were used for prospectivity mapping (in Chapter 3 ).

$\%$ of samples considered altered by predictor maps

\begin{tabular}{lcc}
$\begin{array}{l}\text { Predominant } \\
\text { mineral in samples }\end{array}$ & $\begin{array}{c}\text { Map from ASTER band } \\
\text { ratio 4/6 }\end{array}$ & $\begin{array}{c}\text { Map from Landsat band } \\
\text { ratio 5/7 }\end{array}$ \\
\hline White micas & 39 & 49 \\
Kandites & 50 & 80 \\
Smectites & 37 & 50 \\
Any one of the & 42 & 62 \\
previous minerals & & \\
\hline
\end{tabular}

These statistics suggest that the pixels where kandites-group minerals predominate in the surface samples were most frequently classified as hydrothermally altered than those that covered the other minerals, and surprisingly, that the maps derived from Landsat are better representations of the most conspicuous types of clay alteration minerals in LISEDs than those derived from ASTER. This may indicate that the advantages of ASTER's higher spectral resolution are probably obscured by other factors such as its relatively coarse spatial resolution, which is probably the case when dealing with small areas of alteration, as those in small LISEDs. However, this relatively low performance in classification accuracy of the maps derived from ASTER may also indicate that the methods of alteration mapping, application of thresholds, and subsequent resampling were probably inadequate. The final cell size used for the predictor maps, undoubtedly degraded the original detections in some degree, although the degradation should have been higher for the products of Landsat because of the much larger cell size used for regional-scale than for district-scale maps (1000 m vs $100 \mathrm{~m}$ ) 


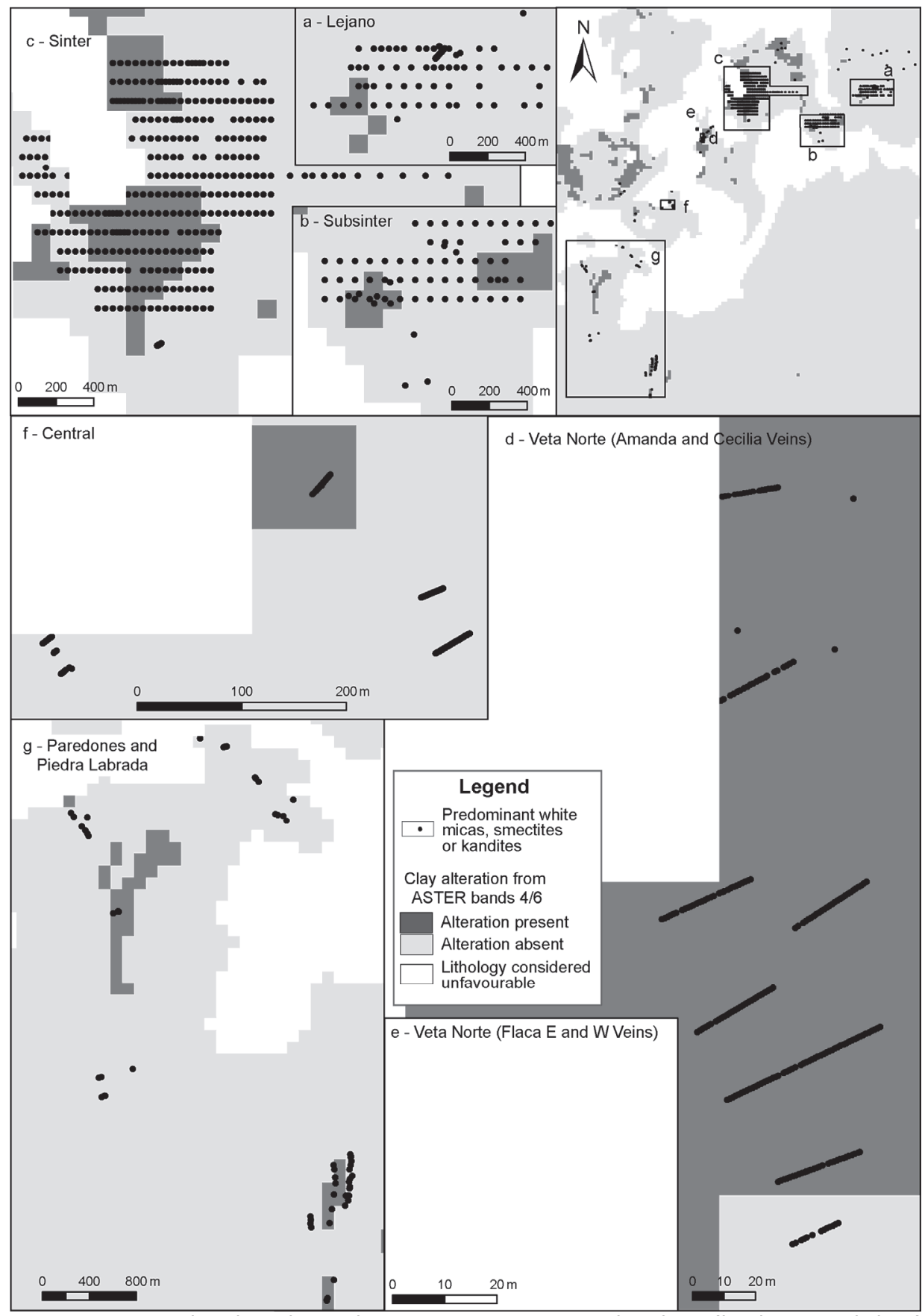

Figure 7.1: Samples that show white micas, smectites or kandites (kaolinite or dickite) as predominant minerals overlain on the binary predictor map derived from the ASTER band ratio $4 / 6$, and used for district-scale predictive mapping. 


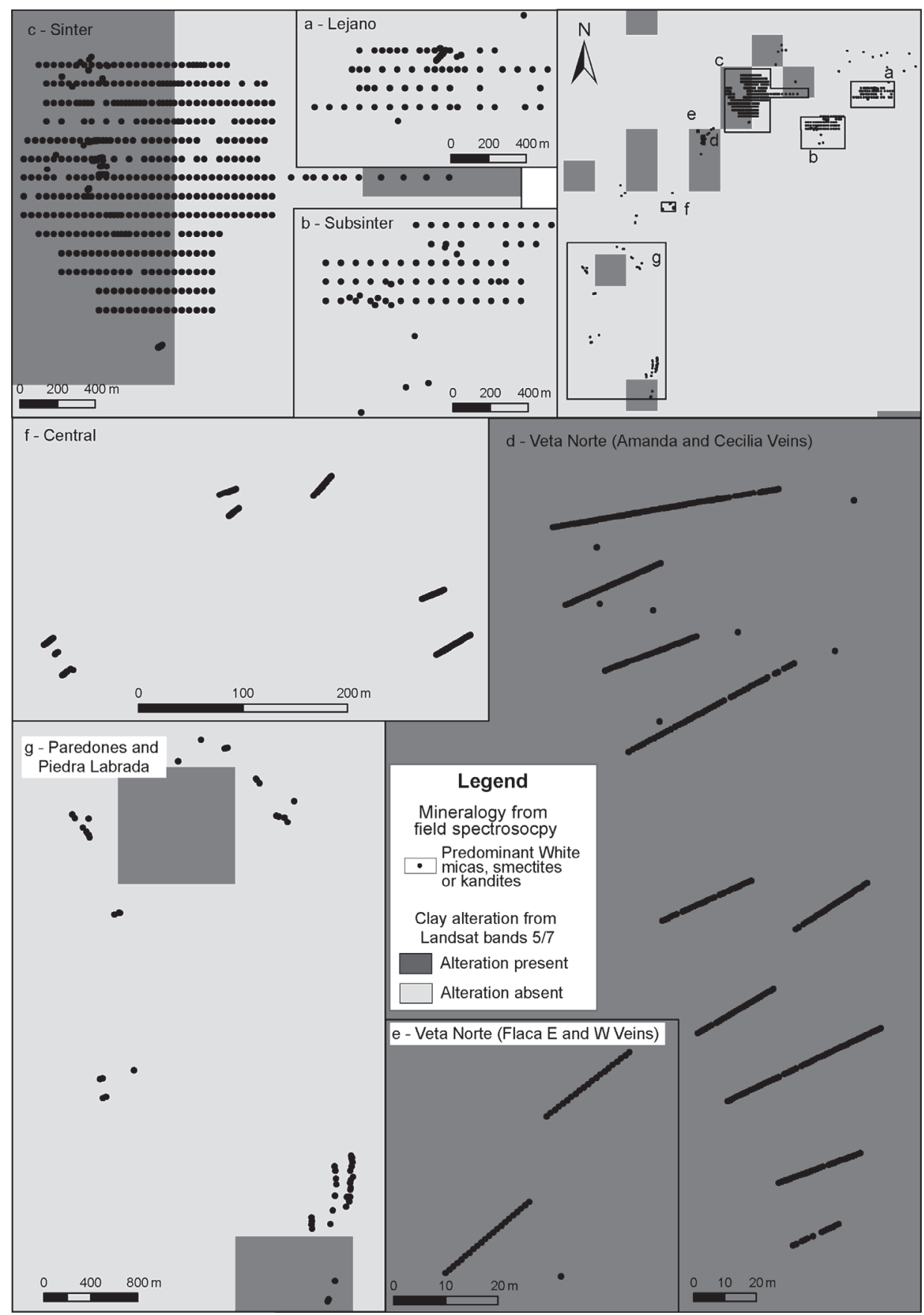

Figure 7.2: Samples showing white micas, smectites or kandites (kaolinite or dickite) as predominant minerals overlain on the binary predictor map derived from the Landsat band ratio $5 / 7$, and used for regional-scale predictive mapping. 


\subsubsection{Geochemical and spectral indicators}

The geochemical and spectral indicators that were developed and presented in chapters 5 and 6 can be used for improving the efficiency of mineral exploration surveys.

At the scale of the deposit, the most effective geochemical indicators of mineralized zones in the La Josefina epithermal deposit are anomalously high concentrations of $\mathrm{Au}, \mathrm{Cu}, \mathrm{Hg}, \mathrm{V}, \mathrm{Co}, \mathrm{Mn}, \mathrm{MgO}, \mathrm{Cr}, \mathrm{P}, \mathrm{Pb}, \mathrm{Zn}, \mathrm{FeO}, \mathrm{CCPI}$ (chlorite-calcite-pyrite index), $\mathrm{As}$ and $\mathrm{Ni}$; and anomalously low concentrations of $\mathrm{Ba}, \mathrm{Be}$ and $\mathrm{CaO}$. If the lithology and alterations in the area are slightly different to those in the Veta Norte area of the La Josefina deposit, probably the anomalously high concentrations of $\mathrm{Au}, \mathrm{Cu}, \mathrm{Pb}, \mathrm{As}, \mathrm{Hg}$, and $\mathrm{Co}$ should be considered more relevant.

The effect of weathering, which is often overlooked during geochemical surveys, should always be kept in mind. At deposit-scale surveys, if the geochemical data are collected from the upper parts of the regolith profile, $\mathrm{Co}, \mathrm{Mn}, \mathrm{Pb}, \mathrm{Zn}$ and $\mathrm{MgO}$ would better be avoided as indicators of mineralized zones. In addition, variations in the concentrations of $\mathrm{Cu}$ should be interpreted with caution because they can also be strongly affected by weathering.

Spectral parameters and minerals can be used either as indicators of the locations of paleo-conduits and their potential for being mineralized, or as indicators of the position that a studied area would represent from the epithermal paleo-system.

Kaolinite is probably the best spectrally derived indicator of potentially mineralized zones. Its abundance and patterns of occurrence are good indicators of the general position in the epithermal paleo-system. Broad areas (i.e., >100-200 m), strongly dominated by kaolinite, are indicative for the upper levels of the epithermal paleo-system around the main paleoconduits; broad areas in which kaolinite occurs, but only locally dominant, may indicate the upper levels around secondary paleo-conduits or even at distance from them. Narrow (i.e., <50 m), elongated areas with abundant kaolinite probably indicate positions of paleo-conduits at lower levels in the epithermal system, where the potential for finding mineralized rocks is high. The absence of kaolinite and presence of chlorite may indicate lower parts in the paleo-system or areas located far away from the paleo-conduits; both cases show relatively low potential for finding mineralized areas. In addition, high values of kaolinite crystallinity are good indicators of the location of veins and other paleo-conduits, regardless of the level in the paleo-system. Therefore, relatively narrow, elongated areas in which high crystallinity 
kaolinite predominates would be the best indicators of the presence of potentially mineralized paleo-conduits.

The crystallinity and wavelength position of the $\mathrm{AlOH}$ absorption feature in white micas and smectites are also good spectral indicators for different parts of the paleo-system. White micas with wavelengths below $2197 \mathrm{~nm}$ and relatively high crystallinity indicate the upper levels of the paleo-system and are related to silicified rocks produced from steam-heated waters. Areas where wavelength positions are consistently between 2197 and $2210 \mathrm{~nm}$ may contain veins or other paleo-conduits, which may be mineralized.

The new insights acquired during this research are probably not directly applicable at regional scale with the currently available datasets in the Deseado Massif. When intending to use geochemical indicators for exploring broad areas, for instance as evidence layers during new mineral prospectivity exercises, it should be kept in mind the necessity to generate the geochemical datasets. That is expensive and time-consuming, although many exploration companies are accustomed to produce large geochemical datasets. The results from this research may help those companies to produce and interpret geochemical datasets more efficiently and effectively, by selecting the right set of elements to be used.

Probably, the most advantageous strategy for applying the spectral indicators determined in this research, for future exploration in the Deseado Massif would involve the use of remote sensing datasets for deriving the spectral indicators over relatively large areas and at relatively low cost. However, hyperspectral remote sensing seems necessary for that, because the calculations of crystallinity and extraction of wavelength position of the absorption features cannot be adequately accomplished with the available multispectral datasets.

Since kaolinite is amongst the best spectral indicators, according to the results presented in this research, its detection should have a high priority in future exploration campaigns in the Deseado Massif. In theory, kaolinite may be detected by applying the correct image processing and mineral mapping techniques to the available ASTER data. In reality however, that would be only partially true, since the coarse spatial resolution of ASTER would hinder that selective detection for the relatively small areas in which kaolinite predominates in these types of deposits.

An alternative strategy is to collect the spectroscopic data with field portable spectrometers, as it was done for this research. Considering that most areas in the Deseado Massif show low relief and relatively easy access, this second option may be the most likely applied in the near future, with the advantage 
of having the high resolution provided by field spectrometers. This field data collection may even be extended to geochemistry if portable XRF devices can provide the necessary detection limits for the indicator elements to be useful.

\subsection{Towards new insights in LISED in the Deseado Massif}

The third objective of this research, which was stated in the introduction, has been addressed during most of this research but mainly by the study of geochemistry and spectroscopy presented in chapters 5 and 6 and the interpretation of the results considering the geological context.

Much of the newly acquired insights in geochemistry and spectroscopy integrates smoothly with the existing geological knowledge, which was synthesised mainly in chapters 2 and 4 , by studying the available geological information about the Deseado Massif, and in particular of the La Josefina deposit. New data helped to better understand several issues related with the formation of LISEDs. One of the most important issues is that about the genesis of kaolinite in the epithermal paleo-system, and its possible relation with the process of Au precipitation through adiabatic boiling (section 7.3.2). This is partially contrasting with previous ideas about a supergene origin (weathering) of kaolinite in the deposit, and is explaining better the cause of the observed association of kaolinite with the mineralized veins. Supergene kaolinite is however, likely present in some parts of the system, which was inferred from bimodal populations of kaolinite crystallinity and from their spatial distribution.

In addition, this research contributes to the general geological understanding of the Deseado Massif and its environment of formation, including its volcano-tectonic setting. Low-sulfidation epithermal deposits can be formed in continental or island arc rifts; they occur in intra-, near-, or back-arc settings, and during or after subduction or collision. On the other hand, the intermediate-sulfidation deposits occur mainly in volcanic arcs. Because of these affinities with certain volcano-tectonic setting, the types of epithermal deposits can be used as geological evidence to help defining the tectonic setting of a region.

In the Deseado Massif, the predominance of low-sulfidation deposits may be a reason to advocate a rift-related tectonic setting. However, during the last years, at least two intermediate-sulfidation deposits were recognized, as well as the presence of intermediate-sulfidation fluids participating in the formation of other deposits, such as La Josefina. This suggests that there may have been relatively strong links of these deposits with magmatic sources, such as those occurring in volcanic arcs and that are more typical of 
the intermediate-sulfidation deposits. Although not tested in this research, it would be instructive to analyse the spatial distribution of all deposits with indications of intermediate-sulfidation state in the Deseado Massif. This may serve to test possible links between the evolution of the volcanism and its tectonic environment towards the southwest of the Deseado Massif, with the types of epithermal deposits or with the degree of participation of intermediate-sulfidation fluids in the deposits.

Deposits with indications of intermediate-sulfidation fluids include San JoseHuevos Verdes, Mina Marta, La Josefina, and Cerro Leon. Except the last deposit, which is located in the center of the Deseado Massif, all are located in the center-west or west of the Deseado Massif. This suggests that towards the west of the region the contribution of fluids with intermediate-sulfidation state was more common, and this would be in agreement with the proposed evolution of the volcano-tectonic setting. However, this issue should still be further investigated.

\subsection{Recommendations for future research}

During the execution of this research, many questions that could not be solved appeared. Those that are considered more fundamental are described in the following paragraphs in the hope that future research will address them.

- Weathering proved to be effective in modifying the concentrations of several elements, turning them into unsuitable geochemical indicators when using data collected from upper parts of the regolith profile. Because the geochemistry and hydrothermal alterations are inseparable, effects of weathering on the hydrothermal alteration mineralogy and spectral parameters are foreseen, but yet unknown, and therefore, should be investigated.

- Kaolinite and its degree of crystallinity were found to be good indicators of the position in the paleo-system and of possible presence of paleoconduits. However, at least two populations of kaolinite were detected according to its crystallinity. It was hypothesized that kaolinite with lower degrees of crystallinity may have been produced by weathering. This issue, which is partially related to the previous one, claims for further research aimed to discover the origin of the different kaolinite populations. Discriminating between genetically different populations of clays, would help improving the use of clay alteration as geological evidence of mineral deposits. 
- Other issue related to the usefulness of kaolinite as indicator, is the apparent relationship between kaolinite crystallinity and depth and temperature of deposition. In this research, higher crystallinity kaolinite was inferred to have been deposited in the paleo-conduits and therefore, at higher temperature than kaolinite deposited in the upper levels of the system. However, this should still be proved by follow up research devised specifically to do so, in La Josefina and probably other deposits. If the relationship between crystallinity and temperature and depth can be established, it becomes possible to predict the temperature or depth of formation by using the kaolinite crystallinity, which is relatively easy to determine.

- In this research, abundant data from weathered rocks in trenches were studied. At the surface, those rocks are often covered by debris and soils, which suffer some degree of movement. Therefore, the features that are detected on the surface do not fully represent those in the subsurface (i.e., in the trenches). This needs to be investigated to determine up to what extent the surface represents the subsurface, and therefore, to infer the usefulness of different remote sensing datasets.

- It was determined in chapter 3, that silica abundance is useful to improve the prospectivity mapping. In addition, it was learned in chapter 6 that white micas with short wavelength position of their $\mathrm{AlOH}$ absorption $(2186-2197 \mathrm{~nm})$ is specifically associated with strong silicification in the upper parts of the epithermal paleo-system. Considering the difficulties of dealing with thermal remote sensors, relationships between silicification and features from minerals detectable in the SWIR range of the spectrum (e.g., the mentioned short wavelength), is useful to exploit, in order to obtain silica abundance by detection of minerals that are spatially associated with silica. Additional research is needed in this direction, for instance, starting with determining the genetic relationships between silicification and the short wavelength position of the $\mathrm{AlOH}$ absorption feature in white micas. 


\section{Bibliography}

Abrams, M., Hook, S. and Ramachandran, B., 2002. ASTER user handbook, version 2: Advanced Spaceborne Thermal Emission and Reflection Radiometer. Jet propulsion laboratory.

Agterberg, F., 2011. A Modified Weights-of-Evidence Method for Regional Mineral Resource Estimation. Natural resources research, 20(2): 95101.

Agterberg, F.P. and Cheng, Q., 2002. Conditional Independence Test for Weights-of-Evidence Modeling. Natural resources research, 11(4): 249255.

Alperin, M., Echeveste, H., Fernández, R. and Bellieni, G., 2007. Análisis estadístico de datos geoquímicos de volcanitas jurásicas del Macizo del Deseado, provincia de Santa Cruz. Revista de la Asociación Geológica Argentina, 62: 200-209.

Andrada de Palomera, P., van Ruitenbeek, F.J.A., van der Meer, F.D. and Fernández, R., 2012. Geochemical indicators of gold-rich zones in the La Josefina epithermal deposit, Deseado Massif, Argentina. Ore Geology Reviews, 45: 61-80.

Andrada de Palomera, R.P. and Carranza, E.J.M., 2005. Analysis of spatial distribution of epithermal gold deposits in the Deseado Massif, Santa Cruz province. Actas del XVI Congreso Geologico Argentino, 19-23 September 2005, La Plata: 715-722.

Arribas, A.J., Schalamuk, I.B., de Barrio, R., Fernández, R. and Itaya, T., 1996. Edades radimétricas de mineralizaciones epitermales auríferas del Macizo del Deseado, provincia de Santa Cruz, Argentina, XXXIX Congresso Brasileiro de Geología, Salvador, Brasil, pp. 254-257.

Asadi, H.H., 2000. The Zarshuran gold deposit model applied in a mineral exploration GIS in Iran, $190 \mathrm{pp}$.

Austin, J.R. and Blenkinsop, T.G., 2009. Local to regional scale structural controls on mineralisation and the importance of a major lineament in the eastern Mount Isa Inlier, Australia: Review and analysis with autocorrelation and weights of evidence. Ore Geology Reviews, 35(34): 298-316.

Battaglia, S., 2004. Variations in the chemical composition of illite from five geothermal fields: a possible geothermometer. Clay Minerals, 39(4): 501-510.

Behnia, P., 2007. Application of Radial Basis Functional Link Networks to Exploration for Proterozoic Mineral Deposits in Central Iran. Natural resources research, 16(2): 147-155.

Berger, B.R. and Silberman, M.L., 1985. Relationships of trace-element patterns to geology in hot-spring-type precious metal deposits. In: B.R. Berger and P.M. Bethke (Editors), Geology and Geochemistry of 
Epithermal Systems. Reviews in Economic Geology 2. Society of Economic Geologists, pp. 233-247.

Biel, C., Subías, I., Acevedo, R.D., Yusta, I. and Velasco, F., 2012. Mineralogical, IR-spectral and geochemical monitoring of hydrothermal alteration in a deformed and metamorphosed Jurassic VMS deposit at Arroyo Rojo, Tierra del Fuego, Argentina. Journal of South American Earth Sciences, 35(0): 62-73.

Bierwirth, P., Huston, D. and Blewett, R., 2002. Hyperspectral mapping of mineral assemblages associated with gold mineralization in the Central Pilbara, Western Australia. Economic Geology, 97: 819-826.

Boleneus, D.E., Raines, G.L., Causey, J.D., Bookstrom, A.A., Frost, T.P. and Hyndman, P.C., 2001. Assessment method for epithermal gold deposits in northeast Washington State using weights-of-evidence GIS modeling. US Geological Survey, Open-File Report 01-501: 52.

Bonham-Carter, G.F., 1994. Geographic information systems for geoscientists., 398 pp.

Bonham-Carter, G.F., Agterberg, F.P. and Wright, D.F., 1989. Weights of evidence modeling: a new approach to mapping mineral potential. In Statistical Applications in the Earth Sciences, Eds. F.P. Agterberg and G.F. Bonham-Carter. Geological Survey of Canada, Paper 89-9., : 171183.

Booden, M.A., Mauk, J.L. and Simpson, M.P., 2011. Quantifying Metasomatism in Epithermal Au-Ag Deposits: A Case Study from the Waitekauri Area, New Zealand. Economic Geology, 106(6): 999-1030.

Browne, P.R.L. and Ellis, A.J., 1970. The Ohaaki-Broadlands geothermal area, New Zealand: mineralogy and related geochemistry. American Journal of Science, 269: 97-131.

Bryan, S.E. and Ernst, R.E., 2008. Revised definition of Large Igneous Provinces (LIPs). Earth-Science Reviews, 86(1-4): 175-202.

Bryan, S.E., Riley, T.R., Jerram, D.A., Stephens, C.J. and Leat, P.T., 2002. Silicic volcanism: An undervalued component of large igneous provinces and volcanic rifted margins. Geological Society of America; Special Paper 362: 99-120.

Buchanan, L.J., 1981. Precious metal deposits associated with volcanic environments in the southwest. Arizona Geological Society, Digest 14: 237-262.

Carranza, E.J.M., 2002. Geologically-constrained mineral potential mapping (examples from the Philippines), $480 \mathrm{pp}$.

Carranza, E.J.M., 2004. Weights of Evidence Modeling of Mineral Potential: A Case Study Using Small Number of Prospects, Abra, Philippines. Natural resources research, 13(3): 173-187.

Carranza, E.J.M., 2011. Analysis and mapping of geochemical anomalies using logratio-transformed stream sediment data with censored values. Journal of Geochemical Exploration, 110(2): 167-185. 
Carranza, E.J.M. and Andrada de Palomera, R.P., 2005. Evidential belief mapping of epithermal gold potential in the Deseado massif, Santa Cruz Province, Argentina., XVI Congreso Geologico Argentino. Actas, La Plata, pp. 451-458.

Carranza, E.J.M. and Hale, M., 2000. Geologically constrained probabilistic mapping of gold potential, Bagio district, Philippines Natural Resources Research, 9(3): 237-253.

Carranza, E.J.M. and Hale, M., 2001. Geologically Constrained Fuzzy Mapping of Gold Mineralization Potential, Baguio District, Philippines Natural Resources Research, 10(2): 125-136.

Carranza, E.J.M. and Hale, M., 2003. Evidential belief functions for datadriven geologically constrained mapping of gold potential, Baguio district, Philippines. Ore Geology Reviews, 22(1-2): 117-132.

Carranza, E.J.M. and Sadeghi, M., 2010. Predictive mapping of prospectivity and quantitative estimation of undiscovered VMS deposits in Skellefte district (Sweden). Ore Geology Reviews, 38(3): 219-241.

Carranza, E.J.M., van Ruitenbeek, F.J.A., Hecker, C., van der Meijde, M. and van der Meer, F.D., 2008. Knowledge-guided data-driven evidential belief modeling of mineral prospectivity in Cabo de Gata, SE Spain. International Journal of Applied Earth Observation and Geoinformation, 10(3): 374-387.

Cathelineau, M., 1988. Cation site occupancy in chlorites and illites as a function of temperature. Clay Minerals, 23: 471-485.

Cathelineau, M. and Izquierdo, G., 1988. Temperature - composition relationships of authigenic micaceous minerals in the Los Azufres geothermal system. Contributions to Mineralogy and Petrology, 100(4): 418-428.

Cathelineau, M., Oliver, R., Nieva, D. and Garfias, A., 1985. Mineralogy and distribution of hydrothermal mineral zones in Los Azufres (Mexico) geothermal field. Geothermics, 14(1): 49-57.

Cedillo Frey, A., Paez, G., Ruiz, R., Bauluz Lázaro, B. and Subías Pérez, I., 2009. Mineralogía de la Alteración Hidrotermal en el Yacimiento Epitermal Mina Martha, Macizo del Deseado, Argentina. Revista de la Sociedad Española de Mineralogía, Macla, 11: 57-58.

Chan, L.S., Wong, P.W. and Chen, Q.F., 2007. Abundances of radioelements ( $K, U, T h$ ) in weathered igneous rocks in Hong Kong. Journal of Geophysics and Engineering, 4(3): 285-292.

Chang, Z. and Yang, Z., 2012. Evaluation of inter-instrument variations among short wavelength infrared (SWIR) Devices. Economic Geology, 107(7): 1479-1488.

Chittleborough, D.J., 1991. Indices of weathering for soils and palaeosols formed on silicate rocks. Australian Journal of Earth Sciences, 38(1): 115-120. 
Chung, C.F. and Fabbri, A.G., 2003. Validation of Spatial Prediction Models for Landslide Hazard Mapping. Natural Hazards, 30: 451-472.

Cobos, J.C. and Panza, J.L., 2003. Hoja Geológica 4769-I, El Pluma. Servicio Geológico Minero Argentino, Instituto de Geología y Recursos Minerales.

Cooke, D.R. and Simmons, S.F., 2000. Characteristics and genesis of epithermal gold deposits. In: S.G. Hagemann and P.E. Brown (Editors), Gold in 2000. Reviews in Economic Geology 13. Society of Economic Geologists, pp. 221-244.

Coupland, T., 2009. Update report on the Cerro Moro Project, Santa Cruz province, Argentina. Technical Report (NI 43-101) prepared for Exeter Resource Corporation and Extorre Gold Mines Ltd.

Crósta, A. and Moore, J.M., 1989. Enhancement of Landsat Thematic Mapper imagery for residual soil mapping in SW Minais Gerais State, Brazil: a prospecting case history in Greenstone belt terrain., 7th ERIM Thematic Conference: Remote sensing for exploration geology, Calgary, Canada, pp. 1173-1187.

Cudahy, T.J., Yang, K. and Scott, K.M., 1996. Spectral study of the Star Gold Deposit, Mount Magnet, Western Australia. AMIRA, Exploration and Mining Report 177R: $41 \mathrm{pp}$.

Darce, M., Levi, B. and Nystrom, J.O., 1991. Chemical changes during alteration of volcanic rocks and gold ore formation, La Libertad, Nicaragua. Journal of South American Earth Sciences, 4(1-2): 87-97.

Davis, J.C., 1986. Statistics and data analysis in Geology. John Willey \& Sons, New York, 641 pp.

de Barrio, R., Panza, J.L. and Nullo, F., 1999. Jurásico y Cretácico del Macizo del Deseado, provincia de Santa Cruz. In: R. Caminos (Editor), Geología Argentina, anales 29. Instituto de Geología y Recursos Minerales, pp. 511-527.

de Barrio, R.E., Palma, R.M. and Panza, J.L., 1986. Deseado Massif, correlation with the Andean region. In: The Geologic Evolution of South America, Servicio Geologico Nacional. Unpublished Report.

de Boorder, H., 2012. Spatial and temporal distribution of the orogenic gold deposits in the Late Palaeozoic Variscides and Southern Tianshan: How orogenic are they? Ore Geology Reviews, 46(0): 1-31.

De Giusto, J.M., Di Persia, C. and Pezzi, E., 1980. Nesocratón del Deseado. In Geología Regional Argentina, Academia Nacional de Ciencias, Córdoba, II: $1389-1430$.

de Quadros, T.P., Koppe, J., Strieder, A. and Costa, J.C.L., 2006. MineralPotential Mapping: A Comparison of Weights-of-Evidence and Fuzzy Methods. Natural resources research, 15(1): 49-65.

Deng, M., 2009. A Conditional Dependence Adjusted Weights of Evidence Model. Natural resources research, 18(4): 249-258. 
Dietrich, A., Gutierrez, R., Nelson, E. and Layer, P., 2012. Geology of the epithermal Ag-Au Huevos Verdes vein system and San José district, Deseado massif, Patagonia, Argentina. Mineralium Deposita, 47(3): 233-249.

Dinger, J.S., Andrews, R.E., Wunsch, D.R. and Dunno, G.A., 2002. Remote sensing and field techniques to locate fracture zones for high-yield water wells in the Appalachian Plateau, Kentucky, Proceedings of the National Ground Water Association Fractured-Rock Aquifer 2002 Conference, Denver, Colorado, pp. 195-199.

Dirección Nacional del Servicio Geológico, 1994. Mapa Geológico de la Provincia de Santa Cruz (escala 1:750,000), República Argentina. Dirección Nacional del Servicio Geológico, Secretaría de Minería.

Duke, E.F. and Lewis, R.S., 2010. Near infrared spectra of white mica in the Belt Supergroup and implications for metamorphism. American Mineralogist, 95: 908-920.

Duzgoren-Aydin, N.S. and Aydin, A., 2009. Distribution of rare earth elements and oxyhydroxide phases within a weathered felsic igneous profile in Hong Kong. Journal of Asian Earth Sciences, 34(1): 1-9.

Duzgoren-Aydin, N.S., Aydin, A. and Malpas, J., 2002. Distribution of clay minerals along a weathered pyroclastic profile, Hong Kong. Catena, 50(1): 17-41.

Echavarría, L., 2004. Los fluidos hidrotermales formadores de la mineralización epitermal el Dorado-Monserrat, Macizo del Deseado. Revista de la Asociación Geológica Argentina, 59(1): 70-82.

Echavarría, L.E., Schalamuk, I.B. and Etcheverry, R.O., 2005. Geologic and tectonic setting of Deseado Massif epithermal deposits, Argentina, based on El Dorado-Monserrat. Journal of South American Earth Sciences, 19(4): 415-432.

Echeveste, H., 2010. Control estructural de la mineralización epitermal del distrito Manantial Espejo, Santa Cruz. Revista de la Asociación Geológica Argentina, 66(3): 325-334.

Einaudi, M.T., Hedenquist, J.W. and Inan, E.E., 2003. Sulfidation state of fluids in active and extinct hydrothermal systems: transitions from porphyry to epithermal environments. Society of Economic Geologists, Special Publication 10, 2003: 285-313.

Fernández, R., Echeveste, H., Tassinari, C. and Schalamuk, I., 1999. Rb-Sr age of the La Josefina epithermal mineralization and its relation with host volcanic rocks. Macizo del Deseado, Santa Cruz Province. Argentina., 20 Simposio Sudamericano de Geología Isotópica, Villa Carlos Paz, Córdoba, pp. Actas:462-465.

Fernández, R., Pérez, D., Moreira, P., Andrada de Palomera, R.P., Albornoz, S. and Penzo, H., 2005. Exploración de la "Zona de Fractura Mogote Hormigas", prospecto La Josefina, Santa Cruz, Argentina., XVI Congreso Geológico Argentino, La Plata, pp. 731-736. 
Fernández, R.R., Blesa, A., Moreira, P., Echeveste, H., Mykietiuk, K., Andrada de Palomera, P. and Tessone, M., 2008. Los depósitos de oro y plata vinculados al magmatismo jurásico de la Patagonia: revisión y perspectivas para la exploración. Revista de la Asociación Geológica Argentina, 63: 665-681.

Fernández, R.R., Echeveste, H., Echavarría, L. and Schalamuk, I.B., 1996. Control volcánico y tectónico de la mineralización epitermal del área de La Josefina, Macizo del Deseado, Santa Cruz, Argentina. In XIII Congreso Geológico Argentino y III Congreso de Exploración de Hidrocarburos, Buenos Aires, Actas III: 41-54.

Feruglio, E., 1949. Descripción geológica de la Patagonia (3 tomos). Yacimientos Petrolíferos Fiscales (inédito).

Ford, A. and Hart, C.J.R., 2013. Mineral potential mapping in frontier regions: A Mongolian case study. Ore Geology Reviews, 51(0): 15-26.

Fritsch, E., Balan, E., Régina Do Nascimento, N., Allard, T., Bardy, M., Bueno, G., Derenne, S., Melfi, A.J. and Calas, G., 2011. Deciphering the weathering processes using environmental mineralogy and geochemistry: Towards an integrated model of laterite and podzol genesis in the Upper Amazon Basin. Comptes Rendus Geoscience, 343(2-3): 188-198.

Gemmell, J.B., 2007. Hydrothermal Alteration Associated with the Gosowong Epithermal Au-Ag Deposit, Halmahera, Indonesia: Mineralogy, Geochemistry, and Exploration Implications. Economic Geology, 102(5): 893-922.

Giacosa, R., Zubia, M., Sánchez, M. and Allard, J., 2010. Meso-Cenozoic tectonics of the Southern Patagonian foreland: structural evolution and implications for Au-Ag veins in the Eastern Deseado Region (Santa Cruz, Argentina). Journal of South American Earth Sciences, 30(3-4): 134-150.

Giacosa, R.E., Césari, O. and Genini, A.D., 1998. Hoja Geológica 4766-III y IV, Puerto Deseado. Servicio Geológico Minero Argentino, Subsecretaría de Minería de la Nación. Programa Nacional de Cartas Geológicas de la República Argentina (1:250000), Boletin No240.

Giacosa, R.E., Márquez, M.M. and Panza, J.L., 2002. Basamento Paleozóico Inferior del Macizo del Deseado. In M.J. Haller (Edit.) Geologia y Recursos Naturales de Santa Cruz. Relatorio del XV Congreso Geologico Argentino, El Calafate, I-22.

Gifkins, C., Herrmann, W. and Large, R.R., 2005. Altered volcanic rocks : a guide to description and interpretation. Centre for Ore Deposit Research, University of Tasmania, Hobart, 275 pp.

Godeas, M.A., 1985. Geología del Bajo de La Leona y su mineralogía asociada, Provincia de Santa Cruz. Revista de la Asociación Geológica Argentina, 40(3-4): 262-277. 
González-Álvarez, I., Porwal, A., Beresford, S.W., McCuaig, T.C. and Maier, W.D., 2010. Hydrothermal $\mathrm{Ni}$ prospectivity analysis of Tasmania, Australia. Ore Geology Reviews, 38(3): 168-183.

Gonzalez Guillot, M., de Barrio, R. and Ganem, F., 2004. Mina Martha: un Yacimiento epitermal argentífero en el Macizo del Deseado, provincia de Santa Cruz, Actas 70 Congreso de Mineralogía y Metalogenia, Río Cuarto, pp. 199-204.

Goodchild, M.F., 2011. Scale in GIS: An overview. Geomorphology, 130(12): 5-9.

Grant, J.A., 1986. The isocon diagram; a simple solution to Gresens' equation for metasomatic alteration. Economic Geology, 81(8): 1976-1982.

Gresens, R.L., 1967. Composition-volume relationships of metasomatism. Chemical Geology, 2: 47-65.

Grove, C.I., Hook, S.J. and Paylor, E.D., 1992. Laboratory reflectance spectra for 160 minerals $0.4-2.5$ micrometers. Jet Propulsion Laboratory (JPL), Publication 92-2.

Guan, P., Ng, C.W.W., Sun, M. and Tang, W., 2001. Weathering indices for rhyolitic tuff and granite in Hong Kong. Engineering Geology, 59(1-2): 147-159.

Guido, D., 2004. Caracterización de los fluidos hidrotermales en el área Chispas, este del Macizo del Deseado, provincia de Santa Cruz, 70 Congreso de Mineralogía y Metalogenia, pp. 213-218.

Guido, D.M., 2002. Geología y metalogénesis del sector oriental del Macizo del Deseado, Provincia de Santa Cruz. PhD Thesis Thesis, Facultad de Ciencias Naturales y Museo, Universidad Nacional de La Plata, La Plata, $226 \mathrm{pp}$.

Guido, D.M., Jovic, S.M. and Schalamuk, I.B., 2005. A new metallogenical association ( $\mathrm{Sn}-\mathrm{Cd}-\mathrm{In}-\mathrm{Zn}-\mathrm{Ag}-\mathrm{Au}$ ) in the Deseado auroargentiferous province, Deseado Massif, Patagonia, Argentina. In: J. Mao and F.P. Bierlein (Editors), Mineral Deposit Research: Meeting the Global Challenge. Springer Berlin Heidelberg, pp. 965-968.

Guilbert, J.M. and Park, C.F., 1986. The geology of ore deposits. W. H. Freeman and Company, New York, 985 pp.

Gust, D.A., Biddle, K.T., Phelps, D.W. and Uliana, M.A., 1985. Associated middle to late Jurassic volcanism and extension in southern South America. Tectonophysics, 116(3-4): 223-253.

Harris, D. and Pan, G., 1999. Mineral Favorability Mapping: A Comparison of Artificial Neural Networks, Logistic Regression, and Discriminant Analysis. Natural resources research, 8(2): 93-109.

Harris, J.R. and Sanborn-Barrie, M., 2006. Mineral potential mapping: examples from the Red Lake Greenstone Belt, Northwest Ontario. In: J.R. Harris (Editor), Special Publication 44: GIS applications in earth sciences. Geological Association of Canada, pp. 1 -22. 
Hayba, D.O., Bethke, P.M., Heald, P. and Foley, K.L., 1985. Geologic, mineralogic, and geochemical characteristics of volcanic-hosted epithermal precious-metal deposits. In: B.R. Berger and P.M. Bethke (Editors), Geology and Geochemistry of Epithermal Systems. Reviews in Economic Geology. Society of Economic Geologists, pp. 129-167.

Hedenquist, J.W., Arribas, A.R. and Gonzalez-Urien, E., 2000. Exploration for epithermal gold deposits. In: S.G. Hagemann and P.E. Brown (Editors), Gold in 2000. Reviews in Economic Geology Society of Economic Geologists, pp. 245-277.

Hedenquist, J.W. and Henley, R.W., 1985. Hydrothermal eruptions in the Waiotapu geothermal system, New Zealand: their origin, associated breccias, and relation to precious metal mineralization. Economic Geology, 80(GEOBASE): 1640-1668.

Henley, R.W., 1985. The geothermal framework of epithermal deposits. Reviews in Economic Geology, 2: 1-24.

Herrera, P.A., Closs, L.G. and Silberman, M.L., 1993. Alteration and geochemical zoning in Bodie Bluff, Bodie mining district, eastern California. Journal of Geochemical Exploration, 48(2): 259-275.

Hung, L.Q., Batelaan, O. and De Smedt, F., 2005. Lineament extraction and analysis, comparison of LANDSAT ETM and ASTER imagery. Case study: Suoimuoi tropical karst catchment, Vietnam. In: V.M. Ehlers and M. Ulrich (Editors), Remote Sensing for Environmental Monitoring, GIS Applications, and Geology. Proceedings of SPIE, Bellingham, WA.

Huston, D.L., Kamprad, J. and Brauhart, C., 1999. Definition of hightemperature alteration zones with PIMA: an example from the Panorama VHMS district, central Pilbara Craton. AGSO Research Newsletter 30: $3 \mathrm{pp}$.

INREMI, 1996. Informe geologico-minero del area de reserva La Josefina (Fomicruz S.E.), Provincia de Santa Cruz., Unpublished report for Fomicruz S.E.

Ishikawa, Y., Sawaguchi, T., Iwaya, S. and Horiuchi, M., 1976. Delineation of prospecting targets for Kuroko deposits based on modes of volcanism of underlying dacite and alteration halos. Mining Geology, 26: 105-117.

Japas, M.S., Sruoga, P., Kleiman, L.E., Gayone, M.R., Maloberti, A. and Comito, O., 2013. Cinemática de la extensión jurásica vinculada a la Provincia Silícea Chon Aike, Santa Cruz, Argentina. Revista de la Asociación Geológica Argentina, 70: 16-30.

John, D.A., 2001. Miocene and Early Pliocene Epithermal Gold-Silver Deposits in the Northern Great Basin, Western United States: Characteristics, Distribution, and Relationship to Magmatism. Economic Geology, 96(8): 1827-1853.

John, D.A., Hofstra, A.H., Fleck, R.J., Brummer, J.E. and Saderholm, E.C., 2003. Geologic Setting and Genesis of the Mule Canyon Low-Sulfidation 
Epithermal Gold-Silver Deposit, North-Central Nevada. Economic Geology, 98(2): 425-463.

Jones, S., Herrmann, W. and Gemmell, J.B., 2005. Short wavelength infrared spectral characteristics of the HW horizon: Implications for exploration in the Myra Falls volcanic-hosted massive sulfide camp, Vancouver Island, British Columbia, Canada. Economic Geology, 100: 273-294.

Jovic, S., Guido, D., Schalamuk, I., Ríos, F., Tassinari, C. and Recio, C., 2011. Pingüino In-bearing polymetallic vein deposit, Deseado Massif, Patagonia, Argentina: characteristics of mineralization and ore-forming fluids. Mineralium Deposita, 46(3): 257-271.

Jovic, S., Guido, D.M., Tiberi, P. and Schalamuk, I.B., 2004. Cerro León, una variación del modelo epitermal de baja sulfuración del Macizo del Deseado, Actas 70 Congreso de Mineralogía y Metalogenia, Río Cuarto, Argentina, pp. 225-230.

Koike, K., Nagano, S. and Ohmi, M., 1995. Lineament analysis of satellite images using a Segment Tracing Algorithm (STA). Computers \& Geosciences, 21(9): 1091-1104.

Large, R.R., Gemmell, J.B., Paulick, H. and Huston, D.L., 2001. The Alteration Box Plot: A Simple Approach to Understanding the Relationship between Alteration Mineralogy and Lithogeochemistry Associated with Volcanic-Hosted Massive Sulfide Deposits. Economic Geology, 96(5): 957-971.

Lepage, R., Rouhana, R.G., St-Onge, B., Noumeir, R. and Desjardins, R., 2000. Cellular neural network for automated detection of geological lineaments on Radarsat images. IEEE Transactions on Geoscience and Remote Sensing, 38(3): 1224-1233.

Lesta, P.J. and Ferello, R., 1972. Región extraandina de Chubut y norte de Santa Cruz. In: Geología Regional Argentina. Academia Nacional de Ciencias: 601-654.

Levinson, A.A., 1974. Introduction to exploration geochemistry. Applied Publishing Ltd., Calgary, $612 \mathrm{pp}$.

Malpas, J., Duzgoren-Aydin, N.S. and Aydin, A., 2001. Behaviour of chemical elements during weathering of pyroclastic rocks, Hong Kong. Environment International, 26(5-6): 359-368.

Marjoribanks, R., 2010. Geological Methods in Mineral Exploration and Mining. Springer-Verlag Berlin Heidelberg, 238 pp.

Márquez, M.J., Giacosa, R.E. and Godeas, M.A., 2002. Los Granitoides gondwánicos del borde oriental del Macizo del Deseado. In M.J. Haller (Edit): Geología y Recursos Naturales de Santa Cruz. Relatorio del XV Congreso Geológico Argentino, El Calafate, I-4: 57-70.

Mauk, J.L. and Simpson, M.P., 2007. Geochemistry and Stable Isotope Composition of Altered Rocks at the Golden Cross Epithermal Au-Ag Deposit, New Zealand. Economic Geology, 102(5): 841-871. 
McLeod, R.L., Gabell, A.R., Green, A.A. and Gardavsky, V., 1987. Chlorite infrared spectral data as proximity indicators of vocanogenic massive sulfide mineralization, Proceedings of Pacific Rim Congress 87, pp. 321324.

Miyatake, S., 2002. Regional lineament analysis and alteration mineral mapping for intrusive-related copper exploration in the Myanmar central volcanic belt., 23rd Asian Conference on Remote Sensing (papers on-line). GIS Development, Katmandu, pp. 4.

MMAJ, 2000. Technical development report: Examination of indices for discriminating rocks and minerals and their universal validity (In Japanese with English abstract). (III): 1-31.

Moon, C.J., Whateley, M.K.G. and Evans, A.M. (Editors), 2006. Introduction to Mineral Exploration. Blackwell Publishing, $481 \mathrm{pp}$.

Moor, D.S. and McCabe, G.P., 1999. Introduction to the practice of statistics. W.H. Freeman and Company, New York, 825 pp.

Moreira, P., 2005. Geología y Metalogénesis del Distrito La Josefina, Macizo del Deseado, Provincia de Santa Cruz. Tesis Doctoral. Facultad de Ciencias Naturales y Museo, Universidad Nacional de La Plata, pp. 383.

Moreira, P., Andrada, P., Fernández, R.R. and R.O., E., 2001. Fragmentos de rocas metamórficas portadoras de oro en una brecha hidrotermal de la Formación Chon Aike, distrito La Josefina, Santa Cruz, 70 Congreso Argentino de Geología Económica, Salta pp. 105.

Moreira, P., Echeveste, H., Fernández, R., Hartmann, L.A., Santos, J.O.S. and Schalamuk, I., 2009. Depositional age of Jurassic epithermal goldsilver ore in the Deseado Massif, Patagonia, Argentina, based on Manantial Espejo and La Josefina prospects. Neues Jahrbuch für Geologie und Paläontologie - Abhandlungen, 253(1): 25-40.

Moreira, P., Fernández, R., Cabana, C. and Schalamuk, I., 2008. Analisis estructural de las mineralizaciones jurasicas del proyecto epitermal La Josefina (Au-Ag), Macizo del Deseado, Santa Cruz. Revista de la Asociación Geológica Argentina, 63(2): 244-253.

Moreira, P., Fernández, R., Hervé, F., Fanning, C.M. and Schalamuk, I.A., 2013. Detrital zircons U-Pb SHRIMP ages and provenance of La Modesta Formation, Patagonia Argentina. Journal of South American Earth Sciences(0).

Moreira, P., Fernández, R., Ríos, J. and Schalamuk, I.A., $2004 a$. Caracterización de la esfalerita de las manifestaciones epitermales del area La Josefina, Macizo del Deseado, Provincia de Santa Cruz, Actas VII Congreso de Mineralogía y Metalogenia, Río Cuarto (Córdoba) pp. 89-94.

Moreira, P., Fernández, R., Schalamuk, I. and Echeverry, R., 2002. Depósitos carbonaticos de hot spring relacionados a manifestaciones epitermales (Au-Ag), distrito La Josefina, Macizo del Deseado, Provincia de Santa Cruz. XV Congreso Geologico Argentino, El Calafate. 
Moreira, P. and Fernández, R.R., 2015. La Josefina Au-Ag deposit (Patagonia, Argentina): A Jurassic epithermal deposit formed in a hot spring environment. Ore Geology Reviews, 67(0): 297-313.

Moreira, P., Fernández, R.R., Schalamuk, I.A., Etcheverry, R.O. and Rolando, A.P., 2005. Jurassic magmatism and Au-Ag mineralization in the Deseado Massif (Patagonia Argentina): Lead and sulfur isotopic studies. In: J. Mao and F.P. Bierlein (Editors), Mineral Deposit Research: Meeting the Global Challenge. Springer Berlin Heidelberg, pp. 801-804.

Moreira, P., López, K., Echeverry, R. and Fernández, R., 2004b. Caracterización de la argilización asociada a las manifestaciones epitermales de Au-Ag del area La Josefina, Macizo del Deseado, Santa Cruz, 70 Congreso de Mineralogía y Metalogenia, Río Cuarto pp. 249254.

Murakami, H. and Feebrey, C.A., 2001. Geology and geophysical expression of the Yamagano low-sulfidation epithermal Au-Ag deposit, Southwest Kyushu, Japan. In: C.A. Feebrey, T. Hayashi and S. Taguchi (Editors), Epithermal Gold Mineralization and Modern Analogues, Kyushu, Japan. Guidebook Series. Society of Economic Geologists, pp. 31-47.

Mykietiuk, K., Fernández, R. and Azevedo, F., 2005. Alteraciones hidrotermales superpuestas: producto de fluidos de $\mathrm{pH}$ neutro y ácido en el cerro Guanaco, Macizo del Deseado, Santa Cruz. Revista de la Asociación Geológica Argentina, 60(1): 23-31.

Nelson, E.P., Dalziel, I.W.D. and Milnes, A.G., 1980. Structural geology of the Cordillera Darwin -collisional-style orogenesis in the southernmost Chilean Andes. Zeitschrift: Eclogae Geologicae Helvetiae, 73(3): 727751.

Nykänen, V. and Ojala, V.J., 2007. Spatial Analysis Techniques as Successful Mineral-Potential Mapping Tools for Orogenic Gold Deposits in the Northern Fennoscandian Shield, Finland. Natural resources research, 16(2): 85-92.

Páez, G.N., Ruiz, R., Guido, D.M., Jovic, S.M. and Schalamuk, I.B., 2010. The effects of K-metasomatism in the Bahía Laura Volcanic Complex, Deseado Massif, Argentina: Petrologic and metallogenic consequences. Chemical Geology, 273(3-4): 300-313.

Páez, G.N., Ruiz, R., Guido, D.M., Jovic, S.M. and Schalamuk, I.B., 2011. Structurally controlled fluid flow: High-grade silver ore-shoots at Martha epithermal mine, Deseado Massif, Argentina. Journal of Structural Geology, 33(5): 985-999.

Pankhurst, R.J., Leat, P.T., Sruoga, P., Rapela, C.W., Márquez, M., Storey, B.C. and Riley, T.R., 1998. The Chon Aike province of Patagonia and related rocks in West Antarctica: A silicic large igneous province. Journal of volcanology and geothermal research, 81(1-2): 113-136. 
Pankhurst, R.J., Riley, T.R., Fanning, C.M. and Kelley, S.P., 2000. Episodic Silicic Volcanism in Patagonia and the Antarctic Peninsula: Chronology of Magmatism Associated with the Break-up of Gondwana. Journal of Petrology, 41(5): 605-625.

Panza, J.L., 1982. Descripción geológica de las Hojas 53e "Gobernador Moyano" y 54e "Cerro Vanguardia". Servicio Geológico Nacional (inédito). $197 \mathrm{p}$.

Panza, J.L., 1994a. Hoja Geológica 4966 - I y II, Bahía Laura, Provincia de Santa Cruz. Dirección Nacional del Servicio Geológico, Secretaría de Minería de la Nación. Programa Nacional de Cartas Geológicas de la República Argentina (1:250000), Boletin No 214: 83.

Panza, J.L., 1994b. Hoja Geológica 4969 - II, Tres Cerros, Provincia de Santa Cruz. Dirección Nacional del Servicio Geológico, Secretaría de Minería de la Nación. Programa Nacional de Cartas Geológicas de la República Argentina (1:250000), Boletin No 213: 103.

Panza, J.L., 2001. Hoja Geológica 4769-IV Monumento Natural Bosques Petrificados, escala 1:250.000, Santa Cruz. Boletín 258. . Servicio Geológico Minero Argentino (SEGEMAR).

Panza, J.L. and Cobos, J.C., 2001. Hoja Geológica 4769-III, Destacamento La Maria. Servicio Geológico Minero Argentino, Subsecretaría de Minería de la Nación. Programa Nacional de Cartas Geológicas de la República Argentina (1:250000), Boletin N0296.

Panza, J.L. and Marín, G., 1998. Hoja Geológica 4969-I, Gobernador Gregores. Servicio Geológico Minero Argentino, Subsecretaría de Minería de la Nación. Programa Nacional de Cartas Geológicas de la República Argentina (1:250000), Boletin N0239.

Peñalva, G.A., Moreira, P. and Chernicoff, C.J., 2005. Area La Josefina, Macizo del Deseado, Provincia de Santa Cruz: nuevas evidencias geofísicas y geoquímicas, XVI Congreso Geológico Argentino, Actas 2, La Plata pp. 807-814.

Permuy Vidal, C., Páez, G.N., Guido, D.M., Jovic, S.M. and Ruiz, R., 2014. Vulcanismo pre, sin y post-mineral en el distrito epitermal Cerro Negro (Au-Ag), Macizo del Deseado, Provincia de Santa Cruz, XIX Congreso Geológico Argentino, Córdoba, pp. 2.

Pirajno, F., 1992. Hydrothermal mineral deposits: principles and fundamental concepts for the exploration geologist. Springer-Verlag, Berlin, 709 pp.

Pirajno, F. and Santosh, M., 2014. Rifting, intraplate magmatism, mineral systems and mantle dynamics in central-east Eurasia: An overview. Ore Geology Reviews, 63(0): 265-295.

Pontual, S., Merry, N. and Gamson, P., 1997. Spectral Analysis Guides for Mineral Exploration (G-MEX). AuSpec International Pty. Ltd., (8 volumes). 
Porwal, A., Carranza, E. and Hale, M., 2006. A Hybrid Fuzzy Weights-ofEvidence Model for Mineral Potential Mapping. Natural resources research, $15(1): 1-14$.

Porwal, A., Carranza, E.J.M. and Hale, M., 2003. Knowledge-driven and datadriven fuzzy models for predictive mineral potential mapping. Natural Resource Research, 12(1): 1-25.

Porwal, A., González-Álvarez, I., Markwitz, V., McCuaig, T.C. and Mamuse, A., 2010. Weights-of-evidence and logistic regression modeling of magmatic nickel sulfide prospectivity in the Yilgarn Craton, Western Australia. Ore Geology Reviews, 38(3): 184-196.

Post, J.L. and Noble, P.N., 1993. The near-infrared combination band frequencies of dioctahedral smectites, micas, and illites. Clays and Clay Minerals, 41(6): 639-644.

Prakash, A., 2001. Radiometric Aspects (Chapter 8). in Janssen, L. L. F., and Huurneman, G. C., eds., Principles of remote sensing. ITC Educational Textbook Series, International Institute for Aerospace Survey and Earth Sciences (ITC).

Raines, G.L., 1999. Evaluation of Weights of Evidence to Predict EpithermalGold deposits in the Great Basin of the Western United States. Natural Resources Research, 8(4): 257-276.

Ramos, V.A., 2002a. El magmatismo paleógeno de la Cordillera Patagónica. In: M.J. Haller (Editor), Relatorio del XV Congreso Geológico Argentino: Geología y Recursos Naturales de Santa Cruz. Asociación Geológica Argentina, El Calafate, pp. 165-174.

Ramos, V.A., 2002b. Evolución Tectónica. In: M.J. Haller (Editor), Relatorio del XV Congreso Geológico Argentino: Geología y Recursos Naturales de Santa Cruz. Asociación Geológica Argentina, El Calafate, pp. 1-23.

Reimann, C. and Filzmoser, P., 2000. Normal and lognormal data distribution in geochemistry: death of a myth. Consequences for the statistical treatment of geochemical and environmental data. Environmental Geology, 39(9): 1001-1014.

Reimer, W., Miller, H. and Mehl, H., 1996. Mesozoic and Paleozoic Paleostress fields of the South Patagonian Massif deduced from structural and remote sensing data. In: Storey, B.C., King, E.C., and Livermore, R.A. (eds.), Weddell Sea tectonics and Gondwana break-up, Geological Society Special Publication No 108: 73-85.

Riley, T.R., Flowerdew, M.J., Hunter, M.A. and Whitehouse, M.J., 2010. Middle Jurassic rhyolite volcanism of eastern Graham Land, Antarctic Peninsula: age correlations and stratigraphic relationships. Geological Magazine 147 (4): 581-595.

Riley, T.R. and Knight, K.B., 2001. Age of Pre-Break-Up Gondwana Magmatism. Antarctic Science, 13(02): 99-110. 
Riley, T.R., Leat, P.T., Pankhurst, R.J. and Harris, C., 2001. Origins of Large Volume Rhyolitic Volcanism in the Antarctic Peninsula and Patagonia by Crustal Melting. Journal of Petrology, 42(6): 1043-1065.

Rios, F.J., Alves, J.V., Fuzikawa, K., Schalamuk, I.A., de Barrio, R. and del Blanco, M., 2000. Fluid evolution in the La Josefina Au-epithermal system, Macizo del Deseado, southern Patagonia, Santa Cruz, Argentina. Revista Brasileña de Geociencias, 30(4): 769-774.

Rolando, A.P. and Fernández, R.R., 1996. Alteracion hidrotermal del sector nor-oriental del prospecto epitermal La Josefina, Santa Cruz., III Reunión de Mineralogía y Metalogenia. INREMI, Universidad Nacional de La Plata, La Plata, pp. 209-216.

Sabins, F.F., 1999. Remote sensing for mineral exploration. Ore Geology Reviews, 14(3-4): 157-183.

Sandefur, R.L., 2007. Lomada Leiva Project, Santa Cruz Province, Argentina. Technical Report (NI 43-101) prepared for Patagonia Gold PIc.

Sanders, G., 2000. Regional geologic setting of the gold-silver veins of the Deseado Massif, Southern Patagonia, Argentina. Argentina Mining 2000: Exploration, Geology, Mine Development and Business Opportunities Conference, Engineering and Mining Journal and LatinoMineria, Mendoza.: 60.

Sawatzky, D.L., Raines, G.L., Bonham-Carter, G.F. and Looney, C.G., 2009. Spatial Data Modeller (SDM): ArcMAP 9.3 geoprocessing tools for spatial data modelling using weights of evidence, logistic regression, fuzzy logic and neural networks. http://arcscripts.esri.com/details.asp?dbid $=15341$.

Schalamuk, I.A., Del Blanco, M.A., de Barrio, R.E., Etcheverry, R.O., Marchionni, D.S. and Tesone, M.O., 1998. Características mineralógicas de la paragénesis epitermal del prospecto La Josefina, Macizo del Deseado, Provincia de Santa Cruz, IV Reunión de Mineralogía y Metalogenia, Bahia Blanca, Argentina pp. 259-266.

Schalamuk, I.B., de Barrio, R.E., Zubia, M., Genini, A. and Echeveste, H., 1999. Provincia auroargentífera del Deseado, Santa Cruz. In: E. Zappettini (Editor), Recursos Minerales de la República Argentina. Instituto de Geología y Recursos Minerales, SEGEMAR, pp. 1178-1188.

Schalamuk, I.B., de Barrio, R.E., Zubia, M.A., Genini, A. and Valvano, J., 2002. Mineralizaciones auroargentíferas del Macizo del Deseado y su encuadre metalogénico, Provincia de Santa Cruz. In: M.J. Haller (Editor), Relatorio del XV Congreso Geológico Argentino. Asociación Geológica Argentina, El Calafate, pp. 679-713.

Schalamuk, I.B., Zubia, M., Genini, A. and Fernandez, R.R., 1997. Jurassic epithermal Au-Ag deposits of Patagonia, Argentina. Ore Geology Reviews, 12(3): 173-186. 
Scott, K.M., 2001. Weathering in the Parkinson Pit and its implications for exploration in the Mt Magnet Mining District, Western Australia. Geochemistry: Exploration, Environment, Analysis, 1(4): 341-352.

Scott, K.M., Yang, K. and Huntington, J.F., 1998. The application of spectral reflectance studies of chlorites in exploration. EM Rpt 545R, CSIRO.

Selby, M.J., 1993. Hillslope Materials and Process. Oxford University Press New York.

Shatwell, D., Clifford, J.A., Echavarria, D., Irusta, G. and Lopez, D., 2011. Discoveries of Low-Sulfidation Epithermal Au-Ag Veins at Cerro Negro, Deseado Massif, Argentina. Society of Economic Geologists, Newsletter, 85.

Silberman, M.L. and Berger, B.R., 1985. Relationships of trace element patterns to alteration and morphology in epithermal precious metal deposits. In: B.R. Berger and P.M. Bethke (Editors), Geology and Geochemistry of Epithermal Systems. Reviews in Economic Geology. Society of Economic Geologists, pp. 203-232.

Sillitoe, R.H., 1993. Epithermal models: genetic types, geometrical controls, and shallow features. Geological Association of Canada Special Paper 40: 403-417.

Sillitoe, R.H., 2002. Rifting, bimodal volcanism, and bonanza gold veins., Society of Economic Geologists, Newsletter No 48, pp. 24-26.

Sillitoe, R.H. and Hedenquist, J.W., 2003. Linkages between volcanotectonic settings, ore-fluid compositions, and epithermal precious metal deposits. Society of Economic Geologists, Special Publication 10, 2003: 315-343.

Simmons, S.F. and Browne, P.R.L., 2000. Hydrothermal minerals and precious metals in the Broadlands-Ohaaki geothermal system: Implications for understanding low-sulfidation epithermal environments. Economic Geology, 95(5): 971-999.

Simmons, S.F., White, N.C. and John, D.A., 2005. Geological characteristics of epithermal precious and base metal deposits. Economic Geology, 100 th Anniversary Volume: 485-522.

Simpson, M.P. and Mauk, J.L., 2011. Hydrothermal Alteration and Veins at the Epithermal Au-Ag Deposits and Prospects of the Waitekauri Area, Hauraki Goldfield, New Zealand. Economic Geology, 106(6): 945-973.

Simpson, M.P., Mauk, J.L. and Simmons, S., 2001. Hydrothermal alteration and hydrologic evolution of the Golden Cross epithermal Au-Ag deposit, New Zealand. Economic Geology, 96(4): 773-796.

Singer, D. and Kouda, R., 1999. A Comparison of the Weights-of-Evidence Method and Probabilistic Neural Networks. Natural resources research, 8(4): 287-298.

Snedecor, G.W. and Cochran, W.G., 1967. Statistical Methods: 6th Ed. Iowa State University Press. 
Somoza, R., Vizán, H. and Taylor, G.K., 2008. Tectonic rotations in the Deseado Massif, southern Patagonia, during the breakup of Western Gondwana. Tectonophysics, 460(1-4): 178-185.

Sruoga, P., Japas, M.S., Salani, F.M. and Kleiman, L.E., 2014. La Peligrosa caldera $\left(47^{\circ} 15^{\prime} \mathrm{S}, 71^{\circ} 40^{\prime} \mathrm{W}\right)$ : A key event during the Jurassic ignimbrite flare-up in Southern Patagonia, Argentina. Journal of volcanology and geothermal research, 269: 44-56.

Thompson, A.J.B., Hauff, P.L. and Robitaille, A.J., 1999. Alteration Mapping in exploration: application of short-wave infrared (SWIR) spectroscopy. Society of Economic Geologists, Newsletter, 39: 15-27.

Thompson, A.J.B., Scott, K.M., Huntington, J. and Yang, K., 2009. Mapping mineralogy with reflectance spectroscopy: examples from volcanogenic massive sulfide deposits (Chapter 4). Reviews in Economic Geology, 16: $25-40$.

U.S. Bureau of the Budget, 1947. United States National Map Accuracy Standards. U.S. Bureau of the Budget, Washington, D.C.

Uliana, M.A., Biddle, K.T., Phelps, D.W. and Gust, D.A., 1985. Significado del Vulcanismo y extensión mesojurásicos en el extremo meridional de Sudamérica. Asociación Geológica Argentina, Revista, 40(3-4): 231253.

van Ruitenbeek, F.J.A., Cudahy, T., Hale, M. and van der Meer, F.D., 2005. Tracing fluid pathways in fossil hydrothermal systems with nearinfrared spectroscopy. Geology, 33(7): 597-600.

van Ruitenbeek, F.J.A., Debba, P., van der Meer, F.D., Cudahy, T., van der Meijde, M. and Hale, M., 2006. Mapping white micas and their absorption wavelengths using hyperspectral band ratios. Remote Sensing of Environment, 102(3-4): 211-222.

Varela, R., Pezzuchi, H., Genini, A. and Zubia, M., 1991. Dataciones de rocas magmáticas en el Jurásico inferior del nordeste del Macizo del Deseado, Santa Cruz. Asociación Geológica Argentina, Revista 46, 3-4: 257-262.

Warren, I., Simmons, S.F. and Mauk, J.L., 2007. Whole-Rock Geochemical Techniques for Evaluating Hydrothermal Alteration, Mass Changes, and Compositional Gradients Associated with Epithermal Au-Ag Mineralization. Economic Geology, 102(5): 923-948.

White, N.C. and Hedenquist, J.W., 1990. Epithermal environments and styles of mineralization: Variations and their causes, and guidelines for exploration. Journal of Geochemical Exploration, 36(1-3): 445-474.

White, N.C., Leake, M.J., McCaughey, S.N. and Parris, B.W., 1995. Epithermal gold deposits of the southwest pacific. Journal of Geochemical Exploration, 54(2): 87-136.

Yang, K., Browne, P.R.L., Huntington, J.F. and Walshe, J.L., 2001 a. Characterising the hydrothermal alteration of the Broadlands-Ohaaki geothermal system, New Zealand, usign short-wave infrared 
spectroscopy. Journal of volcanology and geothermal research, 106: 53-65.

Yang, K., Huntington, J.F., Browne, P.R.L. and Ma, C., 2000. An infrared spectral reflectance study of hydrothermal alteration minerals from the Te Mihi sector of the Wairakei geothermal system, New Zealand. Geothermics, 29(3): 377-392.

Yang, K., Huntington, J.F., Cudahy, T.J., Mason, P. and Scott, K.M., 2001b. Spectrally mapping the compositional variation of white micas in hydrothermal systems and the application in mineral exploration, Geoscience and Remote Sensing Symposium, 2001. IGARSS '01. IEEE 2001 International, pp. 3294-3296 vol.3297.

Yang, K., Huntington, J.F., Gemmell, J.B. and Scott, K.M., 2011. Variations in composition and abundance of white mica in the hydrothermal alteration system at Hellyer, Tasmania, as revealed by infrared reflectance spectroscopy. Journal of Geochemical Exploration, 108(2): 143-156.

Yang, K., Lian, C., Huntington, J., Peng, Q. and Wang, Q., 2005. Infrared spectral reflectance characterization of the hydrothermal alteration at the Tuwu Cu-Au deposit, Xinjiang, China. Mineralium Deposita, 40(3): 324-336.

Yilmaz, H., 2003. Exploration at the Kuscayiri $\mathrm{Au}(\mathrm{Cu})$ prospect and its implications for porphyry-related mineralization in western Turkey. Journal of Geochemical Exploration, 77(2-3): 133-150.

Zhai, W., Sun, X., Sun, W., Su, L., He, X. and Wu, Y., 2009. Geology, geochemistry, and genesis of Axi: A Paleozoic low-sulfidation type epithermal gold deposit in Xinjiang, China. Ore Geology Reviews, 36(4): 265-281.

Zubia, M. and Genini, A., 2003. Yacimientos auroargentíferos epitermales del Macizo del Deseado, Provincia de Santa Cruz. Serie Contribuciones Técnicas, Recursos Minerales 13/D. Servicio Geológico Minero Argentino (SEGEMAR).

Zubia, M.A., Genini, A.D. and Schalamuk, I.B., 1999. Yacimiento Cerro Vanguardia, Santa Cruz. In Recursos Minerales de la República Argentina (Ed. E. Zappettini), Instituto de Geología y Recursos Minerales, SEGEMAR, Anales 35, T. II: 1189-1202. 


\section{Summary}

The purpose of this research was to develop tools for better predicting the location of $\mathrm{Au}-\mathrm{Ag}$ epithermal deposits in the Deseado Massif and similar areas, and to acquire new insights about those deposits in that region. To achieve this, the Weights of Evidence (WofE) data driven method was used to map prospectivity of $\mathrm{Au}-\mathrm{Ag}$ low- and intermediate-sulfidation epithermal deposits (LISEDs) in the Deseado Massif. Three types of evidence were used as input of the WofE method: structural, hydrothermal alteration and lithological. The prospectivity mapping exercise produced useful maps at regional and district scales, and suggested that better understanding the clay alteration evidence and including other types of evidence, such as geochemistry, may improve the results of prospectivity mapping.

The emplacement of epithermal systems modify the mineralogy and chemical composition of their host rocks, likely resulting in zonation of elements concentrations and alteration minerals, which can be used as vectors to mineralized areas. In general, the spatial distributions of elements and alteration minerals in LISEDs are already known. In detail however, these factors are poorly known, especially in the Deseado Massif.

The spatial distribution of elements and hydrothermal alterations were studied in the La Josefina low- to intermediate-sulfidation epithermal deposit. At deposit scale, the geochemistry of a mineralized zone was compared with that of an adjacent non-mineralized zone. At detailed-scale, the progressive variation of element concentrations with increasing distance from Au-rich veins was studied. In addition, the overall effect of weathering on geochemical distributions in surface and subsurface materials was investigated. The hydrothermal alterations were studied with reflectance spectroscopy from samples of outcrops and trenches, characterizing different parts of the La Josefina deposit that are believed to be formed in different positions in the epithermal paleo-system. The characterization was done in terms of mineralogy, crystallinity of white micas and kaolinite, and the wavelength position of the $\mathrm{AlOH}$ absorption feature in white micas and smectites. This was done for learning new insights of these types of systems, and for determining spectral indicators that can help reconstructing the configuration of other paleo-systems as well as to indicate the possible location of mineralized zones.

At deposit-scale, 18 geochemical variables are possible indicators of mineralized zones. These indicators include higher concentrations of $\mathrm{Au}, \mathrm{Cu}$, $\mathrm{Hg}, \mathrm{V}, \mathrm{Co}, \mathrm{Mn}, \mathrm{MgO}, \mathrm{Cr}, \mathrm{P}, \mathrm{Pb}, \mathrm{Zn}, \mathrm{FeO}, \mathrm{CCPI}, \mathrm{As}$ and $\mathrm{Ni}$, and low concentrations of $\mathrm{Ba}, \mathrm{Be}$ and $\mathrm{CaO}$. From these, the best 10 indicators are $\mathrm{Au}$, $\mathrm{Cu}, \mathrm{Hg}, \mathrm{V}, \mathrm{Co}, \mathrm{Mn}, \mathrm{MgO}, \mathrm{Cr}, \mathrm{P}$ and $\mathrm{Ba}$. At detailed scale, the strongest 
indicators of proximity to the Au-rich veins are $\mathrm{Au}, \mathrm{P}, \mathrm{Cu}, \mathrm{Pb}, \mathrm{Hg}, \mathrm{Ba}$, and $\mathrm{MgO}$. In strongly oxidized rocks, some indicators of mineralized zones ( $\mathrm{Co}$, $\mathrm{Mn}, \mathrm{Pb}, \mathrm{Zn}$, and $\mathrm{MgO})$, and some indicators of proximity to Au-rich veins ( $\mathrm{P}$, $\mathrm{Au}, \mathrm{Cu}, \mathrm{Hg}$, and $\mathrm{Ba}$ ), should be used with caution or be avoided, because weathering modifies their quality as indicators.

Kaolinite was found a useful spectral indicator of potentially mineralized zones and of general position in the paleo-system. Its abundance and patterns of occurrence are indicators of the general position in the paleosystem. The predominance of kaolinite over broad areas (i.e., >100-200 m) indicates the upper parts of the paleo-systems; in that case, strong predominance of kaolinite may indicate proximity to the main upflow zone, while only locally dominant kaolinite would indicate marginal positions with respect to that zone. Narrow (i.e., $<50 \mathrm{~m}$ ), elongated areas of abundant kaolinite probably indicate paleo-conduits at lower levels in the epithermal system, where the potential for finding mineralized rocks is high. The absence of kaolinite and presence of chlorite may indicate lower parts in the paleo-system or areas located far away from the paleo-conduits; in both cases, the potential for finding mineralized areas is relatively low. In addition, high values of kaolinite crystallinity are good indicators of veins and other paleo-conduits, regardless of the level in the paleo-system. Therefore, relatively narrow, elongated areas in which high crystallinity kaolinite predominates would be the best indicators of the presence of potentially mineralized paleo-conduits.

The wavelength position of the $\mathrm{AlOH}$ absorption feature in white micas and smectites is also a good spectral indicator of different parts of the paleosystem. Wavelengths below $2197 \mathrm{~nm}$ indicate the upper levels of the paleosystem and are related to silicified rocks produced from steam-heated waters. Wavelength consistently between 2197 and $2210 \mathrm{~nm}$ indicate areas that may contain veins or other paleo-conduits, which may be mineralized.

The mineralogy determined during the spectroscopic study confirmed that the binary predictor maps of hydrothermal clay alteration used as input for the prospectivity mapping captured only a relatively small part of the clay alteration. These predictor maps were already determined as week evidence by the spatial association analysis. Therefore, the spectroscopic data confirmed the usefulness of the spatial association analysis for assessing layers of evidence.

Some of these spectral indicators may be detected with remote sensing to produce new evidence layers that can improve the predictions of prospectivity and contribute for the exploration of the Deseado Massif and geologically similar areas. 


\section{Samenvatting}

Het doel van dit onderzoek was om methoden te ontwikkelen voor een betere modelering van het voorkomen van Au-Ag epithermale ertsvoorkomens in het Deseado Massif en vergelijkbare gebieden, en om nieuwe inzichten in dit type erstvoorlomen in dit geologische gebied te verkrijgen. Om dit te bereiken, werd de statistische Weights OF Evidence (WOFE) methode gebruikt om de mogelijkheid van het voorkomen van $\mathrm{Au}-\mathrm{Ag}$ low- and intermediate-sulfidation epithermal deposits (LISEDs) in het Deseado Massif te voorspellen en in kaart te brengen. Drie GIS data lagen werden gebruikt als input voor de WOFE methode: Geologische structuren, hydrothermale omzettingen en lithologie. De op die manier verkregen prospectiviteitskaarten voorspelden de locaties van Au-Ag voorkomens naar tevredenheid op zowel regionale als district schaal. Tevens gaven de resultaten aan dat een beter begrip van de soorten hydrothermale omzettingen en het gebruik van andere soorten data, zoals geochemie, het resultaat van de voorspelling van $\mathrm{Au}-\mathrm{Ag}$ voorkomens kunnen verbeteren.

Door de aanwezigheid van epithermale systemen in de ondergrond, worden de mineralogische en chemische samenstelling van gesteenten gewijzigd. Dit resulteert in een zonering in de verdeling van chemische elementen en mineralen die gebuikt kan worden voor de opsporing van ertsvoorkomens. De ruimtelijke verdelingen van elementen en omzettingsmineralen van LISEDs is in grote lijnen reeds bekend. Op een meer gedetailleerd niveau zijn deze factoren echter niet in voldoende mate bekend, zeker niet in het Deseado Massif.

De ruimtelijke verdeling van chemische elementen en hydrothermale omzettingen werden bestudeerd in de low- to intermediate-sulfidation epithermal deposit van La Josefina. Op schaal van de gehele afzetting werd de geochemische samenstelling van gemineraliseerde zones vergeleken met die van aangrenzende niet-gemineraliseerde zones. Op gedetailleerde schaal werd de verandering van element concentraties als functie van de afstand tot de goud-bevattende aders bestudeerd. Ook was het totale effect van verwering op de element concentraties aan de oppervlakte en in de ondergrond onderzocht. De hydrothermale omzettingen werden bestudeerd met behulp van reflectiespectroscopie van gesteentemonsters die afkomstig zijn van ontsluitingen en uit sleuven. De monsters zijn representatief voor de verschillende delen van de La Josefina afzetting die van verschillende onderdelen van het epithermale paleo-systeem deel uitmaakten. De reflectie spectra werden gebruikt om de mineralogische samenstelling te bepalen, evenals de kristalliniteit van witte mica's en kaoliniet en de golflengte positie van de $\mathrm{AlOH}$ absorptie banden in witte mica en smectieten. Dit resulteerde in nieuwe inzichten in de ruimtelijke verdeling van mineralen in dit soort 
systemen. De in dit onderzoek verkregen spectrale indicatoren kunnen gebruikt worden bij het reconstrueren van de configuratie van andere paleosystemen alsmede de mogelijke locatie van ertsvoorkomens.

Op de schaal van de gehele ertsafzetting, zijn 18 geochemische variabelen gevonden die gebruikt kunnen worden als mogelijke indicatoren voor de aanwezigheid van gemineraliseerde zones. Deze indicatoren zijn de (verhoogde) concentraties van $\mathrm{Au}, \mathrm{Cu}, \mathrm{Hg}, \mathrm{V}, \mathrm{Co}, \mathrm{Mn}, \mathrm{MgO}, \mathrm{Cr}, \mathrm{P}, \mathrm{Pb}, \mathrm{Zn}$, $\mathrm{FeO}, \mathrm{CCPI}$, As en $\mathrm{Ni}$, en lage concentraties van $\mathrm{Ba}$, $\mathrm{Be}$ en $\mathrm{CaO}$. Van deze 18 elementen zijn er 10 die het beste gecorreleerd zijn met ertsvoorkomens, namelijk $\mathrm{Au}, \mathrm{Cu}, \mathrm{Hg}, \mathrm{V}, \mathrm{Co}, \mathrm{Mn}, \mathrm{MgO}, \mathrm{Cr}, \mathrm{P}$ en $\mathrm{Ba}$. Op gedetailleerde schaal zijn de beste indicatoren voor de nabijheid van gouaders: $\mathrm{Au}, \mathrm{P}, \mathrm{Cu}, \mathrm{Pb}, \mathrm{Hg}$, $\mathrm{Ba}$ en $\mathrm{MgO}$. In sterk geoxideerd gesteenten moet een aantal indicatoren voor de gemineraliseerde zones ( $\mathrm{Co}, \mathrm{Mn}, \mathrm{Pb}, \mathrm{Zn}$, en $\mathrm{MgO}$ ) en voor nabijheid van goudaders $(\mathrm{P}, \mathrm{Au}, \mathrm{Cu}, \mathrm{Hg}$, and $\mathrm{Ba})$ met voorzichtigheid toegepast worden omdat verwering invloed heeft op hun ruimtelijke verdeling.

Kaoliniet bleek een bruikbare spectrale indicator van gemineraliseerde zones en van de algemene positie in het epithermale paleo-systeem. De aanwezigheid van kaoliniet en zijn ruimtelijke verspreiding kunnen gebruikt worden voor de bepaling van positie in de paleo-systeem. Het dominante voorkomen van kaoliniet in uitgebreide gedeelten van het systeem (dwz> 100-200 m) geeft aan dat deze gevormd moeten zijn in de bovenste delen van de paleo-systeen. De aanwezigheid van kaoliniet geeft in dat geval de nabijheid aan van de belangrijkste upflow zones van hydrothermale vloeistoffen. Plaatselijke dominante voorkomens van kaoliniet wijzen op marginale posities ten opzichte van upflow zones. Smalle (dwz $<50 \mathrm{~m})$, langgerekte zones met kaoliniet duiden waarschijnlijk op de aanwezigheid van paleo-strucuturen op lagere niveaus in het epithermal systeem, waarbij de kans op de aanwezigheid van gemineraliseerde aders hoog is. De afwezigheid van kaoliniet en de aanwezigheid van chloriet kan lagere delen in de paleo-systeem of de gebieden ver weg van de paleo-strucutren aan geven; in beide gevallen is de kans op de aanwezigheid van gemineraliseerde aders relatief laag. Hoge waarden van de kristalliniteit van kaoliniet zijn goede indicatoren voor het voorkomen van goudaders en andere gemineraliseerde paleo-structuren, ongeacht het niveau in het paleo-systeem waarin ze gevormd zijn. Relatief langgerekte zones die hoogkristallijn kaoliniet bevatten zijn waarschijnlijk de beste indicatoren voor de aanwezigheid van gemineraliseerde paleo-structuren.

De golflengte positie van de $\mathrm{AlOH}$ absorptie band in witte micas en smectieten is ook een goede spectrale indicator voor de verschillende delen van het paleo-systeem. Golflengten van minder dan $2197 \mathrm{~nm}$ zijn geassocieerd met de meest ondiep niveaus van het paleo-systeem nabij het 
aardoppervlak, en komen voor in nabijheid van verkiezelde rotsen die zijn gevormd in door stoom verwarmd water. Mineralen met golflengte posities tussen 2197 en $2210 \mathrm{~nm}$ zijn gerelateerd aan gebieden die gemineraliseerde aders of andere paleo-structuren bevatten.

De mineralogische samenstelling van epithermale systemen, bepaald met het spectroscopische onderzoek, bevestigde de diversiteit van mineralogische parameters in deze systemen. Dit bevestigt de initiële observatie dat de binaire predictor kaarten van hydrothermale omzettingen zoals gebruikt voor het maken van de prospectiviteitskaarten slechts een klein deel van de aanwezige omzettingsmineralen in kaart brengen. Uit de WOFE berekeningen bleek al dat de hydrothermale omzettingslaag een relatief zwakke voorspeller was voor het voorkomen van epithermale mineralisaties. De spectroscopische gegevens bevestigen het nut van de ruimtelijke associatieanalyse van de WOFE methode voor het bepalen van de voorspellende waarde van een data laag.

Sommige van de gebruikte en ontwikkelde spectrale indicatoren kunnen worden gebruikt om met remote sensing de voorspellingen van het voorkomen van Au-Ag ertsen te verbeteren. Dit zal het exploratiesucces van Au-Ag voorkomens in het Deseado Massief en in geologisch vergelijkbare gebieden vergroten. 


\section{Biography}

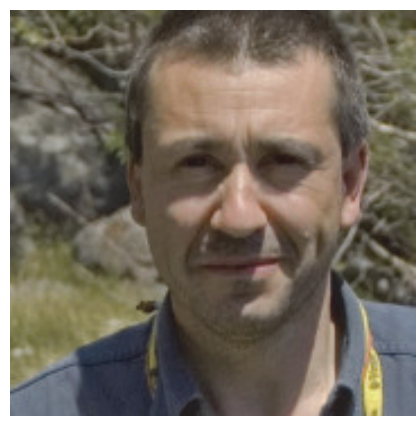

Pablo Andrada de Palomera was born on August 11, 1967, in Río Gallegos, Argentina. He studied geology in the University of Buenos Aires, completing his studies in 1992. He worked as an assistant in geomorphology in the University of Buenos Aires and received a scholarship from that University for carrying out research in geomorphology. In 1996 he joined Compañía Minera Polimet S.A., a subsidiary of Yamana Gold Inc., for which he worked as exploration geologist mainly in the Deseado Massif but sporadically in other areas, acting as field geologist and as link between the management of the Company and different geochemical laboratories. In 1998 he joined Fomicruz S.E., a mineral exploration company from the Argentinian Government, where he is currently Head of Department of Regional Exploration. In 2004 he received an MSc degree (with distinction) in Geoinformation Science and Earth Observation from ITC (International Institute for Geo-information Science and Earth Observation) in The Netherlands (2002-2004), and in 2007 he was accepted as a sandwich PhD student in the Faculty of Geo-information Science and Earth Observation of the University of Twente, conducting his research most of the time at home along with his regular exploration activities. Currently, his main research interests focus on ore geology investigations and the use of remote and field-based sensing data for improving the results of mineral exploration; those interests have motivated his $\mathrm{PhD}$ research.

\section{Peer-reviewed publications}

Andrada de Palomera, P., van Ruitenbeek, F.J.A. and Carranza, E.J.M., 2014. Prospectivity for epithermal gold-silver deposits in the Deseado Massif, Argentina. Ore Geology Reviews (in Press).

Andrada de Palomera, P., van Ruitenbeek, F.J.A., van der Meer, F.D. and Fernández, R., 2012. Geochemical indicators of gold-rich zones in the La Josefina epithermal deposit, Deseado Massif, Argentina. Ore Geology Reviews, 45: 61-80.

Fernández, R.R., Blesa, A., Moreira, P., Echeveste, H., Mykietiuk, K., Andrada de Palomera, P. and Tessone, M., 2008. Los depósitos de oro y plata vinculados al magmatismo jurásico de la Patagonia: revisión y perspectivas para la exploración. Revista de la Asociación Geológica Argentina, 63: 665681. 
Andrada de Palomera, R.P. and Carranza, E.J.M., 2005. Analysis of spatial distribution of epithermal gold deposits in the Deseado Massif, Santa Cruz province. Actas XVI Congreso Geológico Argentino (La Plata): 715-722.

Andrada de Palomera, P., Moreira, P. and Fernández, R., 2005. Manifestaciones de tipo "hot-spring" asociadas al vulcanismo jurásico del área La Esperanza Oeste, Macizo del Deseado, Provincia de Santa Cruz. Actas XVI Congreso Geológico Argentino (La Plata).

Carranza, E.J.M. and Andrada de Palomera, R.P., 2005. Evidential belief mapping of epithermal gold potential in the Deseado massif, Santa Cruz Province, Argentina. Actas XVI Congreso Geológico Argentino (La Plata): 451458.

Fernández, R., Pérez, D., Moreira, P., Andrada de Palomera, R.P., Albornoz, S. and Penzo, H., 2005. Exploración de la "Zona de Fractura Mogote Hormigas", prospecto La Josefina, Santa Cruz, Argentina., Actas XVI Congreso Geológico Argentino, La Plata, pp. 731-736.

Andrada de Palomera, R.P., 2002. Geomorfología del valle de Esquel y alrededores de las lagunas Willimanco, Zeta y Carao, noroeste del Chubut.R.P. XV Congreso Geológico Argentino, Actas en CD-Rom, 6 pp., El Calafate, Argentina.

Fernández, R., Andrada, P. and Alterín, M., 2000. Características geoquímicas de la manifestación tipo "hot-spring" La Marcelina, Provincia de Santa Cruz. In: I. Schalamuk, M. Brodtkorb and R. Etcheverry (Editors), Mineralogía y Metalogenia 2000, Publicación No6. INREMI, La Plata, pp. 121-128.

González Díaz E.F., Fauque L., Costa C., Giaccardi A., Andrada de Palomera P., Pereyra F., 1997. La avalancha de rocas del "Potrero de Leyes", Sierras Pampeanas Australes, Sierra Grande de San Luis, Argentina (320 30' lat. S).Revista de la Asociación Geológica Argentina, 52(1):93-107.

Andrada de Palomera, R.P. and González Díaz, E.F., 1996. Geomorfología de la zona comprendida entre las localidades de Leleque y Esquel, noroeste del Chubut, Argentina. XIII Congreso Geológico Argentino y III Congreso de Exploración de Hidrocarburos. Actas, IV: 333-343.

González Díaz, E.F. and Andrada de Palomera, P., 1995. Los "sistemas de morenas terminales" de Caldenius al sur de la localidad de Ñorquinco, sudoeste de la Provincia de Río Negro. Revista de la Asociación Geológica Argentina, 50(1-4): 212-218. 


\section{MSc Thesis}

Andrada de Palomera, P., 2004. Application of remote sensing and geographic information systems for mineral predictive mapping, Deseado massif, Southern Argentina., ITC, Enschede, The Netherlands, 73 pp.

\section{Presentations}

Andrada de Palomera, R.P., van Ruitenbeek, F.J.A., van der Meer, F.D., Hale, M. and Fernández, R., 2009. Spatial distribution of alteration minerals in La Josefina epithermal deposit, Deseado Massif, Southern Argentina. Abstract + powerpoint, Annual General Meeting of the GRSG AGM 2009 - Exploration Remote Sensing: the 20th Annual Meeting of the Geologic Remote Sensing Group., London. 


\section{ITC Dissertation List}

http://www.itc.nl/research/phd/phd graduates.aspx 